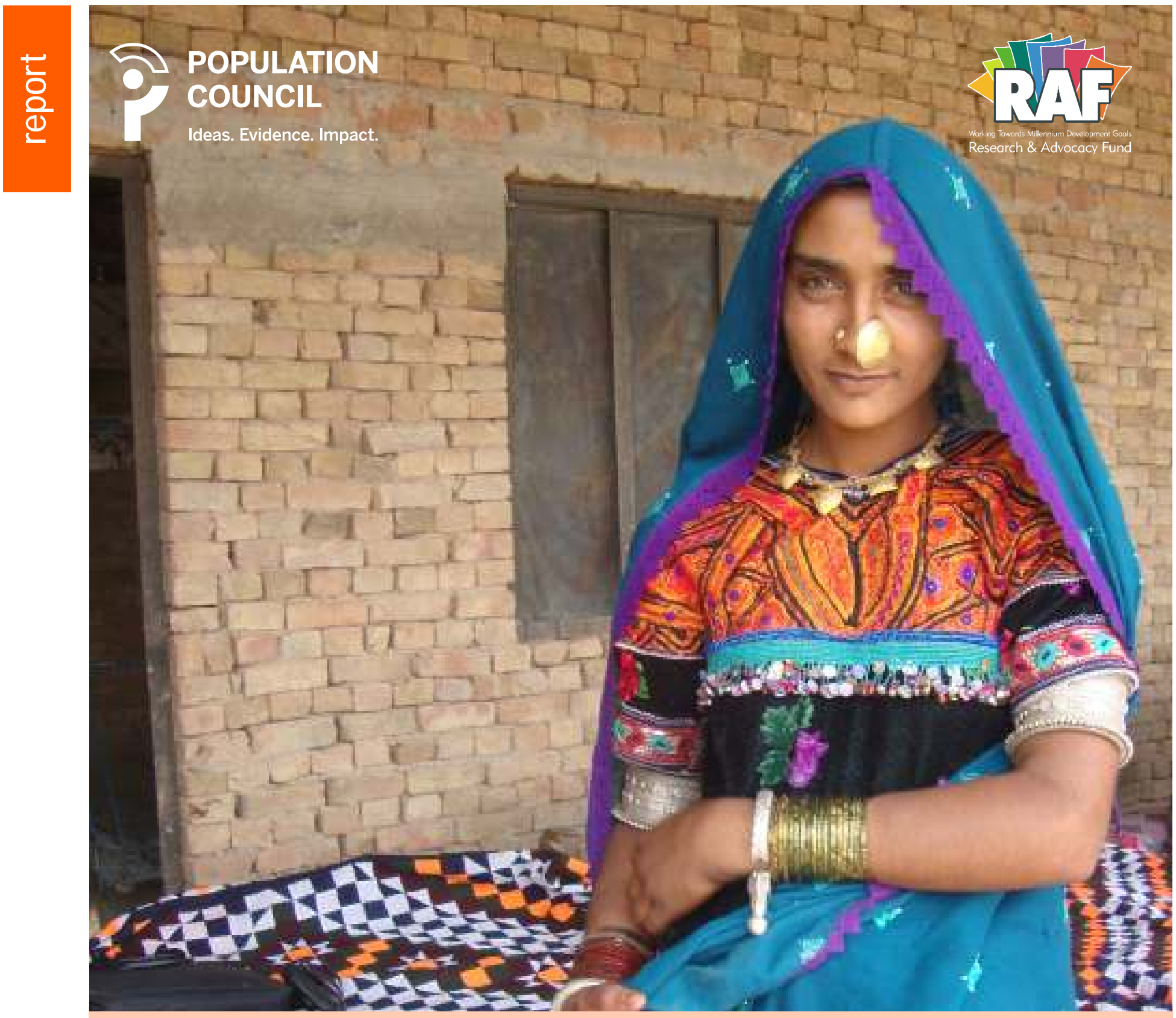

\title{
Investigating the Low Patterns of Modern Contraceptive Use in Pakistan
}




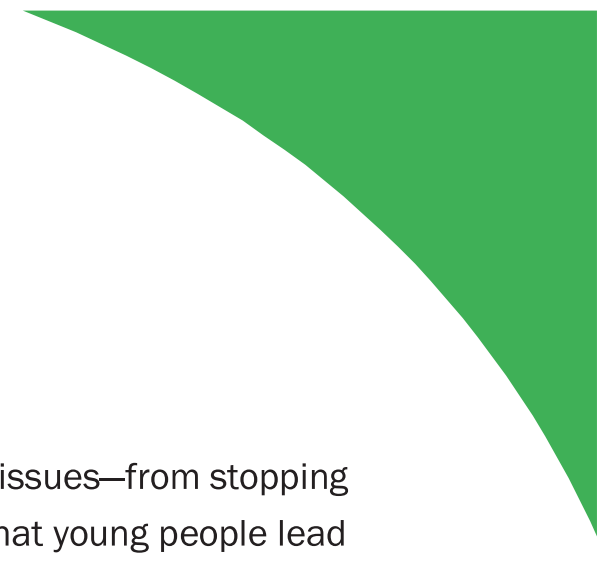

The Population Council confronts critical health and development issues-from stopping the spread of HIV to improving reproductive health and ensuring that young people lead full and productive lives. Through biomedical, social science, and public health research in 50 countries, we work with our partners to deliver solutions that lead to more effective policies, programs, and technologies that improve lives around the world. Established in 1952 and headquartered in New York, the Council is a nongovernmental, nonprofit organization governed by an international board of trustees.

Population Council

House \#7, Street 62, F-6/3, Islamabad, Pakistan

Tel: 92518445566

Fax: 92512821401

Email: info.pakistan@popcouncil.org

Web: http://www.popcouncil.org 


\section{(2) POPULATION 7 COUNCIL \\ Ideas. Evidence. Impact.}

The Population Council confronts critical health and development issues - from stopping the spread of HIV to improving reproductive health and ensuring that young people lead full and productive lives. Through biomedical, social science, and public health research in 50 countries, we work with our partners to deliver solutions that lead to more effective policies, programmes, and technologies that improve lives.

(c) 2015 The Population Council, Inc.

\section{Declaration}

"I have read the report Investigating the Low Patterns of Modern Contraceptive Use in Pakistan, and acknowledge and agree with the information, data and findings contained."

$$
\begin{array}{r}
\text { Reba A. Aethan } \\
\text { Dr. Zeba A. Sathar } \\
\text { Country Director, Population Council }
\end{array}
$$

Islamabad

Acknowledgment

Investigating the Low Patterns of Modern Contraceptive Use in Pakistan is a project funded by the Maternal and Newborn Health Programme, Research and Advocacy Fund (RAF), and is implemented by Population Council, Pakistan.

\section{Disclaimer}

This document is an output from a project funded by the UK Department for International Development (DFID) and the Australian Department of Foreign Affairs and Trade (DFAT) for the benefit of developing countries. The views expressed and information contained are not necessarily those of or endorsed by DFID, DFAT, or the Maternal and Newborn Health Programme, Research and Advocacy Fund (RAF), which can accept no responsibility or liability for such views, for completeness or accuracy of the information, or any reliance placed on them. 


\section{Table of Contents}

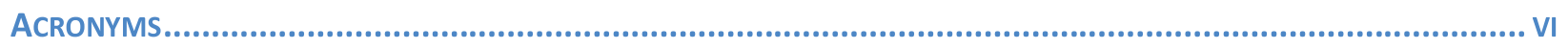

ACKNOWLEDGMENTS...........................................................................................................VIII

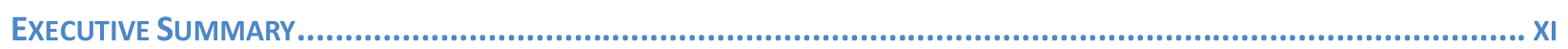

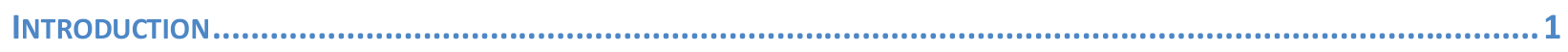

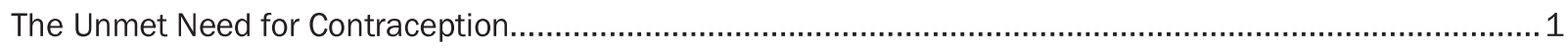

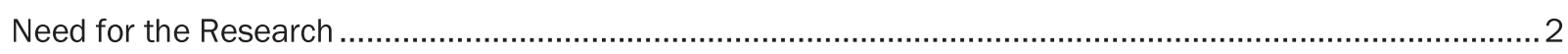

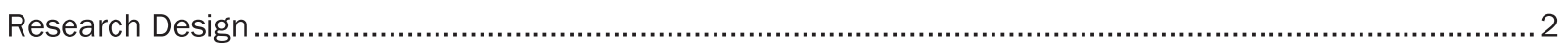

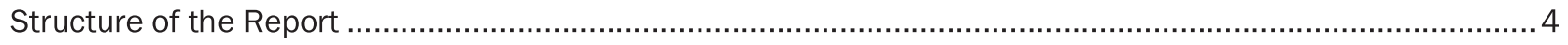

Methodology.....................................................................................................................

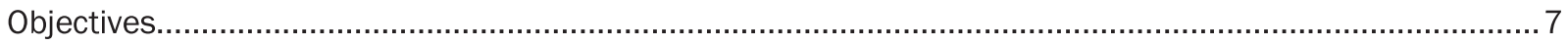

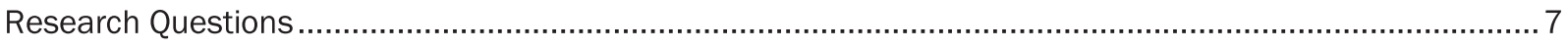

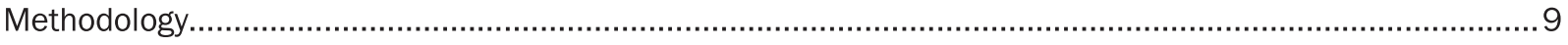

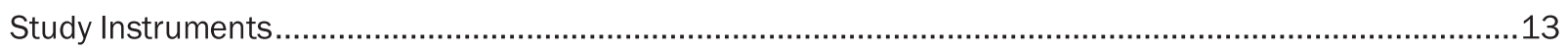

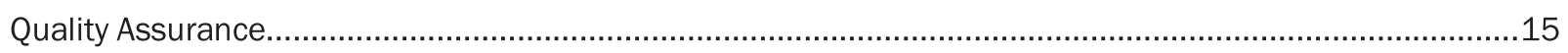

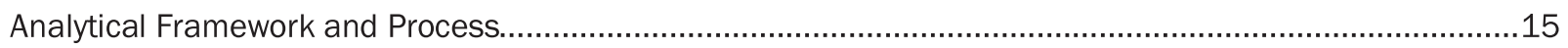

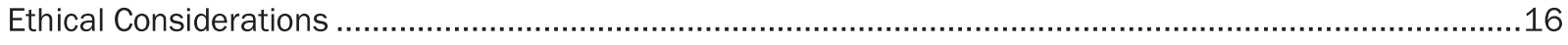

HINDRANCES TO ACCESS TO FAMILY PLANNING SERVICES ................................................................... 19

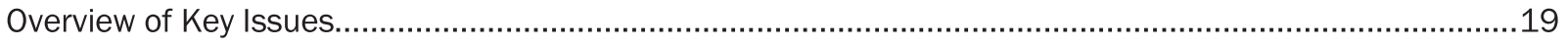

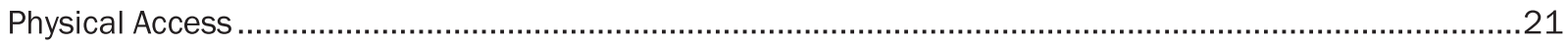

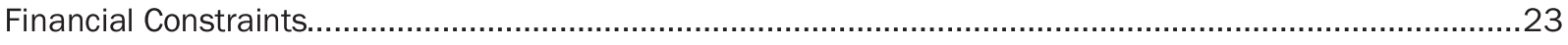

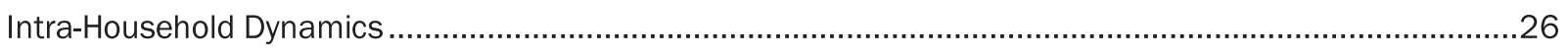

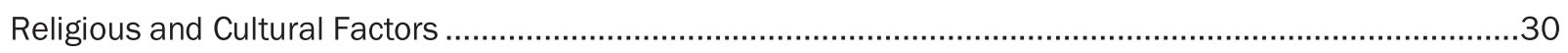

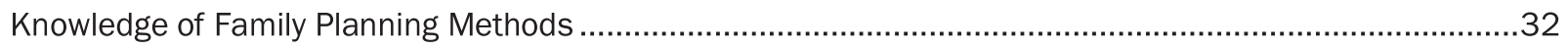

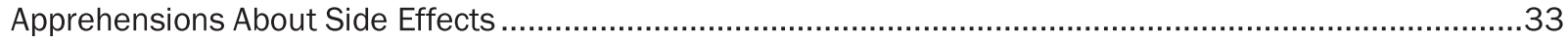

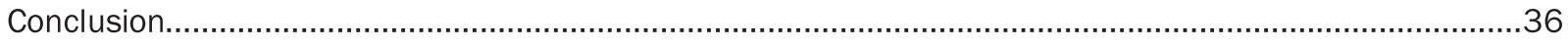

QUALITY OF CARE............................................................................................................. 39

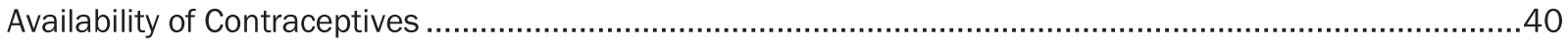

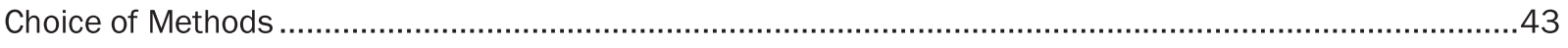

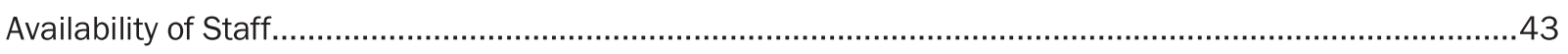

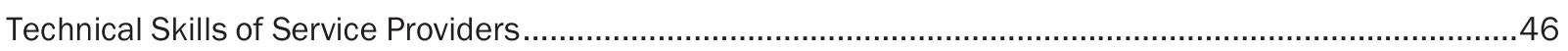

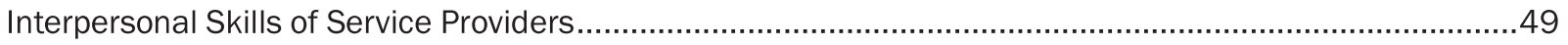

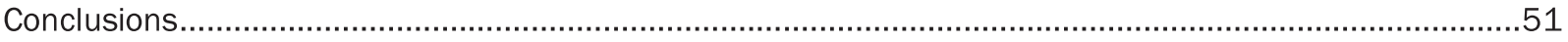

CONTRACEPTIVE PREFERENCES.......................................................................................... 55

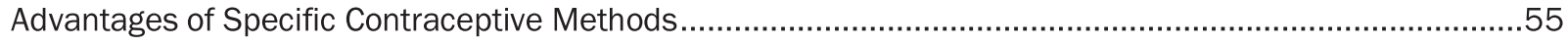




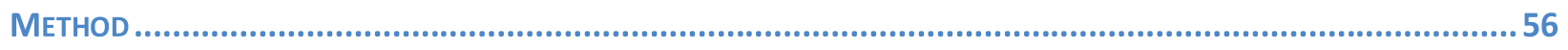

Modern versus Traditional Family Planning Methods ...............................................................................63

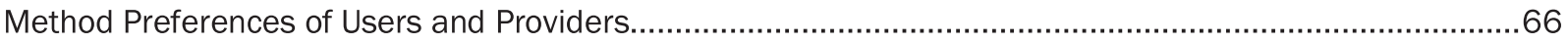

Methods Avoided by Users and Providers ...........................................................................................68

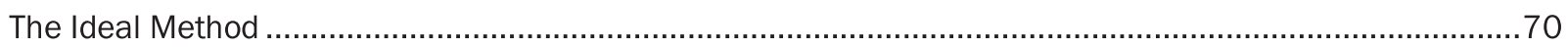

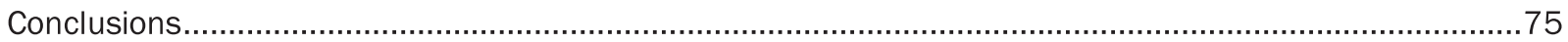

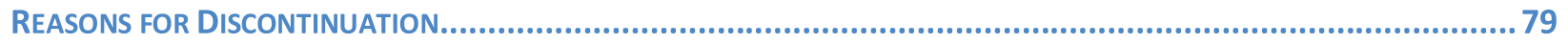

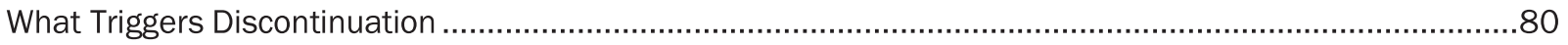

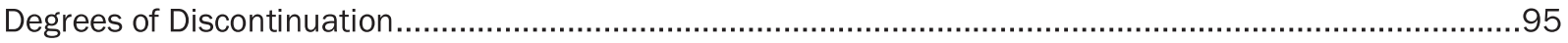

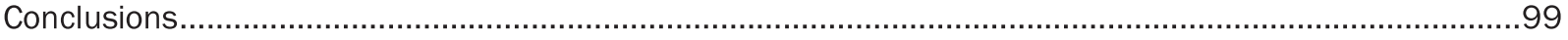

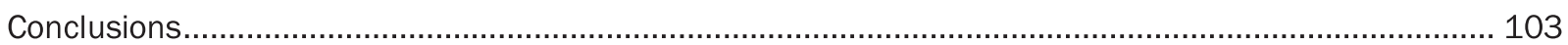

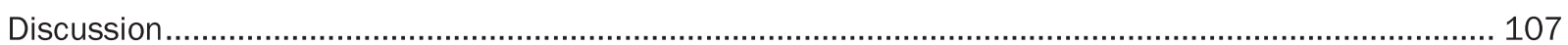

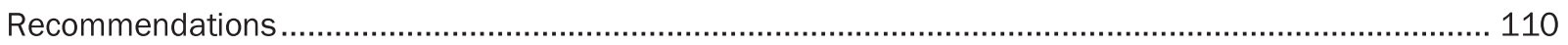

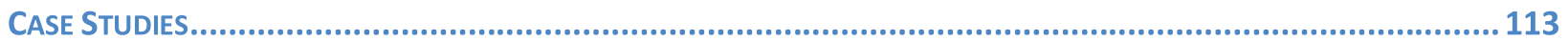

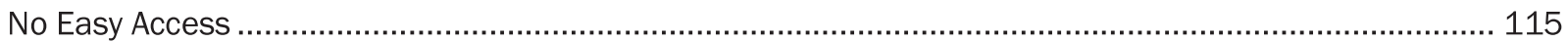

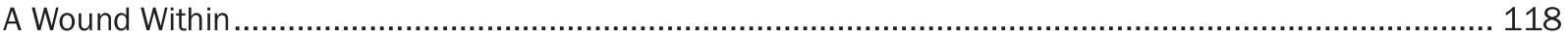

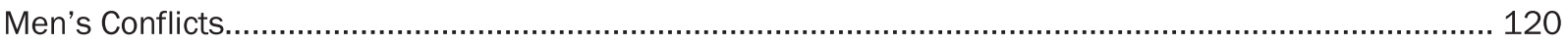

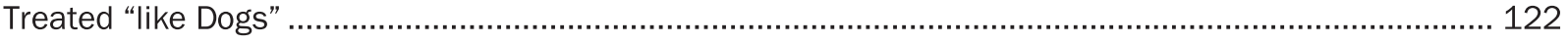

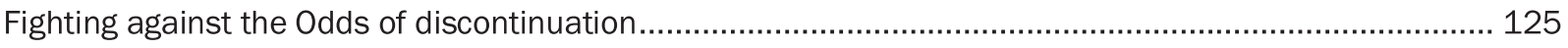

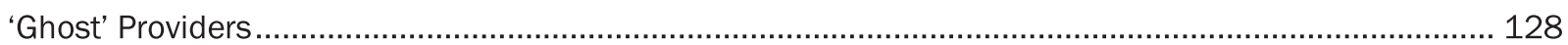

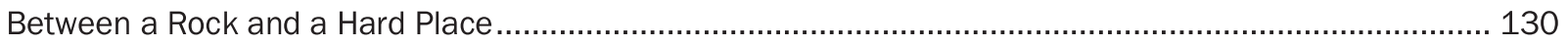

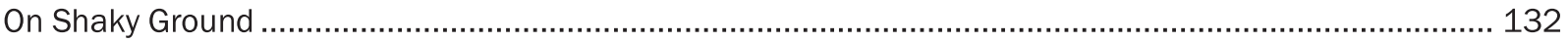

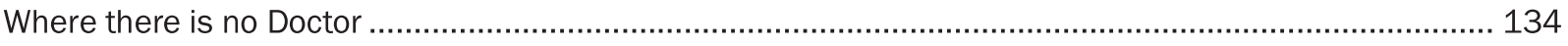

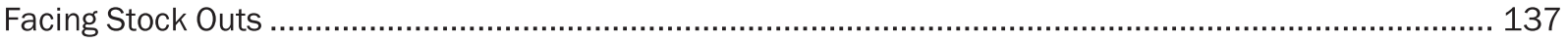

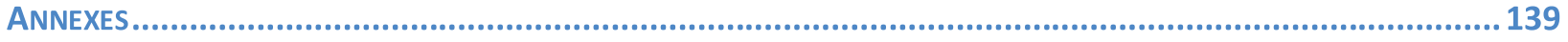

Annex A: Conceptual framework of the whole study (including all 4 sub studies)...................................... 140

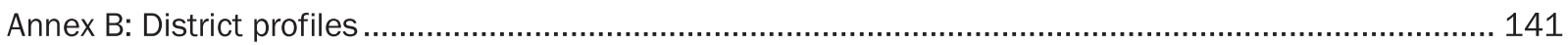

Annex C: Process of selecting 64 service providers for the study: ...................................................... 142

Annex D: Social-demographic characteristics of male/female respondents of FGDs

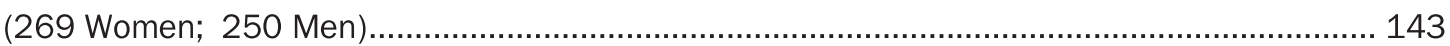

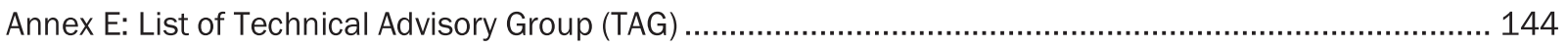

Annex F: Names and designations of field staff and Translators ........................................................... 145 


\section{List of Tables}

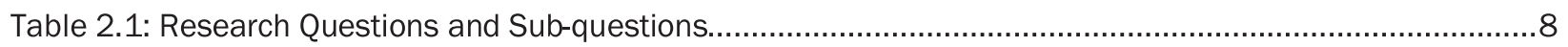

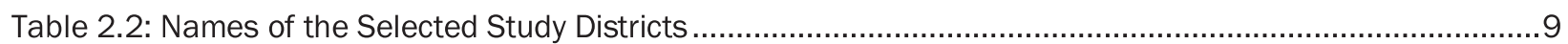

Table 2.3: Socio-demographic Characteristics of Community Respondents (33 Men; 56 Women).................. 12

Table 2.4: Socio-Demographic Profile of Lady Health Workers Interviewed $(n=23)$........................................ 12

Table 2.5: Socio-demographic Profile of Service Providers Interviewed $(n=64)$.............................................. 13

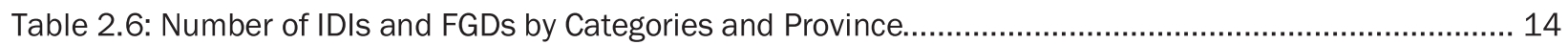

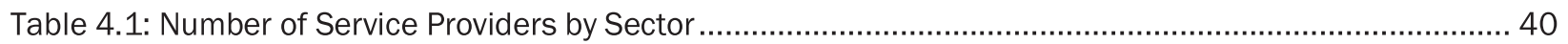

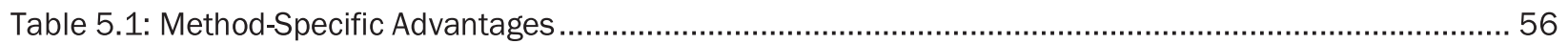

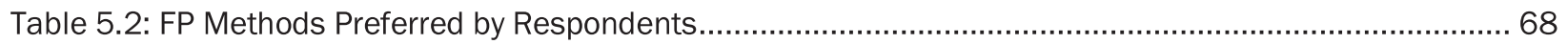

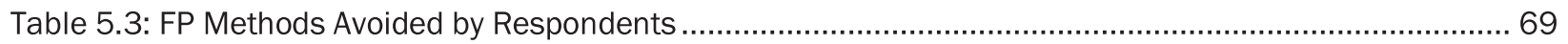

Table 6.1: Experienced Side Effects of Modern Contraceptive Methods....................................................... 83

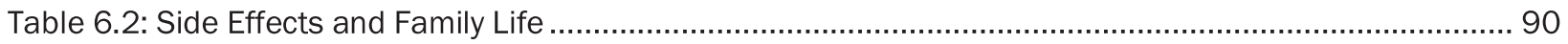

\section{List of Figures}

Figure 1.1: Conceptual Framework for Literature Review and Qualitative Study .............................................3

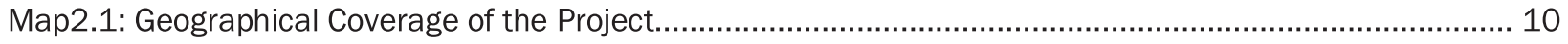

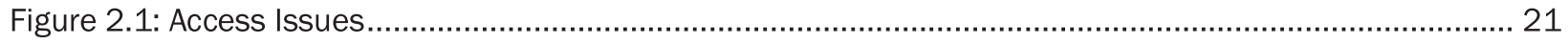




\section{Acronyms}

\begin{tabular}{|c|c|}
\hline $\mathrm{BHU}$ & Basic Health Unit \\
\hline CPR & Contraceptive Prevalence Rate \\
\hline DHQ & District Head Quarter \\
\hline DfID & Department for International Development \\
\hline ECP & Emergency Contraceptive \\
\hline FALAH & Family Advancement for Life and Health \\
\hline FFGD & Female Focus Group Discussion \\
\hline FGD & Focus Group Discussion \\
\hline FHT & Female Health Technician \\
\hline FIDI & Female In-depth Interview \\
\hline FMT & Female Medical Technician \\
\hline FP & Family Planning \\
\hline FWC & Family Welfare Center \\
\hline FWW & Family Welfare Worker \\
\hline GIS & Geographical Information System \\
\hline GYN & Gynaecologist \\
\hline HANDS & Health and Nutrition Development Society \\
\hline IDI & In-depth interview \\
\hline IEC & Information Education Communication \\
\hline IRB & Institutional Review Board \\
\hline IUCD & Intrauterine Contraceptive Device \\
\hline KP & Khyber Pakhtunkhwa \\
\hline LAM & Locational Amenorrhea Method \\
\hline LHV & Lady Health Visitor \\
\hline LHW & Lady Health Worker \\
\hline MAQ & Multidimensional Anxiety Questionnaire \\
\hline $\mathrm{MCH}$ & Mother and Child Health \\
\hline MBBS & Bachelor of Medicine and Surgery \\
\hline MFGD & Male Focus Group Discussion \\
\hline MHT & Male/ Medical Health Technician \\
\hline MICS & Multiple Indicator Cluster Survey \\
\hline MIDI & Male In-depth Interview \\
\hline MO & Medical Officer \\
\hline NGO & Non-Governmental Organization \\
\hline
\end{tabular}




$\begin{array}{ll}\text { PDHS } & \text { Pakistan Demographic Health Survey } \\ \text { PIDs } & \text { Pelvic Inflammatory Diseases } \\ \text { PPHI } & \text { Peoples Primary Health Initiative } \\ \text { PRSP } & \text { Punjab Rural Support Program } \\ \text { Pub } & \text { Public } \\ \text { Pvt } & \text { Private } \\ \text { QoC } & \text { Quality of Care } \\ \text { RAF } & \text { Research and Advocacy Fund } \\ \text { RH } & \text { Reproductive Health } \\ \text { RHC } & \text { Reproductive Health Center } \\ \text { SAHR } & \text { Salute, Assess, Help and Reassure } \\ \text { SPs } & \text { Service providers } \\ \text { SMS } & \text { Short Messages Service } \\ \text { THQ } & \text { Tehsil Head Quarter } \\ \text { TV } & \text { Television } \\ \text { UTI } & \text { Urinary Tract Infection } \\ \text { WMOs } & \text { Women Medical Officer }\end{array}$




\section{Acknowledgments}

This national study, "Investigating the Low Patterns of Modern Contraceptive Use in Pakistan", was conducted by the Population Council Pakistan, who gratefully acknowledge the financial support of the Maternal and Newborn Health Programme of the Research and Advocacy Fund (RAF), which made this research possible.

This study could not have been completed without the invaluable leadership of Dr. Gul Rashida, Senior Director Trainings at the Population Council, whose guidance, support, encouragement, and trust inspired the study team to navigate every obstacle with confidence. We greatly relied on the guidance of Dr. Zeba Sathar, Country Director for the Population Council.

We are deeply grateful to the departments of Health and Population Welfare as well as the provincial and district officers of the National Program for Family Planning and Primary Health Care, People's Primary Health Initiative (PPHI), and Punjab Rural Support Program (PRSP) for their cooperation and priceless support in the study districts. We especially thank staff at local basic health units (BHUs), particularly lady health workers (LHWs), for their help in recruiting respondents from communities and arranging in-depth interviews and focus group discussions.

We gratefully thank members of the Technical Advisory Group for their guidance and constructive recommendations in the development of the study report and policy recommendations. All TAG members are named, with their designations and departments, in Annex E.

We acknowledge RAF for the technical review of the report that led to its finalization. We also thank John Townsend, Vice President Reproductive Health and lan Askew, Director, Reproductive Health Services and Research for their invaluable reviews. We also owe our special thanks to Mrs. Seemin Ashfaq, Deputy Director Programs, Population Council for her valuable review of final draft of the report.

We would like to acknowledge and appreciate the contribution of Mr. Rehan Niazi, Deputy Program Officer at Population Council, who supported the study through its many stages, from field monitoring in Punjab and Sindh to resolving software issues for qualitative analysis. We sincerely thank Mr. Khan Muhammad, Deputy Program Manager, who took responsibility for monitoring field teams in Balochistan province despite security concerns. We also express our heartfelt thanks to Mr. Usman Asif, Deputy Training Coordinator, for his great support in obtaining permissions through correspondence and follow up with officials of study districts. We are grateful to Population Council's administration and finance and information technology departments for their invaluable support in every stage of this national study.

We also extend our sincere thanks to Mr. Usman Ghani, who provided outstanding support during field staff trainings, and afterwards managed and organized a huge data set single-handedly. The massive volume of data collected could never have been processed without the rapid translation into English by our energetic young team; we highly appreciate their efforts. We appreciate the contribution of Mr. Shahzad Ahmad with data processing. The contributions of Mr. Haider Abbasi and Mr. Ahmad Hassan, in processing data for software-supported qualitative analysis, were invaluable in producing this report on time; we extend them both our sincere thanks.

We are very thankful to each member of the research team who aptly used guidance for each stage in field work, from conducting interviews to transcription. They are named in Annex F.

We extend our earnest gratitude to the editor of this report, Ms. Kiren Khan, whose tireless efforts made it presentable. We thank Mr. Ali Ammad, who gave shape to this report through formatting and design. 
Finally, we would like to express our deep appreciation and respect to all the respondents who participated in this study and shared sensitive, personal information with our study teams. This study would not have been possible without their cooperation. 



\section{Executive Summary}

This report documents the study "Investigating the Low Patterns of Modern Contraceptive Use in Pakistan" conducted by Population Council Pakistan in 2014, as part of an extensive research project to determine why use of modern contraceptives in the country remains so low, despite large unmet need. The family planning (FP) scenario in Pakistan has changed significantly in recent years, and it is now recognized and understood that the reasons most often cited for unmet need require reappraisal, with qualitative research required for a deeper understanding of the attributes, experiences, reservations, and preferences that women, men, and service providers associate with specific contraceptive methods. Through this qualitative research, in addition to other methodologies, it will be possible to identify and address the real barriers to sustained and increased adoption of modern FP methods in Pakistan.

\section{Study Objectives and Methodology}

This qualitative study was conceived to fill the gaps in our knowledge of stakeholders' opinions of specific methods of modern contraception, with the following objectives: 1) assessing the knowledge, attitudes, and perceptions of men, women and providers about available contraceptives, and identifying reasons for their use and non-use; 2 ) identifying the obstacles to contraceptive availability to clients, particularly in rural areas; 3 ) assessing the existing quality of FP care offered in private and public health facilities, and its impact on client satisfaction and FP adoption; and 4) providing recommendations for strengthening program strategies, delivery mechanisms, and communications to enhance access to services and reduce unmet need for FP.

This study was conducted in eight districts: Khanewal and Rahim Yar Khan in Punjab; Khairpur and Umerkot in Sindh; Mardan and Mansehra in Khyber Pakhtunkhwa (KP); and Pishin and Sibi in Balochistan. This selection of districts provides, from each province in the country, representation from both a lesser and more developed district. Within each district, the study focused on four types of communities-rural and underserved by the public healthcare system; rural; semi-urban; and urban-targeting poor communities, where unmet need is highest. Within each community, primary data were collected in in-depth interviews (IDIs) and focus group discussions (FGDs) with four groups of stakeholders-women, men, lady health workers (LHWs), and service providers (SPs) at static facilities. Men and women were selected to represent current FP users, past users, and "never users". In all, IDls were conducted with 56 women, 33 men, and 23 LHWs. In addition, IDIs with 64 SPs (conducted under a related study) were included. A total of 71 FGDs were conducted separately with women, men, and LHWs. Data were analyzed in a structured process using Nvivo10 software.

\section{Findings and Conclusions}

Access to FP Services: Of all the access issues mentioned by men, women, and SPs, physical access appears to be the real challenge, especially for women in remote areas of Balochistan and KP where services are not available and the difficult terrain and scattered population intensify problems.

The second significant barrier to accessing FP in all districts and communities are financial constraints limiting people's ability to bear travel and contraceptive costs. Contraceptives are available free of cost in public facilities, but fewer public facilities and long distances between them make it difficult for current and intending users to afford the various costs of accessing services.

This study's most encouraging and significant finding is the diminishment of mothers-in-law and husbands' influence negative influences on FP. Instead of resisting FP, husbands are in conversations with their wives about selecting suitable FP methods. Pockets of resistance from husbands and mothers-in-law remain, however, in KP and Balochistan. 
Another important finding relates to the diminished significance of religion in FP decision-making, except in a few remote areas. All discussions with men and women strongly suggest that religion is not a significant factor in FP decision-making and use, although SPs consider it a barrier, citing the lingering influence of mullahs (religious leaders) on household decision-making.

While women and men are aware of almost all modern and traditional FP methods, they lack detailed knowledge on specific methods. This could be a significant block to accessing FP, especially when combined with fear of side effects and perceived harm of contraceptive use.

Quality of Care: Even when women and men are able to surmount the formidable obstacles to their access to FP care, their experience of service utilization may be marred by supply-side issues, specifically poor quality of care (QoC). Health facilities, particularly in the public sector, suffer from a number of shortcomings, including staff shortages or absenteeism, particularly female staff; short and irregular working hours; discourteous behavior and poor communication with clients; both inadequate attention and information provision; and pressure to use providers' private services. In some cases, staff is appointed but not available, or trained but not using its skills effectively or following protocols; moreover, many facilities do not provide client-friendly environments. Shortages or lack of contraceptive supplies further constrain people's method choice. Often a couple's preferred method of contraceptive is not available at a facility and couples are forced to choose another. The quality of contraceptive commodities-which can be poor-also affects whether couples use those methods or services over time.

Some SPs and LHWs report counseling women about potential side effects, and when their clients experience side effects, LHWs refer them to a static health facility for treatment. Users are often dissatisfied with the management of their side effects by public sector SPs, however, saying they lack knowledge or skill, or are absent, which leaves paramedical staff to treat patients in distress. LHWs are considered inadequate for helping with side effects.

These issues are more common in the public sector. Women and men are more satisfied with the quality of services at private health facilities, where they feel treated more respectfully and attentively, given proper checkups, and provided adequate information and counseling. In general, women and men appreciate the LHWs as committed and helpful resources who counsel them on minor issues, are able to supply them some contraceptives, and at times help them navigate public facilities.

Most SPs and LHWs believe FP is compatible with religion, although about a quarter of SPs believe that sterilization is not permissible in Islam.

Contraceptive Preferences: Contrary to general assumptions, people in rural, even remote, areas do not seem to harbor any overwhelming preference for traditional rather than modern methods. In fact, most of this study's respondents favored modern methods over traditional ones, noting that modern methods are more effective and reliable, and provide long term options for spacing, with traditional methods effective only periodically, with high failure rates. The few couples who prefer traditional methods favor them because there are no associated side effects, expenses, or problems with access.

When asked to describe their conception of an ideal contraceptive, respondents suggest similar attributes although different stakeholders and communities emphasize different features. Current and potential FP users, first and foremost, desire a contraceptive method that is completely reliable and providing long term spacing. Importantly, they would like it to be free of side effects, without any adverse effects on people's health or other spheres of life. A number of other attributes were also mentioned, such as painlessness, ease of use, little need for interactions with service providers, among others. 
Women and men suggested a single dose pill, palatable syrup, or a very small implant, like a microchip. Respondents also suggested improved access to this ideal contraceptive, mentioning, in particular, home or community delivery, skilled providers, and quality services. These responses clearly indicate lack of resistance by women and men to modern FP methods; rather, it is the how, when, and what of service delivery that requires reproductive health $(\mathrm{RH})$ policymakers' and implementers' attention.

Reasons for Discontinuation: According to the women and men consulted in this study, modern contraceptives may be discontinued for a host of reasons, broadly be categorized by: 1) changes in family plans, 2) method failure (to prevent pregnancy), 3) significant side effects or dissatisfaction with the method, 4) significant personal, social, and economic costs of living with side effects, and 5) difficulty in accessing the method.

Method failure is commonly associated with traditional methods, which leads couples to switch to more reliable modern methods, such as pills, condoms, or injections. Even modern methods, however, such as pills and condoms, are associated with method failure. Some modern method failures can be due to ineffective use--women often forget to take the pill daily-or to substandard products; in such cases, users often switch to the longer term methods.

Importantly, this study finds that the side effects of contraceptive use are the primary reason for discontinuation. A particularly worrying finding is that women are discontinuing because of side effects even in semi-urban and urban areas, with presumably relatively better access to SPs. Side effects are significant not only for the physical suffering they cause, especially to women, but also the deterioration in their quality of life, by compromising women's ability to work and engage in conjugal relations, or causing extra healthcare expenditures, and damaging marital relationships. Besides dealing with the physical toll of side effects such as heavy or irregular bleeding, women worry about the time, costs, and strain necessary for managing side effects. Sometimes those pressures, and not actual side effects, lead to discontinuation.

Method switching may be driven by method failure, or by side effects and associated life impacts, or by the healthcare system's failure to supply required products and services where and when users need them. In general, when users switch from traditional to modern methods, the direct cause is method failure. When method switching occurs in the opposite direction-from modern to traditional methods, or from hormonal to less reliable barrier methods-the underlying reason is usually side effects and their associated impacts.

A focus on discontinuation is important because traditional social and religious barriers to FP have diminished, and most households now accept FP as a means of managing household expenses, but the gains from this positive development are being undermined by the side effects, mostly women, experience from modern contraceptive use, not all of which are addressed satisfactorily.

\section{Recommendations}

Improving Access: A concerted effort should be made to improve Pakistan's FP service delivery system so it provides more services at people's doorsteps, including counseling and follow up. Lady health workers' roles and status should be extended and expanded, first by increasing the numbers of LHWs and appointing more in under-served and unserved rural areas. Appointing a community-based worker to be an LHW can also contribute significantly to contraceptive acceptance and use because most access problems are directly related to absence of service availability. Under-served areas in remote and rural parts of a district should receive FP services through diverse strategies such as mobile providers and regular camps, among others. Services in these areas should be free or by ability-to-pay. Regular provider visits to distant communities should be arranged to boost uptake of FP methods. 
Improving Quality of Care: Improved staff and contraceptive supply and quality are necessary for encouraging and retaining interest in FP among those who need it the most-individuals in the reproductive age group with limited means and options. Contraceptives should be free of cost and of good quality, to minimize side effects and negative experiences. In addition, in-service training as well as regular refresher trainings are necessary for improving SPs' technical skills and knowledge, in addition to behavioral training to enforce client-friendly attitudes and a client-friendly, welcoming environment in FP facilities.

Addressing Myths and Fears: Myths about contraceptives and fears of side effects need to be addressed by innovative and targeted media strategies. Not enough information is provided, and in a paucity of media and forms, that are both understood and accessible by the majority of reproductive age couples in low income or rural and remote areas. One FP method for which information and services are lacking is vasectomy; addressing this would enable couples to consider an option that limits family size without posing side effects and associated social and economic costs of methods used by women.

Management of Side Effects: Often, side effects propel couples back to traditional methods, which generally they know do not work well, when the balance between managing side effects and having another child favors the latter. A different strategy is necessary for inducing past users to return to FP use, as well as countering the fears of those with unmet need. Management of side effects at home can be one way to address the fear and experience of side effects, and counseling to help users manage those needs at home should account for most users' resource-poor contexts.

Age Specific Solutions: Information, education and communication (IEC), comprising motivation and counseling, should be age specific so users are offered realistic counseling that takes into account their physical and social realities.

Information and Services: A wider use of cellular technology and social media is needed. More comprehensive and widespread use of media is required to contact and engage hard to reach, underserved areas-information on methods and service locations and providers should be available through electronic media but can also be available through mobile SMS. For example, cellular phone and text messages, with graphics for illiterate users, can be used to remind them of pill, injection, or checkup dates; or motivational messages can be sent to husbands that include FP information on FP methods, as well as messages comparing costs of raising a child against all costs related to using a method, among others. Women and men should be able to call a helpline and have a local service provider contact them within 24 hours with FP advice and services. 


\section{Introduction}

This report forms part of an extensive research project to determine why, despite evident demand, contraceptive prevalence remains so low in Pakistan, especially for modern methods. The research has been conducted by Population Council with the support of the Research and Advocacy Fund (RAF), and comprises four component studies, including 1) review of relevant academic, program, and policy literature; 2) a qualitative study of the perspectives of men, women, and service providers (SPs) in the country on family planning (FP); 3 ) a situation analysis of contraceptive quality, supply, and access at health facilities; and 4) an examination of contraceptive availability.

This report presents the findings of the second component, a qualitative study of the perspectives of men, women, and SPs on family planning.

\section{The Unmet Need for Contraception}

Pakistan has one of the highest fertility rates in Asia, and lowest rates of contraceptive use, resulting in poor reproductive health $(\mathrm{RH})$ indicators for women and high neonatal mortality. ${ }^{1}$ In 2002 , the country's abortion rate was estimated at 27 per 1,000, while the rate of post-abortion complications-resulting largely from induced abortions-stood at nine per 1000; by 2012, the rate of post-abortion complications had risen to 15 per 1,000, implying that recourse to induced abortion may have increased. Despite this evident desire to limit pregnancies, however, growth in the contraceptive prevalence rate (CPR) has been slow. In fact, he Pakistan Demographic and Health Survey (PDHS) 2006-07 found that CPR had actually fallen and contraceptive stagnated. PDHS also established a large difference between the numbers of past users and current FP users, reflecting the significant proportion of women who use a method for a short time and discontinue use, returning to the category of unmet need. This phenomenon has been found to be a factor in the large estimated number of induced abortions. ${ }^{2}$

Figures from the latest PDHS (2012-13) indicate a modest increase in the CPR from 29.6 percent in 2007 to 35.4 percent in $2012 .{ }^{3}$ However, most of the increase in contraceptive use is in traditional methods; the use of modern contraceptives remains low. At the same time, a large unmet need persists for methods to space and limit children: overall demand for contraception is 70 percent, with 19.1 percent of respondents wanting a child later; 42.3 percent wanting no more children; and 8.9 percent being sterilized.

On the supply side, past efforts in primarily rural districts show that contraceptive uptake and continuation can be relatively rapid if providers and quality services are available; much of the problems with the delivery of FP services have been identified within the erratic supply chain for contraceptive methods and resultant irregular availability to providers and facilities. ${ }^{4}$

\footnotetext{
${ }^{1}$ Aga Khan University, International Advocacy Seminar on Family Planning and Reproductive Health, February 12-13, 2013 (Karachi: Department of Community Health Sciences, Aga Khan University, 2013).

2 G. Rashida, I. Kamran, K. Eshai and Z. Tasneem, "Post-abortion Care in Pakistan: The Influence of Gender and Poverty"(research brief, Population Council, Islamabad, 2013).

${ }^{3}$ National Institute of Population Studies (NIPS) and ICF International, Pakistan Demographic and Health Survey 2012-13 (Islamabad and Calverton, Maryland, USA: NIPS and ICF International).

${ }^{4}$ A. Mahmood, J. Arshad and M. Sadiq, Stock Analysis at Service Delivery Points for USAID-Supported Contraceptives: Final Report(Islamabad: Population Council, 2012).
} 
Low usage of modern contraceptives is associated with significant health and development costs. One in three pregnancies and childbirth-related deaths could be avoided if women who want to use contraception were able to access it. Use of effective contraception can also reduce the need for induced abortions, which currently lead to 700,000 complications cases at health facilities annually. ${ }^{5}$ Early and closely spaced multiple pregnancies are detrimental to the health of mothers and newborns. Closing the gap between contraception's demand and its supply, particularly in rural and poor urban areas, is essential for reducing maternal mortality, as well as neonatal mortality, and improving the wellbeing of millions of families.

\section{Need for the Research}

Traditionally, the primary reasons for unmet contraception need in Pakistan have been ascribed to supply side issues such as service access and quality and, secondly, to demand side obstacles such as husbands' approval of FP, general approval of modern contraception, and fear of side effects. Such explanations are based on responses to survey questions and appear straightforward. Today there is growing recognition that some reasons are more deeply rooted. Gaps exist for our information and understanding of specific methods of modern contraception, which are important and cannot be addressed entirely through crosssectional surveys. Qualitative research is required for a more in-depth exploration of people's preferences and reservations, including the perspectives of men and women for specific contraceptive methods and the real barriers in people's personal opinions and belief systems that prevent methods from being used.

It is also critical to take into account the ways in which the country's FP scenario has changed. Women and men are demanding FP services much more keenly and urgently now than 10 years ago. Today they may be discouraged from using modern contraception by different factors, such as poor quality of services, disillusionment with contraceptive products and providers, and high costs of procuring FP. Furthermore, while there may be better contraceptive availability, the crux of the issue may be providers themselves and their reluctance to provide FP services, especially within the public health system. Wider issues of healthcare quality may also be important factors.

Population Council's research was planned to investigate beyond the standard explanations of demand and supply constraints for the limited uptake of modern contraception in Pakistan. While the questions asked were similar to previous studies, the methods provided for deeper investigation, and our analysis linked findings from both the need and demand side to the supply side for a holistic and comprehensive view.

The findings of our research are expected to help explain the contraceptive prevalence trends identified by the Pakistan Demographic and Health Survey 2012-13, and to inform the decisions of a wide range of stakeholders, including national and provincial political leadership; policymakers and program managers concerned with FP, both in the public and the private sectors; civil society and research organizations with an interest in reproductive rights and services; and international institutions with an interest in Pakistan's population sector.

\section{Research Design}

Our investigation of the factors for low use of modern contraceptives in Pakistan comprises four studies, including an extensive literature review and three sets of primary data analysis. Specifically, the studies include:

1. Review and analysis of relevant literature, including academic, program, and policy sources on contraception need, demand, and supply in Pakistan;

\footnotetext{
${ }^{5}$ Z. Sathar et al. Post-abortion Care in Pakistan: A National Study (Islamabad: Population Council, 2013).
} 
2. Qualitative study of the perspectives of men, women, and providers, with in-depth interviews and focus group discussions of women and men, to understand their family planning views beyond standard responses, for deeper explanations of the lack of contraceptive use, combined with indepth interviews with service providers to assess their family planning knowledge and skills, belief systems, and level of comfort in discussing and counseling on family planning with clients;

3. Situation analysis of health facilities, gauging the state, quality, and accessibility of family planning services (at a representative set of public and private facilities); and

4. Examination of the contraceptive supply chain, from central warehouse to client, assessing its efficiency and identifying the administrative and logistic issues affecting all contraceptive availability.

Primary data for the latter three studies were collected from a carefully selected sample of communities representing urban and semi-urban, served and unserved, and rural areas in Pakistan's major four provinces. All three studies were conducted in the same districts to derive a complete picture of supply and demand factors, and provincial and national patterns.

Annex A presents a discussion of the overall conceptual framework for the four studies, outlining the features of each study and indicating the links between the studies. Because there are variations in the individual studies' specific objectives, precise research questions, and methodology, these aspects are described within the discussions of the individual studies.

This report presents the results of the qualitative study of the perspectives of men, women, and providers. A summary of the first study-the literature review-is also provided for context. The conceptual framework underlying these two studies is represented graphically in Figure 1.1.

Figure 1.1: Conceptual Framework for Literature Review and Qualitative Study

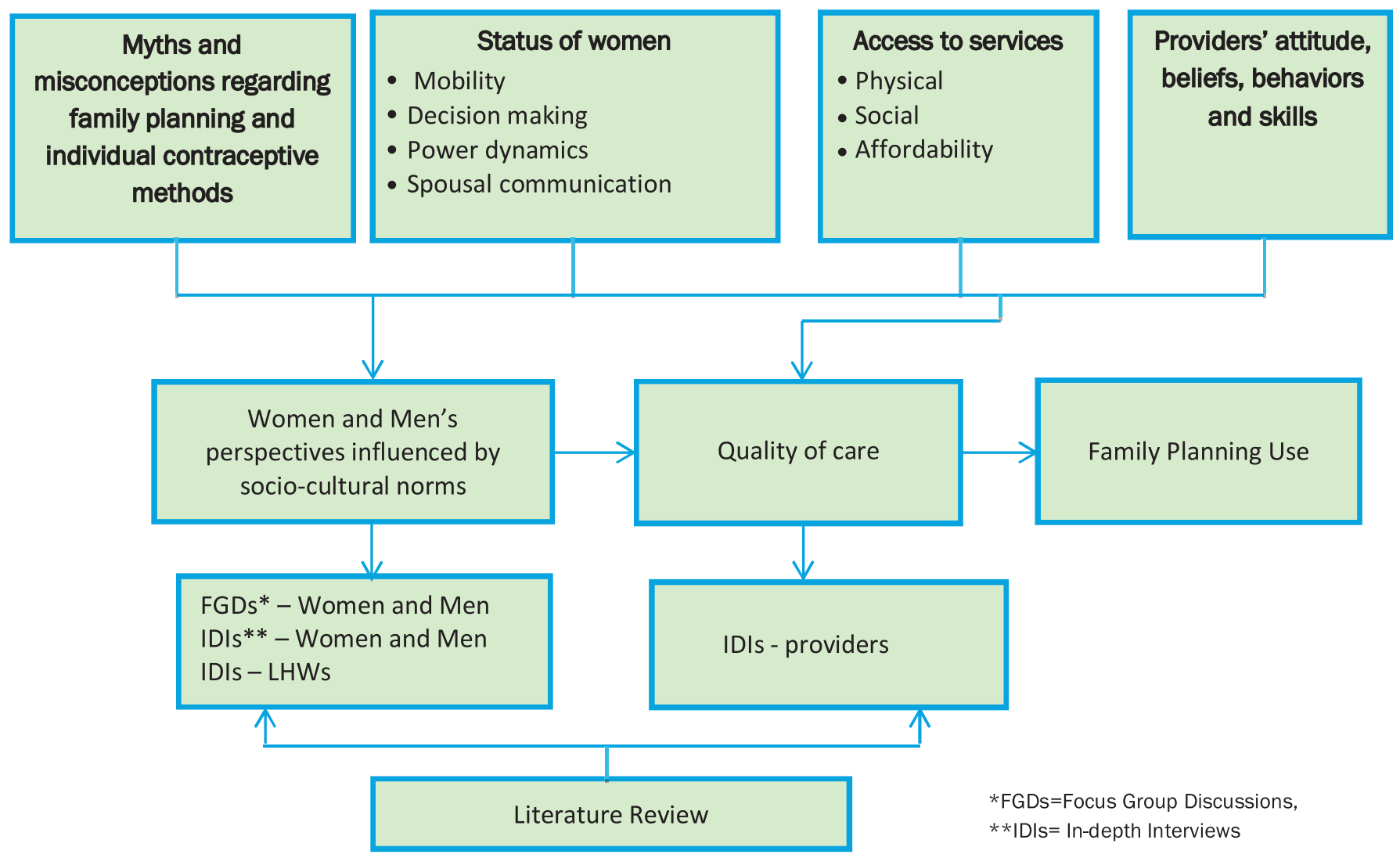




\section{Structure of the Report}

After the Introduction, this report presents the Design and Methodology for the qualitative study of the perspectives of men, women, and providers. In the Findings section, access issues hindering men and women from availing modern contraception are discussed, with further description of the issues of quality of care that affect people's experiences in using modern contraceptives. The contraceptive preferences of men, women, and service providers are also considered, and then the report looks at the reasons and dynamics underlying users' decisions to discontinue FP methods. Finally, the report presents the key Conclusions and a Discussion of the study, along with Recommendations for the way forward. 


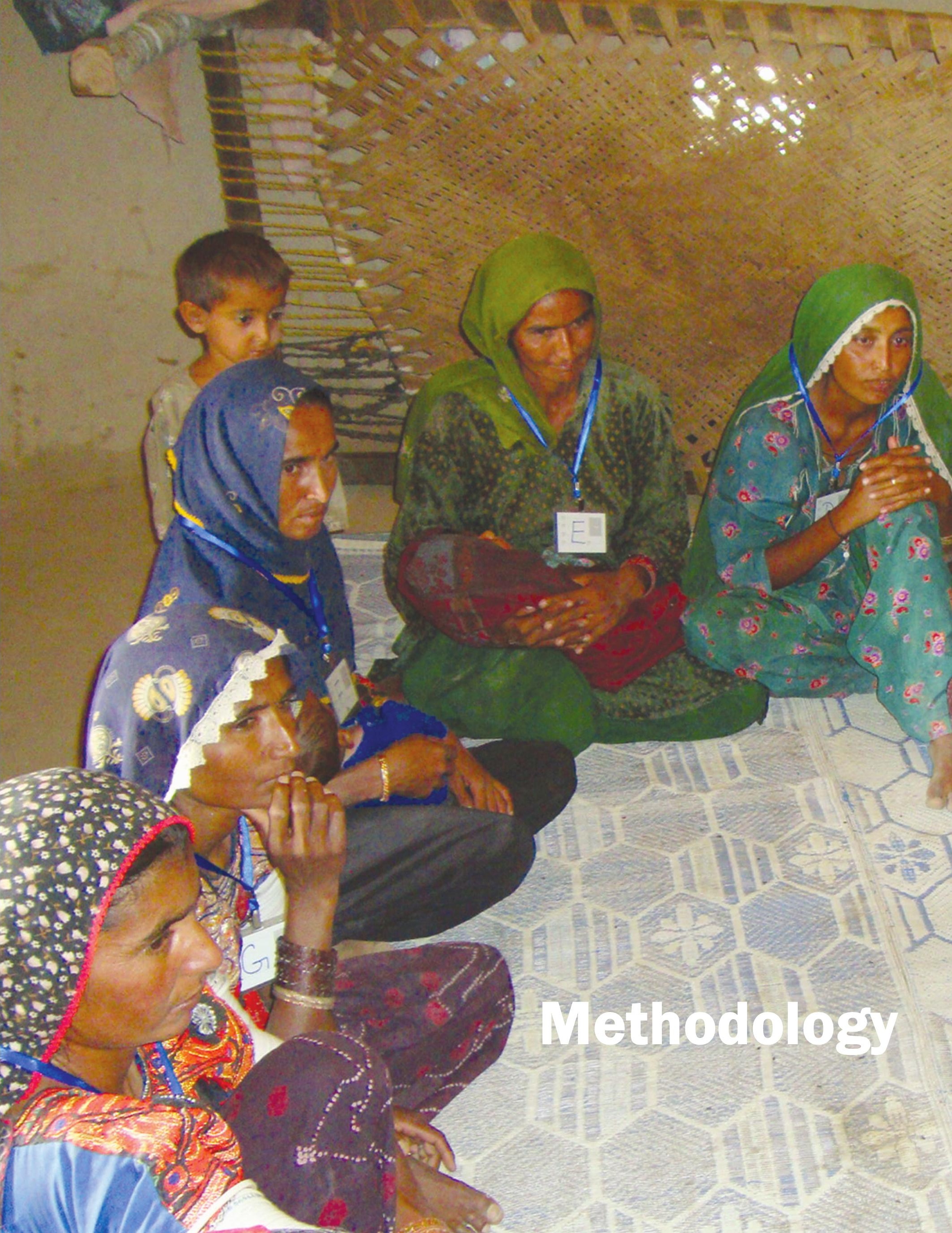





\section{Methodology}

The qualitative study of perspectives of men, women and providers on FP was a major undertaking designed to identify the deeper reasons behind the low modern contraceptive prevalence rate. We focused not only on assessing, more precisely, the knowledge and attitudes that are usually reported in the Pakistan Demographic and Health Survey (DHS), but also on probing the decision-making process to understand exactly what drives women towards choices other than modern contraception, why there is so much discontinuation of hormonal contraceptives, and what motivates and differentiates those women and men who do use contraception successfully and continuously.

A strong focus was maintained in the study on poor women, men and families, particularly those located in rural areas and in urban slums. This is because unmet need for contraception is highest, and contraceptive use lowest, among these groups. Women in poorer communities are most likely to face issues of access due to societal restrictions on their mobility, inability to afford services, dissuasive cultural norms, and overall disempowerment due to lack of education.

A graphical representation of the conceptual framework for this study has been presented earlier in Figure 1.1. This section outlines the objectives, research questions, and methodology of the study.

\section{Objectives}

The objectives of the qualitative study were to:

- Assess the knowledge levels, attitudes and perceptions of men, women and providers about available contraceptives and identify reasons for use and non-use;

- Identify the obstacles that impede the availability of contraceptives to clients, particularly in the rural areas;

- Assess the existing quality of FP care being offered in private and public health facilities and its impact on clients' satisfaction and FP adoption; and

- Provide recommendations for the departments of health and population welfare for strengthening program strategies, delivery mechanisms and communications to enhance access to services and reduce unmet need for FP.

\section{Research Questions}

Based on its objectives, this qualitative study responded to the following five research questions:

1. What are the demand-side factors that hold back women and men, especially those in rural and remote areas, from utilizing FP services (both public and private)?

2. What causes high drop outs and high contraceptive discontinuation rates for modern methods in Pakistan?

3. Why is there a preference for traditional methods?

4. How can we further examine the issue of access and quality of provision of FP services in Pakistan?

5. How important are providers and their own attitudes and beliefs in the delivery of FP services? 
Each of these five research questions were explored through a series of sub-questions:

Table 2.1: Research Questions and Sub-questions

\begin{tabular}{|c|c|}
\hline Primary Questions & Sub-questions/Sub-topics \\
\hline $\begin{array}{l}\text { What are the demand-side factors that } \\
\text { hold back women and men, especially } \\
\text { those in rural and remote areas, from } \\
\text { utilizing FP services (both public and } \\
\text { private)? }\end{array}$ & $\begin{array}{l}\text { - } \quad \text { Fear of modern contraception. } \\
\text { - Hole of religion in influencing adoption of modern contraception. } \\
\text { literacy settings and in certain regions. } \\
\text { - The social and economic costs of one or more visits to a FP provider. } \\
\text { - The degree of inter-spousal communications around fertility choices and } \\
\text { - } \quad \text { How important is the role of perceived and actual access to FP services? } \\
\text { - What are the most important qualities that women and men expect and } \\
\text { want from FP providers? }\end{array}$ \\
\hline $\begin{array}{l}\text { What causes high drop outs and high } \\
\text { contraceptive discontinuation rates for } \\
\text { modern methods in Pakistan? }\end{array}$ & $\begin{array}{l}\text { - The factors and service qualities that cause men and women to lose } \\
\text { trust in FP providers in the public health system. } \\
\text { The relative importance of positive and negative attributes of specific } \\
\text { contraceptive methods from the women's, husbands', and providers' } \\
\text { perspectives (e.g. is this method costly, is it convenient to use, whether } \\
\text { your spouse approves, is it really effective, among others). } \\
\text { - The role of counseling provided to women on side effects and effective } \\
\text { use of modern methods that influences women to try and, most } \\
\text { importantly, continue use of modern contraceptives. }\end{array}$ \\
\hline $\begin{array}{l}\text { Why is there a preference for traditional } \\
\text { methods? }\end{array}$ & $\begin{array}{l}\text { - } \quad \text { Are traditional methods more religiously and socially acceptable? } \\
\text { - } \quad \text { Are there fewer side effects and therefore more 'natural' and therefore } \\
\text { preferable? } \\
\text { - } \quad \text { Are there explicit strategies to cope with their failure-abortions? } \\
\text { - } \text { Are the costs and access of modern contraceptives a deterrent? }\end{array}$ \\
\hline $\begin{array}{l}\text { How can we further examine the issue } \\
\text { of access and quality of provision of FP } \\
\text { services in Pakistan? }\end{array}$ & $\begin{array}{l}\text { - Is distance from FP services the real constraint? } \\
\text { - What aspects other than distance encompass the concept of } \\
\text { accessibility to services? } \\
\text { - Are FP services more readily available in public or private facilities-what } \\
\text { level and type of facilities are more ready to provide such services? } \\
\text { Is there enough choice of contraceptive methods available to women } \\
\text { from poor settings? } \\
\text { How important are the costs related to travel and out-of-pocket } \\
\text { expenditures and waiting time involved? }\end{array}$ \\
\hline $\begin{array}{l}\text { How important are providers and their } \\
\text { own attitudes and beliefs in the delivery } \\
\text { of FP services? }\end{array}$ & $\begin{array}{l}\text { What is the role of quality of services, including availability of providers, } \\
\text { their training and behavior and personal beliefs? } \\
\text { What is the level of readiness to provide FP services in the public and } \\
\text { private sector? } \\
\text { - Are women and men effectively provided informed choices? } \\
\text { Are they given accurate and comprehensive information about how to } \\
\text { use methods effectively? }\end{array}$ \\
\hline
\end{tabular}




\section{Methodology}

A qualitative approach was adopted for this study because of the need for in-depth exploration of individual decision-making. At the outset, research questions and associated sub-questions were developed on the basis of the study objectives. These were used to develop open-ended questionnaires for to be used by interviewers in data collection from women, men and service providers.

The study sample was selected keeping in view the need to represent all four provinces of the country; the three key stakeholders (women and men with contraception need and service providers); and different types of communities (urban, semi-urban, rural and remote).

The two key modes of data collection included focus group discussions (FGDs) and in-depth interviews (IDIs). FDGs and IDIs were conducted with women and men with contraception need from sample communities, while IDIs were conducted with FP service providers. Data was collected in the form of audio recordings which were later assigned unique identification numbers (to preserve respondents' anonymity), transcribed and translated into English. The recorded data was then analyzed through a structured process.

Details about each of these stages are provided below.

\section{Selection of Study Sample}

\section{Districts}

The study was designed as a nationwide assessment. Two districts, one developed and the other less developed were purposively selected from each of the four provinces, Khyber Pakhtunkhwa (KP), Sindh, Punjab and Balochistan. Preference was given to districts that had been covered under an earlier "mapping survey" by Population Council, 6 so that available data of all public and private health facilities of selected districts could be used for sampling.

Selection process of districts from each province was different from each other; for Punjab, districts were selected on their CPR. One district with high and one with low CPR was selected according to latest MICS survey 2011. For Sindh one developed and other less developed districts were selected. The district selection process adopted for KP and Balochistan was different from what was adopted for Punjab and Sindh.

In KP and Balochistan provinces, districts were purposively selected with a view to avoiding the security risks prevailing in parts of both provinces. Districts selected from KP had also been covered under Population Council's earlier mapping survey. Since no GIS mapping survey data was available for any district of Balochistan, this criterion was not applied in selecting districts from the province.

The selected eight districts are listed in Table 2.2 and shown in Map 2.1, while their brief development profiles are provided in Annex- B.

Table 2.2: Names of the Selected Study Districts

\begin{tabular}{lll}
\hline Province & Developed Districts & Less Developed Districts \\
\hline Punjab & Khanewal & Rahim Yar Khan \\
Sindh & Khairpur & Umerkot \\
KP & Mardan & Mansehra \\
Balochistan & Pishin & Sibi \\
\hline
\end{tabular}

${ }^{6}$ Mapping of health and reproductive health services was carried out by Population Council in 35 districts of Pakistan under the FALAH, PAIMAN and Packard projects. 


\section{Map2.1: Geographical Coverage of the Project}

Districts visited for fieldwork

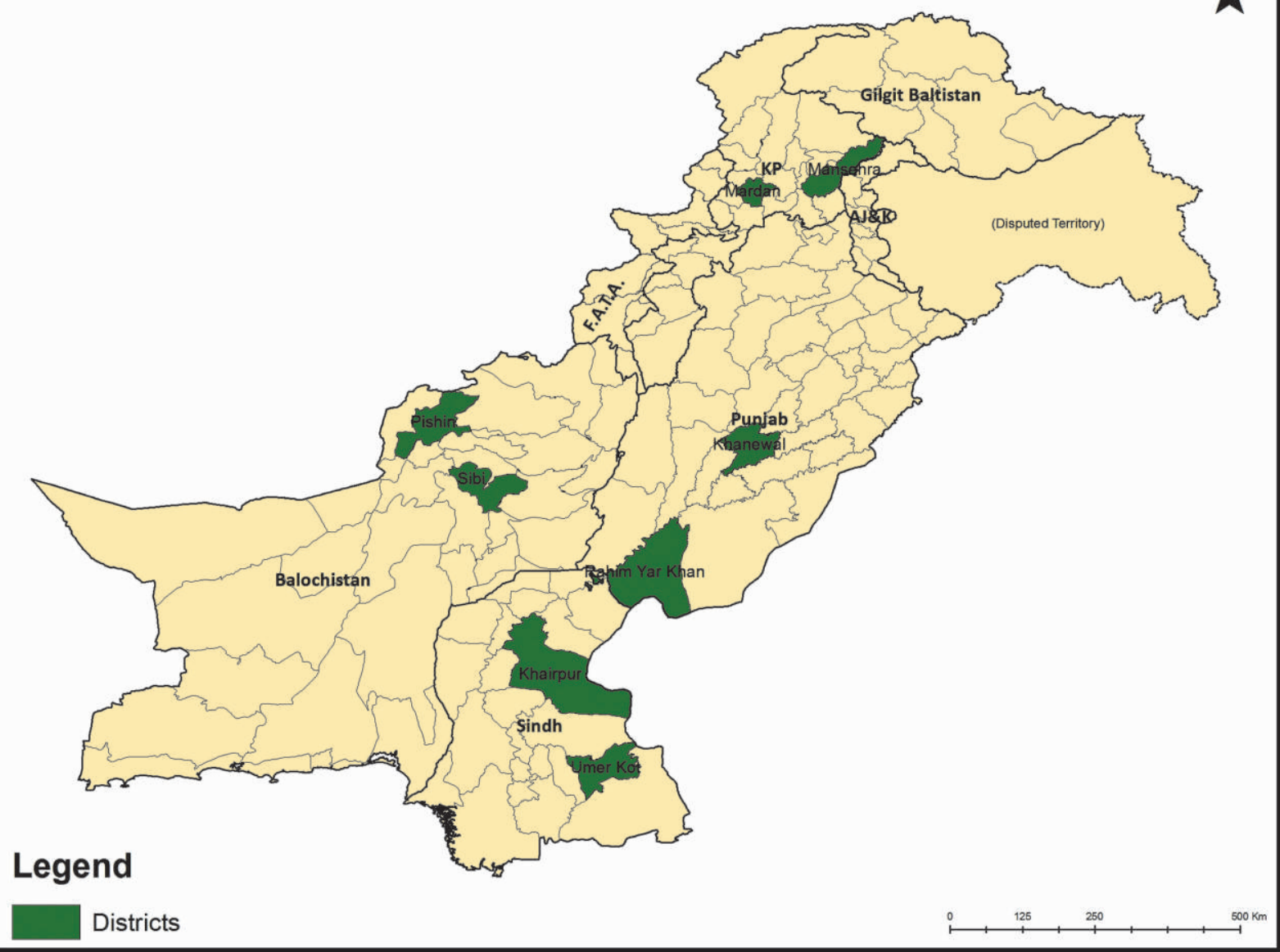

\section{Communities}

In each district, it was planned that three communities-one semi-urban, one rural served and unserved-would be identified for qualitative study. The purpose of selecting different types of communities was to capture the variation in issues related to FP access and quality of services across different development levels. The semiurban communities were quite well served with a number of health and reproductive health services. The rural served communities had a limited range of services available, and were at the very least served by a lady health worker (LHW). Rural unserved communities were defined by a "complete absence of any type of health services." While such communities are hard to identify and reach, their perspectives and experiences help in understanding the real challenges for such populations in accessing FP services.

The study team later decided to add one urban community from each district to the sample. The purpose was to see if there was any difference in preference for traditional over modern methods across the four types of communities. The addition of urban sites raised the total number of communities studied from the planned 24 to 32 (4 per district).

Selection of communities was carried out with the help of LHWs. Primary health and LHW program officials were requested to assign a few LHWs to help the study team identify study communities based on its community selection criteria, and conduct its interviews and group discussions. 
A special strategy was adopted for rural unserved communities, since they were not regularly served by any health care provider, public or private. Here, field teams mostly identified these areas on their own, with solicited guidance from local health officials or from vaccinators, who cover entire districts during vaccination programs and are very familiar with the situation of different types of communities. Sometimes, teams had to visit a number of areas in order to identify a site that met the criteria for "rural unserved area." Influential individuals in the selected rural unserved sites were contacted and requested for help in getting to know the community, rapport building, and organizing FGDs and IDIs.

\section{Selection of Study Respondents}

The study respondents included women and men from served and unserved rural, semi-urban and urban communities; LHWs serving the communities; and service providers at static health facilities.

Men and women from all communities were selected for in-depth interviews as well as focus group discussions. The inclusion criterion was the same for all men and women, i.e. they should currently be married. For in-depth interviews, an additional criterion was their FP use status. Women and men with all three use statuses (never, current and past) were to be interviewed from each community.

LHWs interact regularly with communities and offer special knowledge and insights about the problems that women have to face in adopting FP in the communities they serve. Thus, randomly selected LHWs from both rural and semi-urban/urban areas were also interviewed. Three LHWs were interviewed from every district.

Along with IDIs with community members and LHWs, IDIs with service providers were also conducted specifically under this qualitative study. These service providers were same who were also interviewed (structured) under the third component study forming part of Population Council's research, i.e. the Situation Analysis of Health Facilities. From the 173 IDIs of service providers, 64 were chosen for analysis in this study according to a defined selection process (Annex C).

\section{Men and Women}

In-depth interviews were conducted with a total of 56 women and 33 men from all served and unserved rural, semi-urban, and urban areas. A socio-demographic profile of these respondents is presented in Table 2.3.

Age: By and large, the mean age of men was higher than the mean age of women across the districts. Women from Balochistan were relatively younger though their mean number of children was the same as women from other districts. This may indicate a higher incidence of early age marriages in Balochistan.

Education: There was a sharp contrast in educational attainment between men and women; more than half of the women had never received any formal education (32/56) and amongst those who were educated, the majority had received schooling up to tenth grade. In comparison, almost all of the men are educated (31/33) and most of them had received up to 14 years of schooling.

Fertility: The mean number of children reported was almost the same for women and men from all districts, except in Punjab, where respondents reported a slightly higher number of children than other provinces.

Family planning use status: Among the women interviewed, 19 women were currently using an FP method (current users), 17 had stopped using any method (past users), while 20 women had never used any FP method (never users). Of the 33 men interviewed, nine were current users, 10 were past users and 14 were never users. 
Table 2.3: Socio-demographic Characteristics of Community Respondents (33 Men; 56 Women)

\begin{tabular}{|c|c|c|c|c|c|c|c|c|c|}
\hline & \multicolumn{9}{|c|}{ Provinces } \\
\hline & \multicolumn{2}{|c|}{ Punjab } & \multicolumn{2}{|c|}{ Sindh } & \multicolumn{2}{|c|}{ KP } & \multicolumn{2}{|c|}{ Balochistan } & \multirow{2}{*}{$\begin{array}{c}\text { Total } \% \text { of } \\
\text { Respondents }\end{array}$} \\
\hline & Men & Women & Men & Women & Men & Women & Men & Women & \\
\hline Mean age (years) & 36 & 33 & 33 & 32 & 36 & 33 & 33 & 29 & 33 \\
\hline \multicolumn{10}{|l|}{ Level of education } \\
\hline None & 0 & 8 & 2 & 11 & 0 & 7 & 0 & 6 & 34 \\
\hline $1-5$ grades & 2 & 1 & 3 & 2 & 0 & 2 & 0 & 5 & 15 \\
\hline $6-8$ grades & 3 & 2 & 2 & 1 & 1 & 2 & 0 & 0 & 11 \\
\hline $9-10$ grades & 0 & 2 & 0 & 1 & 2 & 2 & 1 & 2 & 10 \\
\hline 11 grades and above & 1 & 1 & 2 & 1 & 5 & 0 & 3 & 0 & 13 \\
\hline $\begin{array}{l}\text { Mean number } \\
\text { of children }\end{array}$ & 6 & 5 & 3 & 4 & 3 & 4 & 3 & 3 & 4 \\
\hline \multicolumn{10}{|l|}{ FP use status } \\
\hline Current user & 2 & 4 & 2 & 4 & 2 & 6 & 3 & 5 & 27 \\
\hline Never user & 3 & 5 & 4 & 7 & 5 & 3 & 2 & 5 & 34 \\
\hline Past user & 3 & 5 & 3 & 5 & 1 & 4 & 3 & 3 & 27 \\
\hline Total (N) & 8 & 14 & 9 & 16 & 8 & 13 & 8 & 13 & 89 \\
\hline
\end{tabular}

\section{Lady Health Workers}

Almost all of the lady health workers interviewed were young, and a majority had received education up to matriculation; a small number were educated above this level. LHWs in Punjab and KP had more work experience than their peers in Sindh and Balochistan.

Table 2.4: Socio-Demographic Profile of Lady Health Workers Interviewed ( $\mathbf{n = 2 3 )}$

\begin{tabular}{llllc}
\hline & \multicolumn{3}{c}{ Province } \\
\cline { 2 - 5 } & Punjab & Sindh & KP & Balochistan \\
\hline Mean age (years) & 38 & 34 & 37 & 31 \\
$\begin{array}{l}\text { Level of education } \\
\text { Middle }\end{array}$ & 1 & 1 & 3 & 0 \\
Matric & 2 & 1 & 2 & 3 \\
FA & 3 & 3 & 0 & 2 \\
BA & 0 & 0 & 1 & 1 \\
Marital status & & & & 4 \\
$\quad$ Married & 4 & 5 & 4 & 2 \\
$\quad$ Unmarried & 0 & 0 & 2 & 0 \\
$\quad$ Widow & 1 & 0 & 0 & 7 \\
Work experience & & & & $\mathbf{6}$ \\
$\quad$ Mean years & 11 & 8 & 11 & $\mathbf{6}$ \\
Total number of LHWs & $\mathbf{6}$ & $\mathbf{5}$ & & \\
\hline
\end{tabular}




\section{Service Providers at Static Facilities}

Among the 64 service providers selected for inclusion in this study, there was no difference in the mean ages of public and private service providers except in Sindh where private providers were relatively older than their public counterparts.

The majority of service providers with an MBBS qualification were working as woman medical officers (WMOs); a few were also working as gynecologists, particularly at private facilities. Almost all of the service providers who were qualified as $\mathrm{LHVs}^{7}$ were working on the same designation. Since the Population Welfare Department has its own special diploma for family welfare counselors (FWC), all service providers with this qualification were working only for the department. Only one dispenser (male) was interviewed because at one rural health center (RHC) level facility in Pishin district, no female service provider was available.

Mean figures for years of work experience indicated that service providers in the public sector are generally more experienced than providers in the private sector.

Table 2.5: Socio-demographic Profile of Service Providers Interviewed $(n=64)$

\begin{tabular}{|c|c|c|c|c|c|c|c|c|}
\hline & \multicolumn{2}{|c|}{ Punjab } & \multicolumn{2}{|c|}{ Sindh } & \multicolumn{2}{|c|}{ KP } & \multicolumn{2}{|c|}{ Balochistan } \\
\hline & Public & Private & Public & Private & Public & Private & Public & Private \\
\hline Mean age (years) & 38 & 33 & 36 & 52 & 37 & 38 & 41 & 41 \\
\hline \multicolumn{9}{|l|}{ Highest qualification } \\
\hline MBBS & 3 & 2 & 4 & 2 & 2 & 3 & 3 & 3 \\
\hline LHV/FHT diploma & 6 & 4 & 5 & 1 & 6 & 3 & 5 & 0 \\
\hline FWW/FWC diploma & 1 & 0 & 2 & 0 & 2 & 0 & 3 & 0 \\
\hline Others* & 0 & 0 & 0 & 3 & 0 & 0 & 1 & 0 \\
\hline \multicolumn{9}{|l|}{ Designation } \\
\hline Gynacologist & 1 & 1 & 0 & 2 & 0 & 1 & 1 & 0 \\
\hline WMO & 2 & 1 & 4 & 2 & 2 & 2 & 2 & 3 \\
\hline LHV/FHT/FMT & 5 & 4 & 5 & 2 & 6 & 3 & 5 & 0 \\
\hline Dispenser/MHT & 0 & 0 & 0 & 0 & 0 & 0 & 1 & 0 \\
\hline FWW/FWC & 2 & 0 & 2 & 0 & 2 & 0 & 3 & 0 \\
\hline Work experience (Mean years) & 15 & 8 & 12 & 14 & 16 & 11 & 15 & 14 \\
\hline Total number of SPs & 10 & 6 & 11 & 6 & 10 & 6 & 12 & 3 \\
\hline
\end{tabular}

Source: Service Providers.

FHT= Female Health Technician, FMT= Female Medical Technician, FWC= Family Welfare Counselor, FWW= Family Welfare Worker, LHV= Lady Health Visitor, MBBS=Bachelor of Medicine and Bachelor of Surgery, MHT= Male Health technician, WMO= Woman Medical Officer. * Others include Diploma in Gynecology and degree of Bachelor of Sciences in nursing.

\section{Study Instruments}

The study involved asking respondents personal and intimate questions about birth control practices and attitudes for a thorough investigation of their thinking regarding specific aspects of FP. This required the use of qualitative tools that could capture the perspectives of individuals in detail. Accordingly, the study selected IDIs and FGDs as its main tools for collecting data from different categories of respondents.

\footnotetext{
${ }^{7}$ LHVs are mid-level providers (24 months training in Public Health schools) working in static health facilities both public and private. They provide both preventive and curative services.
} 


\section{In-depth Interviews}

Men and Women: A total of 10 IDIs with community members were planned for each district, including six with women respondents and four with men, with the selection of interviewees covering all three FP user statusescurrent users, past users, and never users. A total of 89 such IDIs were actually conducted.

This component was aimed at furnishing the deeper reasons for the low modern CPR. The IDIs probed for personal responses about an array of contraceptives and their attributes, such as whether each method is convenient to use, effective, approved by spouse, affordable, has side effects, whether side effects are bearable or unbearable. These questions were asked of several sets of women and men, to compare those who have maintained continued use of modern or traditional methods to avoid an unwanted pregnancy with those who have discontinued contraceptive use and understand the phenomenon of high discontinuation rates.

The study concentrates, in particular, on the largest and most important group: those with unmet need and not currently using contraception, with a strong focus on poor women and their husbands and families, particularly those in rural areas and urban slums with high unmet need and low contraceptive use. Poor women in such communities are most likely to face issues of access due to societal restrictions on their mobility, nonaffordability of services, dissuasive cultural norms, and overall disempowerment due to lack of education.

LHWs: IDIs with LHWs, 24 in total (3 per district), assessed whether access, quality of care, or other social and cultural reasons pose the major obstacles to contraceptive use.

Service Providers at Static Facilities: Under the related study on situation analysis of health facilities, Population Council conducted IDIs with 173 SPs at static facilities in the same eight districts where the current qualitative study was conducted. The IDIs with SPs sought to understand their beliefs about FP, their perception about access and quality issues discouraging women and men from using contraceptives, related issues, and how SPs manage them. Of those 173 interviews, 64 were selected for analysis for this study.

\section{Focus Group Discussions}

Focus group discussions with women and men elicited responses about service access and quality, and a more general comparison of FP access versus other choices such as abortion, and questions on the religious, social, and economic costs of modern contraception.

A total 71 FGDs were conducted, with eight FGDs in each district, and two per community (served and unserved rural, semi-urban, urban)-one each with women and men (see profile of respondents in Annex D). An additional FGD with LHWs in each district further examined preferences for traditional versus modern methods in those areas (one LHW FGD could not be arranged due to lack of permission from the relevant department).

Table 2.6: Number of IDIs and FGDs by Categories and Province

\begin{tabular}{lccccc}
\hline & Punjab & Sindh & KP & Balochistan & Total \\
\hline IDIs & 14 & 16 & 13 & 13 & $\mathbf{5 6}$ \\
Female & 8 & 9 & 8 & 8 & $\mathbf{3 3}$ \\
Male & 16 & 17 & 16 & 15 & $\mathbf{6 4}$ \\
Service providers & 6 & 5 & 6 & 6 & $\mathbf{2 3}$ \\
LHWs & 8 & 8 & 8 & 8 & $\mathbf{3 2}$ \\
FGDs & 8 & 8 & 8 & 8 & $\mathbf{3 2}$ \\
Women* & 2 & 1 & 2 & 2 & $\mathbf{7}$ \\
Men** & 2 & & & \\
LHWs*** & & & & & \\
\hline
\end{tabular}

Number of respondents: *Women $=272, * * \operatorname{Men}=256, * * * \mathrm{LHWs}=60$. 
All IDIs and FGDs were audio recorded and then transcribed verbatim in the local languages. For each interview, the recorded files were assigned a unique identification number to ensure the anonymity of the respondent. The transcribed texts were then translated into English.

\section{Quality Assurance}

A number of quality assurance measures were undertaken to ensure the maintenance of highest quality of data collection.

Roles and responsibilities of each team member were clearly defined and they were provided with a written set of responsibilities and quality checklist.

A nine days comprehensive training was provided including hands on training on administering the guidelines of FGDs and IDIs through role plays and actual field practice. Emphasis was also given on how to adhere to the standard operating procedures.

During field work, the team supervisors daily discussed the field activities and checked the transcribed data. They also often observed the FGDs and IDIs being conducted to ensure that comprehensive and correct information was being collected. Senior staff of Population Council also visited the site to observe the process and provide on job guidance where needed.

\section{Analytical Framework and Process}

In addition to using the interview guide to develop the analysis codes, all transcripts were reviewed to identify emerging themes using the aims and objectives of the study as well as issues, concepts and themes brought up by the respondents to allow for the generation of new codes based upon the providers' own words.

After the coding of all transcripts using the Nvivo10 software, matrices were created to help identify patterns in the data. The matrices were organized at the IDI level. Each row in each matrix represented one interview and the relevant data from the interviewee were placed in the cell under the column headed with the matching code. The matrices were useful in grouping the different nuances within each theme, discerning differences and similarities between interviewees within themes, and making broader connections. To ensure maximum extraction from the interviews, the data was also sorted in Microsoft Excel using interview level matrices, and then analyzed using Nvivo10.

The major themes driving the analysis were those included in our research questions about general and specific views on contraceptive methods, and obstacles at home and in the community versus other supply side constraints that exclude men and women from accessing FP services. Comparison across communities by distance from foci of FP services, by gender, and by region were of central importance.

The FGDs with women and men, and the IDIs with women, men, and providers were analyzed separately to hone in on the specific perspectives of each type of stakeholder. In the analysis of data from women in particular, the study was able to identify age-related preferences, regional differences, and factors that discern users, nonusers and past users from each other.

Another major product of the analysis was the identification of ten case studies that typify the most commonly stated obstacles women and men face to depict reasons for unmet FP need. 


\section{Ethical Considerations}

Ethical considerations were given due importance at all stages of the study. The guiding principles for the study team included minimizing potential harm to participants, preserving respect for the human rights and dignity of participants at all times.

Ethical Approval: Before initiating the study, ethical approval was obtained from the Institutional Review Board (IRB) of the Population Council's headquarters in New York and the National Bioethics Committee in Pakistan.

Informed Consent: Informed consent was obtained from all study participants after providing an in-depth briefing on the study, its objectives, procedures and uses. Participation was voluntary and respondents were not compensated in any way. The approximate time required for the interviews and group discussion

Permission was obtained for recording the group discussions. Respondents were assured about the anonymity and confidentiality of their responses.

As follow-up of interviewees was required, permission was obtained from participants in advance and acceptable points of contact agreed upon.

Safe Interview Conditions: Participants were informed that they had the right to refuse to answer any question that made them uncomfortable, and they could terminate the interview at any time. Data collectors were especially trained to ensure sensitivity in their approach to limit adverse reactions.

Group discussions and in-depth interviews were conducted in private, maintaining auditory privacy. Interviews were arranged at times that suited the respondents, ensuring privacy and minimizing social risks and income loss. In compensation for their time or travel, refreshment was provided during FGDs.

Confidentiality in Data Storage and Use: All data collected for the study were kept confidential and stored securely, without identifiers of individuals. Access to non-anonymous data was restricted to researchers directly involved in the study. Where possible, any information that could identify or trace research participants was excluded from questionnaires and transcripts. FGD participants were identified only by codes. 


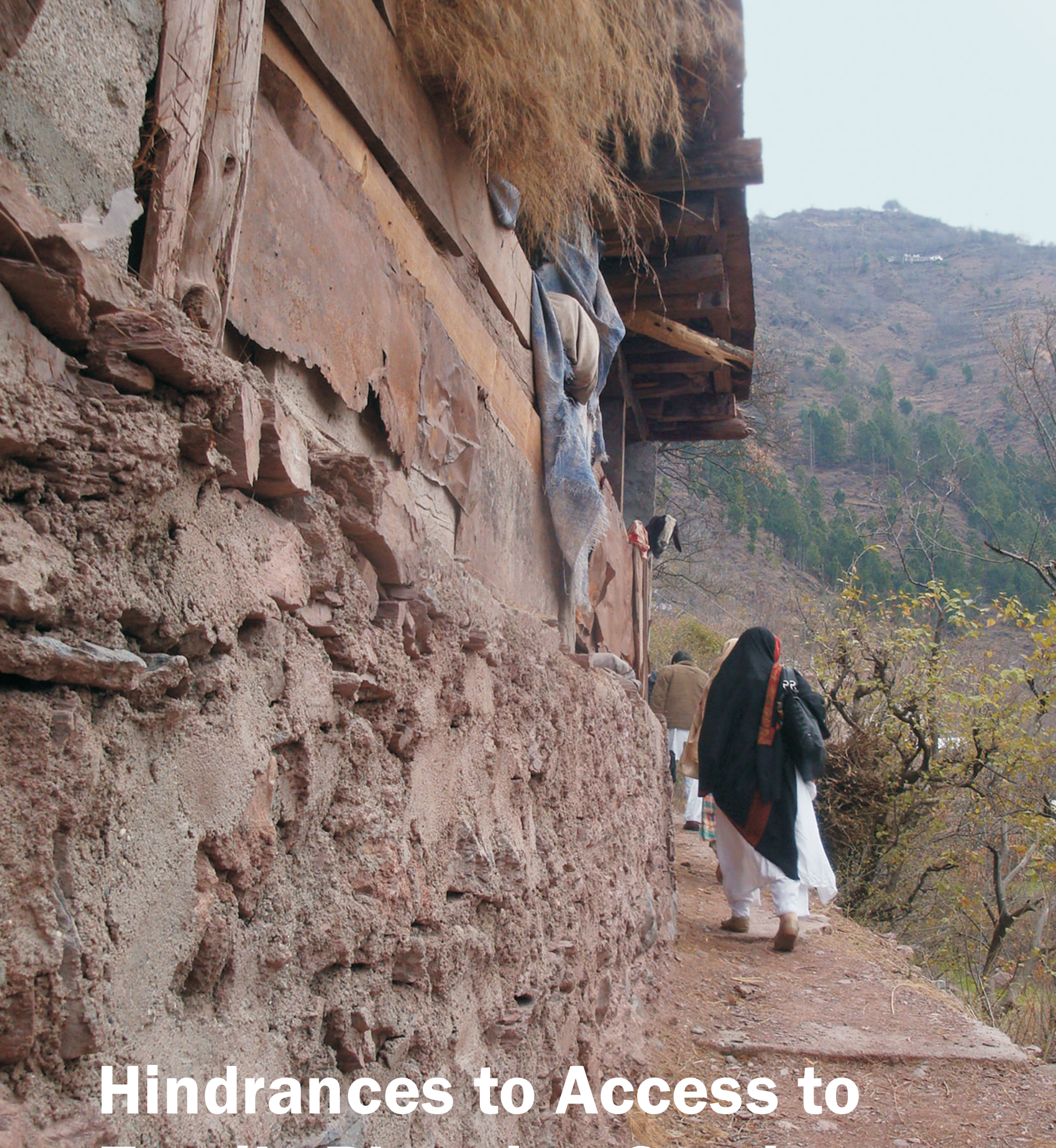

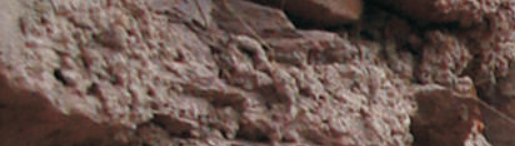

extertion

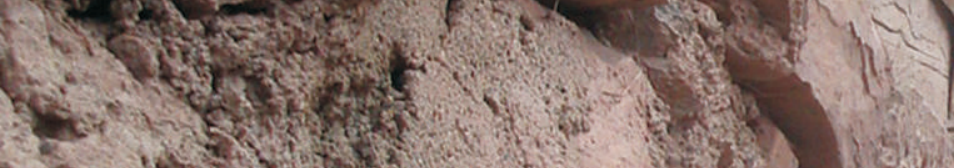

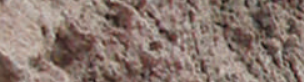

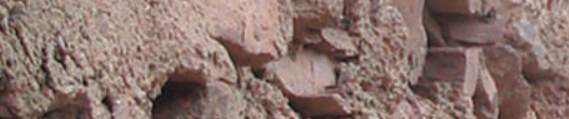




\section{Main Findings}

- Physical access is the real challenge, especially for women who live in rural unserved areas of Balochistan and KP where services are not available and the rugged terrain and scattered settlement pattern further exacerbate the problem.

- The high costs of travel as well as lost time and wages entailed in FP service utilization are unbearable for many cash-strapped families and communities.

- Instead of resisting FP, husbands are taking to their wives about which FP methods to use; their previous negative role is turning into a supportive one.

- The role of mothers-in-law in decision making regarding FP use is diminishing.

- The influence of religion on FP-related decisions and choices has diminished, except in a few rural unserved pockets.

- While men and women are aware of almost all modern and traditional methods of FP, method-specific detailed knowledge is still lacking, which can be a possible hurdle in accessing FP services.

- Men and women in rural areas often lack time to follow up on their FP intentions because they face heavy daily workloads, which are compounded for women by the rigors of bearing and looking after children.

- Apprehensions about side effects of different contraceptive methods comprise an important issue holding men and women back from accessing FP services.

- Negative advocacy related to side effects stops women and couples from adopting FP methods. 


\section{Hindrances to Access to Family Planning Services}

\section{Research questions to be addressed in this section:}

1. What are the demand side factors that hold back women and men?

- Role of religion in influencing adoption of modern contraception

- The particularly low status of women in poor and low literacy settings and in certain regions

- The social and economic costs of one or more visits to a family planning provider

- The degree of inter-spousal communications that takes place around fertility choices and contraceptive use

How important is the role of perceived and actual access to family planning services?

2. How can we further unpack the issue of access and quality of provision of family planning services in Pakistan?

- Is distance from family planning services the real constraint?

- What aspects other than distance encompass the concept of accessibility to services?

- How important are the costs related to travel and out of pocket expenditures?

Newly married couples in Pakistan face significant social pressure to have the first child as soon as possible after marriage, more to establish the wife's ability to bear children than to confirm the husband's potency. Family planning is, therefore, a delayed phenomenon. In most cases, contraception only becomes a possibility after one or two children have been borne. However, even when they want to space their children, and despite knowledge of FP methods (99\% women and 96\% men know at least one FP method according to PDHS 201213), many couples are unable to adopt FP. A key reason for this is that they are unable to access FP services, which prevents them from using contraceptives.

This section explores the main access issues identified by women and men from rural served and unserved, semi-urban and urban areas, as well as by LHWs and other facility-based service providers, based on the perspectives and experiences shared by them during the IDIs and FGDs conducted under this study.

\section{Overview of Key Issues}

This study identified a number of access issues in adoption of FP that had not been anticipated before data collection. The issues and barriers can be categorized broadly as follows:

- Difficulty in physical access,

- Financial constraints,

- Intra-household dynamics,

- Religious and cultural factors,

- Lack of knowledge of FP methods, and

- Apprehensions about side effects.

Perceptions about the importance and role of each issue varied according to the type of community (i.e. whether served or unserved, and rural, semi-urban or urban), the level of service provider, and type of health facility, public or private.

Difficulty in physical access to services was reported as an obstacle by women (30/56), men (21/33), service providers (37/64) and LHWs (7/21). Women and men in almost all of the served and unserved rural communities considered it a major issue in adopting FP. Women and men from semi-urban and urban areas, 
however, did not mention physical access as a significant barrier, as FP facilities were available in their area, and proximity relieved them, at least, of travel costs. Availability of service providers in the private sector also reduces issues of physical access.

Financial constraints are an important issue, and women and men frequently mentioned cost of travel as a barrier, particularly respondents from served and unserved rural areas, whereas cost of contraceptives is hardly discussed as a problem except by a few men, women and service providers who note it more for contraceptives purchased from private providers.

Intra-household dynamics hinder uptake of FP according to service providers (56/64) and LHWs (18/21) based on their observations and perceptions. Two-thirds of women (35/56) and less than half of men (14/33) also noted these hindrances based on their personal experiences and community observations. Notably, the majority of women had not experienced any resistance from husbands, and 44 of the 56 women interviewed spoke of the positive role of their husbands in the decision to take up FP and to choose a method. Despite this experience, however, women did mention husbands in the general discussion about barriers to FP, their observations based perhaps more on the general male decision-making role in society than on actual evidence.

The role of the mother-in-law in decision making related to FP use is also reducing except from KP and Balochistan-both relatively traditional societies. This indicates that, for all practical purposes, the role of husband and family, particularly of the mother-in-law, is not as negative as portrayed in earlier studies. The reason for this change can well be the family set up, increased access to media, and the pressure a large family poses on meager family finances. Though negative roles of husband and mother-in-law are gradually converting into positive now, however, general household responsibilities have been identified as an important factor which can hold women back from accessing FP services and methods across all communities.

Quite surprisingly, only a few respondents from KP and Balochistan mentioned religion as the reason why FP is not acceptable, despite the large number that did discuss religion and culture (31 women, 22 men, 14 LHWs and 50 SPs). In general, the data shows that religion does not act as a barrier in accessing FP services, nor do people take it into account if they want to use contraceptives. Only women and men from Balochistan mentioned that their cultural and tribal practices, which pressurize men to produce more and more children, also prevent them to use FP. Men from all types of communities mentioned that lack of method specific knowledge also acts as a barrier in adopting FP because it becomes hard for them to choose a method.

Lastly, apprehensions about side effects of contraceptive methods came up as a major barrier from over half of the women (31/56) and majority of the service providers (53/64) as compared to men (9/33).8 According to the majority of respondents, rumors related to side effects have a ripple effect in holding women back from FP use. Moreover, side effects were mentioned as a main concern of women from all type of communities, particularly rural unserved areas, due to lack of information.

When the role and importance of each of the access issues are assessed, physical access issues emerge as the main barrier, particularly for served and unserved rural areas. Discouraging household dynamics, such as non-supportive roles of husbands, family in general or mother-in-law, are gradually fading, particularly in Punjab and Sindh, and in semi-urban and urban areas, as is the significance of religion in FP decision-making. Each of these aspects is discussed in the sections that follow.

\footnotetext{
8While "side effects" are medically known to be associated with use of some contraceptives, for the purposes of this discussion, "perceived harm" relates to health problems that are not medically known to be related but which are perceived by users to be connected because they arise during contraceptive use.
} 
Figure 2.1: Hindrances to Access to Family Planning Services

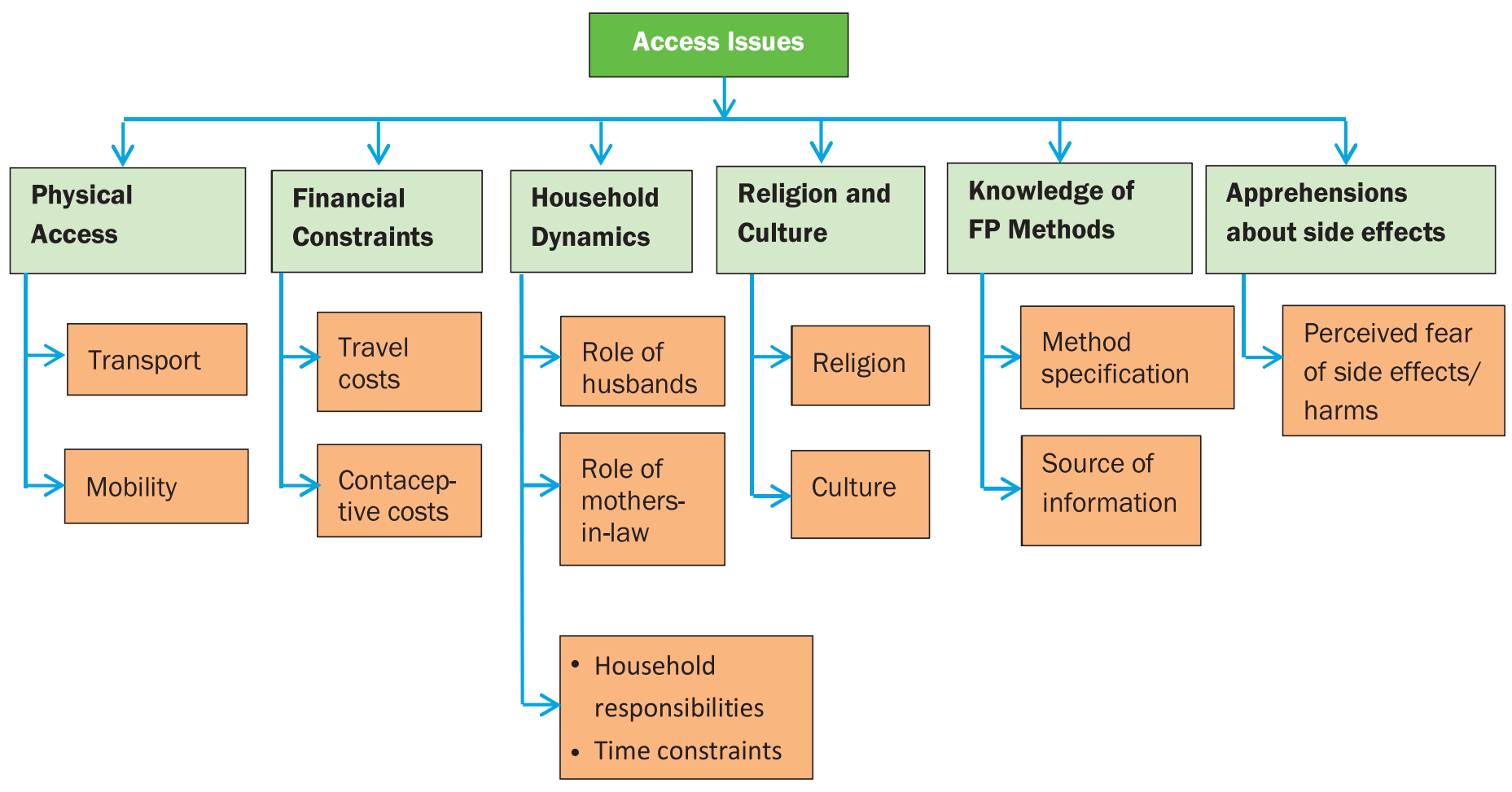

\section{Physical Access}

Overall, the existence of physical access issues is strongly endorsed by service providers (37/64), men (21/33 IDIs), and women (30/56 IDIs and 95/201 FGD respondents). In IDIs and FGDs it was reported as a significant barrier in adopting FP, particularly by women and men belonging to rural served as well as rural unserved areas. These respondents report that not only are FP services unavailable within their communities, but the nearest facilities are also located at considerable distances, so reaching a service provider is a major issue for them. As a man from a rural unserved community in Khanewal adds, the absence of services in the community means the people are deprived of the chance to choose any FP method on their own.

Here, there is no such service available. We have to take them to Sibi. If there is any such service in Sibi, then it is OK. Otherwise, we have to take them to Quetta. The issue is that we don't have services in our village. MIDI-22, 30 years old, 3 children, Current user; Rural served- Sibi

We have lots of problems here. Neither the LHW comes here, nor is there any center nearby where we can get it (contraceptives) from. So people who use it go very far to get it. FIDI-17, 28 years old, 1 child, Past user; Rural unserved- Mardan

In our area, there is no service available. People, especially women, are very worried. They want to get these methods. They want to take these medicines but these are not available to them. FFGD-14; Rural unserved-Pishin

We don't have these facilities here. If someone needs them, he has to travel to Khairpur. It costs 2000 rupees to travel to Khairpur. Poor persons cannot afford it. MFGD-27; Rural unserved-Khairpur 
Generally, service providers from KP (Mansehra) and Balochistan (Pishin and Sibi) consider physical access more an issue for women who live in mountainous areas, where the terrain and hard weather conditions such as rain, snowfall and landslides impede access to services. Sometimes, women have to return home without reaching the facility when they encounter sudden land sliding that blocks the route. In Balochistan, particularly, services are not available everywhere and physical distance becomes an important barrier for scattered communities living in areas far from the main towns.

\section{Transport Issues}

Women and men from rural unserved areas, both during IDIs and FGDs, and service providers particularly from Balochistan mention lack of transportation as one of the key challenges in FP access. In such areas, transportation is not frequently available and sometimes people have to access facilities on foot or on donkey carts. Extreme temperatures exacerbate the problem. SPs note, for example, that, in the intense heat (Sibi often records the highest temperature in the country), couples avoid traveling to service providers unless they have their own vehicles, usually bicycles or motor cycles.

For this (FP) method you need to go to the city. Who would go till there? There should be a transport for going till there. But we don't have anything. FFGD-14; Rural unserved-Pishin

The poor people come here either on foot or on a donkey cart. People come from far away. This is a problem for them. Like, right now, they walk and come here. Heat is intense. It causes problems in eyes. There is a problem of transport. (In the hot summers, only) those people come who have bicycles and motorcycles. IDISP-112, Govt, BHU, FMT; Sibi

Women and men from a semi-urban community in Rahim Yar Khan claim (during FGDs), however, that physical access is not a big issue because, generally, health facilities are available in all areas.

There is no such thing. Every house has a transport. There is no problem in going here and there. When there was no transport, this used to be a problem. Within 20 minutes, people get into the cities. MFGD17; Rural served-RY Khan

There is no problem with the transport. The hospital is nearby and whoever wants to go there can go. FFGD-18; Semi urban-RY Khan

Likewise, service providers of Punjab and Sindh are quite dismissive of physical access as an issue, placing the onus on the determination and will of the women or couple once they decide to use FP. They assume that access is ensured as all areas are served at least by the LHWs, apparently unaware of the situation in underserved and unserved areas.

Now these (methods) are available everywhere. There are different centers from where methods are available to those that are near to them. Injections-they get it from government hospitals and are also available at different stores. IDISP-5, Govt, THQ, WMO; Khairpur

If you talk on that level, how can they not reach? If there is a certain BHU at a place and there are around 30 LHWs and they are coming from different villages, then how cannot the people reach it? I don't think these are the barriers. I don't believe in that. If a family has decided that they will use contraceptives then how is it possible that it is a barrier? The main thing is the will power. IDSP-162, Pvt, DHQ, GYN; Khanewal

\section{Mobility Issues}

Generally, problems of money, time and transport are common across all rural unserved communities. These are further compounded by the restricted mobility of women in the traditional societies of Balochistan and KP, according to the majority of interviewees from these provinces. Faced with so many obstacles, women may not be able to adopt FP even if they want to. 
In our area, there is no service nor is anything available. We have to buy it from the market from the medical store, which we cannot afford. On one hand, our mobility is very difficult and the medical store is also very far away from us. FIDI-26, 30 years old, 3 children, Past User; Rural unserved-Pishin

There are a lot of problems. Roads also close, and they get blocked because of the sliding. This is a huge thing for us; it brings us a lot of stress.FFGD-7; Rural unserved-Mansehra

Male respondents are aware that female mobility is a big problem in rural served areas, particularly of Balochistan, as they cannot go to any facility unaccompanied and it is not socially acceptable for a woman to make repeated visits to a health facility.

There is a clear unmet need among women and men of rural unserved areas considering their positive attitude towards FP and their desire to space pregnancies; practical challenges hold them back from choosing and using contraceptives.

When there is no service provider available in the community, couples may use methods that they can purchase on their own, such as pills. Women from Pishin mentioned that their husbands bring injectables for them but dispensing becomes an issue. The options they have at community level for dispensing may lead to many side effects.

They (husbands) get us pills. We can take them ourselves. Even if they bring an injection, firstly, there is no one to dispense it. Here, there is a man he can dispense it, but we don't get it done from him. Our husbands don't like it. Then, there is a community woman here, she can inject it for us....she has (received no training) learnt it herself. She gives us an injection but after that if the injection stays fine or not, there is no guarantee. It's like shooting an arrow in the dark. If you get it, then it's fine. Otherwise, we get lumps on our arms. FIDI-26, 30 years old, 3 children, Past user; Rural unserved-Pishin

In such circumstances, where facilities are not available, female mobility is restricted, no proper transport is available, and people have to travel on foot or on animal-drawn carts for long hours, particularly in Balochistan, it is not surprising that keeping FP a priority is difficult for women.

Now, look, it is such a problem for the woman to get out of the house. And if you get permission from home, then you can't walk to the hospital, which is so far away. For this, then, we have to arrange for some transport. And when we get the transport, then, after getting there, we get depressed as after all this hospital closes in a short while; if the hospital was open, then we could get the family planning services. FFGD-13; Semi urban-Pishin

Lack of transport affects the service providers as well. According to a member of a rural served community in Sibi district where the LHW does not belong to the local area, since there is no transport, she does not visit, effectively leaving the community an unserved area.

There are no services. LHWs don't have transport. They do not belong to the village. If they were educated in the village, everyone would have the services. There is no educated person in the nearby village or in our own village. MIDI-22, 30 years old, 3 children, Current user; Rural served-Sibi.

\section{Financial Constraints}

Poverty can override the intention to adopt FP, as the financial cost of contraceptives and travel deters potential users. The financial implications of FP were discussed in over half of female IDIs (27) and two thirds of male IDIs (22), as well as in FGDs (approximately one quarter of female FGDs and a fifth of male FGDs) and with SPs (46/64). Travel costs emerged as more significant than contraceptive costs, except in IDIs with SPS, and in female and male FGDs contraceptive costs were said to be more important than travel costs. Both categories of financial costs, however, directly affect the intentions of the poor and those who live in rural served or unserved areas with limited services. 
They want to do it. But they cannot. They don't have clothes on their backs, shoes on their feet, food in their stomachs. They cannot fulfill basic needs and they live in poverty. Their basic needs are not met. There is too much inflation and due to that their needs are not met. FFGD-2; Rural unserved-Khanewal

We are dying from unemployment. There is no money for eating. Who thinks about these things? There is nothing here. MFGD-23; Rural unserved-Sibi

I told you about the financial conditions that on one side there is poverty and on the other hand the hospital is 10 or 12 kilometers away, so for this reason, using these methods is out of our range. MIDI12, 34 years old, 3 children, Never user; Rural unserved-Mardan

\section{Travel Costs}

Access issues are generally compounded by poverty; thus, physical access is a combination of poverty and the other issues discussed earlier. Men from KP explained that all these problems and barriers are interlinked and access is a complex issue. According to men and women, accessing distantly located facilities for FP is often unthinkable for women of rural unserved areas, posing an insurmountable challenge with the combination of money, time, and transport constraints and restrictions on female mobility.

Service providers concede that poverty, travel time and cost and transport may prevent women from visiting FP service facilities and providers but they do not consider physical access an important barrier to accessing services. This gap between provider perspectives and that of potential clients is significant since it may be symptomatic of the dismissive provider attitude that clients often complain as noted in the section of Quality of Care.

Lack of financial means and the cost of transport are concerns voiced by all communities, whether served or unserved in rural area or urban. The financial burden posed by high transport costs, and the virtual absence of public transport connecting rural unserved areas of the districts to the nearest health facility or town where FP services could be availed is enough to deter those who need such services the most.

Yes, they do face a problem in getting there because, sometimes, there is no transport available, and they don't go. Some people are poor and can't pay for it. How can they go then? When the charges of transport are so high, how can a person go? For a poor household even Rs. 10mean a lot. These people think that in the evening they would rather take something worth Rs. 10for their son or daughter. Usually they have a problem with money. This is why they end up leaving it (FP). FIDI-29, 20 years old, 1 child, Never user; Rural served-RY Khan

Yes, this is an issue: that who will go to Umerkot? First they need to have money in their hand, then they will go to Umerkot for spacing between kids. FIDI-56, 43 years old, 5 children, Never user; Rural unserved-Umerkot

A man from rural unserved Punjab elaborates that the main problem is conveyance, since a person who wants to use a method worth six rupees has to spend 65 rupees on transport. When facilities are available locally, it saves time as well as travel costs. The problem of physical access issues compounded by poverty confronts all rural unserved communities across all the provinces.

And even then, how can they think (of taking action on their FP decision)? Consider that Khanpur is at a distance of approximately 35 kilometers and Fairza lies about 40 kilometers away. When the people's pockets do not allow them to travel that distance, how would they be able to go? MIDI-20, 42 years old, 7 children, Never user; Rural unserved-RY Khan

We haven't heard that someone is using any family planning method. Inflation is increasing, fuel is costly, and fares have been increased. We rely on cultivation and profits are the same. How can we afford family planning expenses? MFGD-27; Rural unserved-Khairpur

Transport is problematic, not just in rural unserved communities but also in rural served areas, because facilities are located at relatively long distances. Men from Balochistan explain that they do not feel 
comfortable travelling by public transport with their womenfolk; private vehicles have to be hired for the purpose, which cost about 5,000 rupees for a return journey. In such conditions, keeping FP a priority is hugely challenging for resource-constrained couples, especially given that the availability and quality of services is not assured even when they are able to make the journey, and the fact that a one-time visit may not be enough, especially where side effects of modern methods need to be managed.

Women who live in areas served by LHWs generally do not have a problem getting pills or condoms, as the LHW is the main source for providing these contraceptives. For other methods, however, they have to travel to facilities outside the community or visit the city hospitals, which involve transportation costs that are not easy to manage for rural served, semi-urban or urban women.

Yes, this can also be an issue that people go for some transport but they don't have the required money for paying the fare-that is the reason people back off from doing spacing. FIDI-53, 22 years old, 2 children, Never user; Semi Urban-Umerkot

The situation is different in those semi-urban and urban areas where a range of FP services are available locally, and people do not have to incur travel costs. As explained by a man from a semi-urban, facilities are available in the vicinity, people have to pay only 10 to 15 rupees in transport fares, and the hospital charges only two rupees; thus, physical and financial access is not a problem.

Only a few service providers from Balochistan regard travel costs a major problem when facilities are not nearby, and acknowledged that people willing to bear the cost of contraceptives might be prevented from the prohibitively higher expense of travel.

They can usually buy them; they can get pills for 10 rupees. They will get injection for 150 rupees. If it is not (available) in their district, obviously, then they will go to Pishin, and that will be costly for them. So they will not get it. They will not spend 400 rupees on transport and will not give 150 rupees for DepoProvera. They will give up and say, "Keep sitting here like this. IDISP-77, Pvt, RHC, WMO; Pishin

\section{Contraceptive Costs}

Contraceptive costs were mentioned as an issue by most women in FGDs, but only by a few men and women in IDIs. The poor, who are unable to access public health facilities due to distance or non-availability of their desired contraceptives, are left with no option but private providers, which are more expensive.

It costs money to come and go, and then, in order to buy any method, you need money, which my husband doesn't have. He only earns enough to feed us...We want to have space between our kids but we don't get any method at all, nor can we buy it ourselves. Here, everyone is poor. We make a living with a lot of difficulty. How can they buy any method with money? With a lot of difficulty they arrange dry chapatti for us. Everyone is like this in our village, leading their lives with a lot of difficulty. If one time we even buy a method, then after it finishes, we cannot buy it a second time. Then we leave it and pregnancy stays. FIDI-26, 30 years old, 3 children, Past User; Rural unserved-Pishin

The poor cannot spend much so where should they get family planning methods even if they want to use them? They do not have enough money, so they don't have any option other than giving birth to children because family planning methods are expensive while giving birth is not. I have already spent Rs. 3,0004,000 on these methods but I don't do it anymore. FFGD-1; Rural served-Khanewal

Look, this is also a reason that we don't have medicines (contraceptives) available in the hospitals. I get my wife injected so I get the injections from the medical store. It would have been good if I got this medicine for free. But I buy it with my own money. One injection costs me 150 rupees. I get my wife injected so that she doesn't get pregnant because she gets very ill due to pregnancy. MFGD-21; Semi urban-Sibi

IUDs cannot be used by the poor people because they cost around 500 to 600 rupees. How can they afford it? FIDI-5, 38 years old, 6 children, Past user; Semi-urban-Khanewal 
Women from Pishin district particularly spoke about poverty as a barrier to contraceptive uptake as private clinics charge a heavy amount, especially for IUCDs and female sterilization. Such costs are unaffordable for the poor and they end up not using FP methods.

Yes, [IUCD] is very expensive. Women cannot afford it. This is far from the reach of an ordinary person; this is also why people can't do it. People cannot afford it. FFGD-16; Rural served-Pishin

Poor people only use condoms and pills or the natural methods; nothing other than these, because on these methods, no money is spent. For the injection, there is a separate expenditure. And a lot of money is needed for an operation or button (IUCD). So poor people who don't have enough resources to fulfill their needs of hunger, where will they get money for spending on family planning? This is why people mostly don't prefer these methods on which a lot of money is spent. FFGD-13; Semi urban-Pishin

Another method of nalbandi (female sterilization), no one gets done here. You have to go far away for this as well. And this method is also not in Bohra city. For this, you need to go to Quetta. And who can make a journey of five hours? And then, after going to Quetta, get a checkup done and then give so much more money-it is a very big problem! And this is why, in our area, no one likes it. FFGD-14; Rural unserved-Pishin

On the supply side, there is an interesting difference in perceptions between public and private sector service providers. Providers from the public sector do not consider contraceptive costs a serious issue, mainly because their facilities provide contraceptives free of cost.

No, there is nothing like that. None of our methods are more than three rupees. The IUCD is also for three rupees, so this sort of problem has not been seen. It is another matter if a nurse in the center is giving it to them at different prices. But we have no pressure from the organization. What are three rupees? Anyone can afford it. There is no such problem. IDISP-72, Govt, FWC, FWW; Pishin

On the other hand, service providers in the private sector admit that contraceptive charges are high particularly for IUCDs and implants, and thus hard for people to afford. Their high costs limit the FP methods available to resource-constrained users.

I have told our medical superintendent that people here cannot afford these things (contraceptives) that our institution (a private MCH Center) provides. We provide IUCDs for Rs. 200 and people cannot get these things because of poverty. IDISP-25, Pvt, MCH Center, LHV; Mansehra

Since contraceptive cost is not the only expense that people who come from a distance have to bear, couples may postpone or give up on their desire to use modern contraceptives when they take into account the cumulative expense that will be incurred.

Yes, there are financial problems because obviously they come from afar and after a long travel. And there are places where the service providers charge more so the people say that they cannot afford the expense because in our areas private clinics charge a lot. So that is why the people do not come: because they say that they cannot afford it. IDISP-29, Govt, THQ, WMO; Mansehra

\section{Intra-Household Dynamics}

Family planning decisions are not individual decisions, but involve other family members, such as a spouse or mother-in-law, and are influenced by intra-household dynamics. In Pakistan, the influence of husbands and mothers-in-law has been considered very important, mostly in their opposition to FP. This study reveals, while they still play an important role, it is now a more positive and supportive one. 


\section{Role of Husbands}

An encouraging finding is that husbands are generally supportive of FP, as noted by 44 of the total 56 IDIs and FGDs with women. While a substantial number of service providers still perceive husbands as a barrier, the reality is changing in all provinces, particularly in Punjab and Sindh, where men are becoming more supportive of FP, primarily because it can help avoid the economic burden posed by a large family size.

Communication on family size takes place between all couples regardless of whether they reside in served and unserved rural or semi-urban communities. This positive development suggests that when couples discuss their fertility intentions with each other, in the majority of cases, if not all, there is a possibility of convergence on the use FP methods. As later sections show, husbands are well aware of the side effects of most methodspills, injections, IUCDs-used in their community or by their wives. They are actively involved in choosing the best method, and also encourage her to change a method if side effects are experienced.

We thought about it from the first child. Initially I was very weak and keeping my health in mind he decided on family planning. He said that if there would be young kids then it would be hard for me to take care of them; therefore we should have spacing between births. In this way I would be able to take care of the house and raise them in a better way. This is how we thought about this decision to do family planning. FIDI-3, 30 years old, 4 children, Current user; Rural unserved-Khanewal

The husband will [initiate discussion regarding FP] because he has to bear the costs of raising too many children. Otherwise, the wife will push him to fulfill the expenses of their children. So it is clear that the husband will initiate the matter. MFGD-1; Rural unserved-Khanewal

Yes, we did, that's why I went for two injections because we thought before it gets too late we should start spacing, and I took injections ... Let these kids grow a little ... I was scared that what if I conceive again? ... Then the doctor asked me to continue further, but I refused as now I wanted to have a baby. We both [my husband and I] did. FIDI-51, 28 years old, 4 children, Past user; Rural served-Umerkot

The situation in KP and Balochistan is slightly different; here, culture exerts a relatively stronger influence on the role of husbands. Women, in only a few cases, mentioned the negative and non-supportive attitude of their husbands. Husbands remain the primary decision-makers and play a vital role in enabling or hindering wives from using contraceptives, as noted in the FGDs with women, men and service providers. Thus, when husbands are in favor of FP, they support their wives morally as well as financially, the latter being an important factor, since most women in Pakistan are economically dependent on their husbands, and this support is crucial in overcoming cost and access barriers.

I think the husband's permission is a big problem. Like my husband didn't say it before, so I had three kids. Now when my husband said it, I used the method. If my husband wouldn't have said it to me, I wouldn't have gotten the injection because, without the permission of the husband, women cannot even go to the door of the house. So how can we go to the hospital? FIDI-22, 26 years old, 3 children, Current user; Semi-urban-Pishin

Usually husbands have a problem; they think that when they are providing food on the table, the women of the house should not have a problem in bearing children. Husbands and wives usually get into such arguments. If the husbands don't agree, the wives cannot practice contraception. Usually they come without telling anyone and use [FP] methods. IDISP-55, Govt, BHU, LHV; Mardan

The cultural influence on the role of husbands was clear from conversations in Pishin district, indicating that sometimes a husband does not support his wife in adopting FP because of societal and tribal pressures to prove his masculinity by having more children, particularly sons.

There are a lot of women whose husbands want more kids. If someone has fewer kids then people make fun of them. They say what happened? You are a man. You don't even have the strength to have kids. Due to these things, the husbands don't allow their wives (to use contraceptives). FIDI-22, 26 years old, 3 children, Current User; Semi urban-Pishin 


\section{Role of Mothers-in-Law}

Another surprising finding of this study is the diminished role of mothers-in-law in decision-making regarding FP. Almost half of women (28/56) and men (14/33) interviewed, as well as three fourths of the female FGD respondents, did not mention mothers-in-law as a barrier in FP adoption.

It is evident from the IDIs of women and men, most of the time the decision to adopt FP is taken only with the mutual understanding of husbands and wives.

I don't talk to anyone else except for my husband. Then it is up to him to listen. We discuss with each other before taking any step. FIDI-4, 27 years old, 5 children, Never user; Rural unserved-Khanewal

However, while mother-in-law opposition has faded, in some cases, as in conservative families in KP and Balochistan, their role remains important, especially since they retain control over the mobility of women of the household-giving permission for who goes where and does what remains in their domain. Men from KP and Balochistan explain that elders, particularly mothers-in-law, have a strong influence on decision-making, and since they are more traditional and more likely to listen to the religious clerics, they oppose FP. In such cases, without the permission of the mother-in-law, it is difficult to adopt FP.

Social pressure from the family and community to have more sons can also influence a couple's decision to postpone use of FP methods.

Mothers-in-law ... in our society are very strict; they do not give permission to the women to go outside the house. They cannot go alone to the BHU and the men are embarrassed (to go with them), so this is also an obstacle that they cannot go anywhere because of some problems. MIDI-10, 35 years old, 2 children, Past user; Rural served-Mardan

The husband, mother-in-law and the father-in-law don't agree. They say don't take the daughter- in- law anywhere [for FP] and [she should] produce a baby every year. Because we want more boys and those families who have a large number of boys are considered as the strongest here. They want a son every year, whether the daughter-in-law lives or dies. FIDI-26, 30 years old, 3 children, Past user; Rural unserved-Pishin

Service providers from static facilities place more emphasis on the role of the mother-in-law (54/64) and mention their FP opposition. This may well be based on cases where the woman brings the mother-in-law to the provider so that she can help persuade her.

\section{Women Taking Action in the Face of Opposition}

When support from key household members, such as husbands and mothers-in-law, is not forthcoming, women who are determined use FP secretly. They realize, however, that due to mobility and financial constraints, the likelihood of keeping their use a secret is rather slim.

There are some women, who want to do it without their husbands' knowledge, but they face transport problems and there are some methods for which [SPS] take money and they don't have enough money for it, so they are unable to use any method. FIDI-16, 28 years old, 2 children, Current user; UrbanMardan

Service providers, especially from Balochistan and KP, are aware that women who desire to space births circumvent opposition from husbands or mothers-in-law by concealing their use of FP methods from them. These women face extra challenges because, given the restrictions on mobility, leaving the house and keeping the reason for it hidden is difficult. They try and mitigate this by pretending to accompany a female neighbor, friend or relative to the health provider with the excuse that they need medicines for some general ailments. Sometimes, they are not even allowed to go out without their mothers-in-law; in such situations, the women discuss it with the service provider in private and request her to provide any FP method keeping it confidential. 
There are some women that are not allowed to do family planning by their in-laws or their husbands don't allow for this; they themselves are willing to do spacing. There are also clients that come to me secretly as they are not allowed yet they come and in this way they have spacing between their kids. At times, the mother-in-law also creates issues; there are many women that come out with the excuse of medicine and they come to take some method as well and no one gets to know about anything. IDISP-6, Govt, MCH Center, LHV; Khairpur

People here are very well informed about family planning but the mothers-in-law create a little trouble. So the women say, "Do not give me a family planning method in front of my mother-in-law." A girl came to us and her mother-in-law waited outside so she said, "Please, don't do it in front of her." Another girl who came with her mother-in-law said, "Please, inform my mother-in-law that you gave me injection for pain," but in reality the injection is for family planning. The women here are aware about the family planning methods but the mother-in-laws say, "No, we only want grandchildren." IDISP-30, Govt, RHC, LHV; Mansehra

\section{Household Responsibilities and Time Constraints}

The primary role of women in Pakistan is seen as managing the household. Their responsibilities include the elderly and the children, cooking, laundry, household livestock (cattle, goats, poultry), and fetching fuel and water (where such civic amenities are absent). They may also be involved in wage labor or piecemeal work. This heavy workload in the large households typical of families (6-12 members) take up the better part of the day, leaving little time for anything else.

Women's lack of time for health care and visiting FP service providers was considered an important barrier to accessing FP services by almost one third of service providers (28/64), especially for women in rural, unserved areas, since they have to take out a full day to visit a health care provider, often far away. Women from other areas also find it difficult to leave their houses and children, or take time off from work if they are employed. They cannot be seen to be neglecting their household responsibilities, nor is it easy for them to make any alternate arrangements if they disrupt their daily routine. Thus, women will often postpone appointments, which results in an unplanned pregnancy, or not go at all despite their wish to use a FP method. Often, the long and expensive journey to the health facility ends in disappointment as they arrive just as the facility is closing for the day, a phenomenon experienced by women who may not live too far away, but can only go once they have completed their daily responsibilities. In both cases, repeat visits are not possible for women.

The women here are very busy with work at home. They are either employed as domestic labor or they work on the fields and find it very hard to take out time [for FP]. IDISP-146, Pvt, LHV Clinic, LHV; Khanewal

Some women that come to our health center arrive around 2:00 pm. When they are done with their housework and we also have to leave about this time. So we tell them to come the next day. But by the time they come again, they have already conceived. But we always try that whosoever comes to the health center takes a method. IDISP-123,Govt,THQ,LHV;Umerkot

As pointed out by SPs, men and women also mentioned time constraints as a barrier to adopting FP. The personal experiences of four women emphasize how shortage of time postpones crucial visits to SPs, leading to unwanted pregnancy, and how a single failed visit (due to facility closing or running out of contraceptives) can leave a woman is unable to justify taking time for another visit to unsupportive household members.

I told my husband to take me for the operation but we did not go as we didn't get time for it, and by the time we did, I had conceived and had a baby boy ... I was always stuck due to housework; looking after cows and cattle, etc. ... It is very hard for women to leave the houses. When someone comes from so far away and the medicine is not there, then they don't have permission to leave the houses again. FIDI-45, 42 years old, 7 children, Past user; Rural served- Khairpur 
They are doing all the work. If someone wants to go to the civil hospital, then she should be totally free from household work. It is always crowded, while the private hospital charges a high fee. FFGD-4; Semi Urban-Khanewal

We go spend money, leave our housework, then we can't even do work at home. Time also gets wasted as who can go this far? If [contraception] is made available here, then we can manage both easily. We will even use spacing injections and, along with that, do our housework. In this way, things will be easy and our time will not be wasted. FIDI-55, 39 years old, 4 children, Past User; Rural unserved-UmerKot

Some have their time wasted in the journey. They don't find the time to go to the health center. They keep on delaying it because something always comes up and in the end they don't pay attention as a result. MIDI-2, 32 years old, Past user; Rural unserved-Khanewal

\section{Religious and Cultural Factors}

All the discussions with men and women strongly suggest that religion is not a significant factor in FP decisionmaking and use. There is a sharp discrepancy between perception and practice, and between attitude and behavior. Initially, the never users or past users may state that religious considerations played a role in their decision, but further probing often reveals that the reason for non-FP use lies elsewhere-often in a desire for more sons, temporary or permanent infertility, or long periods of natural spacing. When none of these factors are present, and a decision to space is to be made, it is not considered a "sin" but a need. Only six of the 34 Never Users with whom IDIs were conducted said that their non-use of FP methods was due to religion.

Who follows religion? Religious leaders advise us to offer prayer. Are we offering prayer? Today is Friday. Very few people will offer Friday prayer. Religion is not an issue; the main issue is money. MFGD-27; Rural unserved-Khairpur

No sister, thanks to Allah, we have no such problem in our area. It is in our religion that a mother should feed her milk to her baby for two years. This also causes space. If spacing was a sin, then spacing would not have been mentioned in the Holy Quran. And there is also an Islamic method for spacing. My husband does that. FFGD-22; Rural served-Sibi

Islam also teaches us ... there should be a space of two years ... MFGD-16; Rural served-Pishin

Gender and regional differences are seen in perceptions during IDIs and FGDs. When asked whether religion is a barrier to using FP, generally, men noted that "people" say that spacing or limiting children means to counter God's will, but that in practice people were not against FP.

People call it non-Islamic. This is the murder of humanity. Most people get offended talking on this topic. The people who are educated and intelligent, they use [FP methods]. MFGD-13; Semi urban-Pishin

Some female respondents, mainly from Punjab, even argued that Islam allows FP, referring to Quranic verses and traditions that support breastfeeding so mothers can space pregnancies. They asserted, from a religious point of view, that fewer children are preferable to more children who cannot be taken care of. Most feel, however, that while religion permits spacing, it does not condone terminal methods.

... In Islam, there is permission for family planning. It is written in the Quran that if you breastfeed ... for two years, then those two years should be considered as birth spacing. Recently, on TV, they were talking about how the Quran and Sharia allows having birth spacing. It is not a sin to do family planning according to Quran and Hadith. FIDI-3, 30 years old, 4 children, Current user; Rural unserved-Khanewal

Why can we not do it? They say that when a woman breastfeeds ..., she will not get pregnant. This is family planning. Or some people say that after giving birth ... a woman will not get menses. It is in [accordance with] Islam that people should first look at their economic conditions and then start a family accordingly ... keep on producing kids and later on face problems in educating them. Why isn't there permission? Some people also try to use the withdrawal method. FIDI-29, 20 years old, 1 child, Never user; Rural served-RY Khan 
Men have more to say on this issue; those from KP and Balochistan are more likely to take a conservative view. Men from KP feel maulvis (religious clerics) are the main source of perceptions discouraging people from using FP. Clerics reportedly say things like women who will produce more children will go to heaven and please God and the Prophet (peace be upon him). These emotional appeals affect people, and are accompanied by disapproval of those who practice FP. Sometimes men with few children are taunted for being impotent.

Mostly, the maulvi sahibs [religious clerics] say that our Prophet used to be very happy on the birth of children and on the Day of Judgment our Prophet would be proud that his generation has increased so much. On the Day of Judgment, Prophet and God will be happy, till the time we keep on using the Prophet's method then God will be happy with us. So the religious clerics say about family planning that it is not allowed. MIDI-12, 34 years old, 3 children, Never user; Rural unserved-Mardan

Some religious clerics say that God causes people to be born and God ... will give the food. The saying of the last prophet is that increase my umma. And often the religious clerics target the person ... using family planning. Often they look at the person directly in the mosque and point him out in their lectures. Or they often ask the person that your last child has grown up now, is there a child in the future or is there some masculine weakness? MIDI-10, 35 years old, 2 children, Past user; Rural served-Mardan

Men from Balochistan had a different view as adherence to tribal culture took precedence over religious norms. Tribal culture validates a large family size and justifies it with hadith. This suggests that people use religion only as an excuse; their reasons for not using FP are rooted more in their own traditions, where intergenerational tribal feuds claim the lives of many young adult sons, and so they desire to have more.

We want to use FP, give it a chance, but due to the qabaili [tribal] system, we cannot do it. There is opposition from the family and we get taunted that you are a slave of the woman. MIDI-14, 32 years old, 3 children, Past user; Rural served-Pishin

A lot of people think of it as a standard; mostly qabaili people don't have spacing due to feuds. The Holy Prophet $[\mathrm{PBUH}]$ has also said that I want to see my umma increase. Our elders and maulvi say that children are a very big blessing. MIDI-24, 28 years old, 1 child, Never user; Rural unserved-Sibi

Women in these provinces also identify local mullahs as the source of resistance to FP, saying they often influence household decision-making through the male elders and husbands. In the absence of any other sources of information, the pronouncements of mullahs take on legitimacy.

Interestingly, almost all service providers (50/64), regardless of their districts, level of facility and cadres, were in consensus that religion serves as a barrier in women's adoption of FP and suggested that local religious clerics play a very important role in building such negative beliefs. Since people are generally uneducated and have no other source of knowledge, they simply believe what is taught by them. Service providers elaborated the simplistic ideas clerics inculcate in people's minds related to FP.

Those people who have no knowledge of religion- as you know these people have a little bit of education and then they become clerics [mullah]-they tell people that this isn't in religion. This is how it is. They make up stories and then they tell neighbors that this isn't in religion, it's a sin. They just stick to this and say it's a sin. Is there any book which states to what limits it is correct, has religion permitted it or not? IDISP-108, Govt, RHC, FWW; Sibi

[Clerics] scare the women and say that if you stop having kids you will go straight to hell. IDISP-94, Govt, FWC, FWW; RY Khan

Service providers suggested that mullahs need to be addressed to overcome this barrier.

I think that people don't have much knowledge about Islam; that's why they say [FP] is a sin. They don't have knowledge about Islam and they also don't know how to say their prayers, they don't even read the Quran and on spacing they will start talking about Islam. This is a sunnah that if a mother breastfeeds her child, then she will have spacing for two years. IDISP-119, Govt, MCH Center, WMO; UmerKot 
The majority of men and SPs clearly consider that religious clerics are playing a negative role in FP uptake, against the general desire of people to practice it.

\section{Knowledge of Family Planning Methods}

Thorough knowledge about specific FP methods can remove the fear of the unknown and thereby motivate women to adopt them. During IDIs with men and women, their level of method-specific knowledge was also examined. The discussion with women suggests, across the districts and communities, that women generally know about all modern contraceptive methods, except for vasectomy, which is not known to all women. The most commonly known methods are injectables, pills, condoms, IUCDs, and female sterilization. Women from Sindh also know about implants because this method has been added in their provincial program, and there are frequent camps for its provision. On the other hand, traditional methods, particularly withdrawal, are less known by rural, unserved women. Women from semi-urban and urban areas generally know about all traditional methods as well.

Men also know about most of the modern methods, but interestingly, do not mention vasectomy; in all exchanges, only one man from a semi-urban area of Umerkot referred to it. Men are more aware of traditional methods than women, particularly withdrawal.

While men and women are aware of modern methods, their knowledge about method-specific details seems to be a missing element. The main source of information mentioned by women is the LHW, who is also an indirect source for men. The media, friends and neighbors are also main sources of information, although none of them, other than the LHWs, can provide reliable details of methods. Since LHWs do not provide specific details for all methods to every woman, the gap in information remains.

Lack of information about methods is reported to prevent women from using any method. While women do not see this as a major barrier, men across the districts, particularly from served and I unserved rural communities, do see it as such. According to them, the main reasons for this gap in knowledge are a) absence of any type of FP facility in the area, b) lack of education and c) poverty, due to which they don't have any source of information. They feel people who live in urban areas have more knowledge of FP methods.

We are villagers; we don't know anything-what is new, what it is used for. If we go out of the village, then we will know. If someone tells us, then we will know. No one tells us! And the biggest problem is poverty. We are not educated. If someone tells us the wrong thing then what can we do? What would I know if my kids and I get harmed? There is no lady doctor in our area. If someone has to go, then they take a wagon and take their family members. MIDI-24, 28 years old, 1 child, Never user; Rural unserved-Sibi

They want to obtain the methods of family planning but they cannot do so. They get scared of getting these things because, for example, they might not have the information on how to get them, where to get them.... who would provide them with information?FIDI-3, 30years old, 4 children, Current user; Rural unserved-Khanewal

There is lack of information regarding family planning methods in this area or locality. If we talk to an uneducated husband or wife about family planning, they would say that they haven't even heard about it. Only those people are using these methods that are a little educated and they have information about it. MIDI-34, 41 years old, 4 children, Current user; Urban-UmerKot

No, there is no such hurdle. But we don't know the methods. We don't have services. Everyone is the same. I do not know any Islamic method, who would tell me [about it]? FIDI-40, 25 years old, 3 children, Never user; Rural unserved-Sibi 


\section{Apprehensions About Side Effects}

Modern contraceptives do have known side effects that range from mild to extreme, although the latter are rare. However, it is evident from the discussions with men and women that fear of side effects has an important influence in holding back men and women from using FP. Among all other barriers, service providers $(53 / 64)$ declared it as the first important barrier, women ranked it as the second important barrier (31/56), whereas very few men (9/33) mentioned it as a barrier. According to the majority of SPs and women, most women who decide to use FP do not actually practice any method simply because they come across some story where a woman would have experienced a side effect. These locally circulating stories serve as discouraging cautionary tales for couples who are inclined to use a modern contraceptive method.

Women say that we used injections but still got pregnant...Had pills and even then got pregnant. They tell these things. We get to know about such things from each other. FFGD-18; Semi urban-RY Khan

A lot of women faced a lot of harm after doing family planning. Some started bleeding whereas some started feeling dizzy. Other than this, there are relatives of my mother-in-law who don't know what she used for spacing after her marriage. Now she never had a baby again. This is also why my mother-in-law stopped me. FIDI-24, 26 years old, 2 children, Never user; Rural served-Pishin

One of the women shared how strong fear of side effects prevented her from using any FP method, leading to an unwanted pregnancy subsequently terminated. In this case, abortion was adopted as a FP alternative.

Those that do spacing, they told me about it. That's why I thought, something might happen to me as well. Due to this fear, I did not do any spacing and I conceived [and aborted the pregnancy afterwards]. FIDI-45, 42 years old, 7children, Past User; Rural served-Khairpur

It was shared by women and service providers that women have a strong fear in their minds that due to side effects of FP methods, they would not be able to execute their responsibilities at their workplaces or at home; they would be unable to take care of their families or offer prayers, and this fear of being unable to perform their usual functions acts as a barrier to using FP.

We are all working class people and my husband used to say that you will get weak and will not be able to move. If you use a method then you will get ill. No, we did not use any method. We could not use any method because we are working class people. Due to their use of the methods, our legs would have been affected. One cannot walk after that. FIDI-4, 27 Years old, 5 children, Never user; Rural unservedKhanewal

Most of the people don't even want to do family planning because they are scared of the side effects. As you know, here, there are all poor people; they work in the field the entire day so they are scared of the side-effects; that's why they can't even do it as they have to work. IDISP-143, NGO Clinic, LHV; UmerKot

Fear of Harm

Often, potential FP users also harbor fears of physical harm unrelated to contraceptive use. At times, harm is experienced by FP users not medically known as a side effect (that would be expected to be addressed in counseling on the method by SPs). Any health issues that arise while the contraceptive method is being used are attributed to the method, even though they might not be related. For example, condoms may be held responsible for causing an allergic reaction and pain in men; increased discharge or pain in women; causing "wounding," "infection" or disease, or weight gain. Stories about such harm add to the fears of potential users, who see no difference between these symptoms and actual side effects.

A lot of women say that when their husbands use [condoms], they get wounds. And it hurts a lot. FIDI-21, 25 years old, No child, Never user; Rural unserved-Pishin 
Women say that they have chemical coating which makes our stomachs bloat. I have also seen that mostly women who use it have bloated stomachs... That's why the people also get scared from this. FIDI5, 38 years old, 6 children, Past user; Semi urban-Khanewal

Service providers have also heard of these complaints.

Women say that with condoms they have irritation and itchiness; that's why they don't like it much. IDISP-17, Pvt, BHU, LHV; Khairpur

The fear of harm from implant and IUCDs is particularly strong. It may emanate from a few cases where an IUCD became dislodged or inadequate counseling was provided prior to insertion, but it has given rise to rumors that graphically describe its travel through the body. Men and women fear that IUCDs can move upwards inside the body and cause cancer.

My sister-in-law says that a woman got it inserted. It had been five years since she had it placed but it slipped from the side. In our tribe, there was a woman who got it inserted. It had been 10 days, they had intercourse and her tube was displaced upwards. FIDI-31, 31 years old, 9 children, Past user; Semi urban-RY Khan

[About the] Copper-T, they are scared that something would happen ... the women also say that it would reach their heart, meaning that they are scared that it would move upwards to their heart. They are scared about how it is planted in the uterus. IDI-SP34-Govt.FWC-FWW-Mansehra

(Women say) If we get an IUCD, then it will get displaced, and if it is displaced then it is dangerous. They also say that you get cancer of uterus with IUCD. IDISP-109, Govt, DHQ, WMO; Sibi

Cancer is the most feared disease perceived to be linked to contraceptive use-mainly IUCDs and implants. Many women and men echo the fear of cancer, apparently associated with fear of a foreign object in the body.

[My wife] talked about getting IUCD but my elders used to say that it causes cancer and tumors. That's why I did not agree to that method. MIDI-1; 31 years old, 2 children, Past user; Rural unserved-Khanewal

Cancer disease is caused by this [implant]. FIDI-11, 20 years old, 2 children, Current user; Semi urbanMansehra

[Women] say about the bleeding that takes place while inserting it in the arm, they are scared of it. They also say that damage will take place, or their hand will end up having cancer, or they will get some disease. They hear all this from these other women. That's why they fear it. IDILHW-22; Semi urbanUmerkot

Women also use the Copper-T but it has only side effects and no benefit. It causes wounds in the uterus and obesity and this further causes many diseases. There is a risk of cancer in them. FGDM-10; Semi urban-Mardan

Misconceptions about women getting infections from pills and injections, gaining weight, and getting internal injuries abound among both women and men:

There is a wound in the kidneys. They get pain, and they get side effects a lot. FFGD-33; Rural served Pishin

People say that someone took the pills and got harmed by them or someone got the injection and got harmed by it. MFGD-5; Rural served-Mansehra

Many women and men narrate stories of different diseases and other health issues that emerged after a couple used contraceptives, including weight gain, diabetes, and cancer, which are not medically known to be directly associated with contraceptives. These fears result partly, of course, from real side effects experienced by women they know, inextricably linked with other health issues those women may already have, such as diabetes or obesity, or are at risk of contracting, such as cancer. One exasperated SP noted: 
If they gain weight, then they will have high blood pressure or, if they have [diabetes]; even due to this, they stop using injections. IDISP-121, Govt, DHQ, FWC; Umerkot

One of the main reasons for these fears is that service providers and LHWs do not provide proper counseling regarding possible side effects of certain methods to mentally prepare them and spare them undue stress from minor effects. Another reason is the relatively poor capability of service providers in general and LHWs in particular to manage side effects. When a side effect is experienced by a woman, unless it is properly managed by a service provider, it gets worse. Not only does this experience discourage the user, but the news spreads in the entire community and many other women considering use of any FP method change their minds.

Yes, people are very scared of side effects. If something happens to someone in one corner, then the whole village finds out. And then those people also don't use it. FIDI-25, 22 years old, 1 child, Never user; Urban-Pishin

And some people delay using because of the harmful effects. When a woman is harmed by it, she tells a second woman so she also doesn't use it for this reason, even though everyone has a unique body, [a side effect] can happen to someone but it doesn't happen to everyone, but people just believe in rumors and then are unable to use [the method]. FIDI-16, 28 years old, 2 children, Current user; Urban-Mardan

After getting the injection, when my wife started bleeding, it was so severe that it seeped through the bedding. When we brought, the ambulance the relatives did not know but when we had to tell the doctors in front of the relatives then everyone expressed their displeasure, saying what had I done. And then, later on, the private doctor also confirmed that indeed that was the problem. .... It may also be possible that the side effects were due to something else but a lot of women stayed away after seeing this. MIDI-19, 43 years old, 9 children, Past user; Urban-RY Khan

There is difficulty in obtaining the methods and they are also scared of getting injections after hearing stories about other people and their side effects because most women believe what they hear. FIDI-3, 38 years old, 4 children, Current user; Rural unserved-Khanewal 


\section{Conclusion}

The findings presented in this section reveal, of all the access issues mentioned by men, women, and service providers during IDIs and FGDs, physical access is the real challenge, especially for women who live in rural, unserved areas of Balochistan and KP, where services are not available and the rugged terrain and scattered settlement pattern further exacerbate the problem.

Financial constraints comprise the second significant barrier to accessing FP across districts and communities since they limit people's ability to bear travel and contraceptive costs. Although contraceptives are available for free in public facilities, the small number of such facilities and their distance from the communities that need them make it difficult for current and intending users to access services. The high costs of travel as well as lost time and wages entailed in FP service utilization are unbearable for many cash-strapped families and communities. Private service providers offer an alternative-though this too eludes rural unserved areas-but, again, the price of contraceptives becomes a barrier. Determined couples do seek out public or private FP services but access remains a major challenge for most.

The encouraging and major finding from this study is the diminished negative role of husbands and mothers-inlaw. Instead of resisting FP, the study found that husbands are in conversation with wives about different methods and selection of the most suitable one. While pockets of resistance remain in KP and Balochistan, they are relatively few, and analysis of individual responses shows that the real reason lies elsewhere-either in the expenses involved or, as subsequent sections show, the side effects, availability and attitudes of providers.

Similarly, the evidence from this study points to the diminished significance of religion in the making of FP decisions and choices, except in a few rural unserved pockets. In-depth analysis and probing of responses citing religion as a factor revealed that, in most cases, it was the desire for another child or a son that lay beneath apparent resistance and reluctance to use FP methods.

Women's reproductive responsibilities and their economic activities as well as men's productive work leaves little time for them to follow up on their FP intentions. While they are aware of almost all modern and traditional methods, method-specific detailed knowledge is still lacking, which can be a possible hurdle in accessing FP services.

Apprehensions about side effects of different contraceptive methods emerged as an important issue that holds men and women back from accessing FP services. News of side effects of any method spreads like wildfire through communities and this negative advocacy stops women and couples from adopting a family planning method they might be considering. Fear of harm and side effects could be a result of absence of FP services in the community or insufficient counseling from SPs.

We note that women and men are approving FP and are ready to adopt it; provision of FP services at their doorsteps would erase the physical and financial access barriers that hinder them, and go a long way in increasing the use of modern contraceptive methods. Once services are made accessible, however, the next important issue will be maintaining the quality of services offered. As the next chapter explains, this is another essential element for motivating new users and preventing existing clients from getting discouraged with modern FP methods. 


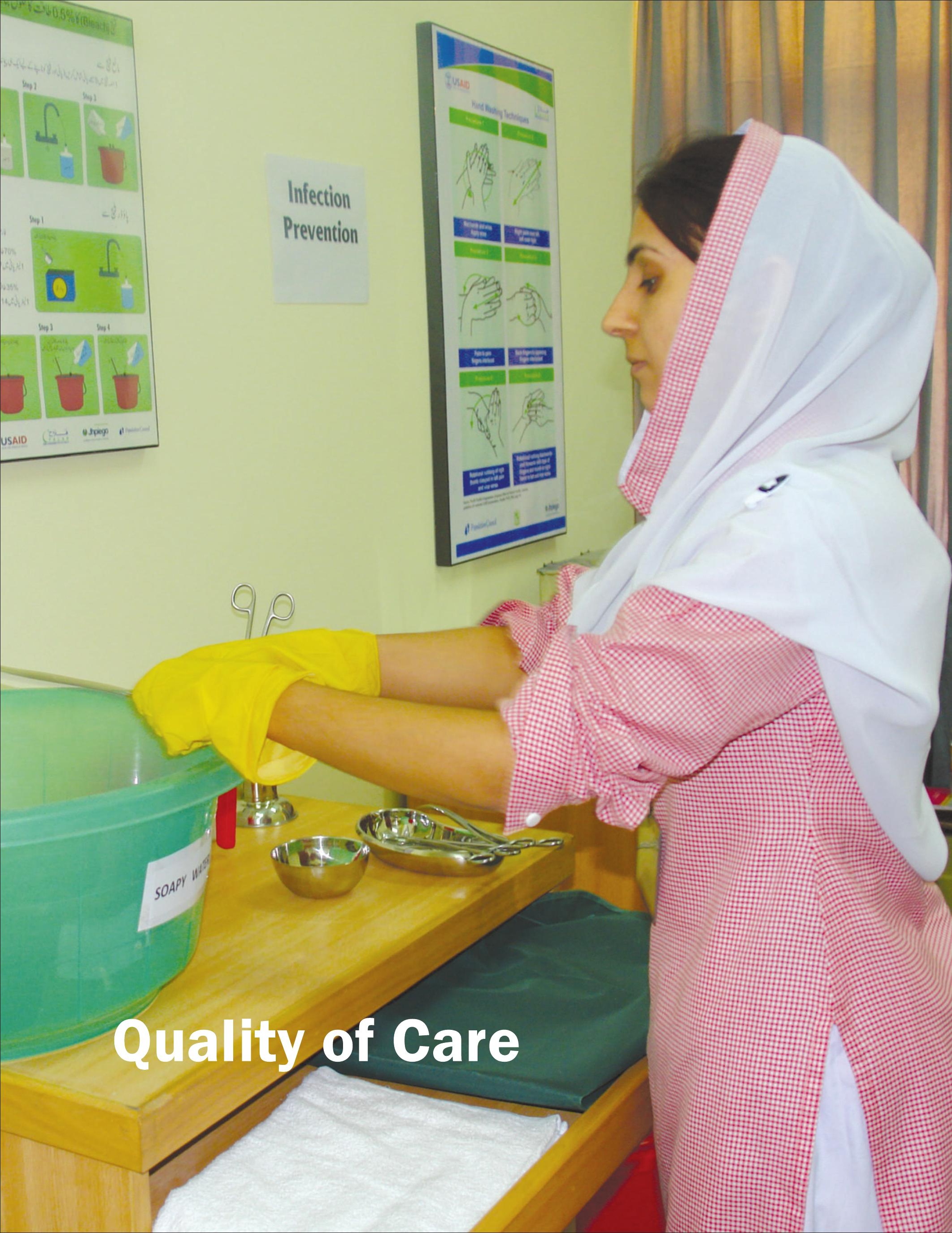




\section{Main Findings}

- Shortage and frequent absence of female service providers at public facilities compels women to return home without obtaining any FP method or care, which can discourage future visits.

- Short and irregular working hours of public health facilities minimize the utilization of services.

- Shortages and non-availability of contraceptive supplies constrain the choice of methods available, forcing couples to adopt less preferred methods or not practice FP at all.

- Unsupportive and discourteous behavior of service providers at public facilities makes it difficult for women to share their concerns.

- Skilled staff at times leaves paramedical staff to counsel and treat patients in distress: apart from depriving clients of the required standard of services, this damages their confidence in FP services and discourages future use.

- Despite the low quality of care, public-sector facilities continue to cater to a large clientele because their services are very affordable and usually the only option for poor people.

- Women and men appreciate the LHWs as committed and helpful resources at the community level.

- One reason for preference for private facilities is their better availability: their timings are longer-facilities are usually open till late evening or round the clockand service providers provide time for a full consultation.

- Most service providers and LHWs believe family planning is compatible with Islam, although about a quarter of them believe that tubal ligation and vasectomy are not permissible.

- Service providers who consider any or all FP methods against Islam cannot help clients with the requisite initiative and drive. 


\section{Quality of Care}

\section{Research questions to be addressed in the section:}

1. What are the demand side factors that discourage women and men, especially those living in served and unserved rural areas, from utilizing FP services (both public and private)?

- What are supply and demand side constraints influencing contraceptive availability at the facility level?

2. What causes high dropouts and high contraceptive discontinuation rates of modern methods in Pakistan?

- The factors and service qualities that cause men and women to lose trust in FP providers in the public health system.

3. How can we further examine the issue of access and quality of provision of FP services in Pakistan?

- Are FP services more readily available in public or private facilities- what level and type of facilities are more ready to provide such services?

- Is there enough choice of contraceptive methods available to women from poor settings?

- How important are the costs-travel and out of pocket and time waits involved?

4. How important are providers and their own attitudes and beliefs in the delivery of FP services?

- What is the role of quality of services- including availability of providers, their training, and behavior and personal beliefs?

This section draws on perspectives of women, men, and service providers themselves to portray the quality of care encountered by current and potential users when they seek FP service providers.

Quality of care $(\mathrm{Q} \circ \mathrm{C})$ has been defined as "the way individuals and clients are treated by the system providing services." According to the framework defined by Bruce and Jain, which applies mainly to clinical services, the quality of care in FP programs can be gauged from six fundamental elements: choice of contraceptive methods, information given to patients, technical competence, interpersonal relationships, continuity and follow up, and the appropriate constellation of services. ${ }^{9}$ While these parameters are helpful in assessing service provider behavior and facility infrastructure, they do not indicate how clients perceive the programspecifically, whether they feel supported by it in managing their FP needs and aspirations-even though this perception would be central in clients' own assessment of quality and affect their future care seeking behavior. As the respondents in this study reveal, their perceptions of QoC do shape their FP seeking behavior and practice. However, perceptions and their influence are not limited to the point of service delivery but begin long before a client arrives at a health facility, and continue after she leaves.

It is only in recent years that QoC indicators have begun to include client perceptions of their care. For example, three of the twenty-five indicators in the USAID Maximizing Access and Quality (MAQ) Initiative ask whether clients participated in and were involved in method selection, whether they received the method of their choice, and whether they believed that confidentiality would be maintained by the providers. ${ }^{10}$

9 Judith Bruce, “Fundamental Elements of Quality of Care: A Simple Framework," Studies in Family Planning 21, no. 2 (1990): 61-91; Anrudh K. Jain, "Fertility Reduction and the Quality of Family Planning Services," Studies in Family Planning 20, no. 1 (1989): 1-16.

10 Liz C. Creel, Justine C. Sass, and Nancy V. Yinger, “Client-Centered Quality: Clients' Perspectives and Barriers to Receiving Care," New Perspectives on Quality of Care, no. 2 (Washington, DC: Population Reference Bureau, Population Council, MEASURE Communication), www.prb.org/pdf/NewPerspQOC-Clients.pdf. 
An action research project by Population Council Pakistan (1999-2001) resulted in the "SAHR Protocol" to guide service provider interaction with clients who come in for FP/reproductive health (RH) services. ${ }^{11}$ SAHR, which stands for "Salute, Assess, Help and Reassure," spells out the sequence of steps a service provider should follow from the moment a client enters to when she leaves. The protocol responds to almost all of the six indicators noted in the QoC framework, as well as the three client-centered MAQ indicators noted above.

Keeping in view the fundamental QoC elements identified by Bruce and Jain, the MAQ indicators of client perception and satisfaction, and the good practices defined in the SAHR Protocol, this study sought to assess the quality of FP care in the study area against the following QoC indicators:

- Range of contraceptives available to users;

- Ability of current and potential users to obtain the FP method of their choice;

- Availability of service providers at facilities;

- Technical skills of service providers;

- Interpersonal skills of service providers (including their behavior and handling of clients); and

- Service providers' beliefs about FP (which would be expected to affect their work and client handling).

The findings presented in this section are based on the responses of men, women, public and private sector health service providers, and LHWs in IDIs and FGDs. The majority of women (45/56) and men (31/33) interviewed talked about quality of FP care. Of these, 29 women and 22 men had experience of seeking care from public health facilities while 16 women and nine men had sought services from private facilities. The participants of the FGDs (female 24/25 and male 23/24) commented mostly on their QoC experience in the public sector.

As mentioned in the section of Methodology, the SPs whose perspectives are presented belonged to the same districts as the men and women interviewed. Table 4.1 shows the number of public and private sector service providers interviewed.

Table 4.1: Number of Service Providers by Sector

\begin{tabular}{lccc}
\hline Designation & Public & Private & Total (N) \\
\hline Gynaecologist & 2 & 4 & 6 \\
WMO & 10 & 8 & 18 \\
LHV/FHT & 21 & 9 & 30 \\
FWW/FWC & 9 & - & 9 \\
Dispenser/MHT/PHT & 1 & - & 1 \\
Total number of SPs & $\mathbf{4 3}$ & $\mathbf{2 1}$ & $\mathbf{6 4}$ \\
\hline
\end{tabular}

\section{Availability of Contraceptives}

Contraceptive availability is critical for bridging unmet FP need, especially for younger couples. No less important is the availability of a range of contraceptives so that couples can choose what is most appropriate for them based on medical eligibility, needs, pockets, and social circumstances. Since choice can attract more users as well as prevent dropouts, it is as significant an aspect of QoC as availability of contraceptives.

\footnotetext{
11 Sathar, Zeba, Anrudh Jain, Saumya RamaRao, Minhaj ul Haque, and Jacqueline Kim. 2005. “Introducing client-centered reproductive health services in a Pakistani setting," Studies in Family Planning 36(3): 221-234
} 
Respondents expressed satisfaction with the availability of contraceptives at public health facilities in Mardan and Khanewal-in these districts, contraceptive products are supplied on time and no shortage is reported.

They (clients) don't face any difficulty regarding availability (of contraceptives). We demand the stock after every three months and are provided with enough, so we never face any problem. IDISP-165, Govt, FWC, FWC; Mardan

In general, compared to other provinces, most facilities in KP fulfill the FP needs of clients.

All the methods that I have used till today, I got them from the government center and they were absolutely all right; there was no problem in them. When I got the IUCD, I got it implanted at the government hospital and when I had to remove it then I got it removed at the dispensary here. They complete their work and it is very satisfactory. FIDI-15, 42 years old, 8 children, Past user; Urban-Mardan

In other parts of the study area, however, women and men report that facilities are either short of contraceptives or out of stock when they visit. In semi-urban Rahim Yar Khan, Pishin and Sibi, women and men reported that non-availability of contraceptives compelled them to make repeated visits to nearby facilities. Often, people seeking contraceptives are forced to make treks to distant facilities. There, too, contraceptive supply is not assured.

There is also a common perception that the contraceptives supplied by public health facilities can be of poor quality, leading to method failure or side effects.

In FGDs with rural served and semi-urban communities in Sibi and Umerkot, women and men reported that they encounter a shortage of contraceptives, especially IUCDs, at public facilities. The following quote best sums up the frustration of some communities with government-provided FP services.

The government has formed family planning institutions only to promote family planning but unfortunately these are failed institutions. I am 40 years old and I have never seen any of their workers providing these services. People do not even know about these institutions. Injections, tablets and condoms are available from different sources but these are not provided by any government institution. MFGD-30; Semi urban-Umerkot

Owing to the difficulties many women and men have to endure to simply physically access FP services, such as travel and lost labor costs and mobility restrictions (elaborated in the preceding section), non-availability of contraceptives, or of the preferred contraceptive method, can discourage many users from continuing FP.

I got this injection from the big hospital. Initially, they refused saying the injections are not available [out of stock]. Then I went again with my brother-in-law who works in the hospital, and the doctor gave me the injection. However, if someone's house is far away they cannot go to the hospital [repeatedly]. It is very hard for women to leave the houses. When someone comes from so far away and the contraceptive is not there, then they don't get permission to leave the house again. FIDI-22, 26 years old, 3 children, Current user ;Semi urban-Pishin

Sometimes, they are short of injections so then those who are rich, they go and get these injections from government or private hospitals. FFGD-26; Semi urban-Khairpur

My husband used to get it (condoms) from the market. No medicine and contraceptive is available here and people go to the big hospital. Money is also wasted but they say they get nothing [contraceptives] from there. FIDI-36, 25 years old, 2 children, Past user; Semi urban-Sibi

Condoms are also not available as in hospitals we only get medicines for children and nothing else. I'm saying that for spacing take pills for two or three months and when this time period is finished, again take it. Rest we don't have anything in our hospital only medicine for kids fever. MIDI-25, 47 years old, 7 children, Past user; Rural served-Khairpur 
A large number of public sector service providers (27/43) and LHWs (15/23) agree that contraceptive shortages develop frequently, and such shortages can last for three to six months, or even longer. Short supplies of contraceptives affect both public and private providers, according to $17 / 64$ SPs. Supplies tend to fall short mostly for IUCDs and sometimes for injections, although condoms and pills can run out too.

We ran out of stock. We faced the issue of irregular supply of in-demand methods. There is nonpunctuality. I mean to say that there is no routine. IDILHW-1; Rural-khanewal

When the preferred choice of contraceptive is not available in the facility, the SP may offer an alternative so that clients do not leave without a method. However, women and men are often reluctant to try new methods for fear of new side effects or complications. When contraceptives are not available both public and private sector SPs might also refer clients to a government hospital or health center; instruct them to buy the contraceptive from the market; or procure it from colleagues (LHWs), Greenstar, or the market themselves so as not to lose the client. A few SPs (8) also reported they referred their clients to a Family Welfare Center where contraceptives were available for free.

Our clients have to go somewhere else ... They get it from there. If these things are available here with us then neither we nor our clients would have a problem. They get these things at their homes because when we visit houses we can provide the clients what they need when they need it. Since we don't have these contraceptives we have to refer these same clients elsewhere. IDILHW-17; Semi urban-Sibi

A few SPs have also mentioned that although the stock of contraceptives might be short, it never runs out. If a client seeks a method that is not available in the facility, she is asked to come the next day. Unfortunately, most of these women do not come again to get contraceptives due to access issues such as time and financial constraints, and some become pregnant before their next visit. This is, ultimately, an avoidable failure of the FP system of services.

Usually we always have contraceptive available. Sometimes if a woman comes to us who wants injection and we are out of it, we tell her to use pills meanwhile ad come back after two days. The woman will come back after a month and usually pregnant. IDISP-55, Govt, BHU, LHV; Mardan

Generally, private facilities are thought to offer a better range of services and guidance, but they are expensive and not affordable for everyone. Certain areas of Sindh are served by a public-private partnership in FP services. The provincial government has joined hands with the NGO Health and Nutrition Development Society (HANDS), and the latter's workers, called "Marvi" workers provide contraceptives to people. Women and men from semi-urban areas are served by Marvi workers.

The quality of the methods available at the government hospital is also not very good. They cause diseases. That is why most of the people like to go to the private facilities, spend money, or take it from the Marvi worker. FFGD-31; Semi urban-Umerkot

The standard of availability of facilities; in the private center the better facilities are provided but the government ones are of very bad quality. Often we are given those things (condoms) but there is a lot of fraud in it, they are not worth using. I told you before about the harmful side effects that condom often breaks and it does not give the natural pleasure, pills also dry up the milk and because of the injection the periods start coming daily. MIDI-9, 37 years old, 3 children, Current user; Semi urban-Mardan

Women and men in KP, Balochistan (Pishin), and Punjab also appear dissatisfied with lack of contraceptive options offered by LHWs, who they claim offer only one method, i.e. pills.

The LHW does not have much education and not enough experience through which she can properly perform her job and provide advantage in the proper manner. Often, she has one kind of pill which she gives to every woman. The pill suits some women and for some they can have some reaction because everything has a side effect. This is the reason why we have not used any method till now. MIDI-11, 36 years old, 4 children, Never user; Urban-Mardan 
On the other hand, the LHWs claim that they usually have stocks of quality contraceptives available. If condoms and pills are not available in their stock, they refer their client to a hospital (BHU) or market, buy it themselves, or obtain it from other LHWs to fulfill their clients' demand.

If they come to us in those conditions, then we refer them to the hospital or write it down so that they can get it from the market. It's a problem because we persuade them to accept a method with difficulty and then don't get the stock-we get it later but still it's a problem. I refer them to the hospital and go with them. IDI LHW-8; Rural served-Mardan

\section{Choice of Methods}

Being able to choose the desired FP method is an important component of QoC. Women and men complained during IDIs and FGDs that the method desired by clients is often unavailable at public facilities and they hesitate to accept alternative methods. When SPs manage to persuade them to adopt a method they are unfamiliar with, new side effects or complications can surface. Sometimes, the provider may exhibit a bias and try and motivate the client to accept a particular method based on availability, targets, or price. This attitude may prevent women from using the methods that best suit their needs and circumstances.

Some clients do not choose the alternative suggested by the SP at all, as their husbands may not approve of it or they have concerns about it. In such case, an unsatisfied client leaves the facility, and may need to endure yet another unplanned pregnancy.

The first time I went for injections for FP, the doctor said that the injections have finished. Take pills. But my husband said that you can't take pills. Then I went back and the doctor said come back after five days. This hospital is mostly out of stock. It can be improved if these methods-pills, injections and condoms-are always available. These should be restocked before they finish. It is very hard for women to leave the houses. When someone comes from so far away and the medicine is not there then they don't have permission to leave the houses again. FIDI-22, 26 years old, 3 children, Current user; Semi urban-Pishin

The things that are available at the hospital should be provided to the facility. Some people cannot even go to the hospital. They are somehow bound and they have housework to do too, so they take out some time and go to the health worker. That is why all the methods should be available with the health worker so that they can give it to the people when they go to them. FIDI-9, 25 years old, 2 children, Current user; Semi urban-Mansehra

\section{Availability of Staff}

Public services in Pakistan are often plagued by inadequately staffed facilities or staffed by those who lack technical skills relevant to their responsibilities. Absenteeism is also common, and noted at health facilities by many of the respondents in this study. The challenges posed by non-availability of staff, especially female SPs, were discussed by respondents in nine male and eight female FGDs. Women in Sibi lamented that hospital buildings are there but staff is not. In Pishin and Khanewal, seven women and four men reported that staff is either absent or late when they visit the health facility. The preceding section specifies in some depth the great physical, social, and financial hurdles women and men have to surmount to reach FP services in the first place. Non-availability of relevant staff when they reach the facilities is a great drain on their resources, and, understandably, discourages future visits.

Non-availability of service providers is not limited to absenteeism, but can take many forms, as outlined below.

Shortage of female staff: The problem of absenteeism is exacerbated by the presence of a relatively small number of skilled women providers in the first place, whether they are doctors, lady health visitors (LHVs) or paramedic staff. The presence of female service providers is absolutely necessary because social gender norms preclude women from availing reproductive health services if only male staff is present. 
The issue is conspicuous in Sibi, where facilities are particularly short of female staff, and clients do not feel comfortable discussing their FP issues with male SPs.

There is no facility there. This is why mostly people cannot use contraceptives. Secondly there are no lady doctors. Women cannot talk openly to men. FIDI-36, 25 years old, 2 children, Past user; Semi urban-Sibi

Short consultations and lack of attention: Staff shortages, especially in Balochistan and KP, mean that public facilities are always crowded, with long queues. Many women, often accompanied by men, come from distant served and unserved rural areas for services. It is particularly difficult for these travel-weary visitors to wait long hours for a consultation, especially when ill. At times, the queue is so long only a few are able to actually meet with the SP or receive adequate attention.

The people providing government services don't give time. They are not punctual. They are not available always. Sometimes, the staff isn't present. Sometimes the store person is not there. You know, who listens in a government [facility]? MIDI-14, 32 years old, 3 children, Past user; Rural serve-Pishin

Lower level of care: In the absence of doctors, women and men from Balochistan and Punjab feel they are forced to consult paramedics who have limited knowledge about contraceptives.

No one can go to the big hospital. It is very far away. And if you go there, you don't find any doctor. Sometimes the LHVs are sitting there. Even she doesn't have much information about these things. She doesn't check them properly. FIDI-21, 25 years old, No child, Never user; Rural unserved-Pishin

Sometimes they are not present. If we call them they come. Even the senior doctor sometimes comes and sometimes does not. The compounder checks and prescribes the medicines. MFGD-1; Rural unserved-Khanewal

Early closing of facilities: The respondents in the IDIs and FGDs of all provinces were quite vocal about how clients from unserved and served rural and semi-urban areas are affected by public facilities' opening and closing times. When they close too early, clients from distant areas, or after covering difficult terrain with limited transport options, often cannot arrive on time, and return without contraceptives, and a repeat visit is not always possible before the next pregnancy.

They open it at eight in the morning and I don't know at what time it gets closed. At times we go early and at times we go late or after few days, so I don't know about their timings. FIDI-48, 16 years old, 3 children, Current user; Rural unserved-Khairpur

Women from Khairpur, Pishin, Sibi, and Mardan complain that public facilities are not open long enough. In contrast, private service outlets are open day and night, and staff is present whenever a client visits.

At times, they are available and at time they aren't. Marvi workers are present there, so we take it from them as availability is not assured at hospitals. You should make everyone understand about it that it results in fewer kids. Give information to people and also provide them with transport facility. FIDI-50, 35 years old, 5 children, Current user; Rural served-Umerkot

Women and men of rural unserved Pishin and Sibi communities state that hospitals are remote and SPs are only available for short durations; women arrive after finishing household work, only to find doctors gone.

The hospital is far away and the doctor also comes less, and when he does come, he comes for a very short time. And then he goes away and we don't get the medicine for free. Whenever a woman, after doing her work, goes to the hospital, it takes a lot of time on the way, and when she gets to the hospital, the rooms are closed. And she can't see anyone in the hospital. FFGD-14; Rural unserved-Pishin

Public servants with private practices: Many public sector SPs work in, or run, their own private clinics in the evening, with legal sanction. Communities feel these providers end their office hours at public facilities early, leaving people with little choice but to attend their private clinics. Some providers even discourage their clients 
from coming for checkups in the morning, telling them to visit their private evening practice. In FGDs in Sibi, Mardan, and Khairpur, with women and men even alleged that SPs sold the government supplied contraceptives in the open market or through their private evening practices.

The government has opened a clinic but they don't look after the clients. One said that we came back after sitting there but no one asked us whether we want to have a checkup. Special attention should be given to women. The lady doctors push women out and say to come to our private clinic as we don't want to check you here. Yes, in their private clinic, they do check up properly but they do it for a fee. FIDI-32, 28 years old, 4 children, Current user; Semi urban-RY Khan

In the public hospital, doctors are never available, and if by chance they are, they tell us to visit them at the private hospital in the evening. Doctors are not knowledgeable or educated enough as they write us the medicine which store keepers can't read. They write everything to get it from the medical store; they don't give us anything from the hospital. Even spacing methods they write to get it from the store. MFGD25; Rural served-Khairpur

Sometimes, clients are able to see a doctor but unable to buy contraceptives from the facility as the store incharge or other concerned staff is absent.

Availability of LHWs: The role of LHWs becomes even more important given the dissatisfaction with static public facilities and centers. In general, men and women in rural served, semi-urban and urban areas of KP, Punjab, and Sindh are relatively satisfied with LHWs' roles and presence in their communities. In nine FGDs, women reported that LHWs were able to guide and inform them about FP methods appropriate for them. LHWs sometimes accompany women to the hospital because accompanied by an LHW results in better treatment.

If women go to government (facilities), then they take this 'baji' [big sister, referring to an LHW] along with them. When this bajiis with us, then they look at us properly, in a good manner. When they see this baji with them, then they behave properly and are a little lenient. If we go alone, they say that go today and come tomorrow as this thing is not available now; it's finished. FFGD-26; Semi urban-Khairpur

The services are also provided at the BHU and the LHW also provides them. LHW goes to all the houses and provides the services there and refers to the BHU for the injection. LHW uses a good attitude towards people when she goes to their homes. Good attitude is also present when she refers someone to the BHU. She provides the pills and condoms at home but for the injection she gives a receipt or a token for getting the injection at the BHU. Quality, services and attitude is very good. MIDI-5, 45 years old, 3 children, Current user; Rural served-Mansehra

In some served and unserved rural areas, even when LHWs are appointed, they fail to reach their clientele.

All the staff available in the government hospitals is not up to the standard, like the LHW who visits houses. She does not have much education and not enough experience and therefore she cannot properly perform her job and provide advantage to clients in the proper manner. Often she has one kind of pill which she gives to every woman. The pill suits some women but some can have an allergic reaction because everything has side effects. This is the reason why no such method is used till now. MIDI-11, 36 years old, 4 children, Never user; Urban-Mardan

There is no facility here; the LHW only takes her salaries. They never come here nor have I ever seen her face. In our houses there are such people who have problem in their teeth. They are worried because of headaches, but they don't have any expectation from their family members that they will take them to the hospital. FIDI-25, 22 years old, 1 child, Never user; Urban-Pishin

At times, an LHW's availability is reduced by the fact that she has to cater to too large a population.

There is so much population; there are nearly 73 houses. So this LHW cannot provide medicines to all the houses. Our request is that, for this population of 22,000, there should be at least 10 LHWs. In some cases, when the LHWs of other areas are approached, they don't give it to us. They say that we will provide it to our own area. This is a big problem. FFGD-16; Rural served-Pishin 


\section{Technical Skills of Service Providers}

The technical knowledge and skills of SPs determine the quality of care they can offer, and play a vital role in achieving client satisfaction. This section considers the technical skills of service providers in terms of three aspects: their formal training; the effectiveness with which they counsel clients about FP methods (as perceived by clients); and respondents' views of their management of side effects associated with contraceptive use.

\section{Training}

One way to determine service providers' skill level is to compare the technical training they have received to prepare them for their role. The service providers interviewed from all cadres were found to have received FP trainings commensurate with their responsibilities. Men and women are generally unaware about the training status of the service providers and do not realize the role training in providing FP services and thus hardly discuss this topic. However, a few men did comment that service providers in the government hospitals were properly trained and experienced.

People in government hospitals have more experience as they get trained and have training sessions. They have a lot of information to (manage side effects). MIDI-33, 28 years old, No child, Past user; Semi urban-Umerkot

\section{Counseling for Family Planning}

Women and men respondents did not mention counseling as a service that providers offered. Both public and private sector providers see it as an important feature of their work, however, and the majority $(49 / 64)$ considered counseling and the client-provider relationship to be a crucial element in providing quality care.

Service providers report that they motivate and encourage clients to use FP methods. Pregnant women are advised to start contraceptive use 40 days after delivery. Young women who have two children, women with frequent pregnancies, and those suffering from diabetes, heart problems, uterus complications or malnourishment are advised to use contraceptives for birth spacing.

When a woman has her delivery in here or carrying a baby with her I do suggest her family planning. Beside this a lot of poor people who visit here, we suggest them family planning if they already having a lot of children. IDISP-54, Govt, RHC, LHV; Mardan

Women who have two children are advised to use IUCDs or injections, especially IUCDs, since they provide spacing for a longer period of time.

Those who have five children or more, are anemic or have any other medical condition and come to us for some other problem are given counseling to use contraceptives. Health concerned, poverty ridden and all medically unfit should be suggest to using contraceptive in my opinion. The doctors should suggest it. IDISP-162, Pvt, DHQ, GYN; Khanewal

Often women come for abortion in the facilities. SP discourage abortion and recommend an FP method to these clients. Similarly, women who have five to seven kids or those who think that they do not want any children are recommended tubal ligation.

A woman who has had ten children still has more. She is having an abortion every three or four months so what would you say to such a woman? You would advise family planning; I tell them to stop and get a tubal ligation done. There are a few people who listen to you. Here, a son also counts a lot. In hopes of a son, our women end up having a lot of daughters. They have eight to ten daughters. Those who have miscarriages or anemia should be advised. IDISP-81, Pvt, BHU, WMO; Pishin 
There is a perception among some women and men that counseling and treatment at public health facilities are of poor quality. These respondents complain that public sector SPs fail to provide complete information about contraceptives, their advantages, and side effects, and prescribe medicines without proper checkups, leaving clients confused and unsatisfied. Stories also circulate about disregard for client pain and discomfort, and about flawed surgical procedures.

Only the people who go there can tell this. The sister-in-law of a woman who had her operation there said: "When they took her inside, a little while later, she started screaming very badly and we got scared about what they were doing to her. We wanted to break open the door and go inside. We had never heard of this before and we were scared of what happened to her." Later on she told me that they operated her in a very bad manner. FIDI-34, 40 years old, 7 children, Current user; Urban-RY Khan

When we go [to a public hospital], they don't care about us. When someone goes, their money is also spent, yet no care is seen. That's why l'll go where there is a [private] facility available. They give one tablet that is not taken out from the mouth; this is given by the government hospitals and keeps us on a sack full of water which is not beneficial at all. I did an ultrasound for 250 rupees but they take five to 10 hours for writing and reading. No, here, women don't go. They say that they don't take good care. FIDI45- 42 years old, 7 children, Past user; Rural served-Khairpur

According to women interviewees and FGD participants from Pishin and Sibi, such problems force people from afar to turn to private hospitals. Private facility SPs are aware their services are preferred. They attribute this preference to the fact private facilities offer trained staff who provide complete information on FP methods, the advantages and disadvantages of each method, and side effect management, as well as better client services.

People of this area say that when clients are in the center they have no problem. We are Pathans. Most ... clients ... here are known to us. We have everything here so we try to fully satisfy our clients. We respect our clients and do not misbehave with them. We provide instant services so that they don't have to come ... again and again. We also talk with the maulvis here and counsel them that family planning is only birth spacing between two children and nothing else, so they should also adopt it and not criticize it. IDISP-62, Pvt, BHU, LHV; Mardan

However, public providers are not so impressed, and point out, with some truth, that private care is expensive and not affordable for everyone. They maintain that the preference for private facilities by those who can afford them is more a matter of perception than actual better services. The public providers interviewed did not mention lack of information or skills in management of side effects at their own facilities.

All of them know about the methods. But some people come here while others avail the services elsewhere. People make a mission going to the private doctors. We place Copper-T for free while they charge 3,500 rupees ... The injection that we are giving is for free but the private clinics provide it for 1,200 rupees. The rich people go there; all the poor people come to us, and we try to deal with them in a good manner. They are poor, and we treat them well and with respect. We love the poor people. We give them proper time. Then we write it down in the OPD register that this person came and I gave them advice on family planning. IDISP-91, Govt, MCH Center, LHV; RY Khan

Compared to SPs at static public-sector facilities, LHWs are viewed in a more positive light by many communities. Some IDIs in Khanewal, Mardan and Sibi, and FGDs in rural served KP and Pishin indicate that women are satisfied with the LHW as she pays door-to-door visits and provides contraceptives and related information and knowledge. She is seen as a skilled resource who informs clients about the advantages and disadvantages of different contraceptives. If any side effect is observed, she promptly refers them to the closest relevant facilities for management of the side effects.

Lady health worker satisfies us and encourages us always. We get our methods on time and they're always in stock. She does her work with great skill and those methods are of a very good quality. She also tells us about the side effects and their treatment. She also educates us about hygiene and children's health. FIDI-2, 29 years old, 4 children, Past user; Rural served-Khanewal 
Lady health workers go to every house. They give them awareness and products for free. They provide services. They should also give injections and pills because with the use of condoms as well you can sometimes get pregnant. So they should also teach the proper method for using condoms. FIDI-37, 33 years old, 1 child, Past user; Semi urban-Sibi

Service providers at static facilities do not share this faith in LHWs. Five public and private SPs stated that an LHW has limited knowledge regarding contraceptives and their use and could, therefore, not counsel users as thoroughly and as objectively as a fully trained doctor in making informed FP choices.

We are doctors. We are given special FP training and contraceptive training but we don't give methods. For example, an LHW is just a housewife and look where you have placed her. She cannot explain things like a qualified doctor. She doesn't have that knowledge. Once I was doing a survey on whether these people who are providing contraceptive methods are letting people make informed choices or not. And what I found was that 99 percent of these health workers, regardless of who they were, were forcing their opinion. This meant that they would ask women to take pills and use trial and error methods on them. I was very surprised. IDISP-162, Pvt, DHQ, GYN; Khanewal

\section{Management of Side Effects}

Management of side effects is an integral element of FP healthcare and is discussed separately here due to its great importance in helping women and men continue their use of contraceptives and maintain their resolve to plan their families. Poor management of side effects can lead couples to live in avoidable distress, switch methods needlessly, and eventually even abandon modern contraception at the risk of unwanted pregnancy. The suffering and frustration of such couples may deter others from even trying modern contraceptives. Side effect management is not confined to responding to negative health effects following contraceptive use; it is also a function of effective counseling prior to prescribing a FP method and of follow up after it has been used.

Some men and women express dissatisfaction with the side effect management offered by public sector health professionals. They perceive this, at times, to be due to lack of knowledge or skill. Absence of skilled staff is noted to be another problem in side effect management: there are situations when clients suffering from side effects arrive at facilities to find that the skilled and trained service providers are unavailable. Paramedical staff is unable to manage the side effects because they do not have the requisite training.

If a woman has kept IUCD, and she had more bleeding, then this LHV don't have much related information. They don't have information regarding such illnesses. MIDI-34, 41 years old, 4 children, Current user; Urban-UmerKot

Even when women and men are generally satisfied with their LHW services, they do not trust her to manage contraceptive side effects. This concern was expressed by some men, particularly from KP, and could perhaps be due to the fact LHWs are less educated and do not appear to have the proper information.

A few SPs and LHWs reported that they inform women about the side effects of injections and how to manage them, and women who fear these side effects are advised to adopt another FP method, such as IUCD. Mostly, LHWs report that when their clients experience side effects, they refer them to a static health facility where qualified doctors can treat them properly.

At first people used to think that IUCD causes side effects but then I counseled them that it doesn't happen to everyone, and if it causes the side effects, then we have the solutions to it, so they don't think that anymore. LHWIDI-8; Rural served-Mardan

Clients who visit here for family planning make a mind from their home that they will use a method of family planning. We tell them about its side effects so they know that these things can happen, but if we don't tell them about the side effects, we will lose our patients and it will also affect our reputation because patient will come back to us who is facing side effects. IDISP-163, Pvt, NGO Clinic, LHV; Khanewal 


\section{Interpersonal Skills of Service Providers}

The behavior and attitude of SPs can shape the experience of clients, motivating them to adopt FP and to remain users. Women reach a service provider after navigating various obstacles, and often their FP need is acute. Young women in particular may lack the confidence to make a decision and require proper information and tactful handling. The interpersonal skills of a service provider-how they welcome the client, provide privacy and assure confidentiality, give information, and answer questions-go a long way in making a woman comfortable and seeking FP assistance.

This section explores the interpersonal skills exhibited by service providers in their dealings with FP clients as reflected in their overall behavior and their counseling approaches. The personal beliefs of SP about FP are also considered since these may consciously or unconsciously affect their attitude and interaction with those who need their services.

Questions about provider attitudes in public facilities elicited adverse comments in communities. At public sector facilities, instead of recognizing clients' efforts to seek help, service providers treat them with disdain, if not downright rudeness. In part, this may be a result of a misplaced sense of privilege from service providers, who are better educated, employed, and skilled than most of their low-income clients.

Among interviewees, 22 women and 16 men during IDIs and FGDs reported the misbehavior and rude attitude of public sector SPs towards their clients. They complained that clients are not treated with respect, due attention or care, but in the case of poor women, they have no choice other than to tolerate this negative behavior, since they cannot afford private facilities. Two women from a rural, served community in RY Khan said they were even scolded by the SP for not following instructions during an operation.

In government hospitals, doctor's personal behavior is not good. They misbehave with people. Methods are available but doctors don't have information about it. MIDI-34, 41 years old, 4 children, Current user; Urban-UmerKot

We have to bear with their attitude. If they are absent, then we come back. And if they say something then we have to bear it. What can we do? We are poor people. MIDI-1, 31 years old, 2 children, Past user; Rural unserved-Khanewal

Their behavior is not good, those who sit in government set up. The services are not good. Mostly 'fourth class' [the worst] doctors are on duty in government hospitals. MFGD-10; Semi urban-Mardan

If clients happen to be referred to public facilities by someone known to the SP or related to them, however, their attitude changes and they are more helpful. Likewise, they discriminate between rich and poor. The rude attitudes of public SP compels clients who can afford private care to approach private clinics.

Private hospitals are better ... A person goes there after so much effort; at least the operation should be successful. In the government hospitals, they treat you like dogs. The women working there said ... go back home and keep on producing kids. They told me to get up and leave. They were rude ... She said that your operation will not go well, just go home and keep on producing babies. A very well kept woman said this to me and was rude. FIDI-28, 35 years old, 8 children, Current user; Rural served-RY Khan

Sometimes they are cordial but most of the times they treat us harshly, especially in the government hospital. [Everyone starts talking simultaneously.] The government hospital has good medicines but they do not give you attention. They give timely medicines but treat you like a dog. Nobody listens to the poor and we always get pushed around. FFGD-2; Rural unserved-Khanewal

The staff behaves well with the rich ones, while in case of poor people, they give prescription and ask them to buy medicines from medical stores. MFGD-27; Rural unserved-Khairpur 
On the other hand, responses in IDIs and FGDs indicate that communities view private sector SPs positively. They find them well-behaved, cooperative, and respectful, and are satisfied that they perform proper checkups and provide adequate information.

Their behavior is quite good. The SP here always thinks about our benefit. They provide proper treatment. Thus people are very satisfied from their attitude. FIDI-30, 40 years old, 6 children, Never user; Rural served-Umerkot

They do not treat properly in the government hospital. Once I went there because I had irregular menstruation, but they did not even treat me. Mostly we have to go to the private facilities, where the lady doctors talk pleasantly to us, and provide us treatment properly. FFGD-31; Semi urban-Umerkot

The complaints voiced by the majority of community members about the misbehavior of public-sector SPS appear to be substantiated by this doctor at a BHU.

If my mood is good then I do try making them understand and satisfy them. But I also get angry and then I say to clients to leave me alone now! IDISP-11, Govt, BHU, WMO; Khairpur

However, other public-sector service providers claim they are always attentive and respectful in their dealings.

I also love my clients and behave very politely with them. I don't charge them more nor do I get angry at them. I act very politely. IDISP-11, Govt, BHU, WMO; Khairpur

\section{Service Providers' Beliefs}

The study explored the role of religion in shaping how SPs themselves view FP-did they consider FP practices as compatible with their religious beliefs? Or did they find a contradiction between their work and their beliefs? The purpose was to gauge if personal beliefs affected SPs' work and client interactions.

In general, SPs believe that child spacing is important for ensuring the health of women and their children. Most SPs (57/64) and LHWs (20/21) discussed FP methods in relation to the teachings of Islam and stated that both traditional and modern methods are permissible. Few SPs (4 in all) expressed reservations about FP and its compatibility with religion, and these were mostly from KP and Sindh. Of the 64 interviewed SPs, 57 of 64 believe modern methods such as condoms, injections, IUCDs, and pills are allowed in Islam. The few nonMuslim (Hindu) SPs in Sindh and Balochistan in the sample also report that their religion allows FP methods.

Family planning is allowed in Islam and the reason is that if a woman gives birth to a child, then obviously she needs to take care of the child. So if she gives birth to children again and again then it is going to be hard for her to handle, and for the husband too as he is responsible for giving a good life to his children, and as they are poor, how will he be able to do it? That is why family planning is the best method. LHWIDI-21; Semi urban-Umerkot

A significant number of SPs (17/64) believe tubal ligation (TL) and vasectomy are not religiously permissible, a sin and interference in God's will. They perform TL on women who want it, however. Women with five to seven children, those who do not want more children, or who suffer from diseases posing risks to their lives, are advised TL; even if SPs consider TL religiously prohibited, they consider part of their professional duty.

We also feel when we perform [tubal ligation] that it is a sin, but we have not said openly that it is not allowed. Nevertheless, according to our duty, those woman that agree for operation [tubal ligation], we take them for an operation and those women that agree for contraceptives, we go in the field and give them pills ... [or] injections. IDISP-9, Govt, FWC, FWW; Khairpur

Yes in Islam there is permission to use pills and condoms. And there is withdrawal method in Islam. Breastfeeding, safe period are Islamic methods and in Islam there is permission of injections, hysterectomy and vasectomy aren't allowed in Islam. There is no permission for permanent methods. 
Islam also allows implants and Islam does not allow abortion because it is a type of murder. IDISP-76, Govt, BHU, WMO; Pishin

\section{Conclusions}

Quality of care at public sector health facilities in Pakistan suffers from a number of shortcomings, such as substandard quality and non-availability of contraceptives; shortage or absenteeism of staff, particularly female staff; short and irregular working hours; discourteous behavior and poor communication with clients; inadequate attention and information provision; and pressure to use the providers' private services. These deficiencies, especially the unsympathetic and unfriendly attitudes, make it difficult for women to share their deep concerns and can make them avoid future visits for follow up or other needs. Despite the low quality of care they offer, however, public sector SPs continue to have a large clientele because their services are free and usually the only option for poor people.

The availability and quality of contraceptives affects whether users, current and potential, will use the methods or services over time. Women are most likely to avoid the use of poor quality contraceptives that have adverse effects on their health. Shortages and non-availability of contraceptive supplies further constrain the choice of methods available. Often, the preferred method of contraceptive is not available at the facility and couples are either forced to choose another method or decide not to practice FP at all. These issues are more common in the public health sector.

Women and men are more satisfied with the quality of services being provided at private health facilities. The quality attributes of private facilities include good attitude and behavior, and proper attention. Clients are comfortable enough to discuss their health problems and needs with private providers. Another reason for preferring private facilities and service providers is their timing-such facilities are usually open until late evening or round the clock. Although the services at private facilities are of impressive quality, they are only accessible for those who can afford them. Poor people are left with no other choice than to seek services from public facilities.

When the findings about quality of care presented in this section are placed alongside the findings of preceding section, on access to FP services, the pattern that leads to the large unmet need for FP in Pakistan becomes clearer. Inadequacies in the quality of care offered, especially at public facilities, serves as a deterrent to potential and otherwise motivated users, who overcome many physical, social, and economic barriers to access these services. 



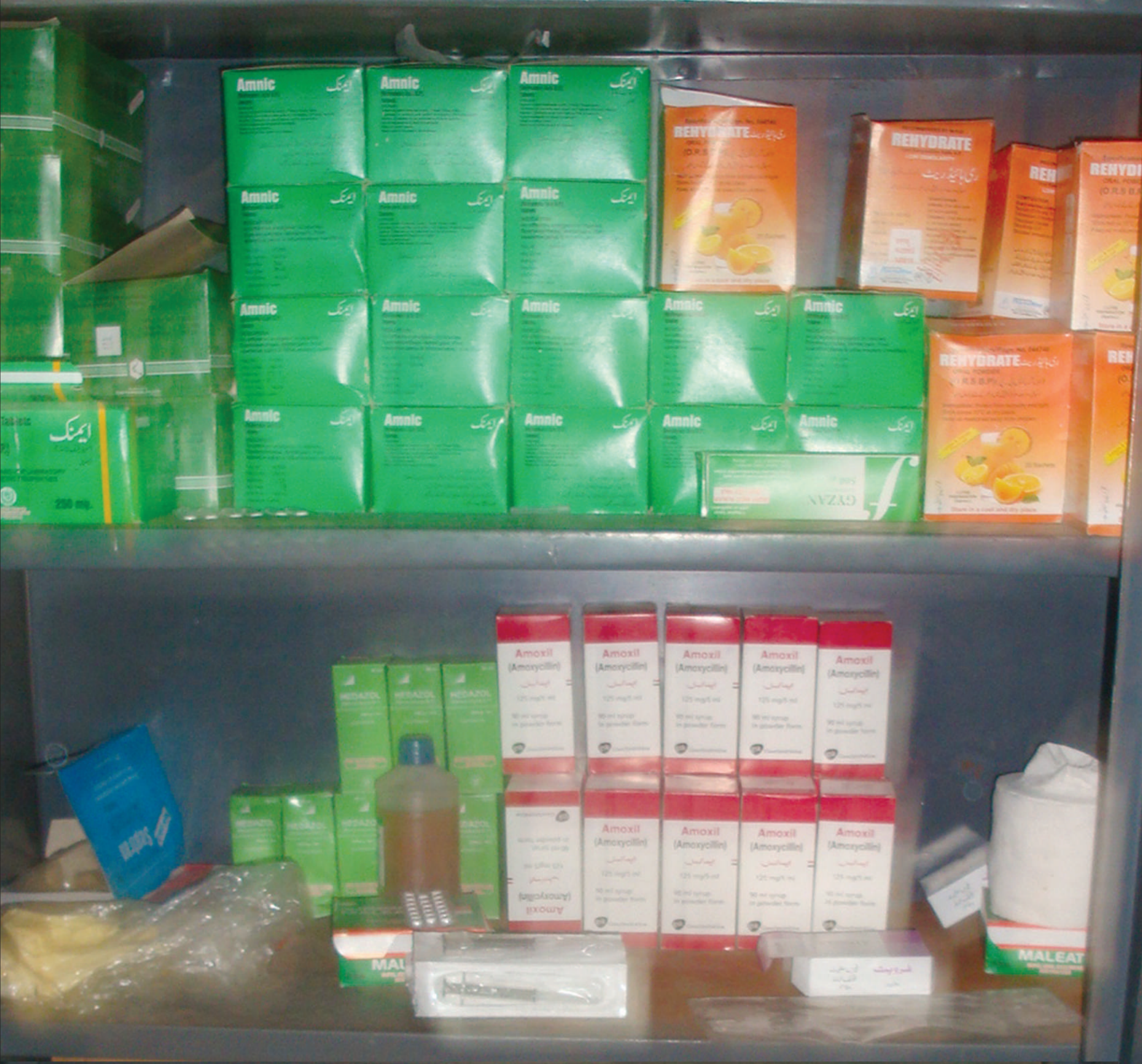

\section{Contraceptive Preferences}




\section{Main Findings}

- Contrary to the common impression, people in rural, even remote, areas do not seem to harbor any strong preference for traditional methods of contraception over modern methods.

- Modern contraceptive methods are being preferred by the majority of men, women and service providers across the districts.

- Men and women feel more satisfied with modern FP methods because of the far lower risk of conceiving compared to traditional methods.

- Most men and women prefer to use condoms, rather than other modern contraceptives, because the method has no side effects for women or men, is readily available almost everywhere, comes at a low cost, and is easy to use.

- LHWs prefer to recommend condoms to their clients; they also prefer this method for their own use.

- Service providers prefer to recommend IUCDs to their clients as the method is long acting, reversible and affordable, and greatly reduces the need for repeat visits; for their own personal use, however, they prefer condoms.

- The least preferred method for women and service providers is contraceptive pills, because women forget to take them daily; for men and LHWs, the least preferred method is injectables, due to side effects.

- The "ideal contraceptive method," according to men and women, would be reliable, long acting, accessible, easy to use, and have no side effects.

- Men and women consider doorstep delivery of FP methods by community workers, such as LHWs, the ideal mode of contraceptive provision. 


\section{Contraceptive Preferences}

\section{Research questions addressed in the section:}

- Why is there a preference for traditional methods?

- Are the traditional methods more religiously and socially acceptable?

- Are traditional methods considered to be more natural and to have fewer side effects?

This section explores what current, past and never users of FP methods consider the attributes of an ideal method to address family planning needs.

In IDIs and FGDs, women (48/56), men (13/33), SPs (6/64), and LHWs (11/23) shared their vision of an ideal contraceptive method, including its features, availability, and method of delivery. A relatively low number of SPs at static facilities responded to these topic, possibly due to their limited interaction with clients, indicating the separation between users and the delivery system; perhaps it also indicates a lack of motivation among SPs to consider clients' perspectives. On the other hand, almost half of LHWs had something to say about an ideal method, possibly due to their closer links with communities.

The section first lists the perceived and experienced advantages of FP methods by women, men, and SPs. We then discuss respondents' views on modern versus traditional FP methods; reasons for methods preferred and discussed the causes of methods rejection by women, men, SPs, and LHWs. Finally, based on their responses, we delineate the form and attributes of the ideal contraceptive method, and the ideal mode of its delivery.

\section{Advantages of Specific Contraceptive Methods}

In in-depth interviews, men, women, and SPs at static facilities, as well as LHWs, were asked their opinions of different contraceptive methods. The advantages stated by respondents for different methods are summarized in Table 5.1.

While women and men voiced what they saw as advantages based on their own experiences, or of people they know, SPs recounted advantages based on their interactions with clients and what they learned in training. The question was framed so it required a response on each method, accompanied by further interviewer questions. Men appeared to be more informed of method-specific advantages than women, including female methods, indicating their interest and concern about FP. 


\begin{tabular}{|c|c|c|c|c|c|c|c|c|c|c|c|c|c|c|c|c|}
\hline \multicolumn{17}{|c|}{ Advantages } \\
\hline Method & 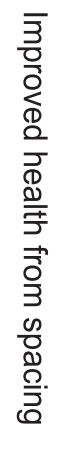 & 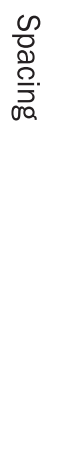 & 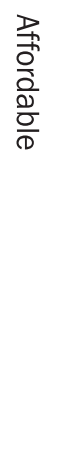 & 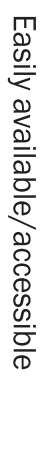 & 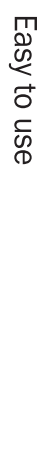 & 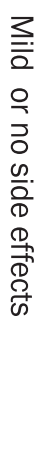 & 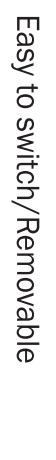 & 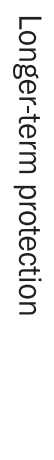 & 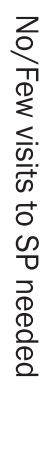 & 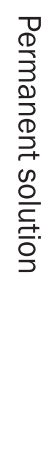 & 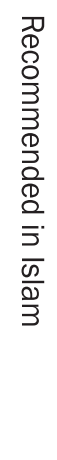 & 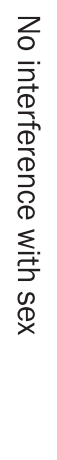 & 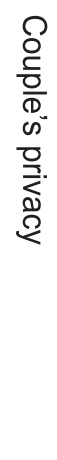 & 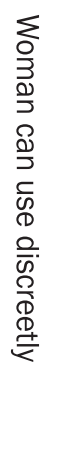 & 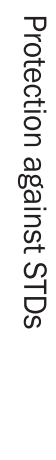 & 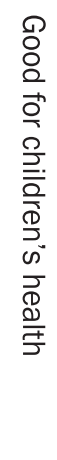 \\
\hline Pills & $\checkmark$ & $\checkmark$ & $\checkmark$ & $\checkmark$ & $\checkmark$ & $\checkmark$ & $\checkmark$ & & & & & & & & & \\
\hline Injection & $\checkmark$ & $\checkmark$ & $\checkmark$ & $\checkmark$ & $\checkmark$ & $\checkmark$ & $\checkmark$ & $\checkmark$ & $\checkmark$ & & & & & $\checkmark$ & & \\
\hline IUCD & $\checkmark$ & & & $\checkmark$ & $\checkmark$ & & $\checkmark$ & $\checkmark$ & $\checkmark$ & & & & & & & \\
\hline Implant & $\checkmark$ & & & & & & $\checkmark$ & $\checkmark$ & & & & $\checkmark$ & & & & \\
\hline Condom & $\checkmark$ & $\checkmark$ & $\checkmark$ & $\checkmark$ & $\checkmark$ & $\checkmark$ & & & & & & & & & $\checkmark$ & \\
\hline $\begin{array}{l}\text { Female } \\
\text { sterilization }\end{array}$ & $\checkmark$ & & & & & & & & & $\checkmark$ & & & & & & \\
\hline $\begin{array}{l}\text { Male } \\
\text { sterilization }\end{array}$ & & & & & & & & & & $\checkmark$ & & & & & & \\
\hline Breastfeeding & $\checkmark$ & $\checkmark$ & & & & $\checkmark$ & & & & & $\checkmark$ & & & & & $\checkmark$ \\
\hline Withdrawal & $\checkmark$ & $\checkmark$ & $\checkmark$ & $\checkmark$ & & $\checkmark$ & & & & & $\checkmark$ & & $\checkmark$ & & & \\
\hline Safe periods & & & & & & & & & & & & & & & & \\
\hline
\end{tabular}

These advantages are discussed below.

\section{Contraceptive Pills}

A large number of community men (24/33) mentioned the benefits of pills and appeared to have more knowledge about the method than actual users, women (26/56). Men discussed the benefits of a variety of pills.

In all districts, women (19/56) and men (15/33) noted the key advantage of pills as spacing, often of two to three years, which allows women to give attention to their home and children. Men (4/33) opined that women neglect their health, and their children as frequent childbearing and the housework takes its toll. The pill gives them the space needed to care for herself and her children. Men in rural unserved areas (12/24) were particularly aware of the benefits of pills. Some people incorrectly assumed, however, that if they used pills for a month, they would be protected for a long time, or that if a woman takes the pill after intercourse, she will not conceive.

From having pills, there is two to three years' spacing, and now when we have a baby, we can have a gap till the baby is grown a little. MIDI-32, 36 years old, No child, Never user; Rural unserved-Umerkot

Its benefit is that pregnancy does not take place and we remain happy and healthy because of having few children. FIDI-45, 42 years old, 7 children, Past user; Rural served-Khairpur 
The pills can be categorized according to their effectiveness be it one year, two years or three years. And then there is a pill which gives a spacing of eight to 10 years. MIDI-2, 32 years old, 2 children, Past user; Rural unserved-khanewal

A few LHWs (4/23) noted that pills have no side effects and can have a positive effect on regulating menses if a woman has problems related to her menstrual cycle. Service providers at static facilities (14/64) also noted that pills have little or no side effects. They also pointed out that pills are easy to access, cost little, and comprise a method that can easily be ended in preference for another.

Tablets are $100 \%$ safe and they do not disturb menstruation. I personally like tablets. SPIDI-62, Pvt, BHU, LHV; Mardan

Access and Affordability A few services providers (14/64) noted several advantages of pills, such as easy to access, inexpensive, can be switched and little or no side effects. These were echoed in a few responses of the communities.

It is easily available at every medical store and is available. It is low cost. MIDI-14, 32 years old, 3 children, Past user; Rural served-Pishin

I have heard that pills are easy to use and they are free as well. And if they finish at the hospital then they are easily available from the market in the city. The women who use pills have never complained about them. FIDI-21, 25 years old, No child, Never user; Rural unserved-Pishin

A few SPs (5/64) stated that sometimes, due to shortage or non-availability of other methods, community members are able to use pills, which are readily available at community level and easily affordable for everyone. LHWs also reported that they provide pills free of cost.

The tablets are cheap and there is no problem. A man took three or four boxes. IDISP-110, Govt, RHC, Dispencer; Sibi

Some people say that there is no one to inject, as there are no facilities in communities-services are far away. So pills are fine and access is not a problem. IDISP-66, Govt, DHQ, GYN; Pishin

(There is) no need to go anywhere; a woman can take pills at home. IDISP-65, Govt, FWC, FWC; Mardan

They (clients) give preference to pills because they are easy to use. Those who want to go to the hospital go there and buy them. And those who want them from me come to my house and take them. And I give them for free. And they get them easily. So, people like it more. IDILHW-10; Semi urban-Pishin

The advantages listed by service providers and LHWs were echoed in responses from the communities.

It is easily available at every medical store...It has a low cost. MIDI-14, 32 years old, 3 children, Past user; Rural served-Pishin

I have heard that pills are easy to use and they are free as well. And if they finish at the hospital, then they are easily available from the market in the city. The women who use pills have never complained about them. FIDI-21, 25 years old, No child, Never user; Rural unserved-Pishin

\section{Injectables}

The benefits of injections were noted by a majority of SPs (57/64), and a large number of women (34/56) and men (25/33). Men from rural served areas in all districts (14/25) reported more advantages of injectables than rural unserved and semi-urban men.

In general, women and men only focused on the benefits of long term spacing while talking about the advantages of injectables, while SPs mentioned other advantages, such as ease of use, need for fewer visits to SPs, and privacy. Only five out of 34 women who discussed about benefits of injectables reported that it does not have side effects. 
For the majority of respondents (18/34 women and 20/25 men), spacing, particularly long term spacing (11/34 women), was the key advantage of injectables, as it relieves the woman of the stress of conceiving for a couple of months, and she can give her full attention to her personal life and household activities.

Repeatedly, the benefit of spacing was linked to being stress free-"no tension" for three or six months for both husbands and wives. Community members also noted that they could end the method easily if they wanted to conceive.

The benefit of the injection is that pregnancy does not occur and the mother remains a bit healthy. Secondly, the menses are regular and due to it the spacing occurs for a longer period of time. The injection for three months causes prolonged spacing. MIDI-5, 45 years old, 3 children, Current user; Rural served-Mansehra

The advantage is that you can have the spacing for as long as you want, for example, one, two, three years. And if you want further spacing, then you can have the injection again or don't have it if you want pregnancy. MIDI-2, 32 years old, 2 children, Past user; Rural unserved-Khanewal

The service providers agreed and added that the woman knows that after three months she can come again for her next dose.

They say it is hard to take a pill daily. They are working and they forget. They prefer the injection for three months because they will relax for three months. IDISP-66, Govt, DHQ, GYN; Pishin

It is because they say that they can afford [injections]. Also for a month or two, they are free and relaxed. Even from their in-laws, they have stress, so they are also free from this. [They can tell themselves] we are doing family planning, so we can't have any issue, even though if we have sex with our husband nothing will happen ... Without this, they are always worried that what if they conceive again? IDISP-20, Pvt, NGO Clinic, GYN; Khairpur

Another advantage mentioned by the service provider (10/57) was the fewer visits needed when using an injectable. None of the women mentioned this benefit however, and only four men did.

Women say that, firstly, it is for three months, so they can easily sit at home for three months and they would not have to face the problem of coming daily. For this reason, they prefer injections. IDISP-34, Govt, FWC, FWW; Mansehra

There is no doctor's fees again and again. MIDI-13, 30 years old, 2 children, Current user; Rural servedPishin

With injections, the benefit is that once injected, even if the husband discharges inside the wife, she cannot get pregnant ... If the required time period of injection finishes, like three to four months, then they go again for injections. MIDI-25, 47 years old, 7 children, Past user; Rural served-Khairpur

A number of service providers (9) also noted that a woman can come to the facility for an injection on the pretext of a general health issue, and her use of it can remain confidential.

They can take injection and with this they can also make an excuse and go out of their house. IDISP-6, Govt, MCH Center, LHV; Khairpur

Service providers from Sibi and Pishin mentioned that injectables are the only method women can use secretly, especially if the husband and mother-in-law do not approve of FP and female mobility is restricted.

They have restrictions in their houses. The biggest reason is that it (the injection) isn't visible. And if we take a look at them, check their blood pressure, and provide them with methods, then they get stable. They don't have any side effects. IDISP-108, Govt, RHC, FWW; Sibi

An additional benefit of using injectables is that they are affordable. A woman can get it free from LHWs. 
Yes, and they (injections) are cheap as well. You can buy it from every medical store, and it works for three months. And you can get it secretly. IDISP-69, Govt, RHC, MO; Pishin

\section{IUCD}

Half of the women (31/56) and nine of 27 men who responded to this question mentioned the benefits of IUCDs. There were only nine personal reports of using the IUCD and not experiencing any side effects or discomfort (8 women, including one SP, and one man whose wife used it). SPs (37/64) and LHWs (7/23) listed more advantages, and some noted that they have not received too many complaints about the method, while others stated that they either counsel patients or remove the IUCD if there is a complaint and offer another method.

Women (24/31) considered the methods of IUCDs as long lasting method that is effective for five to 10 years. In their view, after insertion of the IUCD, they are able to give all their time to their families. The IUCD is effective in preventing pregnancies (9/24) and ensuring spacing (6/27 men). It is viewed as an easier method that does not require frequent visits to an SP, compared for example with an injection, or that has to be taken daily like pills.

The benefit from the IUCD is that people get it inserted for a long period of time and spacing can be practiced by this method. FIDI-9, 25 years old, 2 children, Current user; Semi urban-Mansehra

The advantage is that if it suits a woman, she can keep it for at least four to five years. Then, a person can be free of the daily hassle. It is not like an injection where you have to go after every two or three months. It helps you live your life in peace for the next three to five years. If it does not suit women, they can switch to another method. FIDI-34, 40 years old, 7 children, Current user; Urban-RY khan

If it is kept, then the advantage is that spacing will take place and child birth will not happen. [Women] can peacefully breastfeed the child and if she goes to her husband while having the IUCD, then child birth won't take place at all. MIDI-30, 25 years old, 2 children, Current user; Rural served-Umerkot

Service providers (13/37) explained that if an IUCD is properly inserted, it is very effective in preventing pregnancy, and the failure rate is low. A woman is free from the fear of conceiving for a long period of three to five years, or even more if she chooses this method. Providers believe this method is selected more by couples who have completed their family size but do not want to opt for the irreversible method of sterilization.

With [IUCD], you spend money once and then you are free for five years. It is a long-term spacing method. IDISP-78, Pvt, RHC, WMO; Pishin

Through IUCD, prolonged birth spacing can be practiced and whenever the patient wants they can get it removed. Because getting the injections and taking pills again and again is not so good, so IUCD is the best option. IDISP-25, Pvt, MCH Center, LHV; Mansehra

In the experience of the service providers (8/37), if an IUCD is placed in a correct manner and properly maintained, on its removal a woman can conceive quite quickly if she so desires. And if there are any side effects or hormonal problems, it can be easily removed.

[IUCD] is for five to seven years and if someone is experiencing side effects, she can always have it removed; also, when she wants to get pregnant after one year, two years or three years whenever she decides, we remove it instantly so that she can conceive. IDISP-153, Govt, BHU, LHV; Khanewal

The Copper-T gives space for one year or two years or five years altogether. If they want to get pregnant, they can get it removed as well. IDILHW-15; Urban-RY Khan

Service providers (7/37) feel that IUCD has no particular side effects, and can be used even by breastfeeding mothers. And if any side effects are experienced at the beginning after IUCD insertion, these can be easily managed. Problems can also be avoided if clients are properly counseled. Only four women reported that IUCD has no side effects. 
It is a long space and I will be free for a long time. I have had no problem from this and I breastfed my baby for two years and then had an IUCD placed. IDISP-94, Govt, FWC, FWW; RY Khan

Whoever used it had regular periods. And nothing happened to them and they did not get any pain or leucorrhea. They don't have any discomfort or any harm. Three or four women here are using it and they are not facing any trouble. There is no side effect. Two or three women even suggested me to use it. I told them that I will think about it. FIDI-2, 29 years old, 4 children, Past user; Rural served-Khanewal

There are IUCDs for one year, two years and three years. The baby will be healthy and the mother will also be healthy. Those people who have more kids, their women are now ill. The advantage of using an IUCD for three years is that you don't have to come and go every day. And when you want a baby, you can also get it removed. MIDI-14, 32 years old, 3 children, Past user; Rural served-Pishin

A few women noted that it was inexpensive or available for free from the hospital. Service providers also reported that the IUCD is provided free of cost at health facilities.

\section{Implants}

Implants, often known by the brand name Norplant, are tiny rods inserted under the skin in the upper arm. The rods release small amounts of the hormone progestin into the bloodstream. In Pakistan, this method has only recently been introduced at government facilities in Sindh. A few private sector providers also offer it.

One fourth of women (13/56), a few men (4/33), and fewer (4/64) SPs reported that its main benefit is spacing. Some women were also incorrectly informed that it remains inserted for six months.

Its benefits are that you remain healthy and happy; (having) fewer children results in the mother being able to give time to housework as well as the children; there should be no harm. I've heard [of implants, but] haven't seen it. FIDI-45, 42 years old, 7 children, Past user; Rural served-Khairpur

About this I have heard that people get it implanted for five or four or three years and their birth spacing occurs by it. FIDI-11, 20 years old, 2 children, Current user; Semi urban-Mansehra

One-time insertion means that there is only one visit to the doctor for three to four years of contraception. There is no link with the intercourse. IDISP-162, Pvt, DHQ, GYN; Khanewal

There are a lot of patients that come for implants and we doctors refer this method a lot. Implants are a good method and there is no irritation in it. We make the patients understand that we just put the canola in the arm. We give two capsules. The male partner also does not have any sort of problem because this method has no such complications. Irregular menses and bleeding is possible, but we make the patients understand through proper counseling. There is no problem in this method and it is safe for you and your child, and it is safe for your husband too. IDISP-20, Pvt, NGO Clinic, GYN; Khairpur

Service providers reported that camps are arranged for districts for implant insertions. If women experience any problems, they have nowhere to go, and nearby facilities are not trained in managing implant side effects.

\section{Condoms}

Women (42/56) and the majority of men (27/33) mentioned the advantages of condom. Service providers $(27 / 64)$ mentioned fewer advantages as compared to community men and women, though more LHWs $(13 / 23)$ noted these benefits because they provide condom to females clients in community. Generally, more of the men in rural served areas (16/27) across the districts reported the advantages of the condom, possibly because of the presence of LHWs in their communities.

About half of women (24/42) and half of men (14/27) who noted the benefits of condom use mentioned spacing. A few SPs from facilities and LHWs noted that condom use protects women from infection and transmitted diseases; to a lesser extent, protection was mentioned by women and men as well. A doctor from Mardan also recommended condoms to women to be safe from diseases. 
It was also pointed out that condoms' ease of use meant they could be used by a couple without visits to SPs or any breach of their privacy.

A person is saved and protected; no illness/sickness takes place, and spacing takes place due to which women don’t conceive. FIDI-47, 28 years old, 2 children, Current user; Sami urban-Khairpur

The man can get the satisfaction that while intercourse with the wife the semen or discharge remains safe with the use of a condom. MIDI-10, 35 years old, 2 children, Past user; Rural served-Mardan

Male condoms are more visible. Female condoms are invisible and the chances of infection are high so male condoms are comparatively better. If they use male condoms and take pills at the same time, then the success rate will be high even if they forget taking pills, barrier method saves them from sexually transmitted diseases. STDs are very common. IDISP-148, Govt, DHQ, WMO; Khanewal

Some people use condoms because of the fear of hepatitis. The man or the woman may have it, and to save each other from it, they use condoms. IDISP-91, Govt, MCH Center, LHV; RY Khan

One [advantage] is that it has no side effects, and the second that there is no transfer of disease from the male to female or vice versa. IDILHW-13; Rural served-RY Khan

The absence of side effects was noted as a distinct advantage by all groups of respondents, especially given that side effects cause women to drop other methods.

I trust [condoms]. There is no side effect and it does not cause any infection. Since I am the only woman in the house, and if I get sick then there is no one to take care of the household, that's that is why for my health, I use condoms and I also trust it. FIDI-3, 30 years old, 4 children, Current user; Rural unserved Khanewal

Men use that and women say nothing about it (condoms). Women do the housework easily and take care of their children, and it has no side effects and the health also stays good. LHWIDI-7; Urban-Mardan

I say that a condom is a good method. Both the men and the women don't have any side effects. It is very easy to use and they can take it from our center at any time they want. IDISP-91, Govt, MCH Center, LHV; RY Khan

Condoms are inexpensive, and as SPs note, provided free by LHWs and also widely available at market stores.

Because it is easy to use and a person does not get ill with it. It is cheap and there is no problem like having to take it every night, as with pills. With this the menses also stay fine. It's less expensive and more effective. FIDI-52, 45 years old, 4 children, Never user; Urban-UmerKot

According to the advice of doctors, medical supervisors and neighbors, it is OK. One doesn't need a prescription or go anywhere [particular to get it] and there is no disadvantage. You can get them from anywhere. MIDI-2, 32 years old, 2 children, Past user; Rural unserved-khanewal

[Condoms] are easy to use and easily available. Other methods are also easily available, but this is also very easy to use and has fewer side effects ... IDILHW-8; Rural served-Mardan

Some men feel LHWs' stocks of condoms are of low quality, and those available in the market are of higher quality, albeit more expensive.

They are not of good quality. The ones which are of good quality ... are expensive ... around 50 rupees per condom minimum, and the cheap one is not of good quality and it also does not give the natural pleasure. MIDI-9, 37 years old, 3 children, Current user; Rural served-Mardan

The unspoken issue in condom use is, of course, male cooperation, which comes up even when the method's advantages are discussed.

I have a three year old daughter and I am pregnant again. I used condoms before; I was a past user of condoms. This is why I don't have any hormonal problem, and there is no side effect. It is a good method. 
The uterus isn't harmed and it isn't mixed in the blood. It happens with personal understanding. It is important for the man to be cooperative. Thankfully I don't have any such problem. IDISP-81, Pvt, BHU, WMO; Pishin

Condoms are very easy to use. If the husband gives permission for family planning then there is no other method that is better than this. It is also a cheap method. And this method has no side effects. IDILHW10; Semi urban-Pishin

\section{Female Sterilization}

Sterilization is a safe alternative to long term contraception for a couple who have achieved their desired family size. Less than half of women $(17 / 56)$ and men $(14 / 33)$ mentioned its benefits.

Of those who did mention the method, (13/17) women and (12/14) men thought it was the best method for couples who had completed their family. Men were aware that the client is paid a small amount and that service providers arrange for transport to drop clients home after the procedure. Respondents recognized that the method meant that couples could be free of all the expense, stress and hassle of acquiring FP methods.

Its benefit is that when a person has four to five children and then, after this, they go for an operation, in this, children remain healthy as well as the mother. And children can have good food, wear good clothes, etc. If they have many children, like eight to ten, then it is very difficult to give them proper upbringing due to the increasing expense. FIDI-57, 40 years old, 4 children, Past user; Urban-Umerkot

The advantage of the operation is that if a man or woman gets it, then all of that [birth control] 'game' is finished. MIDI-17, 40 years old, 3 children, Never user; Rural served-RY Khan

Both the husband and the wife's health is improved. They are tension-free and can also take care of household expenses if they have fewer children. MIDI-30, 25 years old, 2 children, Current user; Rural served-Umerkot

The "tension free" advantage is good for the health of the woman, as noted by the respondents, as she does not live in fear of another pregnancy, especially in their forties.

\section{Male Sterilization}

Compared to other methods, vasectomy was not discussed much by women, men or SPs. Only four women and one man spoke of its advantages, possibly because there is no information available on this method, or it is not offered at all facilities, or it is not a preferred option at all.

The only benefit is that spacing occurs between children through this method [vasectomy, female sterilization]. FIDI-12, 38 years old, 3 children, Past user; Rural unserved-Mansehra

Yes, I did ask one woman that your husband has done operation, so when you have sex is it all o.k. or there is some kind of weakness, etc.? She replied that there was no weakness, nothing at all, and they were both are satisfied. FIDI-57, 40 years old, 4 children, Past user; Urban-Umerkot

\section{Withdrawal}

Withdrawal is one of the traditional male methods, and women (13/56), men (9/33), and SPs (5/64) mentioned some advantages of it. The method was not mentioned by male respondents in Punjab, and by only four men in Pishin district in Balochistan. The respondents who did speak about the advantages of withdrawal were mostly from rural unserved and rural served areas. People from urban area did not discuss this method.

Women and men were aware that withdrawal has no side effects, unlike modern methods, and no access or cost issues. Proper use of this method can prevent pregnancy. 
No money is spent in the use of the Islamic method. And the man also stays happy. And the woman also doesn't get ill. FIDI-21, 25 years, No child, Never user; Rural unserved-Pishin

Its advantage is that it does not harm the woman at all and it does not cause pregnancy and also the woman does not gain weight because of it, not does it cause any other harm. My sister-in-law uses this method and this method is easy to use because it does not hurt in any way. FIDI-10, 38 years old, 7 children, Current user; Semi urban-Mansehra

It is a simple method as it doesn't require going to any doctor and neither are any medicines required; this is just in a person's control. During intercourse, the semen is discharged outside. MIDI-10, 35 years old, 2 children, Past user; Rural served-Mardan

\section{Lactation Amenorrhea Method (LAM)}

Only a few (4/56) women, one third of men (11/33), and few (5/64) SPs commented on the benefits of the LAM method. Men appeared to know more about the method, noting that a woman cannot conceive for two to two and a half years while breastfeeding. There are no side effects of LAM and the health of the woman and child improves. As it is mentioned in the Quran, men thought that women should follow this method. One man from Mansehra reported that breastfeeding protects the child against infection (by supplying antibodies).

The mother breastfeeds her child for two years, due to which birth spacing occurs naturally, and this is the only [source of] antibodies. MIDI-5, 45 years old, 3 children, Current user; Rural served-Mansehra

It means that you can have two years' space between your children. Then have more children. With this, the woman's health is also not affected. The baby will also be healthy. It won't be ill or weak. The second thing that I have heard: the woman who has a baby for the first time, she gives the baby her milk for six months. With this, you don't have kids for four, five or six months. MIDI-13, 30 years old, 2 children, Current user; Rural served-Pishin

I would personally prefer the breastfeeding method. During the time when the child breastfeeds, the period comes regular and the child also keeps breastfeeding due to which his/her health also stays good. Birth spacing also occurs and the health also stays fine. FIDI-5, 38 years old, 6 children, Past user; Semi urban-khanewal

\section{Safe Period}

The advantages of the safe period method were mostly unknown to local women and men, and even SPs did not mention it, as they think it is difficult to make women, who are mostly uneducated, understand how to calculate safe days and follow the method. Only two women discussed the advantages of the safe period method.

This [rhythm method] also avoids pregnancy. FIDI-4, 27 years old, 5 children, Never user; Rural unserved-Khanewal

Generally, women do not have correct knowledge about the safe period and they misunderstand the safe and unsafe days ... When menses were finished and she goes to her husband [has intercourse], then she will conceive. If she goes immediately after finishing her menses, she will conceive. If she does not have intercourse for four to seven days then she will not conceive. FIDI-51, 28 years old, 4 children, Past user; Rural served-Umerkot

\section{Modern versus Traditional Family Planning Methods}

Most of respondents favored modern methods in comparison to traditional ones. Most women (31/56), men (17/33), and SPs (46/64) noted in IDIs that modern methods are more effective and reliable. It was also mentioned in almost all FGDs with men (13/24) and women (16/24) that modern methods are usually preferred over traditional methods in their communities. 


\section{Advantage of Modern Methods: Effectiveness}

The primary advantage mentioned by both women and men is the reliability of the modern method as compared to traditional methods. Modern methods provide long-term options for spacing while traditional methods are effective only at times and their failure rate is high.

Our grandparents were very wise. They used all methods. Nowadays, the women are not that smart and you cannot expect them to use the [traditional] methods. And I think the traditional methods are no longer useful. Whatever remedies that they used are no longer beneficial. However, the modern methods have a lot of advantages. FIDI-2, 29 years old, 4 children, Past user; Rural served-Khanewal

Now people prefer the latest methods because in the traditional methods even after being careful you still have a baby. This is why the trust of people on these methods is diminishing and it's moving to latest methods. FIDI-22, 26 years old, 3 children, Current user; Semi urban-Pishin

Mostly people prefer the use of modern methods more because the modern methods provide spacing according to the new era. Whereas these old methods are a failure and they are not reliable. That is why people like modern methods more. They mostly use condoms and pills. MIDI-23, 40 years old, 3 children, Past user; Rural served-Sibi

We don't have faith in the older methods. My neighbor used an older method but she got pregnant and I got scared after hearing this. FFGD-17; Rural served-RY Khan

Natural methods are not that safe; there is a chance of pregnancy in them. But in new methods, birth control is definitely done. MFGD-6; Semi urban-Mansehra

Service providers also reported that clients have no trust traditional methods due to their high failure rate. Many women who visit facilities share with them that they were using traditional methods, but these failed, and they became pregnant.

They use modern methods and stop using traditional methods because of high failure rates. They are not satisfied because they are not safe and they will get pregnant. Traditional method users are fewer than modern users. Yes, they are not satisfied [with withdrawal or calendar method]. IDISP-158, Govt, FWC, FWC; Khanewal

They prefer new ones. Natural methods all fail. Maybe five out of a hundred [clients] like natural methods like withdrawal, breastfeeding and menstrual cycle method. IDISP-62, Pvt, BHU, LHV; Mardan

Respondents mentioned that couples feel satisfied and relaxed using modern FP methods as there is "no tension" about conceiving; however such fear remains with traditional methods.

Women noted that while withdrawal is a natural process, it is difficult for men to control themselves and sometimes they may not observe withdrawal as it gives less satisfaction. The method is not widely known in some communities.

People use pills and injections more. They prefer them more because they are in a lot of difficulty. Men don't use withdrawal method, so what can the woman do? He doesn't like withdrawal. FIDI-25, 22 years old, 1 child, Never user; Urban-Pishin

They say that when a man is about to discharge, he should move to the side, but men here don't do it. There is a proper system of a man; they probably can't. They might know about it but we don't. Maybe they are not satisfied with them. They say that they don't have faith in this method. FIDI-34, 40 years old, 7 children, Current user; Urban-RY Khan

They don't trust the traditional method and they can't even have control on themselves. They don't have trust over themselves that will they be able to use this Islamic method; that's the reason they don't give importance to it. MIDI -28, 45 years old, 3 children, Past user; Semi urban-Khairpur 
If the man cooperates, the women then prefer natural methods, and if they don't, the woman goes for newer methods. The man says that don't conceive, but I can't live without sex. Then the woman comes to us and asks us what she should do. We tell her a suitable method and then the rest is on Allah to keep it working. IDISP-60, Pvt,THQ, WMO; Mardan

Men do not abstain, as it is their wish. They say that they do not get satisfaction by the withdrawal method as they cannot control themselves. Due to the lack of education they do not understand the complications.

FFGD-1, Rural served-khanewal

Using LAM has its drawbacks too as women do not follow breastfeeding instructions properly, and supplement their babies' diets, which reduces the effectiveness of the method.

They are breastfeeding, but then these women work in the village in the farms, so they cannot feed the baby on time. IDISP-134, Govt, BHU, LHV; UmerKot

When they feed the baby at night, pregnancy doesn't happen. The traditional method is this. The chances are less. They don't wake up at night and feed the baby. The poor woman works the entire day. Mostly she gives the baby syrup at night. She puts the baby to sleep and she goes to sleep. Then she wakes up in the morning. IDISP-112, Govt, BHU, FMT; Sibi

The calendar (safe days) method is not well known in communities and difficult to explain to people who are uneducated. Service providers are informed about traditional methods, and discuss withdrawal and LAM with communities, but do not talk about the calendar method as much.

No, they don't give much preference to traditional methods because they don't have much knowledge about these methods, so they give more preference to modern methods. Yes, I do ask, but they don't use them ... breastfeeding, the withdrawal method-I have also told my clients about these methods but they say that they can't use these methods. IDISP-128, Govt, FWC, FWA; Umerkot

\section{Advantage of Traditional Methods: No Side Effects, Expense or Hassle}

According to respondents, the few couples who use traditional methods prefer them because there are no associated side effects, expenses, or access problems, as there can be with modern contraceptives. Moreover, the couple can keep their FP effort confidential and practice these methods without any third person's involvement.

This is because, in Islam, there is a method of breastfeeding which we will adopt, but they dislike the latest methods, but then in breastfeeding you (can) get pregnant. They are scared of latest methods because there are more side effects. When the wife's health gets very bad then the husband shouts that now I cannot do anything. I got treatment [FP method] for you on your insistence-so now you suffer. FIDI23, 32 years old, 2 children, Current user; Semi urban-Pishin

A lot of people prefer the Islamic method. Maybe they like these methods because nowadays there is a lot of poverty. Those people, who are strict, use the Islamic methods. They don't let the women go out. MIDI-21, 47 years old, 9 children, Past user; Semi urban-Sibi

Here, there is no government [sponsored] method present ... women just breastfeed ... If spacing happens ... it is a big thing. Otherwise they have a baby every year. The withdrawal method is also used in this area. Some people like using it because other methods are not present, and people use methods which are in their means. FFGD-14; Rural unserved-Pishin

Quite a few people use it. When we tell someone that use a method for spacing, they say that we are already using the withdrawal method. This is because the women don't have to use any medicine then. When they use medicines, they get very lazy [lethargic] and they feel mentally stressed. The men then think that it is better to use the withdrawal method. They do but very little. We tell them about the eight or ten days in between and tell them to avoid intercourse during those days. IDISP-91, Govt, MCH Center, LHV; RY Khan 
The reason for [traditional methods' use] is that it does not have any harmful side effects and getting it is easy. Obviously when she is doing lactation (breastfeeding), it is easy for her. If she is breastfeeding her child then it's obvious that she won't have to get anything from outside and the breastfeeding acts like a contraceptive for her. Mostly, people are in favor of lactation and withdrawal, but the safe period method is used by very few. The ones who come from very far off places, they use these traditional methods. IDISP-27, Pvt, RHC, WMO; Mansehra

\section{Education and Method Selection}

Service providers state that educated users prefer modern methods more compared to those who are illiterate. Women also mentioned in FGDs that illiterate people do not use traditional methods.

People that are educated, they give preference to modern methods, and those ... uneducated, they give more preference to traditional methods. IDISP-35, Govt, BHU, LHV; UmerKot

Those people who are educated, they do it (use modern contraceptive methods). We are illiterate; that's why we don't do it. FFGD-25; Rural served-Khairpur

They do not follow Islamic [withdrawal] method because they are illiterate. FFGD-25; Rural served-Khairpur

\section{Method Preferences of Users and Providers}

The preceding discussion reveals that variations exist in the method preferences of current and potential contraceptive users depending on the advantages or disadvantages they deem most significant. To explore these variations more deeply, this study looked at the method preferences of categories of stakeholders, including women, men, SPs at static facilities, and LHWs. The preferences of SP and LHWs were considered from two perspectives: their prescription preferences as SPs and LHWs, and their personal usage, to see whether they preferred the same method for themselves as they prefer for clients and, if not, for what reason.

\section{Women}

Women (16/36) favored using the condom since it had no side effects for women or men, it is inexpensive, easily available, it is not difficult to use and prevents pregnancy. In particular women from Punjab and KP mentioned the benefits of condom use.

I like condoms for myself because they are not harmful for the health or body. FIDI-12, 38 years old, 3 children, Past user; Rural unserved-Mansehra

I use condoms and I also trust them. Condoms are better than the Islamic methods and all other methods because due to this method nothing happens to the woman and a lot of people here have confidence on condoms. I would say that condoms are the best because due to its use, there is no harm to the woman nor any side effect. And despite that, there is no pregnancy. FIDI-3, 30 years old, 4 children, Current user; Rural unserved-Khanewal

I like condoms because people remain clean and the objective is easily achieved, meaning that spacing occurs. FIDI-19, 35 years old, 4 children, Current user; Semi urban-Mardan

\section{Men}

Men seem to echo women's preference for the condom; across districts, more often in KP and Balochistan (Sibi), men (27/33) cited it as a preferred method because it has no side effects for women or men, is easily available almost everywhere at a low cost and is easy to use.

I like the condom because it is easy to use and it is even available in my area. Whenever I want I can go and buy it. In order to use it I don't need anyone's help, as with an injection. Nor does my wife have to suffer any pain. MIDI-23, 32 years old, 3 children, Past user; Rural served-Sibi 
I like the condom method. Its advantage is that it does not have any side effects and can be used for a longer period of time. This is why I like it. MIDI-5, 45 years old, 3 children, Current user; Rural servedMansehra

The quality of the low-quality condom should be improved as the condom does not badly affect the health of the man and woman. MIDI-11, 36 years old, 4 children, Never user; Urban-Mardan

\section{Prescription Preferences of Service Providers}

Most SPs from all districts (45/64) are partial to recommending IUCDs to their clients. According to them, the preference is based on their experience of what women request of a method. The method provides long lasting cover, eliminates the need for repeat visits, can be removed, and is affordable (even free, if taken from government facilities). Further, after the one-time insertion, it does not require any effort on the part of the user, making it easy to use. In service providers' view, side effects are not a major issue since the IUCD can be removed if any adverse effects accrue.

IUCD is a good method. [IUCD] is a long-term method and clients don't have to come again and again. And if, for example, they are experiencing side effects, they can get it removed. IDISP-158, Govt, FWC, FWC; Khanewal

[I like the] Copper-T, as at least for 10 years, there is no danger from this. One has to go get pills or take injections; in that sense, it is best to use Copper-T and it can also be for five years. Whenever a couple is planning on having a baby, then they will remove it. IDISP-9, Govt, FWC, FWW; Khairpur

The reason is that through IUCD, prolonged birth spacing can be practiced and whenever the patient wants, they can get it removed. Because getting the injections and eating pills again and again is not good too, so IUCD is the best option. IDISP-25, Pvt, MCH Center, LHV; Mansehra

As noted by the SP from Mansehra, IUCD is preferred over injections, a view shared by most, including those from Punjab.

\section{Prescription Preferences of LHWs}

LHWs (8/19) prefer to recommend condoms to their clients, not least because these protect against sexually transmitted diseases. The second method preferred by LHWs is injections: they report that if a couple is not ready for condoms, they prescribe injectables because this method provides longer spacing and, importantly, the woman can use it secretly.

I like condoms because if they have any genital problem then they are saved from each other. This is a very easy method and has to be used every time you have intercourse. IDILHW-5; Rural served-Mansehra

It's a good method for family planning. It's o.k. The easiest method is condoms. IDILHW-18; Semi urbanSibi

\section{Personal Preferences of SPs and LHWs}

The contraceptive method preferred for personal use by SPs is the condom, as it is easily available, easy to use and does no harm. This choice is in contrast with their frequent suggestion to clients to use the IUCD to avoid repeat visits.

The reason is that I have fibroid in my uterus. I can take neither hormones nor IUCD. That is why I use condoms and my husband is cooperative, so it is easy. IDISP-158, Govt, FWC, FWC; Khanewal

The thing is that my husband has agreed to use condoms and as long as he is willing, I will use this method. My husband also says use tubal ligation but the thing is my in-laws don't agree to this. IDISP134, Govt, BHU, LHV; Umerkot 
I use condoms more. As I have told you, it does not cause any harm. It has been approximately four years [of use] and I have had no problems. IDISP-112, Govt, BHU, FMT; Sibi

LHWs give equal preference to condoms and IUCDs for themselves.

I myself have been using condoms and they cause no problem. IDILHW-9; Rural served-Mardan

My husband has been in Saudi Arabia for two years and before that I was using condoms. My husband was comfortable using condoms. LHWIDI-3; Semi urban-Khanewal

The findings about method preferences and underlying reasons noted for each category of respondents are summarized in Table 5.2 .

Table 5.2: FP Methods Preferred by Respondents

\begin{tabular}{ll}
\hline Respondents & Top preference \\
\hline Women & Condom \\
Men & Condom \\
Service Providers (as provider) & IUCD \\
Service Providers (as Users) & Condom \\
LHWs (as provider) & Condom \\
LHWs (as Users) & Condom and IUCD \\
\hline
\end{tabular}

\section{Methods Avoided by Users and Providers}

The preceding discussions show which methods women, men, SPs, and LHWs prefer, yet it is also useful to consider the methods respondents do not prefer, and the underlying reasons.

During discussions it emerged that women (24/36) prefer neither the pill nor injectable contraceptive methods. The reasons are similar for both: side effects, such as menstrual problems, irregular bleeding or heavy bleeding, and dizziness. Women are also likely to forget to take the pill and sometimes delay their next injection resulting in an unplanned pregnancy.

Only that it [pills and injections] causes much harm. Blood [period] starts and they then do not stop. It causes a lot of bleeding and this also creates a lot of problems. The only reason is that it causes a lot of harm and has very little advantage. FIDI-13, 30 years old, 3 children, Past user; Rural unservedMansehra

My elder sister used [pills]. She became very ill. She had a lot of bleeding. She just used to change her clothes every day. She also used to get wounds due to heavy bleeding. This is why I don't like this method at all. My sister told me that after taking them, you feel very nauseous. And you don't even feel like doing anything. I don't like it because I think it has no benefits. Men also don't like it. FIDI-24, 26 years old, 2 children, Never user; Rural served-Pishin

My friends say that you shouldn't take pills. Her husband also says that don't take them because they cause harm. When they cause side effects, the person falls sick. Blood starts to flow because of heated body temperature. There are palpitations. FIDI-4, 27 years old, 5 children, Never user; Rural unservedKhanewal 


\section{Men}

In general, men across the districts did not particularly dislike any method. Only (8/19) men from rural served areas were against injection, because it is expensive, requires a skilled SP, and causes heavy bleeding in women that leaves them weak.

Getting the injection involves a lot of work. First, buy an injection. Spend money on this as well then find someone who can give the injection and give them money. Rather than going through so much difficulty, it is better that no one gets it. I have also heard about its side effects that it causes weakness in women. They get dizzy and women get ill. After spending so much money and after working so hard even then if the wife is ill, then it is better not to use that method. This is why I don't like it at all. MIDI-23, 32 years old , 3 children, Past user; Rural served-Sibi

The injection is not good. It has side effects. Sometimes the baby gets upside down. MIDI-15, 36 years old, 3 children, Current user; Rural served-Pishin

\section{Service Providers}

Some SPs (16/45) do not recommend pills and injections: They think women forget to take their daily pills and then complain that they conceived; women also have problems with their menses. After injections, women complain of irregular menses, spotting, irregular bleeding, and even heavy bleeding.

Hormonal problems are caused by it (injections). And the menstrual cycle gets upset. Spotting starts or menses completely stops. And the patient complains that they are not getting their menses or they cannot pray. We feel tense and we avoid injection because of the side effects. IDISP-158, Govt, FWC, FWC; Khanewal

I don't prefer pills because they have no guarantee and the women forget to take them. IDISP-107, Pvt, NGO Clinic, LHV; RY Khan

I do get disturbed by the pill because it happens that at times you have to go somewhere and you may miss your pill or you forget to have it. IDISP-140, Pvt, BHU, WMO; UmerKot

[The safe period method] is difficult and also people who are educated accept this method and pick it quickly and it is easy for us to tell them about this method. (But with uneducated people) it's like explaining (what you told) a student of $10^{\text {th }}$ grade to a student of kindergarten. IDISP-151, Govt, RHC, LHV; Khanewal

Lady health workers said they did not suggest the injection method to their clients. They explained that injection has many side effects related to menses, nausea, and dizziness.

I don't like spacing injections, because from this, they have bleeding and weakness. IDILHW-23; UrbanUmerkot

I don't like injections. Because most women say that their periods get irregular. IDILHW-5; Rural servedMansehra

The methods users and providers would rather avoid are summarized in Table 5.3.

Table 5.3: FP Methods Avoided by Respondents

\begin{tabular}{ll}
\hline Respondents & Most avoided methods \\
\hline Women & Pills \\
Men & Injectable \\
Service Providers (as Provider) & Pills \\
LHWs (as provider) & Injectable \\
\hline
\end{tabular}




\section{The Ideal Method}

The preceding discussion of advantages of specific contraceptive methods, traditional and modern methods, and methods preferred and not liked by respondents has indicated, to a large extent, what women, men, and SPs look for in a contraceptive method. This study then went a step further to ask respondents directly what they would consider an ideal FP method. Respondents were asked what attributes such a method should have, what form it should take, and how it should be delivered.

In response, women generally discussed a wide range of methods, including an ideal method, while men only mentioned a few, such as syrups, injections, pills, condoms, and capsules. Few SPs were able to imagine an ideal method and its attributes, possibly because SPs are based in static facilities and have less communication with clients from the community. By contrast, LHWs had more ideas, possibly due to the fact they go door-to-door in communities, not only educating women about a range of FP methods, but also listening closely to their complaints, fears, and constraints.

The preferred forms suggested for the method were syrup, pill and a very small implant, such as the SIM card used in cell phones.

Different stakeholders and communities emphasized different features, but the main attributes that emerged from discussions of an ideal method included the following:

- Reliable-does not fail to prevent pregnancy

- Provides long-term spacing (and does not need frequent administration)

- Has no side effects

- Easy and painless to use

- Does not interfere with sex

- Inexpensive

- Easily accessible and available

- Supported with correct information and service support

- Does not require frequent provider interaction

- Can be used discreetly

- Is compatible with religion.

The attributes, forms, and service provision of an ideal contraceptive method, according to respondents, are outlined the following section.

\section{Form}

Most women (16) said that the ideal method should be in a pill form that could be taken only once for a long time (not daily) and discontinued when women want to have a child. Pills can be easily used and family members, e.g. mothers-in-law, would not have to know, as they might discourage it. Pills should be made for three to five years for women who want longer spacing and should be only for women because men do not like to take any medicines for FP. Opinions were mixed on who the method should be centered on: for men, for women, or for both.

Lady health workers (9) also preferred a pill as an ideal method, taken only once. A few men (4) also reported that it should be up to the users to take it whenever they wanted and as long as they wanted without any fear of side effects that could potentially cause harm to women's health. 
Few SPs (3) in private and public facilities in Sind and Punjab, however, thought a pill should provide spacing for five years.

It should be for five years or three years for the person who wants a longer space. He can even buy one for 10 years. I will say it should be in the form of a pill. I will say it should be for women. Men will not use it; they will say: You do it. We are not going to take any medicine. They don't believe in it and think that it might create a problem. Yes, for women. A woman can use it. FIDI-34, 40 years old, 7 children, Current user; Urban-RY Khan

It should be such a method that shouldn't be harmful. Mostly, women who are weak get swelling in their body after taking pills. So they should make it according to the body and strength of the woman so that people don't have a problem in using it. It should be like pills or syrup, but I would like pills more. FIDI-23, 32 years old, 2 children, Current user; Semi urban-Pishin

It should be easy to use, like pills. It should be for both men and women. If it's free then ... very good. MIDI-23, 32 years old, 3 children, Past user; Rural served-Sibi

It should be a method which must not be taken often. Like, it should be pills for a year so that one becomes tension free after using it. It shouldn't have any side effects; the people shouldn't be hurt by that. LHWIDI-6; Semi urban-Mansehra

After pills, the next most popular form for the ideal method appears to be syrup, followed by injections. Few women (9) and men (3) considered the injection to be an ideal method. Women (8) and men (3) noted that the syrup should be sweet so it could be easily consumed and should not cause any pain, and should also provide spacing for a longer period of time. Only a few SPs and LHWs thought the new method could be in syrup form.

It should be such a method that isn't harmful. Mostly women who are weak get swelling in their body after eating pills. So they should make it according to the body and strength of the woman so that people don't have a problem in using it. It should be like pills or syrup. FIDI-23, 32 years old, 2 children, Current user; Semi urban-Pishin

There should be syrup, I think. It should have a good taste so that if someone uses it, they like it. It should taste like fruits and its flavor should be good. And it should not have any side effect. MIDI-33, 28 years old, No Child, Past user; Semi urban-UmerKot

In my opinion there is no such method. Like this we think a lot. We have a lot of desires. It shouldn't harm us. The Maulvi should also not say anything. It should be syrup. It should be simple; there shouldn't be a lot of running about. It should be obvious to people. MIDI-14, 32 years old, 3 children, Past user; Rural served-Pishin

Women also suggested an injection, perhaps one for men as well, similar to what is available for women. LHWs (3) and one SP felt that the injection should not cause harm to the body.

This method should be in the form of an injection or a drip for strength, with which the strength in a person's body increases and there is also spacing. No one stops us from getting drips; the men are happy that with this our woman will get strength. This method should be included in the drip which gives strength. FIDI-22, 26 years old, 3 children, Current user; Semi urban-Pishin

No one is harmfully affected ... very easy to use. It should be like something edible or in the form of a drink. It should be for six to twelve months period, just like an injection is for six to twelve months. MIDI27, 30 years old, 6 children, Never user; Rural served-Khairpur

I think there should be an injection for duration of six months to a year for the man, which is going to be a best solution, even if it is for a woman. You have told that there is an injection for three months but if it is for a year then it is better. MIDI-17, 40 years old, 3 children, Never user; Rural served-RY Khan

Surprisingly, a few women (8) and only one man from Punjab suggested that there should be a method available for men just like there are methods for women as it is only the women who go through the pain and 
suffering of using FP methods. They also have a lot of responsibilities looking after children and household chores and doing wage work. FP should also try to convince men to have vasectomies. Only three SP and LHWs also mentioned there should be method for men.

I think it should be ... for men. The way you said that there is operation for men, then the new method should be similar ... that would be good [for men]. The method should be ... for the rest of the life, as someone wants not to have any more children as the ones they have are enough then this method should be for such people, so that their ability to have children just ends ... a medicine due to which the process of having children just stops completely so that people get free of the day to day problem. I don't know about the rest, but just that it should be a medicine which could be easily used. FIDI-16, 28 years old, 2 children, Current user; Urban-Mardan

There should be such a product which both the men and women use for themselves respectively. There is just one thing available for the man (vasectomy). The women have numerous options. MIDI-18, 31 years old, 3 children, Current user;-Semi urban-RY Khan

Mostly men should start using it because women are already using a lot and are in much pain and issues. So I would say that this new method should be used by men only because mostly these men aren't doing any operation, and on other hand, all issues are for women (to face) like to do spacing, tubal ligation [etc.]. There should be a method that is used by men other than condoms. IDISP-9, Govt, FWC, FWW; Khairpur

Few people considered IUCD, implants, pills, or condoms an ideal personal method: IUCD results in heavy bleeding while condoms are not trustworthy. Interesting suggestions for an ideal method included spacing for a longer period of time and no discomfort for women.

Yes, even with (the implant) capsule, it gets easy, but the [Norplant] capsule is very big. There should be something that is smaller. It should be something small like a 'chip' [microchip]. MIDI-34, 41 years old, 4 children, Current user; Urban-Umerkot

\section{Attributes and Provision}

\section{Reliable and Longer-term Spacing}

The number one attribute women and men would like to see in an ideal contraceptive is reliable, long term spacing against conception. Already burdened with ill health and household responsibilities, women live in constant fear of yet another unplanned pregnancy. Ideally, the contraceptive should provide spacing for at least three to seven years.

\section{Free of Side Effects}

The issue of side effects looms large in the minds of women and men-just the rumor of them is enough to scare potential users from modern methods. Side effects of currently available modern methods are not only difficult to manage, but costly and sometimes more expensive than methods themselves. A few women also report household work suffering due to FP side effects and complications. Men also report that contraceptives, especially IUCD, cause heavy bleeding in women leading to weakness and fatigue. Respondents were emphatic that an ideal contraceptive has no side effects.

It should not cause ... blood pressure. Neither should it give a headache. Nor should it make the body fat. It should be such a medicine that doesn't have side effects. It should be a medicine or something else ... It should be cheap and easily available. It should be like condoms that are for one time use. MIDI-16, 33 years old, 2 children, Never user; Rural unserved-Pishin

It should be for three or four years of spacing (like the IUCD). It should be available for 500 to 700 rupees; whatever you think is right. The main thing is that there should be no harm or pain in it for women: no excessive bleeding during periods, and no problem in the uterus. If it is kept properly for one 
person, then the other people will also come, and if not, then due to this, no one will come. FIDI-52, 45 years old, 4 children, Never user; Urban-Umerkot

You should make something like the capsule method [kept in the arm] as people do like it and use it more ... for five years ... we remain well and healthy; that its use would make women happy, not upset or ill. FIDI-45, 42 years old, 7 children, Past user; Rural served-Khairpur

It can be any method but it should be available everywhere. It should be present in every city and every village ... a cheap method, which all types of people can buy. Whatever method the government makes ... It shouldn't be a method which isn't allowed in Islam ... it should not be harmful ... should give space for more than one year ... the mother's health shouldn't be spoilt ... People also don't like these methods ... [that] causes bleeding ... woman's health is also spoilt ... it should be pure from these harmful effects. FIDI-21, 25 years old, No child, Never user; Rural unserved-Pishin

Ideal method or new method should be free of side effects [and] free of failure rates. Be 100 percent perfect: no failure rate or side effects. Also you shouldn't have to take it again and again. It should be long term. IDISP-162, Pvt, DHQ, GYN; Khanewal

A couple of SPs also supported the notion that the ideal method should not cause any side effects, be cheap and available in the nearby village so that women can easily access it. Facilities should be open for long hours so that it is easily accessible and people don't have to travel very far. The facility in the community should educate both men and women to use FP method. Government should try to play its role in providing awareness to people by going door-to door. A LHV in Khanewal reported that LHW should be educated about various FP methods and should be provided with technical guidance so that they can motivate people to use FP methods.

Whatever the method is, I say, it should be easy and in such an area that is not far away. It should be near. There are a lot of services in the city. They can get them but if it is a village, in these areas such centers should be opened that have these services. If not all day, then at least 12 hours a day; if not 12 , then at least eight to 10 hours the center should be open. So they can have those services available there so that they don't have to go to the city that is so far away. IDILHW-17; Semi urban-Sibi

\section{Affordable}

While discussing the features and advantages of ideal method women (51/56) and men (23/33) noted attributes of service provision as well. They said the method should be provided free by the government or be quite inexpensive as the people in the community are poor and cannot afford a method that is expensive.

It should be a method which can be completely safe and easily available, other than this it should be less costly. Apart from all this the method created for a particular purpose should at least be capable of fulfilling that purpose. It should be safe, it should not have harmful side effects, should be available everywhere and it should be free. It should be in the form of an injection. MFGD-5; Rural unservedMansehra

We don't want any other method. Everyone who can afford this method should use it. The pregnancies should get spacing (between pregnancies). There should be conversation at home. Mother in laws should be consulted. The lady health worker [baji] should have information. FIDI-1, 30 years old, 7 children, Never user; Rural unserved-Khanewal

\section{Accessible}

Women and men stated that methods should be available at hospitals and from SPs; if easily accessible and affordable, people will be encouraged to use them. Methods should also be available in local facilities, so women who have trouble leaving home, or with limited mobility, can easily avail a method without any problem. Methods provided at home by health workers are best.

There should be free provision of contraceptives ... so that the poorest person can also adopt these methods. There should be a man in the hospital who can give these things to the men ... also give us information ... There should be a woman for the women. This should be available in all the villages. With 
this, their standard can improve. There should be a man or woman doctor who should give its information. When a doctor says something, everyone listens to him very carefully. And they also follow it. MIDI-23, 32 years old, 3 children, Past user; Rural served-Sibi

All lady health workers should know about it. It should be provided by LHWs, and they should go door-todoor to tell everyone. It should be given to LHWs. Lady doctors should be in the hospital. Contraceptives should be available to the people on their doorsteps. Those that have many kids, they should be provided with [it]. FIDI-46, 28 years old, 3 children, Never user; Semi urban-Khairpur

\section{Endorsed by Media and Local Leaders}

A few women and men suggested that the media can play a major role in raising awareness among community members. In particular, television could play a crucial role, as it is watched in countless homes and can educate people about FP.

Everyone should know this method. Everyone watches TV. There should be information on TV regarding this. FIDI-21, 25 years old, No child, Never user; Rural unserved-Pishin

You can also send the information to TV and newspapers. MIDI-17, 40 years old, 3 children, Never user; Rural served-RY Khan

You should give information in the newspaper, show it on TV; you place different advertisements in which you show people that there is no harm or disadvantage. IDILHW-23; Urban-Umerkot

Community representatives also stated that religious clerics, Councilors (Nazim), and school teachers could be involved in educating people to use FP methods, as they are influential members of society. Group meetings could be held every week to educate and encourage people to use FP methods. Men and women should be encouraged by these community leaders to adopt FP methods.

In my opinion, information about this method should be given to the religious clerics here so that they can make people understand properly, because they are the ones who tell people not to use these methods. FIDI-14, 35 years old, 3 children, Never user; Urban-Mansehra

They should be available from places like the government-run hospitals... There should be a center in the area where it should be available from. The "nambardar," Councilor, or the eminent people of the area should have the information. MIDI-1, 31 years old, 2 children, Past user; Rural unserved-khanewal

It should be given to community leaders or health centers and those who can motivate people well for these methods and make them understand easily because if a person is more attached and near to the community, people will be able to listen to them more and if they are prepared mentally, then they can be motivated for this and this concept is completely finished off that Islam doesn't not allow for family planning or it is considered to be a sin in Islam. IDISP-6, Govt, MCH Center, LHV; Khairpur

In all districts, 22 females and 11 males reported that an LHW should be available in the community so she can go door-to-door and deliver information on contraceptives and their use. It would also be beneficial if LHWs could get more training and thus improve their knowledge. Many women cannot step outside their home either due to household responsibilities or restricted mobility, and since LHWs work in communities, they can provide free contraceptives to women at their homes. LHWs should be provided with contraceptive stock, such as condoms and injections, so they provide them to women, who don't have to go to a facility to get them. LHWs can also give women $\mathrm{RH}$ information and how to manage side effects of contraceptives. Women in the community can trust an LHW and share and discuss their problems. LHWs should try to engage people in the community by arranging meetings and motivating women to use FP methods.

The only demand is that there should be a center in this area and a lady health worker should be introduced here. Cooperative staff is important and health should be taken care of completely. MIDI-12, 34 years old, 3 children, Never user; Rural unserved-Mardan 
I think all the information related to it should be provided to the LHW. If it is, then that would be much better because they do their work very properly and the one before this one was also very nice and did her work in very good way. FIDI-20, 41 years old, 7 children, Never user; Semi urban-Mardan

The health worker should have all the things available so that the user can easily access it. If, for example, they are out of condoms, then the user has to get them from the stores where the people make fun of them saying that they should take care now because of their white beard. There are no such problems if you get them from LHW. The women can easily go and get the methods if they (LHW) have the stock. MIDI-19, 40 years old, 9 children, Past user; Urban-RY Khan

In both districts of Sindh, especially Umerkot, women and men in IDIs and FGDs reported that Marvi workers have all the methods and go door-to door to provide free methods to women. Respondents trust these workers and suggest they be involved in distributing the ideal method.

(Contraceptives should be available) with Marvi workers and in the civil hospital. Poor persons can get them easily. They should be for free so that everyone can take them. We only have these two places with us. You should keep it with the Marvi workers, so that they can give it to us. They will come door-to-door and inform us. FIDI-53, 22 years old, 2 children, Never user; Semi urban-UmerKot

Okay, it (contraceptives) should be given to Green star, LHW, and Marvi workers and also advertisements (should be aired) on television. Nowadays, FM radio is also common and has access for everyone. These should be provided by the Marvi workers, and medical store [contraceptives]. MIDI-33, 28 years old, No child, Past user; Semi urban-UmerKot

\section{Conclusions}

This section began with women's and men's understanding of the advantages FP methods offer, recounts debates between traditional and modern methods, and method preferences. These perspectives and experiences reveal what people want from FP methods and services, and all of these responses help to build a composite of what an ideal method and services should offer.

The primary element is spacing: an ideal method should provide safe, reliable, risk-free, and provide spacing for long terms. As noted in next section on Discontinuation, FP users do not prefer terminal methods unless it is a last option. Hence, any long term spacing method that is not terminal and is failproof is desirable.

Of extreme significance is the absence of side effects, especially ones that damage women's health and disrupt family and social life. An ideal method is free of such side effects allows users to fulfill their responsibilities satisfactorily and creates a stress-free environment. Side effects such as excessive or irregular menses, infections, and temporary infertility mars experiences with current contraceptives.

As can be noted from the section, there is no resistance to FP methods; rather it is the how, when, and what of the service delivery that requires the attention of $\mathrm{RH}$ policymakers and implementers.

Contrary to general opinion, people in rural unserved and rural served areas do not seem to harbor any overwhelming preference for traditional methods. While a small number of people do prefer traditional methods due to the absence of side effects and compatibility with religion, for the most part women and men are aware that these methods do not guarantee birth control, and they take a quite pragmatic view of modern contraception. Generally, so-called preference for traditional methods is actually driven by lack of access to modern methods, and, to a lesser extent, by fear of side effects of modern methods, which women and men have observed, experienced, or heard about, and which are difficult to manage and live with in resourceconstrained and largely uneducated households. 
According to current and potential FP users, the ideal contraceptive should require a single, simple to administer dose, be inexpensive, and should lend itself to discreet use. This implies minimum user-provider interaction, as well as availability at easy to access venues.

The current form of contraceptive use necessitates user-provider interaction that dissuades use. An innovative suggestion from a respondent was that the contraceptive can be an implant but smaller in size than the SIM card used in a cell phone, and should be inserted in a way that it is not visible. Another suggestion was that it be marketed in syrup form or long long-term once once-only pills (that provide spacing for 3-5 years). A few individuals also suggested that such methods could also be developed for men.

Women and men also made suggestions on how access can be improved: through doorstep or community based delivery systems, skilled providers, quality services, use of media and engagement of local religious, political and educational leaders. 


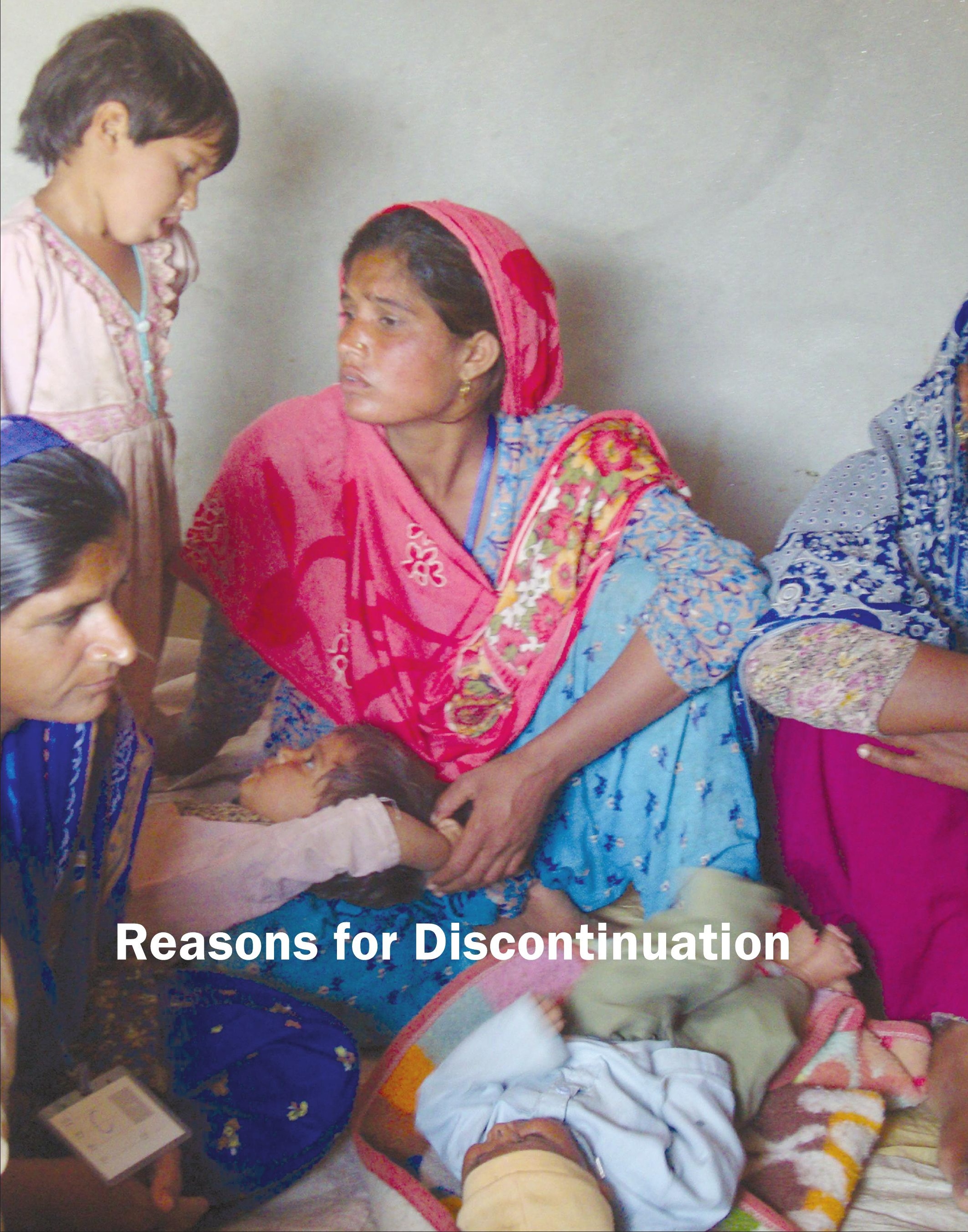




\section{Main Findings}

- Discontinuation of FP is driven mostly by experiences of side effects of modern contraceptive methods.

- Side effects are reported more for injectables and IUCDs.

- Women are discontinuing because of side effects even in semiturban and urban areas, where presumably there is relatively better access to healthcare providers.

- Apart from the actual side effects, the personal, social and economic costs of living with side effects also force women to discontinue FP use.

- Short-term discontinuation is usually the result of a conscious decision to have a child, or a temporary problem in accessing contraceptives or health providers.

- Discontinuation in the form of method switching is induced by method failure, by side effects and their associated life impact, or by chronic difficulties in accessing products.

- Long-run discontinuation usually occurs after method switching fails to yield freedom from side effects.

- Couples become exhausted by persistent debilitating physical symptoms; the profound personal, social and financial problems that riddle their lives as they struggle to live with side effects; and chronic issues in accessing health services and obtaining quality care. 


\section{Reasons for Discontinuation}

\section{Reasons Research questions addressed in this section: \\ What causes high drop outs and high contraceptive discontinuation rates of modern methods in Pakistan?}

- The factors and service qualities that cause men and women to lose trust in family planning providers in the public health system.

- The relative importance of positive and negative attributes of specific contraceptive methods from the women's, husbands' and providers' perspectives.

- The role of counseling women about side effects and effective use of modern methods, which influences them to try and, most importantly, continue modern contraceptive use.

A recent baseline survey of 29 districts revealed that 45 percent of women stopped using their chosen contraceptive method within a year; a quarter of injectable contraceptive users did not return to health facilities for the second dose. Hormonal methods, especially the pill and the IUCD, are known to have higher discontinuation rates than the natural methods ${ }^{12}$.

Even as policymakers and implementers struggle to mainstream use of modern contraceptives among couples with unmet need, 'ever use' of contraception-the phenomenon of individuals using a contraceptive method at some point and then discontinuing it-is rising steadily in Pakistan. Ever use of contraceptives has risen from 21 percent at the start of the demographic transition in $1991^{13}$ to 34 percent in $2001^{14}$, 49 percent in $2007^{15}$ and finally 55 percent in $2013^{16}$.

This qualitative study paid special attention to understanding why users feel compelled to change their family planning methods-at times even exchanging modern for traditional methods-and why they temporarily or permanently opt out of using modern contraceptives altogether.

In the following discussion, we first look at the factors that trigger discontinuation. Notably, the triggers may be positive in some situations. For example, a couple might decide to discontinue a method to have a baby, or to adopt another method that provides more reliable protection, or better suits their personal and health needs. Such decisions to temporarily discontinue FP or switch methods are positive developments that are consistent with the FP aim of giving couples choice and a measure of control over their reproductive lives. This study finds, however, that the reasons for discontinuation are more often to be found in despair that stems from the chronic problems users encounter in accessing, using, and coping with the effects of modern contraceptives.

The first part of this section examines the five key reasons cited by women, men, and SPs for discontinuing the use of different kinds of contraceptives, including both modern and traditional methods. We then take a closer look at the three degrees of discontinuation-switching methods to less reliable or traditional ones; complete short-term discontinuation; and finally, complete long-term discontinuation-to identify the dynamics that lead users who start out so hopefully to become disillusioned in modern FP and finally give up.

12S Naz and A Mahmood, Contraceptive Use Dynamics in Pakistan (Islamabad: Population Council, 2012).

13 National Institute of Population Studies (NIPS) and IRD/Macro International Inc. (1992). Pakistan Demographic and Health Survey 1990-91. Columbia, Maryland USA: NIPS and IRD/Macro International Inc.

14 National Institute of Population Studies (NIPS) [Pakistan]. (2001). Pakistan Reproductive Health and Family Planning Survey (PRHFPS) 2000-01. Islamabad, Pakistan.

15 National Institute of Population Studies (NIPS) and Macro International Inc. (2008). Pakistan Demographic and Health Survey 2006-07. Islamabad,

Pakistan: National Institute of Population Studies and Macro International Inc.

$16 \mathrm{lbid}$ 


\section{What Triggers Discontinuation}

According to the women and men consulted in this study who are past users (27) of modern contraceptive methods, use of modern contraceptive methods may be discontinued for a host of reasons, which may broadly be categorized as:

- Changes in family plans,

- Failure of the method (to prevent pregnancy),

- Significant side effects or dissatisfaction with the method,

- Significant personal, social and economic costs of living with side effects, and

- Difficulty in accessing the method.

The five key triggers of discontinuation are discussed in the following sections.

\section{Changes in Family Plans}

The decision to discontinue contraception might, first and foremost, be made when a couple feels ready to add a child to their family. Eleven past users discontinued use of contraceptive methods because they desired another child; among these, two hoped to have another son.

While these occasions are meant to be short-term interruptions in contraceptive use, and are not worrying, there is a danger of couples becoming past users unless they are followed up by health service providers, where possible, e.g. through postpartum FP counseling.

After my first daughter, I used pills for two years. Then, after my second daughter, I used them for one year. Then I left them so I could have a son. Then Allah gave me a son. After him I started pills again. FIDI-39, 27 years old, 3 children, Current User; Rural served- Sibi

She kept it for a long time and then she wanted to have a baby so she removed it [IUCD]. They leave the injection method the most. If someone starts using condom, then they do not leave it, and if they leave it, then that is because they want another baby. They don't stop using pills but if they do then that is because they want a baby. LHWIDI -22; Semi urban-Umerkot

If a couple has a lot of girls, and they wish to have a son, they stop using methods. My brother did the same thing as he had daughters. MFGD-18; Semi urban-RY Khan

Women also interrupt contraceptive use if their husbands are away from home, overseas or in other cities, for long periods of time.

My husband is abroad and he comes home sometimes and when he comes then we use condoms. During that time, my husband came home once for six months and once for three months and whenever he came home we used condoms ... but this time, my back hurts a lot, so I got the IUCD implanted beforehand. Doctors say that there is a wound in my uterus. FIDI-8, 36 years old, 4 children, Current user; Rural served-Mansehra

The women whose husbands live abroad, they only use injections when their husbands come home, and when they go away, they leave it. LHWIDI-6; Semi urban-Mansehra 


\section{Method Failure}

Failure of a method to prevent conception is often cited by users as a reason for its discontinuation. For the most part, however, this reason applies to traditional methods of contraception and not to modern contraceptives, with the notable exception of condoms and, to a lesser extent, pills.

Method failure may be due to intrinsic unreliability, as for example, in traditional methods like breastfeeding; to ineffective use of products, such as when women forget to take the daily contraceptive pill; or due to defective products-a complaint commonly associated with condoms.

Method failure as a reason for discontinuation is discussed below in the context of specific FP methodsprimarily condoms and traditional methods-that study respondents felt were unreliable.

\section{Condoms}

Among modern contraceptive methods, condoms are considered the least safe method by respondents due to their perceived high chances of failure through rupturing.

I used to take condoms from Sister S [LHW] and use them (condoms). But they ripped twice and because of that I had a girl once and then a boy. FIDI-34, 40 years old, 7 children, current user; Urban-RY Khan.

I got pregnant, I did not leave it but once Sathi [a condom brand] tore open and I got pregnant. FIDI-11, 20 years old, 2 children, current user; Sami urban-Mansehra.

Some respondents also complain about side effects and lack of satisfaction from condom use, which are discussed later in this chapter.

\section{Pills}

Pills often fail to prevent conception because they are not used properly: women forget to take them on time, or use them only when they have intercourse. Apart from this likelihood of incorrect usage, service providers seem to think pills are a good method for women.

Often people say that it's warm in nature and if you forget to take it even for one day in between, there are chances of getting pregnant. People often forget to take it and (overlook the fact that) whether they have intercourse with their husband or not, they have to take the pills. FIDI-18, 30 years old, 3 children, Never user; Rural unserved-Mardan

The pill is good but women perform all the housework so they often forget to take it. MIDI-9, 37 years old, 3 children, Current user; Rural served-Mardan

\section{Withdrawal}

Almost all respondents-women, men and service providers-are somewhat dismissive of withdrawal as an effective method for spacing. Failure rates are high, and service providers are frustrated by the number of women who do not take up modern contraception and conceive within a year of their last childbirth. Women and service providers (16) are unanimous that men generally lack the self-control required for this method to be successful.

After every childbirth and postnatal period, I used to get my menses and then I used to conceive again after eight months. Now, can a man do this for eight months? No, they cannot do this. That's why we did not use this method of withdrawal. FIDI-4, 27 years old, 5 children, Never user; Rural unserved-Khanewal

There are increased chances of getting pregnant then. Also, men can usually not control themselves. IDISP-55, Govt, BHU, LHV; Mardan

In traditional methods, they used withdrawal; but now their husbands do not agree so they take injections. They switch the method. IDISP-151, Govt, RHC, LHV; Khanewal 
Apart from being unreliable, men and some women respondents felt that withdrawal caused "resentment" between couples because it compromised satisfaction:

In my opinion, due to the use of this method, there is a lot of resentment between the husband and wife because a lot of women do not like this method. MIDI-23, 28 years old, 3 children, Past user; Rural served-Sibi

Men don't usually use the withdrawal method because they don't have mental satisfaction. It gives them tension and they don't have mental relaxation. Those men don't do it themselves, they say to their wives to go and do some other method. IDISP-108, Govt, FWC, FWW; Sibi

\section{Breastfeeding}

It is widely recognized among all categories of respondents-women, men, SPs-that breastfeeding might once have served as a natural barrier to conception but can no longer be relied upon to prevent unwanted pregnancy. Many reasons are cited, for example, women do not produce as much milk as they used to, their menses do not stop for one year after delivery, as they did "in the time of our elders"; caesarian deliveries upset the natural system; and mothers do not exclusively breastfeed but supplement their babies' diets with water or soft food which reduces the barrier effect.

Service providers (17) also dismiss breastfeeding as safe, claiming many women practicing it still conceive. Mothers are mindful of the risk, even when following SPs' advice to breastfeed for at least six months.

When my wife had a baby, she took her shower after 40 days, we had intercourse and she got pregnant. She used to breast feed every day, but the quantity was less, so started to bottle feed the baby. MFGD18; Semi urban-RY Khan

This happened with me. I thought that I was experiencing weakness. I did not know that I was pregnant for the fourth time. I got to know about it after being six months into the pregnancy ... In my opinion the breastfeeding method should not be trusted at all in this age. FIDI-3, 30 years old, 4 children, Current user; Rural unserved-Khanewal

They stop using pills saying that they can't continue them. IDISP-49, Govt, MCH Center, WMO;

Mardan

\section{Safe Periods}

The natural method of restricting intercourse to safe periods is not generally talked about by women and men, but is mentioned here as a method with a generally high failure rate that service providers did discuss.

According to SPs, tracking the hormonal cycle and remembering the correct time to avoid conceiving is not something all women and men, especially those who are illiterate, would be able to manage. Two SPs noted that women do not even realize they are eight months pregnant, or the age of their child-how would they calculate and remember when abstinence was required?

For this reason, and due to its relative unreliability, SPs consciously avoid recommending it to clients, and it is not commonly used.

\section{Side Effects}

Our findings indicate that discontinuation of FP is driven mostly by perceptions and experiences of side effects of modern contraceptive methods. In all, 134 respondents gave 370 responses citing side effects as a reason for discontinuing use of modern methods. Women and men from communities as well as SPs listed methodspecific side effects that plague users and force them to switch methods, turn to traditional methods, and at times, finding none safe or useful, discontinue FP altogether. Seventeen respondents said they discontinued use of a contraceptive method due to side effects. 
Side effects experienced and mentioned by respondents ranged from the debilitating (heavy continuous bleeding) to the uncomfortable (itching). Side effects, as experienced by women and women, and corroborated by service providers, are listed according to method in Table 6.1.

Table 6.1: Experienced Side Effects of Modern Contraceptive Methods

\begin{tabular}{|c|c|c|}
\hline Method & \multicolumn{2}{|l|}{ Side Effects } \\
\hline Condoms & \multicolumn{2}{|c|}{$\begin{array}{l}\text { - Allergies/Itching(both women and men) } \\
\text { - Disease/Infection due to chemicals and lubricants on condom } \\
\text { - Dissatisfaction of men }\end{array}$} \\
\hline Pills & $\begin{array}{l}\text { - Irregular bleeding } \\
\text { - Increased blood pressure } \\
\text { - Weight loss/gain } \\
\text { - Heating }\end{array}$ & \\
\hline Injectables & $\begin{array}{l}\text { - Heavy bleeding } \\
\text { - Irregular bleeding/ spotting } \\
\text { - Anemia } \\
\text { - Weakness } \\
\text { - Dizziness }\end{array}$ & $\begin{array}{l}\text { - Weight gain/Swelling/Bloating } \\
\text { - Pain } \\
\text { - Heating } \\
\text { - Infertility }\end{array}$ \\
\hline IUCD & $\begin{array}{l}\text { - } \text { Cysts } \\
\text { - Heavy bleeding } \\
\text { - } \text { Irregular bleeding/ spotting } \\
\text { - Weight gain } \\
\text { - Blood pressure } \\
\text { - Wounds inside }\end{array}$ & $\begin{array}{l}\text { - Infection } \\
\text { - Swelling } \\
\text { - Pain } \\
\text { - Feeling that a foreign item/metal is placed inside the body } \\
\text { - IUCD moves to some other part of the body }\end{array}$ \\
\hline Implants & $\begin{array}{l}\text { - } \text { Cancer } \\
\text { - Infection } \\
\text { - Irregular bleeding } \\
\text { - Continuous bleeding }\end{array}$ & \\
\hline
\end{tabular}

Note: The listed side effects for each method include some aspects that are not strictly side effects but expressions of discomfort or dissatisfaction with the method. While implants have been included, it should be noted that respondents of only four FGDs and 20 in-depth interviews referred to this method-15/24 were from Sindh, and 5 were from Rahim Yar Khan.

A particularly worrying finding was that women are discontinuing because of side effects even in semi-urban and urban areas, where presumably there is relatively better access to healthcare providers.

Overwhelmingly, service providers were of the view that one woman's experience of side effects leads to at least 10 women not using contraceptives, and even more just becoming wary of them.

\section{A woman got IUCD inserted and she had side effects. So she will tell everyone and recommend they \\ not use this method. IDISP-158, Govt, FWC, FWC; Khanewal}

The following subsections outline the side effects experienced by users of different FP methods, which are described in strikingly similar terms by women and men across districts. It should be borne in mind that, while some side effects are known to be associated with certain contraceptive methods, external factors may also have been at play in the users' suffering, such as use of expired or low-quality products, improper use (e.g. lack of hygiene), lack of counseling for effective side effect management, and the heavy physical workloads of women. These aspects are touched on later in this section. 


\section{Condoms}

A common complaint is that condoms cause allergies and pain in men and "itching" in women. In addition, a large number of women and men complain of side effects of condoms that, at first glance, appear unlikely.

The disadvantages are such that some men can get allergy from it. For example, I got the allergy and was affected by it for two weeks at least. MIDI-10, 35 years old, 2 children, Past user; Rural served-Mardan

Women say that with condoms they have irritation and itchiness; that's why they don't like it much. IDISP-17, Pvt, BHU, LHV; Khairpur

A possible explanation is provided by an LHV who notes that condom users "mostly complain about urinary tract infections (UTI) and those who use condoms for a long time have the problem of PIP (pelvic inflammatory pain/ disease)" IDISP-123, Govt, THQ, LHV; Umerkot.

Both SPs and users believe the fault may lie with local low-quality condoms:

They say that they get allergies from condoms. They only buy the condoms that have come from abroad. IDISP-94, Govt, FWC, FWW; RY Khan

If the condom is of bad quality then there are side effects such as swelling, irritation and pain, etc. FIDI-3, 30 years old, 4 children, Current user; Rural unserved-Khanewal

This side effect compels some couples, who intend to have more children later, to discontinue use of condoms and risk having a baby sooner rather than bear the irritation of protected intercourse.

Doctors do say to use [condoms], but they don't use it anyway. They have complications from this-feel irritated. They say, compared to this, it is better they conceive. Both husband and wife say that this time, after the baby, they will go for tubal ligation. IDISP-20, Pvt, NGO Clinic, DGO; Khairpur

Another complaint repeated by both women and men is that condoms cause internal "wounds" in women. Local healthcare providers have heard this complaint and in some cases agree with it. The wounds are said to lead to health issues that require medical attention, including infections, disease and even infertility.

My elder sister used to use condoms. Her younger son was 10 years. So inside her uterus she got an infection and it had to be cleaned after every three months... She has an internal wound. FIDI-32, 28 years old, 4 children, Current user; Semi urban-RY Khan

It can cause wounds and there is more danger of it getting torn. And some disease can also be caused, meaning that it is not secure that is why people have stopped using this to some extent, because of these side effects these methods are disliked by people. MIDI-12, 34 years old, 3 children, Never user; Rural unserved-Mardan

There can be an infection or any other reason (with condoms). It (condoms) causes PIDS and it is the cause of infertility ... you don't want the client to get infertile. IDISP-77, Pvt, RHC, WMO; Pishin

The chemical coating on condoms is also associated with a number of side effects, including "heating" of the body, harm to the uterus, swelling, and blood deficiency and weakness in men.

From the chemicals of condoms the uterus can also be harmed. MFGD-16; Rural served-Pishin

It's artificial, comes in a packing. The lubricants or oil on the condom are not right and are made up of chemicals which may be harmful to the woman. MIDI-2, 32 years old, 2 children, Past user; Rural unserved-Khanewal

From condom men have blood deficiency, it makes him dry and women have no issue at all. FFGD-29; Rural served -Umerkot

Notably, bloating or weight gain is not commonly associated with condoms and are noted by only four women: 
[Condoms] have chemical coating which makes our stomachs bloat. I have also seen that mostly women who use it have bloated stomachs .... I myself have used [condoms] for two to four times and during those times my stomach also bloated. FIDI-5, 38 years old, 6 children, Past user; Semi urban-Khanewal

By far the most commonly voiced issue is that condom use leaves men dissatisfied, and this is the primary reason for discontinued use. Sometimes, this dissatisfaction is paired with other reasons by the men. Service providers from whom women can take condoms for their husband's use are familiar with this dissatisfaction.

The disadvantages are such that some men can get allergy from it, for example I got the allergy and was affected by it for two weeks at the minimum. And other than this often women can get wounds because of it and there is the danger of it breaking or getting torn. And along with this men do not get much pleasure. The pleasure can be had with the use of injection and pills but they are not trustworthy. And the condom gives more security but the pleasure achieved is very less. MIDI-10, 35 years old, 2 children, Past user; Rural served-Mardan

I did not get much pleasure in using the condom .... otherwise it was better than the injection. MIDI-10, 35 years old, 2 children, Past user; Rural served-Mardan

They say that they don't get the same pleasure that they get without the condom. Men do not get satisfied because of it. IDISP-30, Govt, RHC, LHV; Mansehra

\section{Pills}

Users of pills, and SPs, note side effects common for hormonal contraceptives, with the added disadvantage of having to take the pill every day-something women often forget to do, as their lives are busy and time and schedules often beyond their control. Often, women switch from pills to injectable contraceptives especially because they are required only once every month or three months, and not every day.

Women who took pills complained of heavy and untimely bleeding, heating up of their bodies, increased blood pressure, dizzy spells, bloating or weight gain, nausea, and reduced flow of milk in lactating mothers; many of these are corroborated by male respondents.

I took pills of family planning for three months. I had bleeding three times a month. My body shrank. I stopped taking pills after that. This was the reason, nothing else. I had such an illness that nothing could give me any relaxation. I used to take them and when I left the pills the bleeding stopped. FFGD-18; Semi urban-RY Khan

\section{[I had] issues of more bleeding. FIDI-57, 40 years old, 3 children, Past user; Urban-Umerkot}

When women take pills, they get high blood pressure. Usually women take pills and their blood pressure shoots up. This happens because the pills are hot. I also took them. FFGD-18; Semi urban-RY Khan

Service providers noted that women on pills complained of irregular menstruation, weight gain, stomach cramps and pain, high blood pressure, nausea and dizziness; they felt that sometimes these symptoms are related to other health issues, like diabetes or hepatitis, but women blame it on the pills.

The pills these days are causing a lot of problems. Menses have stopped or they have increased or the body has swollen up. Or they get dizzy and weak. LHWIDI-16; Semi urban-Sibi

Because of side effects she will feel nauseous and dizzy and she stops taking the tablets. IDISP-158, Govt, FWC, FWC; Khanewal

[Pill] results in weight gain ... mostly (women) get high blood pressure even if they do not already suffer from cardiac problems ... [pill] side effects are that at times patients have irregular bleeding IDISP-5, Govt, THQ, WMO; Khairpur

Counseling, providing information beforehand, and screening potential users for health issues would help alleviate some of the complaints and lower discontinuation rates for pills. 


\section{Injectables}

Most women acknowledge that contraceptive injections provide more reliable spacing for overworked mothers who can frequently forget to take the daily pill. A few women also admit the method "suited them." The list of side effects attributed to contraceptive injections by the majority of women interviewed, however, is also long.

The first and foremost complaint from women, echoed by men, is irregular menstruation, continuous spotting spread over weeks, and heavy bleeding. A total of 160 respondents spoke about the disadvantages of injections.

A 30 year old current user with four children describes the different problems that women encounter when they opt for an injectable contraceptive:

Due to injections, two or three women who were my cousins also experienced bleeding profusely ... The women here do get injections. Some stay fine while the others get irregular periods. And when their periods stop, they gain weight through bloating. It is hard for them to walk and move around.

There is another side effect which also occurs due to the injections: ... spotting throughout the month, sometimes lasting for two, three, four or six months. Most people face similar symptoms; that's why they don't trust this. The women are scared. FIDI-3, 30 years old, 4 children, Current user; Rural unservedKhanewal

It was not just women in rural unserved areas who mentioned this issue. Rural served, semi-urban and urban women repeated similar complaints, even though they, presumably, have better access to services.

It's obvious that all the methods that we are told about cannot be a hundred percent successful. I am talking about myself. When I had the injection for the first time, I got pregnant while I was using it. I started bleeding along with that and kept on bleeding for a month. When I had lost too much blood, I was taken to the hospital. The hospital is nearby. There was a doctor there, I went to her and she did my D\&C. FFGD-18; Semi Urban-RY Khan

The bleeding didn't stop (and made me weak and dizzy). FIDI-32, 28 years old, 4 children, Current user; Semi urban-RY Khan

Excessive blood loss causes weakness and anemia, as these two women from an FGD noted.

I also had injections. There used to be pain in my back, pain in my legs, the bleeding never stopped, I was always ill. FFGD-17; Rural served-RY Khan

Service providers note that the method does not suit all women. Many women come with complaints about irregular or heavy menses; at times, they are suffering from anemia and weakness. While treatment is provided in the form of multivitamin and folic acid prescriptions, the constant debilitation and frequent need for visits to health facilities causes people to discontinue the use of injectable contraceptives.

In this (injections), the same complications arise, like irregular menses, etc., and the family members get tired of taking the patient to the hospital again and again. IDISP-20, Pvt, NGO Clinic, DGO; Khairpur

Suppose a woman gets the injection and due to that her menstrual cycle gets disturbed ... then she would go into the community and tell other women not to opt for the injection as it has these disadvantages ... [the] injection, it is very much available here, but it has many disadvantages. The menstrual cycle is disturbed by it and then it is difficult to cover it. Injections have the most (side effects). IDISP-42, Pvt, THQ, GYN; Mansehra

They have left them because most of the people start bleeding. This is why they leave them, there is no other problem ... Women come to me and say that I have an infection. Mostly, injection [-taking] women come and say that I have bleeding. Those who take pills also bleed. IDISP-66, Govt, DHQ, GYN; Pishin 
Another complaint is related to weight gain and obesity, with attendant health problems. Women, men and service providers all acknowledge this side effect.

With the use of injections, they sometimes get bleeding. And, yes, there is also irregularity in menses. With this, some people also have the problem of obesity. In some women, due to excessive bleeding, they get weakness. This is why people don't like it. IDILHW-10; Semi urban-Pishin

I am using the injection now. I have taken pills and used condoms as well. But they weren't right for me. I kept on having injections till last month but that didn't suit me either. My body started to bloat. I wasn't getting my menses. The doctor said that it is because of injections that my body is bloating. FFGD-17; Rural served-RY Khan

Another often mentioned complaint is of the body "heating". Too much bleeding, or none, causes dizziness and heating of the body, which leads to increased blood pressure, or worse, infertility.

My sister had two daughters and her mother-in-law and father-in-law, both told her to get the injection. Now, after that, she does not get her menses. Her younger daughter is seven years old, and no more children till now. She got treatment from a lot of Lady Doctors but still has not got pregnant. FFGD-5I; Rural served-Mansehra

There might be dangers. Sometimes, by their use pills or injections-I have seen a lot of cases-after their use, they don't have kids. MIDI-15, 36 years old, 3 children, Current user; Rural served- Pishin

Due to that (injection), there are a lot of bleeding disorders occurring and amenorrhea is occurring in patients for quite a long time. And then spacing increases in the middle after the injection, sometimes for two years. IDISP-29, Govt, THQ, WMO; Mansehra

\section{IUCDS}

As with injectables, women appreciate the long-term protection afforded by IUCDs, but are discouraged by the side effects. The most frequent complaint voiced by them is irregular or heavy bleeding that created a "wound" inside them, prolonged menstruation, are also reported for IUCDs. Symptoms such as anemia, dizziness, weakness, infertility and fear of disease, such as infections are attributed to IUCD use by women, men, and SPs.

My sister-in-law used this method but she had to face negative consequences because of it. Her whole body swelled up and her menses also completely stopped. Then she went and got it removed but still she was not getting her menses. So she got a lot of treatment to get her menses. I have heard from others that it is very harmful. Due to this, the menses get quite delayed, the menstrual cycle is destroyed, and the whole body swells up. Other than that, I don't know what else happens, but the thing is that the next pregnancy does not occur until it is removed. FIDI-17, 28 years old, 1 child, Past user, Rural unserved-Mardan

My mother used to say that it gets displaced and moves upwards. It causes wounds in the uterus. This causes a wound internally; my mother had kept an IUCD. Due to it, the face of the uterus became rotten. After that, the uterus had to be removed through an operation. I am scared of these things. FIDI-32, 28 years old, 4 children, Current user; Semi Urban-RY Khan

My sister-in-law practiced spacing, due to which she had a lot of pain and then she had a proper checkup done ... She did IUCD spacing and she kept it for three years. After this, she removed it because there was weakness inside her uterus due to which she was bleeding a lot and also a wound was growing. With all this, she became very ill. She was taken to doctors for her treatment due to which she stopped using this [method of] spacing. Then the doctor told us that all this happened to her because of spacing. FIDI-46, 28 years old, 3 children, Never user; Semi-urban-Khairpur

Women also report that the frequent periods caused by IUCDs can further cause "heating", itching, abdominal and back pain, hypertension, weakness and weight gain. 
I don't like keeping an IUCD. Because from this, I had pain, especially abdominal pain and when I used to do housework-washing clothes, dishes, cleaning, etc.-it used to hurt. In this (method), periods also increase, which results in high blood pressure and women get weak. FIDI-47, 28 years old, 2 children, Current user; Semi urban-Khairpur

My daughter used it but her stomach weight increased. That's why she used to say that I have got wounds because of it. That's why she then got it removed. FIDI-15, 42 years old, 8 children, Past user; Urban-Mardan

Men are also aware that IUCDs cause infection, pain, wounds, and excessive bleeding, a possible outcome of having a foreign body placed inside you.

Yes, (my friend is) from Quetta. [IUCD] is not available here. My friend's words were that his wife was in a lot of pain due to IUCD. He got it done, he wanted space. But its side effects were greater. The female had a lot of pain; she could not walk. MIDI-13, 30 years old, 2 children, Current user; Rural served-Pishin

Yes, there are side effects. I had my wife use them and there was infection in her uterus. As a result, there was swelling. MIDI-19, 40 years old, 9 children, Past user; Urban- RY Khan

A few cases were reported by respondents where pregnant women who were not aware of their pregnancy and an untrained provider did the procedure led to complications, including miscarriage. Service providers also blame the use of unskilled providers who are not able to do the procedure correctly, and clients then come to them to resolve the problem.

I have heard about IUCD from my cousin whose wife had got it (from the village midwife). She was pregnant and she got the IUCD. She started bleeding and, as a result, was taken to B. There, the doctors referred her to $\mathrm{N}$ [a hospital]. The doctors at $\mathrm{N}$. scolded her in very strict terms, accusing her of aborting the child on purpose. The couple wanted to do birth spacing but they did not know that they were pregnant. The child was miscarried. They had got it from the village midwife and not from the city. It was the job of those who advised [to use IUCD] to check it properly. This is why the people are scared. She had started bleeding and then as a result miscarried. Then, they got the IUCD removed. MIDI-1, 31 years old, 2 children, Past user; Rural unserved-Khanewal

[Women] usually get the procedure done from the dai. They come to us and say that we have had an IUCD placed by a dai ... and they say that our bleeding isn't stopping and she said it would be perfect. IDISP-94, Govt, FWC, FWW; RY Khan

Service providers are often asked to remove the IUCD because of such complaints.

They get weak and can't work and they don't want [IUCD] placed. We give them medicines after placing it but the women say that it hurts them and they want it removed. IDISP-98, Govt, BHU, LHV; RY Khan

And some also get bleeding. If the bleeding does not stop, then they get it taken out. We will give them another method ... We wait for them for three months to see if it (IUCD) sets completely. If after three months, she still gets bleeding, then we remove it because it didn't suit her. IDISP-116, Govt, FWC, FWC; Sibi

One SP has an interesting perspective on why the IUCD "travels" inside the body or gets displaced:

If they are from this area (for IUCD), it is not a problem for them. But there is a problem for those who are coming from outside. They travel on a motor cycle. When they get the procedure done, due to bumps along the way, the IUCD gets displaced. IDISP-116, Govt, FWC, FWC; Sibi

According to service providers sometimes women fear that men are also harmed by the IUCD.

They say that we used an IUCD, and when we had intercourse with our husbands, it tore and slipped upwards. Some say that they get stuck in tubes and some say that it stings our husbands. IDISP-91, Govt, MCH Center, LHV; RY Khan 
IUCDs can also aggravate pelvic inflammatory diseases (PIDs), and women experience pain, discomfort, and discharge, "and if already someone had PID and they get discharge, then they will have more issues" (IDISP-6, Govt, MCH Center, LHV; Khairpur). In such cases, the health provider removes the IUCD.

For example ... it starts bleeding or gets infected, clients say that this is because of Copper-T and [ask us to] remove it. We try to make them understand that this is not because of Copper-T-[they should] take medicine and it will be fine. [But] they say remove it this time, we will use it again next time. IDISP-153, Govt, BHU, LHV; Khanewal

Pain, wounds, fear of a "foreign body" moving up the body, "chemicals," or cysts lead to women have IUCDs removed after an initial period. Service providers oblige and try to suggest other methods depending on the age of the woman. It is possible that the heavy workload of women aggravates some of the side effects.

\section{Implants}

Contraceptive implants have been introduced mainly in Sindh and are offered free by the government. This is why the number of responses regarding this method is small-a total of 43 responses from 24 respondents. Women who had unsuccessfully tried other contraceptive methods were open to using implants. Issues similar to those of injectable contraceptives and IUCDs have arisen for this method as well-women, corroborated by men, report menstrual irregularity, excessive bleeding, bad headaches, dizziness, weakness and pain in users, leading to stress. They also complain of heating of the body, high blood pressure, and malaise.

There was a woman in our neighborhood, who had it (a Norplant capsule) inserted. It caused some problem and she had to get it removed. She intended to have it for 12 months, but got it removed after just three months. She was bleeding twice a month. FFGD-27; Rural unserved-Khairpur

Women and men are concerned about the swelling and complications at the implant site, and the possibility of cancer from the implant. There is some awareness that complications can be reduced by having the procedure performed by a trained SP.

One lady kept it and she got cancer from it. Then we heard that she died. Don't know what happened: her arm was all swelled up ... maybe it was not properly kept in the arm. That's the reason now no one uses capsule method; not even a single person in our village. This woman got into a condition and within a short span of time she got cancer and got very sick. FIDI-57, 40 years old, 4 children, Past user; UrbanUmerkot

Putting implants...can result in a hard bump. Then they have a fear that maybe their arm might get damaged or [they might develop] some illness. That's why one should always get it inserted by a good doctor, LHV or lady doctor. MIDI -34, 41 years old, 4 children, Current user; Urban-UmerKot

There are period issues. Periods continue for six to seven months ... patients who used implants removed it within two months. IDISP-5, Govt, THQ, WMO; Khairpur

\section{Pressures of Living with Side Effects}

Side effects are important not only due to the physical suffering, especially by women, but also deterioration in their quality of life, by compromising their ability to work and engage in conjugal relations, extra expenditure on healthcare, and damaging marital relationships. Apart from dealing with the physical toll of side effects like heavy or irregular bleeding, women worry about the time, costs, and strain in managing side effects.

She [woman in village] got in a very bad condition. She had a lot of bleeding. She was totally finished. No one had any hope of her survival. Then, at midnight, they took her to Sibi. There, she got her treatment. She is still ill. She is not fine. She has menses two or three times in a month and they are very heavy. My husband had heard about her, and then he stopped me and said that we will do our own withdrawal. We are poor people. If we get ill like this after getting injections, how will we get money for our treatment? FFGD-22; Rural served-Sibi 
Apart from health problems, the impact of side effects can include reduced ability of women to fulfill their household responsibilities, including care of children; reduced marital relations due, for example, to prolonged bleeding; increased spending on healthcare; inability to participate in some social events, such as religious ceremonies; and, as a result of all the other fallout, strained relations with the husband and/or in-laws. These effects are outlined in Table 6.2.

\section{Table 6.2: Side Effects and Family Life}

\section{Side Effects/Symptoms/ Issues with FP Methods}

\begin{tabular}{ll}
\hline Irregular menses* & $\begin{array}{l}\text { Not able to take care of household/children; marital relations affected; } \\
\text { stress; multiple visits to service provider/financial burden, cannot } \\
\text { perform religious worships/ duties as prayer }\end{array}$ \\
\hline Heavy bleeding* & $\begin{array}{l}\text { Not able to take care of household/children; marital relations affected; } \\
\text { stress; multiple visits to service provider/financial burden, cannot } \\
\text { perform religious worships/ duties as prayer }\end{array}$ \\
\hline Pain/ Fever & Household responsibilities affected \\
\hline Infection* & Marital relations affected; medical burden \\
\hline Obesity & Obesity-related health issues: diabetes, blood pressure; mobility affected \\
\hline Heating & Marital relations affected \\
\hline Effect of Chemicals & Illness; medical attention; financial burden \\
\hline Anemia/ Weakness* & Not able to take care of household/children \\
\hline Extended spacing/ Infertility* & Pressure to conceive; incomplete family \\
\hline Unwanted pregnancy* & Stress; tension; increased financial burden; health affected \\
\hline
\end{tabular}

Note: * denotes that the problem is more serious and mentioned often.

\section{Inability to Fulfill Household Responsibilities}

The household responsibilities of women, given the large family size, especially if the extended family is living together, are not to be taken lightly. The complaints of women across urban, semi-urban and rural served communities of RY Khan that they are unable to manage these responsibilities when facing side effects illustrate that this is not a location-specific issue:

When I had the IUCD placed, I got very weak and used to feel dizzy all the time. My complexion had gone pale ... Yes, it did [affect my kids]. They used to say that Mother is always lying down. You can move her a little and give her something to eat, but she hardly eats. I used to feel dizzy all the time. FIDI-34, 40 years old, 7 children, Current user; Urban-RY Khan

I had pain-especially abdominal pain-and when I used to do housework, washing clothes, dishes, cleaning, etc., it used to hurt. In [condition], periods were also heavy which resulted in high blood pressure, making me weak. FIDI-47, 28 years old, 2 children, Current user; Semi urban-Khairpur

[After the tubal ligation] I could not do the household chores. I was in pain and the operation that I had wasn't done properly. I just had these kinds of problems. My household responsibilities were affected. Who would take care of my little kids, and responsibly feed them on time? When these kinds of problems arise, it does pose a challenge. The entire system of one's life gets disrupted. How can the people who have to look after their little kids, take care of the household, look after their husband, work in the fields, sit at home and relax? I was told not to lift heavy weights after my operation. I was instructed not to do any such things, but what can one do? If I don't do it, who else would? FIDI-28, 35 years old, 8 children, Current user; Rural served-RY Khan 
The thing is that here women work a lot like in the farms; it is obvious that here they have a lot of work to do and if they end up having more bleeding then they get fed-up from this and they don't want to have a multi-load or Copper-T. IDISP-116, Govt, FWC, FWC; Sibi

Health providers understand this quite well.

People of the village stop using [IUCDs] more because they say that they have to work in the village and it's very hot and then it results in more bleeding. IDISP-143, NGO Clinic, LHV; Umerkot

Male interviewees also complain of this, noting that women become weak and are unable to perform household responsibilities. For example the cause of the "wound" is attributed by this man to the context in which the users of IUCDs operate:

Women perform a lot of heavy work in the house and in our locality joint family is present so the woman has lots of responsibilities...so the use of this thing is very difficult for them ... meaning that wound can be created inside their body. MIDI-11, 36 years old, 4 children, Never user; Urban-Mardan

Whilst the presence of side effects is acknowledged by all, it begs the question why it takes a heavier toll on women who are not in the upper wealth quintiles. There are no studies available to understand the family planning and contraceptive use of couples in the high income range in Pakistan, and how they deal with the side effects that they may experience, after accounting for quality of care and of contraceptives. It may well be that the context of the lives of women in the lower wealth quintiles is the possible reason why the side effects take such a heavy toll on them. Poverty, household size and dependency ratio as well as available amenities can influence how the side effects are experienced.

\section{Interruption in Marital Relations}

Wounds, excessive or frequent menses and being ill means that the suffering women, in addition to not being able to manage the household, cannot engage in marital relations with their husbands.

[I get menses due to use of injections] about twice in a month and it's on for 15 days ... Yes, and my husband even does not come near me; if he does, then he also feels heated. FFGD-29; Rural servedUmerkot

The big problem is that in order to get them (injections), the people have to go to the hospital. And going there is very hard. This is also why people don't use them. And due to continuous bleeding, the women cannot offer prayers. And the husband also gets angry. IDILHW-10; Semi urban-Pishin

This was corroborated by men, who noted that frequent and heavy menstruation led to a disruption in marital relations, women's failing health, and their resulting inability to meet familial and social responsibilities.

All these symptoms take a toll on marital relations:

There is harm. If a person wants spacing for six months, with its (the pill's) use, it can stretch to 12 months. They could take double time. The other [disadvantage] that I have heard is that there can be an effect on the woman's health... They get fat and they can even have an infection ... With this, they cannot have intercourse. MIDI-13, 30 years old, 2 children, Current user, Rural served- Pishin

In addition to worrying about the effects on her health, the woman also has to consider how her husband will react to her "being of no use" in the house and presumably as a wife.

If we go for injections, our wives don't expect, and they just sit get ill and are of no use; that's why it's harmful. MIDI-25, 47 years old, 7 children, Past user; Rural served-Khairpur

One man remarked sarcastically:

[Injections] has the advantage that it causes a period of six months. It has a lot of harms. It damages both the husband and the wife. MFGD-7; Rural unserved-Mansehra 
The reference to damaging the husband may well refer to the stress, disruption of marital relations or the expense of managing the side effects.

Obviously, during the bleeding their married life is affected. IDISP-63, Pvt, NGO Clinic, LHV; Mardan

When people use IUCDs, they have a concept that they remain dirty and impure [napaak]. They think that when husband and wife meet [have intercourse], they get irritated by the Copper-T and there are more chances of infection to both the man and woman. The man believes that he got the infection because of the IUCD and then he gets upset with the woman, that you have a Copper-T. This is the problem and the reason why they end up removing it. IDISP-20, Pvt, NGO Clinic, DGO; Khairpur

The word "angry" came up several times in conversations on this subject, and it was clear that couples found it stressful to balance their positive view of the protection afforded by contraceptives against their frustration at the interference in their sex life. Method choice, side effects and method efficacy have a clear influence on conjugal relations.

\section{Economic Costs}

The repeated visits to the health providers, to switch from methods that prove unsuitable, or to address side effects, have monetary and time implications that can ultimately force couples to opt out of family planning.

These are the works of rich people. Because for [IUCD], a lot of money is spent. And for this you need to go to Quetta. And you have to get this work done from the doctor there. And this costs a lot of money. FIDI-21, 25 years old, No child, Never user, Rural unserved-Pishin

The economic costs also include lost labor days as men have to accompany women to the service provider, especially if a long distance and a commercial transport means are involved.

It causes the menses to become irregular, meaning that they don't stop. I personally had to face this problem and later I had to spend a lot of money. Then I stopped using the injection and, for the treatment, had to make rounds to the gynecologist but the blood just wasn't stopping. [Even though my wife was near death] but later God made everything better. This is the reason which has created a lot of hatred towards injection now. MIDI-9, 37 years old, 3 children, Current user; Rural served-Mardan

Getting all of them [contraceptives and side effects] causes poverty. Now who can take their wife to the hospital after every one or four months? MFGD-22; Rural served-Sibi

Women also stated that in the absence of resources to obtain a nourishing diet for themselves, managing side effects was difficult.

Those who find it suitable use it. If there is milk in the house and if you keep on drinking it, then it can suit you and if there is a problem of food then [IUCD] causes weakness. There is extreme pain in the legs and you cannot move around and bleeding starts to occur. FIDI-4, 27 years old, 5 children, Never user; Rural unserved-Khanewal

It results in pain in the tubes. Then they take her to the lady doctor and she removes the IUCD and, in this manner, a lot of our money is spent-about 50 to 60 rupees-and it also wastes our time. And at times, it results in even more spending. That's why we think that the IUCD is expensive so it is better we don't use it. Who will use it when their baby gets aborted? Then, 5000 to 6000 rupees, or even 10,000 rupees is spent-and additional transport rental, which is about 5000 rupees, to take the patient to the hospital. FIDI-55, 39 years old, 4 children, Past user; Rural unserved-UmerKot

Following quote elaborates how all above mentioned problems are inter-linked and affects women life.

We used injection for the first two years but it had caused a lot of problems, periods started again and again, my wife remained sick often, even the marital life was affected to some extent, and secondly the child was young and they were not being given proper upbringing. And my wife's health was getting worse day by day. 
Another problem was that my financial condition was going very bad as we had to go to the doctors for the treatment again and again. Whatever I earned I spent it on the treatment of the disease. There was not just the disease in the house that had to be taken care of; there were other needs too like food and other expenditures. Other than this she couldn't go to any relatives' house for the sake of happiness or sadness regarding the family life. That is why we stopped using the injection; after leaving the injection the conditions returned to normal. MIDI-10, 35 years old, 2 children, Past user; Rural served-Mardan

\section{Social Costs}

Side effects, whether because of infections or irregular menses, may keep a woman in the "impure" state for prolonged periods, which also means that she is unable to offer her prayers or participate in other religious rituals. Severe side effects also do not let her attend family and social gatherings.

I had side effects from the injection. There was continuous spotting for three days. The women who had these injections say that we can't offer our prayers and can't recite the Holy Quran. FFGD-18; Semi urban-RY Khan

Due to continuous bleeding the women cannot offer prayers. And the husband also gets angry. With this you start irregular periods. And there is a problem in offering prayers. There is a complaint of headache and the biggest thing is that the husbands don't like it. IDILHW-10; Semi urban-Pishin

\section{Strained Household Relations}

The combined effect of living with side effects is a heavily negative one for couples, especially for women who's 'usefulness' to their husbands may be brought under question. The words "stress," "tension," and "angry" came up multiple times when side effects were being described. The effect of such tensions on family life, especially on relations between husbands and wives, was mentioned by respondents in different ways.

These findings about the negative impact of unmanaged side effects on users' quality of life make it easier to see why couples might eventually be pushed to discard them for less disruptive, even if less reliable, methods to avoid pregnancy.

\section{Failure of Healthcare Delivery}

Temporary or permanent discontinuation can also be triggered by the failure of the healthcare system to provide willing users the support they need to keep up their use of a contraceptive method. As the previous two sections have shown, problems in FP service delivery may relate to access and to quality of care.

\section{Lack of Access or Availability}

Accessing FP services is a struggle especially for users in served and unserved rural communities because of great physical distances, travel costs, time costs, restrictions on women's mobility, and sometimes even lack of spousal or family support for FP. Many of these problems would be avoided if FP services could be delivered within the communities that need them through well-equipped static facilities or LHWs. As mentioned in the section of Quality of Care, however, many areas of the country remain where there are no local health facilities and no LHW coverage either; LHWs are also viewed by some as less informed and under-equipped. It is difficult for very poor and uneducated people to finance their travel to distant locations to meet their FP needs.

Therefore, even if they are able to start using a modern contraceptive, users face great problems in maintaining their use: procuring fresh supplies and getting checkups and counseling to manage side effects pose a considerable challenge. Temporary discontinuation may arise from problems in access and availability. The more committed user will switch to another method but some just drop out.

When the methods are not available then people leave them. Like, for injections, we need to go 10 kilometers to the other village, so they leave this method. MFGD-11; Rural unserved-Mardan 
The financial drain caused by frequent visits necessitated by the side effects, method switching, etc., discourages couples from continuing modern methods. Travel costs and the wage/time loss factor add to the financial burden of managing FP.

Women whose parents marry them of at a young age usually have lots of children and then later think that they cannot meet their expenses because of the large number of children so now they should start using family planning methods (such people use them mostly). People whose financial condition is good, they say reproduce as much as possible; it's in their destiny to use the sustenance that the earth provides. FFGD-1; Rural served-Khanewal

People quit these methods due to poverty. We also don't have a hospital here. These facilities are obtained from private hospitals. MFGD-27; Rural unserved-Khairpur

Poverty can also force a woman or a couple to stop using contraceptive methods.

They take the pills with a lot of difficulty and pain. They don't have a single paisa. If they hear about others' illness, then they leave it, thinking that if we get ill then the husband will not get our treatment done. And if there are such husbands who don't say anything, where will they get the money from? After thinking about this the wife leaves the pills. Then whether she has benefit or harm, she leaves it. FIDI-26, 30 years old, 3 children, Past user; Rural unserved-Pishin

We have to come to the city for treatment where there are private centers. There we have to give very heavy fees. I have come to the city today after a lot of difficulty; I made my husband agree with a lot of difficulty. FIDI-25, 22 years old, 1 child, Never user; Urban-Pishin

In some areas, non-availability of methods at the nearest SP or facility can discourage individuals enough for them to give up contraceptives altogether.

When a method is not available, then people leave it and leave it permanently. MFGD-12; Rural servedMardan

\section{Poor Quality of Care}

All FP users, particularly those who reach health facilities after surmounting the formidable access issues outlined above, are in need of quality care. They expect that service providers will be available, they will be given quality contraceptives, and the behavior of the providers will be helpful. If women are not able to find these services at facilities, there are chances that they will not want to go again and end up abandoning FP use permanently.

As discussed in previous section, the quality of care offered at public sector health facilities often falls quite short. Common problems include early closing of facilities; absence of qualified staff; brusque, unsympathetic attitudes and inadequate attention from doctors; and failure to provide contraceptives, especially quality products.

Perhaps the most important failure of the system relates to provision of adequate information and counseling for effective management of side effects, which, noted earlier, is a primary reason for discontinuation. In some cases, as in rural served and semi-urban areas, women are not informed of all the side effects at the time the method is provided and are unprepared for them. SPs also do not prepare clients for self-management of side effects that do not require clinical attention. Such counseling would alleviate the anxiety women feel, and save the time and costs incurred by them on getting to the SP, thus improving the chances of continued use of contraception.

Users and clients are both aware that effective counseling can prevent women from discontinuing FP. Service providers also know well the problems a dissatisfied client can create: 
If [service providers] don't give [contraceptives] ... properly, then the clients can leave them if they are not properly explained. There is no one to explain [proper usage and management of side effects]. And that woman [who doesn't get counseling] spoils ten women by herself. She also spreads rumors-that is why they leave modern methods, mostly pills and condoms. IDISP-69, Govt, RHC, MO; Pishin

Of course, some service providers are quite effective in counseling users, and try their best to help them cope.

For example, [when they are using] a Copper-T and it starts bleeding or gets infected, clients say that this is because of the Copper-T-remove it. We try to make them understand that this is not because of the Copper-T. Take medicine and it will be fine. They say, remove it this time we will use it again next time. Every method has different reasons. IDISP-153, Govt, BHU, LHV; Khanewal

There are reasons for the wounds. We tell them to take care of cleanliness. We also tell them about the normal discharge and also about the affected discharge. IDISP-27, Pvt, RHC, WMO; Mansehra

The risks of users becoming past users can be significantly reduced with sound counseling. As a service provider noted, "dissatisfaction with one method is no reason for a client to leave as providers try to recommend another method." IDISP-72, Govt, FWC, FWW; Pishin

Counseling for side effective management is examined in more depth in the discussion of QoC in section.

\section{Degrees of Discontinuation}

The five key factors discussed above-changes in family plans, method failure, side effects, pressures of living with side effects, and the failure of healthcare delivery to willing users-can lead women and men to reconsider their FP methods. Their responses can take one of three forms: short term discontinuation, when users temporarily abandon all FP methods; method switching, when users exchange their current contraceptive method for another; and long term discontinuation, when users abandon contraceptive use for good. The factors that shape these three different degrees of discontinuation are outlined below.

\section{Short-term Discontinuation}

Changes in family plans are a common reason for short term discontinuation. Such discontinuation is not in itself a problem, since it does not denote abandonment of FP; rather, it is a positive facet of contraceptivesupported family decision-making. As mentioned earlier, temporary discontinuation of modern contraception to have a baby can sometimes turn into longer term discontinuation, however, as couples fall out of the habit. It is vital for SPs to help such users resume FP methods as soon as they need them, for example, through postpartum counseling.

More worryingly, short term discontinuation may also be induced by temporary inability to access contraceptive products or the experience of side effects that entail pain, fear or stress. At such times, access to a skilled and sympathetic SP who can address the problem and provide necessary counsel and treatment becomes vital for resuming use or switching to another reliable method.

\section{Method Switching}

Method switching may be inspired by method failure; by side effects and associated life impacts; or by the failure of healthcare delivery to supply required products and services where and when users need them. In their responses, most women cited method failure and side effects as their main reasons for switching to other methods, and complained how, as they faced the side effects of various methods, they were unable to get any relief, even after approaching a local healthcare provider, either because no treatment was given, or because the treatment given did not work. 
Contrary to popular perception, women and men are keen to space or limit families, and do attempt to counter side effects of methods they find unsuitable by switching to another, rather than discontinuing FP altogether. Despite numerous obstacles, they persist because the alternative-yet another pregnancy-is even less acceptable. Method switching usually occurs initially from traditional methods, or condoms to pills. If these do not work, or there are side effects, couples switch to injections. If that does not work, then they choose IUCD.

There are different options in the new methods. If one method doesn't suit ... they switch it to another. I started to space after I had four kids. I used an injection but it did not suit me. Then I started taking pills. I used a Copper-T once after consulting my husband and I kept on spotting for one whole month. I got sick of it and had it removed then. The new method didn't suit me. FFGD-18; Semi urban-RY Khan

[I used an IUCD for two to three months.] Then I got internal wounds from it ... I used to get a lot of pain. Then I went for a check-up to a lady doctor; she told me that I have internal wounds ... so I removed it and now I am on spacing injection. FIDI-47, 28 years old, 2 children, Current user; Semi urban-Khairpur

It is interesting to trace the relationship between reason for method switching and its direction. In general, when users switch from traditional to modern methods of contraception, the operating reason is method failure. Finding practices like withdrawal and breastfeeding unreliable for preventing pregnancy, women and men discontinue them in favor of, for example, pills or injections. The same dynamic applies when users switch from less reliable modern methods, such as condoms, to more reliable modern methods, e.g. injections or IUCDs. Here too, the underlying reason for discontinuing the earlier method is its relatively high failure rate.

Condoms can split. It happened with me; then I wanted to get an abortion done, which is sinful. Then we stopped using condoms also. The LHW suggested so then I started using the Copper-T and I also used injections. When I had my children, in the beginning, I didn't know so much; I feared using condoms. I didn't want more children afterwards, so I got a Copper-T placed. Now, after getting it removed, I get injections, because of which I don't get my periods. Then, with the advice of the LHW, I take pills so my periods start. FFGD-11; Rural served-Mardan

The old methods did not give the people proper satisfaction after using them. People still use them but use the new methods more. They have the injection of two to four months, if it suits them, that's well and good. If not, they switch to another method. They either take a pill or get a tube [IUCD] placed. A few people who get sick and tired in between the space of the birth of their kids have an operation. Whoever has around ten kids here has had the operation of family planning. Now people use new methods. FIDI29, 20 years old, 1 child, Never user; Rural served-RY Khan

When method switching proceeds in the opposite direction, from modern to traditional methods, or from hormonal to less reliable barrier methods, the underlying reason is usually side effects and associated life impacts. Such a switch may herald the disappointing ending of a long and painful battle. As this study found, while some couples are easily daunted by the side effects of a first modern contraceptive they try, many others try a range of products before giving in. Among such couples, the initial response to side effects may be a switch to a longer-term product, from pills to injections or IUCDs. It is only when side effects and their associated life problems persist, and the inaccessibility and low quality of healthcare continue to leave couples alone in their struggle, that women and men finally quit and make the 'regressive' move back to simpler or traditional methods, and heightened risk of unwanted pregnancy.

After the last daughter we started to use the methods: first condoms, then Copper-T and injections. [I] used the IUCD for four years ... after four years the bleeding started ... When the problem became severe ... We went to the LHV and told her that we got the Copper-T removed; she said that she could administer an injection with the duration of three months, and then after three months we can come again for it ... After the initial three months, when we got it again ... bleeding started ... every third day, so we left its use ... We did not go anywhere for the treatment. We just left the method. When the duration of the injection finished, the period became normal again after three months. [We are now using withdrawal.] ... Condoms was also o.k. The withdrawal method is also fine. The IUCD method and the injections caused side effects. MIDI-19, 40 years old, 9 children, Past ser; Urban- RY Khan 
Service providers also relate method switches to side effects experienced by users, and say they try to help by offering remedies and suggesting other methods.

When they get a problem related to menses, they leave those methods. Then they think about using another method ... if someone has a problem after using injections then they leave them and start using tablets, and if someone has a problem from tablets, then they leave the tablets and get injections. LHWIDI-17; Semi urban-Sibi

This happens that if anyone has kept multi-load [IUCD] now if it's painful for her at the time of having sex and both [husband and wife] are not satisfied with this, then they switch [to another method]. IDISP-11, Govt, BHU, WMO; Khairpur

\section{Long-term Discontinuation}

As earlier discussion has evinced, the decision to discontinue FP is not one users arrive at in a hurry. At some point in their lives, they consider the health and economic costs of not practicing contraception, and decide to take charge of their reproductive lives. In the quest to prevent unwanted pregnancies, they overcome enormous odds-geographical rural unserved and formidable travel costs; household responsibilities; lack of knowledge about contraceptive methods; sometimes, also unfriendly healthcare system aside from the natural reason of old age, what causes them to give up?

This study's findings indicate that the two key factors underlying permanent discontinuation are side effects, including the disruption they cause in users' lives, and chronic FP access problems, including but not limited to counseling in side effect management from SPs. In the short term, willing users respond to both issues by first switching to other methods, but when method switching repeatedly fails, and side effects or access problems persist, disillusionment sets in. A woman and her husband then feel they are left with three choices: switch back to traditional methods, which, though unreliable, do not pose side effects or access difficulties; undergo sterilization; or risk another pregnancy.

A 29 year old mother of four children explained why she abandoned modern contraception after trying condoms, pills and injections.

I used them for seven months but I got side effects due to that. After the third injection, my menstrual cycle stopped again and my stomach started bloating. If the period came then it was very little with spotting. If I got spotting for one month then the next two or three months there was no period. There was no pregnancy after this. I have problems due to this. I get headaches and muscle aches and bladder discomfort.

One man noted that despite the desire for spacing, due to such side effects, his wife moved from using an IUCD to injections, but the problems persisted until they eventually discontinued FP altogether (RYK Urban).

Side effects, such as severe pain, can also cause reluctant contraceptive users to opt out completely after using only one method.

I have just used one method, the injection, and that too wasn't able to provide relief. After that I did not do anything ... Family planning is not a good thing. FIDI-6, 42 years old, 2 children, Past user; Semi urban- Khanewal

For another 42 year old mother, of eight children, the side effects of contraceptives, combined with social and financial issues in accessing FP, eventually proved too overwhelming:

I stopped using contraceptives because the injection and pills that I used harmed me because my food intake was not good. We did not have financial power to use that and then my face's complexion also got dark because of it; that's why I then stopped using them, and one of the reasons was also that I used it secretly so going again and again was a problem too. FIDI-15, 42 years old, 8 children, Past user, UrbanMardan 
It is interesting to explore why couples risk pregnancy rather than sterilization. Tubal ligation and vasectomy are not preferred FP methods, primarily because they are irreversible and might later be regretted.

Children cannot ever be born again. If, later on, people want to have children, they won't be able to have them. FIDI-16, 28 years old, 2 children, Current user; Urban-Mardan

There was a lady in our area. She had a son and a daughter, and then she went for the operation. Suddenly, her grown-up son passed away and then she came here and asked my paternal aunt to go with her so she could have her closed tube opened so she could conceive again. But then the doctors informed her that she couldn't conceive again as now that she had already been operated. She cried a lot. FFGD-26; Semi urban-Khairpur

Mostly [couples] don't really opt for vasectomy and female sterilization. This is a permanent method which it is very difficult for them to undergo and they fear this because they say, if they do it, what if they later want a baby? So this is there last resort as, after this permanent method, they won't have babies ever. IDI-SP5-Govt,THQ, WMO; Khairpur

Most women and men see sterilization only as the last option for older women (those in their late forties or early fifties) who already have a large family.

I have six kids and every year l'm giving birth and then in the seventh year I did my operation. It's been six years to my marriage and I have six kids. FFGD-29; Rural served-Umerkot

Vasectomy is not even considered in most discussions on FP. Only nine respondents spoke about it, and men and women alike believe it leads to impotency.

With the operation, the sperms of the man get destroyed. They cut down the tubes of semen. With this, the sperms don't go any further. My friend had it done and he said that they either cut the tube or tie it up and put medicine on it. MFGD-17; Rural served-RY Khan

The men say that we will become impotent; this is why they don't like it. IDISP-91, Govt, MCH Center, LHV; RY Khan

Another reason for avoiding sterilization or the "operation,"13 as they call it, is that it introduces a lot of problems when performed incorrectly. Incorrectly performed operations have led to pregnancies. One woman conceived even after tubal ligation, and is now using injectables for spacing; FIDI-28; Rural served-RY Khan.

In our area, a woman got pregnant even after her operation. When she got her menses, she found out.

She thought she got operated so she won't get pregnant. FFGD-11; Rural served-Mardan

Service providers admit that sometimes the operations may not have been performed correctly.

I will tell you something. I performed a tubal ligation case. This woman conceived after 15 to 16 months. First, she got worried that there is some issue and she couldn't believe that she is expecting. Then, when she came to us, we did an ultrasound and the result showed she had been pregnant for the last six months! Now she is also worried and also the villagers that if we take this pain and even after this we conceive, what is its benefit to us that we will do tubal ligation. IDISP-9, Govt, FWC, FWW; Khairpur

Even where sterilization effectively prevents pregnancy, women may still be beset with side effects-pain, internal heating, festering wounds, menstrual problems and obesity. Some women believe the procedure leads to cancer. Some side effects are corroborated by SPs.

[Women] say that cancer also occurs (due to female sterilization). They say that if there is a small problem it gets complicated afterwards. I had a neighbor who had had this operation and she was fine for seven or eight months and afterwards I know what happened, that she got cancer and died. FIDI-5, 38 years old, 6 children, Past user; Semi urban-Khanewal

13 Respondents often used the term "small operation" to refer to tubal ligation and "big operation" to refer to hysterectomy. 
After tubal ligation, they face problems. Some women stop having their menses altogether. They get a problem of hormones and the patients become very fat. There is a natural process going on and if we block that process, obviously it will have side effects. IDISP-89, Govt, RHC, WMO; R Y Khan

One service provider recounted how a diabetic client had a vasectomy, and his subsequent "weakness" was attributed to the operation rather than his pre-existing illness.

My sister told her husband to have an operation. He said why are you trying to kill me? Then my sister had it. She had it done, but when she became fat he used to fight her. FFGD-18; Semi urban-RY Khan

It is the mindset of men that after vasectomy men will lose their strength IDISP-158, Govt, FWC, FWC; Khanewal

It is possible for couples to continue to practice traditional methods of birth control when they give up modern methods. Time and again, however, women and men said no one believes in the efficacy of traditional methods anymore, and only those who have "natural spacing," or conceive with difficulty, practice such methods.

\section{Conclusions}

This section identifies some of the key reasons why couples discontinue contraceptive use, despite a desire to space or limit families, including method failure; side effects; the social and economic fallout of side effects; and chronic difficulties in accessing quality care.

Short term discontinuation is usually the result of a conscious decision to have a child, or a temporary problem that prevents access to contraceptives or health providers. Another form of discontinuation, method switching, is induced by method failure, by side effects and their associated life impact, or by chronic difficulties in accessing the products, services and counseling required to cope with side effects. Long term discontinuation usually occurs after method switching fails to yield freedom from side effects. Couples become exhausted by persistent debilitating physical symptoms; the profound personal, social and financial problems that riddle their lives as they struggle to live with side effects; and the chronic access and quality issues, particularly lack of adequate counseling, that prevent the healthcare system from helping them cope.

Conjugal relations and family life are affected by the choice of method, its side effects, and its efficacy. Continued illness that does not let a woman take care of herself, her family and her husband creates marital tension. The financial burden related to managing side effects elevates stress levels further, and the result of such expenses does not always provide relief.

A focus on discontinuation is important since a key finding of this study is that traditional barriers to FP have diminished. Men are now supportive of FP, and are aware of the side effects since the fallout from the side effects experienced by their wives affect them too, such as disruption in marital life; medical costs of treating side effects; reduced attention to children and household care due to weakness, anemia or backaches. Instead of resistance, there is a concern that different methods are not providing relief. Spousal communication in use of FP-whether initiated by husband or wife-appears to be common and the choice of method is more often than not mutually decided upon.

The same can be said for resistance to FP based on religion. While this reason for not using FP methods is cited in some cases, it is also heavily and scornfully countered by others, who argue that while the basic tenets of religious teaching, such as honesty, praying five times a day, kindness, are routinely ignored, religion is produced as an excuse for not adopting FP. As one respondent retorts, even if FP is a sin, so be it, given that they are already sinners: 
We don't offer prayers five times a day. We don't wear veils. And when the conversation comes to these things [using contraceptives], then we say that this is a sin. FIDI-10, 38 years old, 7 children, Current user; Semi urban-Mansehra

The semi-urban women are more vocal and almost impatient with the usual excuses of religion and ignorance to space and limit family size. They are aware that poverty, high household dependency, and a lone earner constrain their circumstances and the needs of the family cannot be met.

All categories of respondents-LHWs, male and female interviewees, and SPs at static facilities-note that these social and religious barriers no longer exist. This is due to increased awareness of FP, especially spacing. National advocacy on FP, education, electronic media, and economic constraints have led to a change in attitude in favor of smaller families. Households are accepting FP as a means to managing household expenses.

The gains from these positive developments are undermined by the method-specific side effects experienced, not all of which are addressed satisfactorily. The issue of side effects is serious. Given that side effects are the major reason cited by couples for changing contraceptive methods, and given the disadvantages listed of modern methods, a concerted effort is required to address this aspect keeping in view the social and physical environment of a Pakistani woman, her household responsibilities (high dependency ratios, large household size) and context (lack of water and sanitation, and inadequate or unaffordable care facilities).

In some cases, as in rural served and semi-urban areas, women are not informed of all the side effects at the time the method is provided and are unprepared for them. Service providers also do not prepare clients for self-management of side effects that do not require clinical attention. Such counseling would alleviate the anxiety women feel, and save the time and costs incurred by them on getting to the SP. 

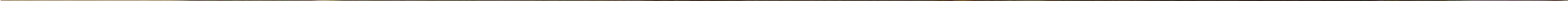


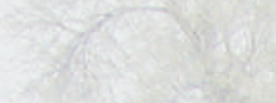

ar

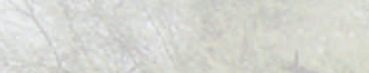

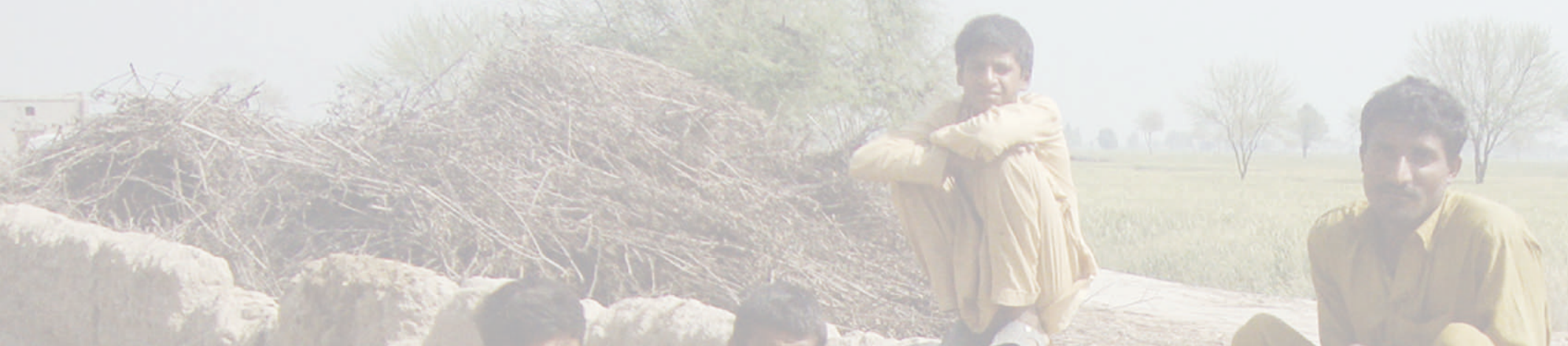

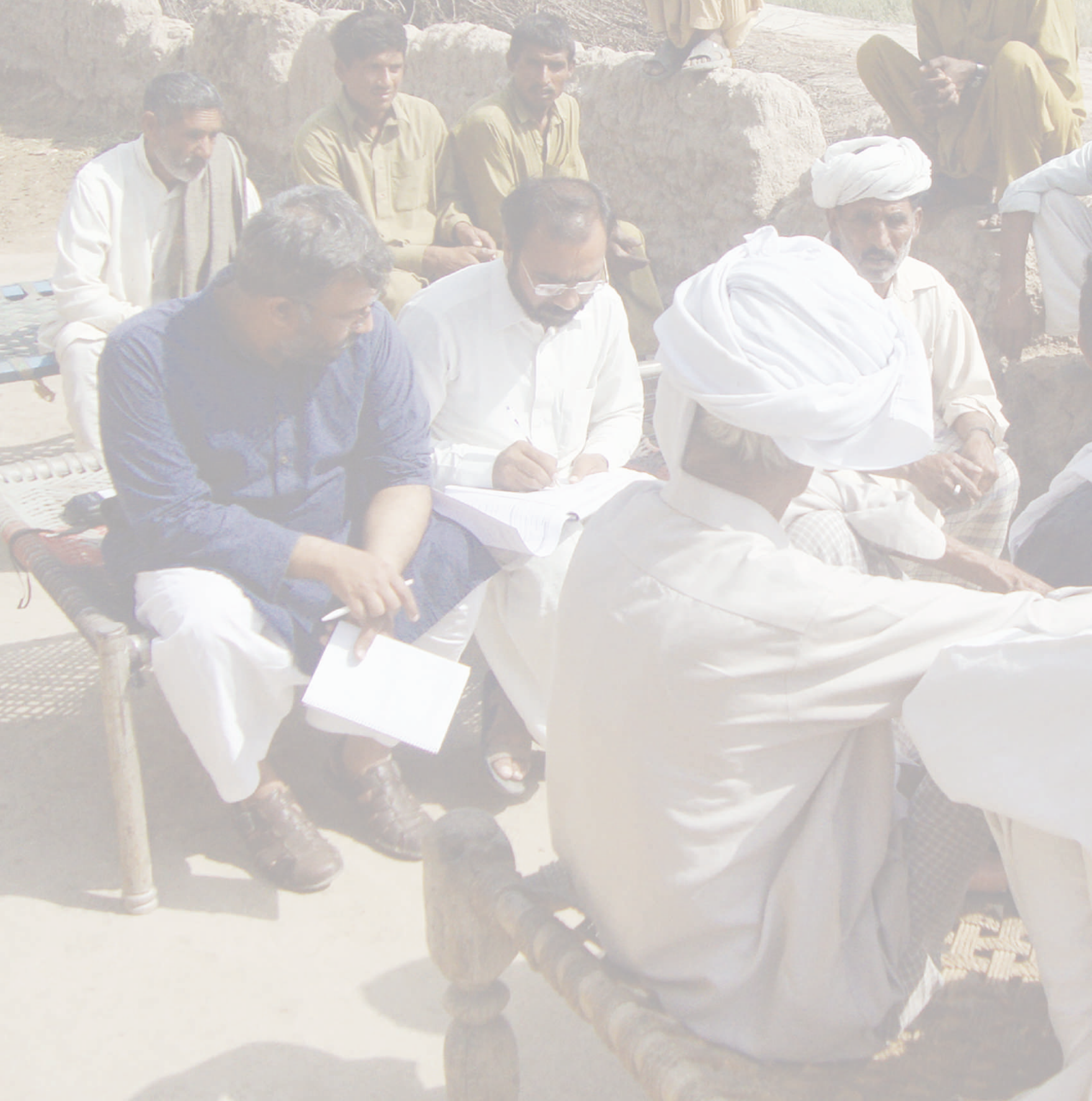




\section{Conclusions}

\section{Hindrances to Access Family Planning Services}

Of all the access issues mentioned by men, women, and service providers, physical access appears to be the real challenge, especially for women who live in remote areas of Balochistan and KP, where services are not available and the difficult terrain and scattered population intensify problems.

The second significant barrier to accessing family planning (FP) in the districts and communities is financial constraints limiting people's ability to bear travel and contraceptive costs. In public facilities, contraceptives are available free of cost; however, fewer facilities and the distances between them make it difficult for current and intending users to access services. The high travel costs and time and wage losses entailed in reaching and utilizing FP services cannot be borne by cash-strapped families and communities.

The encouraging and major finding from this study is the diminished negative role of husbands and mothers-inlaw. Instead of resisting FP, husbands are in conversation with wives about selecting suitable FP methods. Pockets of resistance from husbands and mothers-in-law remain in KP and Balochistan, but these are few, and even there, women find ways to confidentially obtain FP services from SPs. Women's reproductive responsibilities and couples' economic activities, however, leave little time for following up on FP intentions.

Another important finding relates to the diminished significance of religion in FP decision-making, except in a few remote areas. All the discussions with men and women strongly suggest that religion is not a significant factor in FP decision-making and use, although SPs do consider it a barrier, citing the lingering influence of mullahs (religious leaders) on household decision-making. Many women, especially in urban and semi-urban communities, ask why religion is selectively applied to FP, while others argue that religion in fact supports FP. Probing the responses that cite religion as a factor reveals that, in most cases, the actual reason for eschewing FP lies elsewhere, such as a desire for another child. In Balochistan, cultural and tribal practices continue to pressurize men to prove their manhood by producing many children.

While they are aware of almost all modern and traditional FP methods, women and men lack detailed methodspecific detailed knowledge. This could be a significant mental block to accessing FP, especially when combined with fear of side effects and perceived harm from contraceptive use, reported as a major barrier by over half of the women from all types of communities and the majority of service providers. Rumors related to side effects have a further ripple effect in discouraging women's FP use.

\section{Quality of Care}

Even when women and men are able to surmount the formidable obstacles that block their access to FP care, their experience of service utilization may be marred by supply side issues, specifically, poor quality of care. Health facilities, particularly in the public sector, suffer from a number of shortcomings, including shortage or absenteeism of staff, particularly female staff; short and irregular working hours; discourteous behavior and poor communication with clients; inadequate attention and information provision; and pressure to use the providers' private services. It appears in some cases that staff is appointed but not available, trained but not using its skills effectively or following protocols and the facility does not provide a client-friendly environment. These deficiencies, especially unsupportive attitudes, make it difficult for women to share their concerns and can make them avoid future visits for follow up or other needs.

Shortages and non-availability of contraceptive supplies further constrain choice of available methods. The quality of contraceptives-which can be poor-also affects use of methods or services over time. Often, a preferred method of contraceptive is not available at a facility, and couples are forced to choose another. 
These issues are more common in the public health sector. Despite the low quality of care, however, public facilities continue to cater to a large clientele because their services are very affordable and usually the only option for poor people.

Some service providers (SPs) and lady health workers (LHWs) reported that they inform women of side effects of injections and how to manage them, and women who fear these side effects are advised to adopt another FP method, such as the IUCD. Mostly, LHWs report that when their clients experience side effects, they refer them to a static health facility where qualified doctors can treat them properly. Some users are dissatisfied, however, with contraceptive side effect management by public sector health professionals. They perceive this to be due to lack of knowledge or skill, or to absence of skilled staff, which leaves paramedical staff to counsel and treat patients in distress. Lady health workers are considered inadequate for treating and counseling users facing side effects.

Women and men are more satisfied with the quality of services being provided at private health facilities, where they feel they are dealt with more respectfully and attentively, given proper checkups and provided adequate information and counsel. Clients are comfortable enough to discuss their problems. Another reason for preferring private facilities and SPs is their timing-such facilities are usually open until late evening or round the clock. Although the services at private facilities are of impressive quality, they cost significantly more than public services, however, and are not financially accessible for everyone.

In general, women and men appreciate LHWs as committed and helpful resources who counsel them on minor issues, are able to supply them some contraceptives, and at times help them navigate public facilities. People complain, however, that they provide a very limited range of contraceptives (condoms and pills), which are sometimes of poor quality. Moreover, they are not trained to help users manage side effects.

Most SPs and LHWs believe FP is compatible with religion, although about one quarter of SPs believe tubal ligation and vasectomy are not permissible in Islam. They do not share these views with clients, however, and do recommend or perform these procedures where a case merits them and the client wishes it.

\section{Contraceptive Preferences}

Contrary to the common impression, people in rural, even remote, areas do not seem to harbor any overwhelming preference for traditional methods of contraception over modern methods. In fact, most of this study's respondents favored modern methods in comparison to traditional ones, noting that modern methods are more effective and reliable, and provide long-term options for spacing, while traditional methods are effective only at times and their failure rate is high.

The few couples who prefer traditional methods favor them because there are no associated side effects, expenses, or access problems. Moreover, traditional methods can be practiced confidentially, without any third person's involvement, and are perfectly compatible with religion.

In general, however, use of traditional methods is not based on a preference for these methods, but on lack of access to modern methods, and, to a lesser extent, on fear of side effects of modern methods, which women and men have observed, experienced, or heard about, and which would be difficult to manage and live with for their resource-constrained and largely uneducated households.

All four categories of respondents-men, women, SPs at static facilities, LHWs-prefer condoms as their method for personal use (although LHWs also use IUCDs). The second preference for most stakeholders is injectables, although men favor pills and use of the traditional withdrawal method. Methods respondents avoid most include pills (by women and SPs) and injectables (by men and LHWs). Women and men are fully aware of the different modern methods of contraception and can compare their relative advantages. 
When asked to describe their vision of an ideal contraceptive, respondents suggest similar attributes, although different stakeholders and communities emphasize different features. In the view of current and potential FP users, the ideal contraceptive method would, first and foremost, be completely reliable, providing long-term spacing. Very importantly, it must be free of side effects, so it can be used without any adverse effects on health or other spheres of life. Moreover, the method should be painless, involving no discomfort or reduction in satisfaction, and easy to use. The method should not involve frequent administration or provider interaction. It should lend itself to discreet use so privacy is preserved. In addition, the method should be easily affordable and physically accessible and availablepreferably, delivered at the doorstep by LHWs. Finally, complete information about the method should be available to users, it should be compatible with religion and endorsed by the local leadership and media.

Women and men suggested the method might be a single dose pill, palatable syrup, or a very small implant, like a microchip. Respondents also suggested ways to improve access to this ideal contraceptive, mentioning, in particular, doorstep- or community-based delivery systems, skilled providers, and quality services.

These responses clearly indicate no resistance by women and men to modern FP methods; rather the how, when, and what of the service delivery that requires reproductive health policymakers' and implementers' attentions.

\section{Reasons for Discontinuation}

According to the women and men interviewed in this study, use of modern contraceptive methods may be discontinued for a host of reasons, which may broadly be categorized as: (1) changes in family plans, (2) failure of the method (to prevent pregnancy), (3) significant side effects or dissatisfaction with the method, (4) significant personal, social and economic costs of living with side effects, and (5) difficulty in accessing the method. Discontinuation may take one of three forms: short-term discontinuation, in which all FP methods are temporarily discontinued; method switching, in which a user exchanges one FP method for another; and longterm discontinuation, in which a user decides to stop using FP methods altogether.

Changes in family plans or situations, e.g. when a couple wants a baby or the husband works in another town and is away for long durations, can cause short term discontinuation of FP methods, which is not in itself worrying, but which may turn into long-term discontinuation as couples fall out of the habit. Timely counseling by alert SPs or LHWs can prevent this latter outcome.

Method failure is commonly associated with traditional methods of birth control, and causes couples to switch to more reliable modern methods, such as pills, condoms or injections. Even among modern methods, however, pills and condoms are associated with method failure. This can at times be due to ineffective usewomen commonly forget to take the pill daily-or to use of substandard products. In such cases, users often switch to the longer-term hormonal methods, such as injectables and IUCDs.

Importantly, this study finds that side effects of contraceptive use are the primary reason for discontinuation. Men, women, and SPs list side effects of each modern method that range from annoying (such as mild itching) to debilitating, including heavy and protracted bleeding and anemia. A particularly worrying finding is that women are discontinuing because of side effects even in semi-urban and urban areas, with presumably relatively better access to healthcare providers. Overwhelmingly, SPs believe that one woman's experience of side effects leads to at least 10 women not using contraceptives, and even more becoming wary of them.

Side effects are important not only because of women's physical suffering, but also their deterioration in quality of life, by compromising their ability to work and engage in conjugal relations, along with extra expenditures on healthcare, and damaged marital relationships. Apart from dealing with the physical toll of side effects such as heavy or irregular bleeding, women worry about the time, costs, and strain in managing side effects. Sometimes these pressures, and not actual side effects, lead to discontinuation. 
The same problems of access and quality of care that make it difficult for women and men to start using modern FP methods can also make it difficult for them to maintain contraceptive use once they start. Users, especially in unserved rural communities, face great problems in maintaining use of contraceptives: procuring fresh supplies and getting checkups and counseling to manage side effects can prove too challenging. Problems in access and availability may initially lead to short-term discontinuation. When such problems persist, however, some users may drop out. Likewise, In terms of quality of care, perhaps the most important failure of the system relates to provision of adequate information and counseling for effective management of side effects, which, as noted above, comprise the primary reason for discontinuation.

Method switching may be inspired by method failure; by side effects and associated life impacts; or by the failure of healthcare delivery to supply required products and services where and when users need them. In general, when users switch from traditional to modern methods of contraception, the operating reason is method failure. However, when method switching proceeds in the opposite direction, i.e. from modern to traditional methods, or from hormonal to the less reliable barrier methods, the underlying reason is usually side effects and associated life impacts.

This persistent finding indicates that the two key factors underlying permanent discontinuation are side effects, including the disruption they cause in users' lives, and chronic problems in accessing quality FP care. In the short run, willing users respond to both issues by first switching to other methods. When side effects or problems in access to care persist, however, disillusionment sets in. Few couples opt for sterilization, which is unpopular due to irreversibility and risk of surgical complications; most take the regressive step back to traditional methods, or none.

A focus on discontinuation is important since traditional social and religious barriers to FP have diminished, and households are accepting FP as a means to managing household expenses. The gains from this positive development are undermined by the side effects experienced from modern contraceptive use, not all of which are addressed satisfactorily. A concerted effort is required to address this aspect keeping in view the social and physical environment of an average Pakistani woman, her heavy household responsibilities and her limited access to basic facilities. 


\section{Discussion}

Husbands now support use of FP methods, even in traditional communities. This study finds that most couples communicate about their fertility issues, regardless of whether they live in rural or urban, and served or unserved areas. Husbands play a positive role; in fact, in most cases, men initiated the discussion of FP use. This is a good sign: other studies show spousal communication on FP is a primary factor influencing the use of contraception in Pakistan, ${ }^{14}$ and communication by couples increases men's contraceptive use in Pakistan. ${ }^{15}$

Earlier studies suggested that husbands were perceived as an important barrier to FP uptake in Pakistan. A 2001 study showed that a main obstacle to using contraception was women's perceptions that their FP choices or behavior would conflict with their husbands' desires or attitudes towards FP. ${ }^{16}$ That pattern is now changing. According to a 2013 study in rural Punjab, economic pressure is the main motivating factor for men's now favorable view of FP. ${ }^{17}$ This study also implies that husbands are supportive and concerned about women's health in all districts. While there are, at times, social and tribal pressures on men to have more children, particularly sons, they personally want to space births and limit the number of children.

Men's readiness and concern to use FP can be assessed from their demand for method-specific knowledge to enable them to make informed method choices. A number of local, regional and global studies also show that one of the greatest hindrances to the use of FP services, especially modern methods, is the lack of knowledge and awareness regarding the use of specific methods and their benefits. ${ }^{18,19,20}$

\section{Multiple issues of physical access to FP services pose real challenges, especially for men and women from unserved rural areas of Pakistan. Absence of locally available FP services reduces the chances of FP uptake among many willing men and women because of the formidable difficulties they face in reaching health facilities. Lack of available transportation is the main problem for women in unserved rural areas, and the cost of travel is another major issue, particularly in Balochistan and KP. In many areas, it is neither socially acceptable for women to frequently leave their homes for FP services, nor permitted by household workloads. A number of global studies also suggest that easy access to FP services by possible users is an important element in its acceptance and use, and this has been a source of the global increase. ${ }^{21,22}$}

Poverty is a major issue facing men and women from served and unserved rural areas in all districts. Family planning cannot be a priority for people deprived of basic facilities, such as food and water, as is often the situation of people living in unserved and distant areas; lack of water is a particular problem in Balochistan. For communities facing such critical deprivations, the problems of accessing FP are compounded by poverty, and the resultant inability to bear travel costs or forego daily wages to visit health facilities. PDHS 2012-13 shows that household "wealth" is associated with women's contraceptive use: CPR rises with increases in household wealth, and women in the lowest wealth quintile have a CPR of 21 percent, compared to 46 percent for those in the richest quintile. ${ }^{23}$

14 Mahmood, N., Ringheim, K., 1996, Factors affecting contraceptive use in Pakistan, The Pakistan Development Review, 1-22.

15 Framurz, M., Kiani, K., 2003, Motivation and Involvement of Men in Family Planning in Pakistan, The Pakistan Development Review 42(3): 197-217

${ }^{16}$ Casterline, J., Sathar, Z. A., Haque, M. 2001, 'Obstacles to Contraceptive Use in Pakistan: A Study in Punjab', Studies in Family Planning; 32[2]: 95-110.

17 Kamran, I., Khan, M., \& Tasneem, Z. (2013). Involving Men in Reproductive and Fertility Issues: Insights from Punjab. Population Council

$18 \mathrm{lbid}$

19 Kragelund NK, Nielsen SM, Butler R, Lazarus JV. 2012, “Key barriers to the use of modern contraceptives among women in Albania: a qualitative study', Reproductive Health Matters 20(40): 158-165

${ }^{20}$ Cindoglu, D., Sirkeci, I., Sirkeci, RF., 2008, 'Determinants of choosing withdrawal over modern contraceptive methods in Turkey', The European Journal of Contraception and Reproductive Health Care, 13(4):412-421

${ }^{21}$ Gakidou, E., Vayena, E., 2007, 'Use of Modern Contraception by the Poor Is Falling Behind', PLoS 4(2): e31

22 Hamid, S., Stephenson, R., 2006, Provider and health facility influences on contraceptive adoption in urban Pakistan, International family planning perspectives, 71-78.

$23 \mathrm{lbid}$. 
This study also finds that people who do not have any public facility available nearby or who are not satisfied with the quality of services of public facilities are left with no option other than seeking services from private facilities. Since private services are more expensive, however, this option is closed to those who are poor. According to a study, low-income families in Pakistan are less likely to use modern forms of contraception due to issues of access and cost, especially for services being provided through the private sector. ${ }^{24}$ According to another study in rural Pakistan, users are satisfied with the quality of services at private facilities, but their high cost is a barrier; on the other hand, they find public facilities affordable but unsatisfactory. ${ }^{25}$

The significance of religion in FP decision-making has diminished, except in a few remote areas. Many studies have attributed the relatively low use of contraception in Pakistan to religious beliefs and misperceptions, or feelings of religious prohibition 26,27 . All discussions with men and women during this study strongly suggest that religion is not a significant factor, however, in FP decision-making. There is a sharp discrepancy between perception and practice by men and women. Men particularly feel that mainly maulvis (religious clerics) are building religious perceptions against FP. Their influence has waned, however: in FP decision-making, spacing children is not considered a "sin" but a need.

\section{Myths and fear of side effects of contraceptive methods prevent women from using any method, even when} they want to limit births. Myths and fears of side effects of modern contraceptives are widely prevalent in Pakistan, and the 'mechanism' for their propagation is strengthened by the absence in many communities of service providers or facilities to explain or dispel the rumors. Consequently, many couples fear side effects and health concerns, even when they have not experienced any directly. Health concerns and fear of side effects are some of the more common reasons given for non-use of contraception by married women who have an unmet need. A global study found that 20 to 50 percent of women at risk of unintended pregnancy cited these reasons for non-use. ${ }^{28}$ In Pakistan, fear of side effects due to myths and misconceptions about using modern methods led to low use among currently married young urban women ${ }^{29}$ as well as rural women. ${ }^{30}$

\section{Experiencing side effects of contraceptive methods leads women to switch to different FP methods and, if problems persist, to eventually give up all contraceptives. As PDHS 2012-13 shows, about 38 percent of} women who have discontinued FP methods have done so due to side effects or failure of method. ${ }^{31}$ This study also suggests that people are generally in favor of using modern contraceptives, because they recognize that traditional methods are far less reliable in preventing pregnancy, but when they experience (or perceive) side effects, they start to lose their trust in modern methods. While some give up at the first method, many continue other modern methods, in the hope one will suit them. If they continue to face side effects, however, they too eventually stop using any methods. The decision to stop is forced not only by the malaise, pain or weakness experienced, but also by the impact of the users' ill health on their financial, family and social situation, as health care costs rise, marital relations are interrupted by symptoms, household tasks are neglected, and ability to participate in social and religious gatherings is reduced. Problems in access to service providers and quality of care exacerbate the issue by depriving users of the help they need in coping with side effects.

\footnotetext{
${ }^{24}$ Agha, S., 2000, 'Is low income a constraint to contraceptive use among the Pakistani poor?', Journal of Biosocial Science, Volume 32 , Issue 2, pp 161-175

25 Khurram, S., Mohsina, B., Hafsa, M., Noah, S., Waqas, H., 2009, Barriers and perceptions regarding different contraceptives and family planning practices amongst men and women of reproductive age in rural Pakistan: A qualitative study, International Journal of Gynaecology and Obstetrics, Volume 107, Supplement 2

${ }^{26}$ Ibid.

$27 \mathrm{lbid}$.

28 Sedgh G., Hussain, R., Bankole, A., Singh, S., 2007, Women with an unmet need for contraception in developing countries and their reasons for not using a method, Occasional Report, New York: Guttmacher Institute, No. 37

29 lbid.

30 Ibid.

31 lbid
} 
Most men, women and service providers prefer modern contraceptive methods to traditional ones. Although PDHS 2012-13 finds a CPR of just 25 percent for modern methods and increasing trends in traditional methods, 32 this study did not find a preference for traditional methods among men and women. On the contrary, most of the study's respondents favored modern methods in comparison to traditional ones, noting that modern methods are more effective and reliable, and provide long-term options for spacing, while traditional methods are effective only at times and their failure rate is high.

\section{Service providers who consider any or all FP methods against Islam cannot help clients with the requisite} initiative and drive. Service providers' own biases for or against certain methods influence the methods married women use. ${ }^{33}$ This study found that a number of service providers (17/64) believe that religion does not allow tubal ligation and a few (4/64) also consider spacing methods to be against religion. Service providers having such beliefs may be able to provide FP services as part of their duties but cannot be expected to motivate or counsel potential users to adopt the methods they consider prohibited as a priority or with dedication.

In general, low utilization of FP services is no longer due to low demand but to inadequacies on the supply side, especially in the public sector. In unserved areas, although men and women intend to use FP, nonavailability of services creates hurdles for them. In served areas, the quality of services provided at public facilities is generally poor; availability of contraceptive stocks and female providers are major issues, particularly in Balochistan and Sindh, and the facility timings are also limited, which greatly narrows the window for clients to avail services. Even where female service providers are available at public facilities, their behavior is often found to be rude and impolite, which discourages women from visiting. In short, men and women want to use FP but they do not have the trust or confidence that they will be warmly welcomed and service providers will provide the best services. This perception prevents them from seeking FP care and eventually results in low use of contraceptives. Other studies also suggest that lack of female staff to attend to the clients, ${ }^{34}$ providers' competence, ${ }^{35}$ their negative attitude ${ }^{36}$ and poor quality of care act as large barriers to contraceptive use.

A previous study has found organizational capacity to be strongly linked with provision of services; better service delivery and quality of care lead to longer-term use of contraception and better client satisfaction. ${ }^{37}$ Another study compared family planning services in 15 countries and discovered that 7 to 27 percent of women ceased to practice contraception within a year of starting due to the low quality of service delivery. 38 This study also concludes that users are overcoming practical hurdles at household level, however, the health care system is not yet meeting all of them halfway: non-availability of local FP services and lack of readiness of health facilities and service providers are mainly responsible for low use of modern contraceptives.

\footnotetext{
32 Ibid.

${ }^{33}$ Nishtar NA., Sami N., Alim S., Pradhan N., Hasnain FU., 2013, Determinants of contraceptives use amongst youth: an exploratory study with family planning service providers in Karachi Pakistan, Global J Health Sci, 5;5(3):1-8

${ }^{34}$ Shah, N A., Nisar, N., Qadri, MH., 2008, Awareness and pattern of utilizing family planning services among women attending Urban Health Care Center Azizabad Sukkur, Pak J Med Sci, 24(4), 550-5.

35 Khan, A., Shaikh, BT., 2013, An all time low utilization of intrauterine contraceptive device as a birth spacing method-a qualitative descriptive study in district Rawalpindi, Pakistan, Reproductive health, 10(1), 10.

${ }^{36}$ Azmat, SK, 2012, 'Barriers and perceptions regarding different contraceptives and family planning practices amongst men and women of reproductive age in rural Pakistan: a qualitative study', Pak J Public Health, 2(1).

37 Hamid, S., Stephenson, R., 2006, Provider and health facility influences on contraceptive adoption in urban Pakistan, International family planning perspectives, 71-78.

${ }^{38}$ Blanc, A. K., Curtis, SL., Croft, TN., 2002, Monitoring contraceptive continuation: links to fertility outcomes and quality of care, Studies in family planning, 33(2), 127-140.
} 


\section{Recommendations}

Improving Access: A concerted effort should be made to improve the FP service delivery system such that it provides more services at the doorstep, including counseling and follow up. The role and status of LHWs should be extended and expanded, by increasing the LHW strength, appointing more LHWs in under-served and unserved rural areas. Appointing a community-based worker as a LHW can also contribute significantly to contraceptive uptake because most of the access problems are directly related with absence of services. Recruiting women as LHWs, where they are available, will allow expansion of the kind and level of services that LHWs are able to offer.

Under-served areas in remote and rural parts of a district should receive FP services using diverse strategies such as mobile provider services, regular camps, etc. Services in these areas should be provided free of cost or on some ability-to-pay basis. Regular provider visits to distant communities should be arranged to boost uptake of FP methods. The days, timings and hours of such visits, including should be scheduled for a whole year and this information should be available at key locations in the communities to be visited. Such follow-ups will ensure timely management of side effects and provision of subsequent doses (whether pills or injections) so that the dropout rate is effectively countered. The LHW or other skilled community based provider has an especially important role to play.

Improving Quality of Care: Improved supply and quality of staff and contraceptives are needed to encourage and retain interest in FP among those who need it the most-individuals in the reproductive age group who have limited means and options. Contraceptives should be available free of cost and should be of good quality to minimize side effects and negative experiences.

Timings of health facilities need to be critically reviewed. Availability of services at least till evening particularly at public facilities is a serious requirement to maximize the utility of FP services by women.

Training, and regular refresher trainings are needed to improve the technical skills and knowledge of SPs as well as behavioral training to enforce client-friendly attitudes and a client-friendly, welcoming environment in the FP facility.

Addressing Myths and Fears: Myths about contraceptives and fears of side effects need to be addressed through innovative and targeted media strategies. There is not enough information provided in forms and ways that would be accessible and understood by the majority of reproductive age couples in low income or rural and remote areas is needed. One area where information and services are lacking is vasectomy and addressing these would allow them to make the choice that allows them to limit family size without having to go through the side effects and associated social and economic costs of methods used by wives.

Managing Side Effects: Often side effects drive couples to fall back on the traditional methods that they know do not work well. The tradeoff between managing side effects and giving birth to yet another child is tipped in favor of the latter. A different strategy is required to draw past users back to FP use, and to counter the fears of those with unmet need. Mobile providers should visit women who have recently adopted a method to check on their side effects; the LHW can be asked to follow up and mobile phones can also be used for the purpose.

Management of side effects at home can be one way to address the fear and experience of side effects. Counseling to help users manage needs at home should be mindful of the users' resource poor context.

Local Solutions: Pockets where resistance to modern FP methods persists and that show low CPR need to be addressed locally, with mapping of such pockets by the district health and population departments. The heterogeneity among users, their contexts, and their socio-economic status requires strategies that are highly localized; instead of national or provincial, such strategies should be district specific. 
Age Specific Solutions: Information, education and communication involving motivation and counseling should be age specific. For example, there should be specific information for young couples given the strong social norm of having a first child soon after marriage, and of not considering permanent methods until family size is complete. (Time should not be wasted on trying to motivate younger couples or families to choose sterilization or traditional methods, which are ineffective.)

Information and Services: A wider use of cellular technology and social media is needed. A more comprehensive and widespread use of media is required to penetrate the hard to reach, under-served areasinformation on methods and service locations and providers should be available through the electronic media but can also be made available through mobile phone SMS messaging services. For example cell phones/text messages with graphics for illiterate users can be used to remind them of when, for example, their pill, injection, or checkup is due; or motivational messages can be sent to husbands that include FP information on methods, messages that compare costs of raising a child against all costs related to using a method, among others. There are help lines set up in different provinces for reporting traffic incidents, domestic violence, and others. Similar help lines should be set up for FP services and counseling. Women and men should be able to call such a helpline and have a local service provider contact them within 24 hours with FP advice and services. 



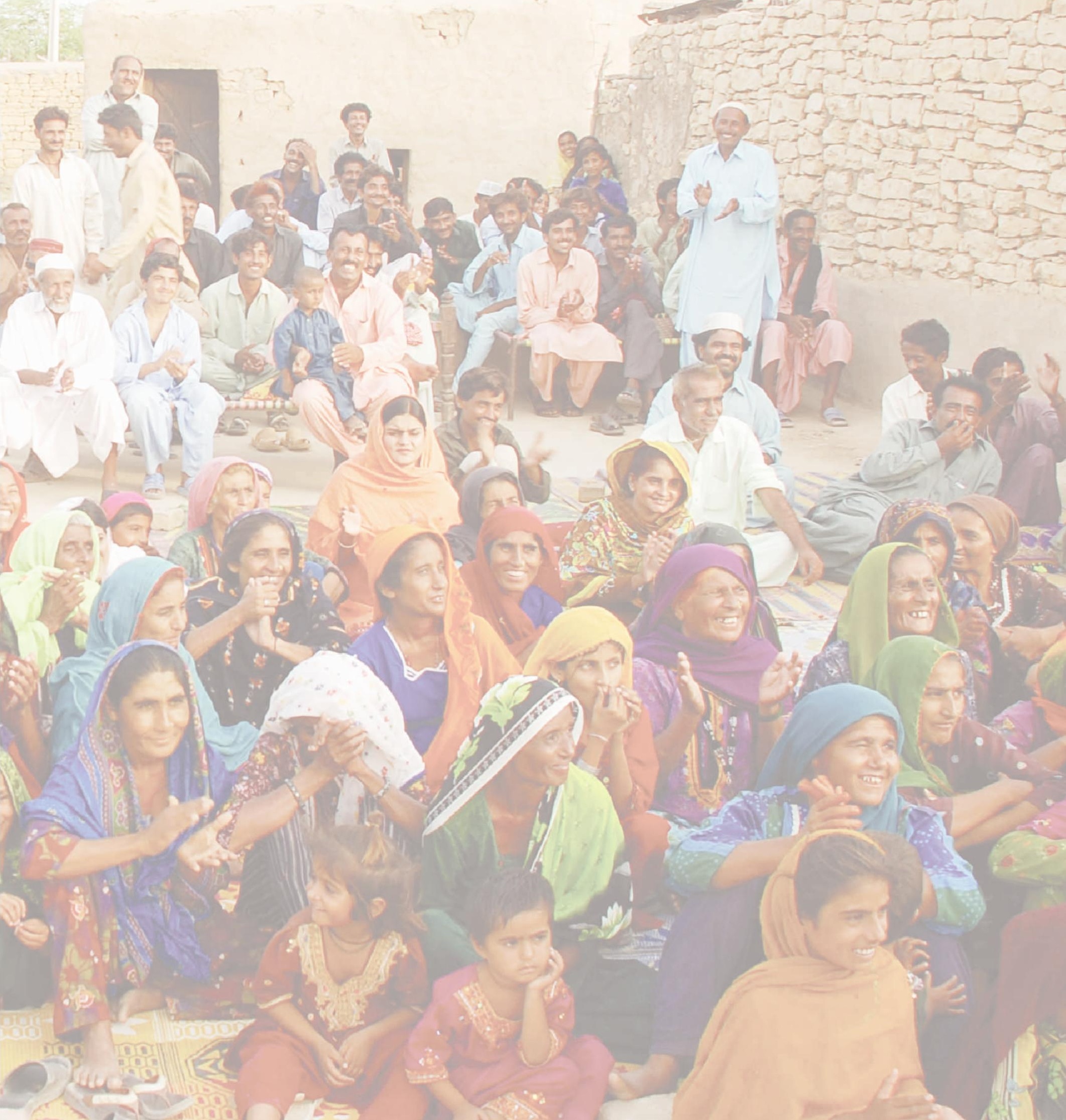




\section{No Easy Access}

\section{Poverty and non-availability of local services prevent willing communities from using contraceptives}

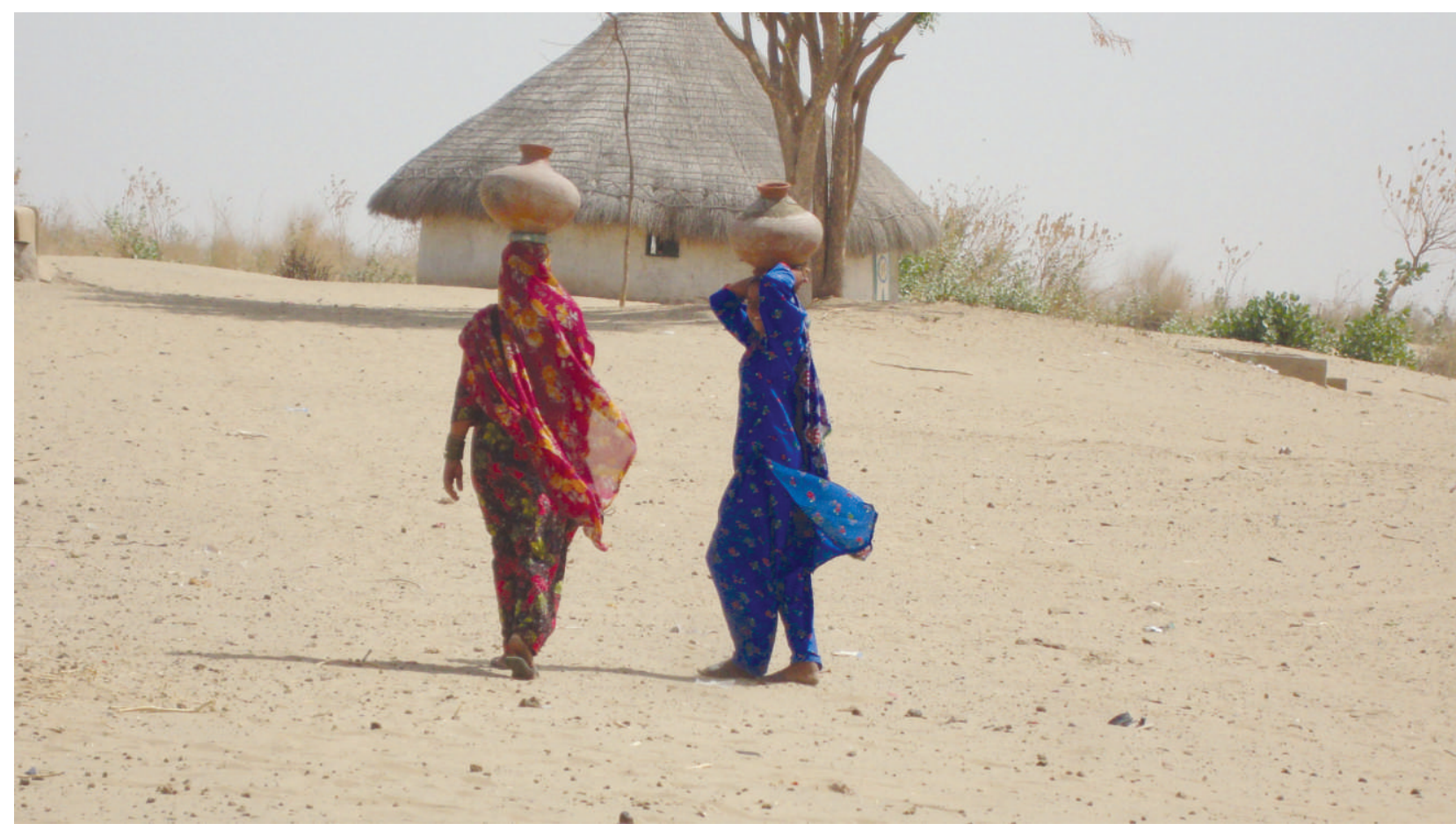

Hajran, ${ }^{39}$ 30, lives in Barshore Chingan with her husband, three children, and her husband's family. She is illiterate and a housewife. Her 35-year-old husband works in the fields. Jamila was 22 when she got married; in eight years of her marriage, she has borne three sons and is expecting her fourth baby.

Situated in district Pishin, Balochistan, Barshore Chingan is currently 'unserved': there are no local health facilities in the area, not even a private medical store, nor is it visited by lady health workers (LHWs). Water is short, due to which farms do not produce enough crops. Most of the local people are very poor and struggle to meet basic household expenses. The nearest health facility is about 40 kilometers away but mobility is hindered by non-availability of transport, as well as restrictive tribal customs.

Jamila became pregnant nine months into her marriage. Although tribal communities are highly conservative, it is encouraging that, following the birth of the child, she and her husband discussed ways to delay the next pregnancy. But they could not find a method they could afford.

In our area there are no health facilities, not even a BHU (basic health unit) or a dispensary. We have to buy contraceptives from the market, from the medical store, which we cannot afford. The medical store is very far away and there is no transport for people. It is very expensive to go and buy any contraceptive method. My husband earns only enough to feed us. With great difficulty he arranges dry chapatti for us. We don't even get one pill of Disprin (aspirin) in the community; we have to buy it ourselves. Here, everyone is poor; we make a living with lot of difficulty. So how can they buy any contraceptive method?

${ }^{39}$ Names have been changed to protect respondents' privacy. 
Even traditional methods proved impossible. Jamila's husband did not agree to practicing withdrawal. On the other hand, since she was too under-nourished to breastfeed her baby beyond 40 days, the lactation amenorrhea method (LAM) was not possible.

My husband and I spoke with each other that we should use a method but we could not afford it. We would have liked to use a method immediately after our marriage but could not find any such method. We are dying from poverty. My husband does not prefer to practice withdrawal method, and I cannot breastfeed after 40 days as I don't have any milk. We cannot buy any milk from the market so the baby stays hungry. If I had milk then it would have been very good and my baby would also stay healthy and I would also have spacing. When I myself cannot get food then how will I have milk?

Before long, Jamila conceived again and had another son. After the birth of their second child, the worried couple decided to use contraceptive pills, which was the only method available that they felt they could afford. Jamila's husband made the expensive trip to the market and returned with a month's supply of pills. However, they could not afford another trip a month later, so Jamila used no further pills; she soon found herself pregnant with their third baby.

Due to economic problems, we want to have fewer children as we cannot feed them or give them anything to drink. We don't even get a single pill from the government. We cannot get treatment for our children. We cannot feed them; this is why we wanted to space. If we had a choice of methods, we would have adopted any method. We could not get an injection because there is no one in the village to dispense it. The only choice was pills, so my husband bought it from the market in the city 40 kilometers away for 50 rupees for one pack. I took them for one month but because we could not afford to purchase the pills again I stopped using them and then became pregnant.

Jamila is aware that she and her husband are not alone in this predicament. Many other couples like them in the community want to use family planning are prevented by lack of access and poverty. If they purchase a method once, they cannot maintain it because of shortage of money, and in the meantime the woman becomes pregnant. Women use only those methods that are bought by their husbands from the market, like pills or injections, and there is nobody to guide them in their use.

Everyone is like us in our village: leading their lives with a lot of difficulty. Even if we buy a method one time, we cannot buy it a second time and when we leave it, we become pregnant. We don't know much but our husbands bring methods for us that we can use easily at home, such as pills.

Some couples in the community opt to use injections, despite the fact that no female service provider is available to administer them. In this situation, women visit an entirely untrained woman in the community whose success in administering injections is known to be uncertain.

If they bring an injection, first, there is no one to dispense it. In this village, there is one man who gives injections but our husbands don't allow us to have the injection from him. However, there is a woman in the community who gives injections; although she is not trained, she has learnt through experience. She gives us an injection but there is no guarantee that she has given it correctly. It is like (shooting) an arrow in the dark: if you happen to get it correctly, it is fine; otherwise we get lumps in our arms.

She may be illiterate, but her problems have forced Jamila to identify, quite accurately, the reasons why her community's need for family planning remains unmet, including distance from health facilities, financial constraints, cultural and religious discouragement, and fear of unmanageable side effects.

There are a lot of problems that act as hurdles in decision making and adopting family planning methods. Firstly, there is no easy access to methods as the medical store is in the city which is 40 kilometers away from us. It costs us money to come and go. It takes time as well because it takes one hour in coming and going.

The maulvis in the village say, 'You are limiting the followers of the Prophet, which is wrong and Allah will be angry.' 
Then, usually, the husband, mother-in-law and father-in-law do not agree because they want many sons and want their (wife or) daughter-in-law to produce a child every year-but boys; even if they have nine sons, they would not want a daughter. They want a son every year whether the daughter-in-law lives or dies.

Finally, if a woman has side effects with pills, then they cannot afford to get treatment because of poverty so they stop. This deters other women from using pills.

As she waits for the birth of her fourth baby, Jamila has no choice but to hope against hope that a family planning method will be easily available in her community after the delivery.

I would like to use a method if I can get it-pills, because they are the cheapest. This will help space my children; then my baby and I will stay healthy.

With its grinding poverty, geographical remoteness, and limited female mobility and decision-making, Jamila's village represents the type of community that has the highest need for local provision of family planning services. Addressing unmet need for contraception is critical in such communities, where chronic hunger forces couples to stand up to entrenched customs against birth control and to desperately seek, despite very limited means, ways to limit the number of mouths they have to feed. In such circumstances, the continued inaccessibility of both static facilities and LHWs becomes an enormity that must be redressed urgently. 


\section{A Wound Within}

\section{Unmanaged side effects are a core reason for discontinuation of contraceptive use}

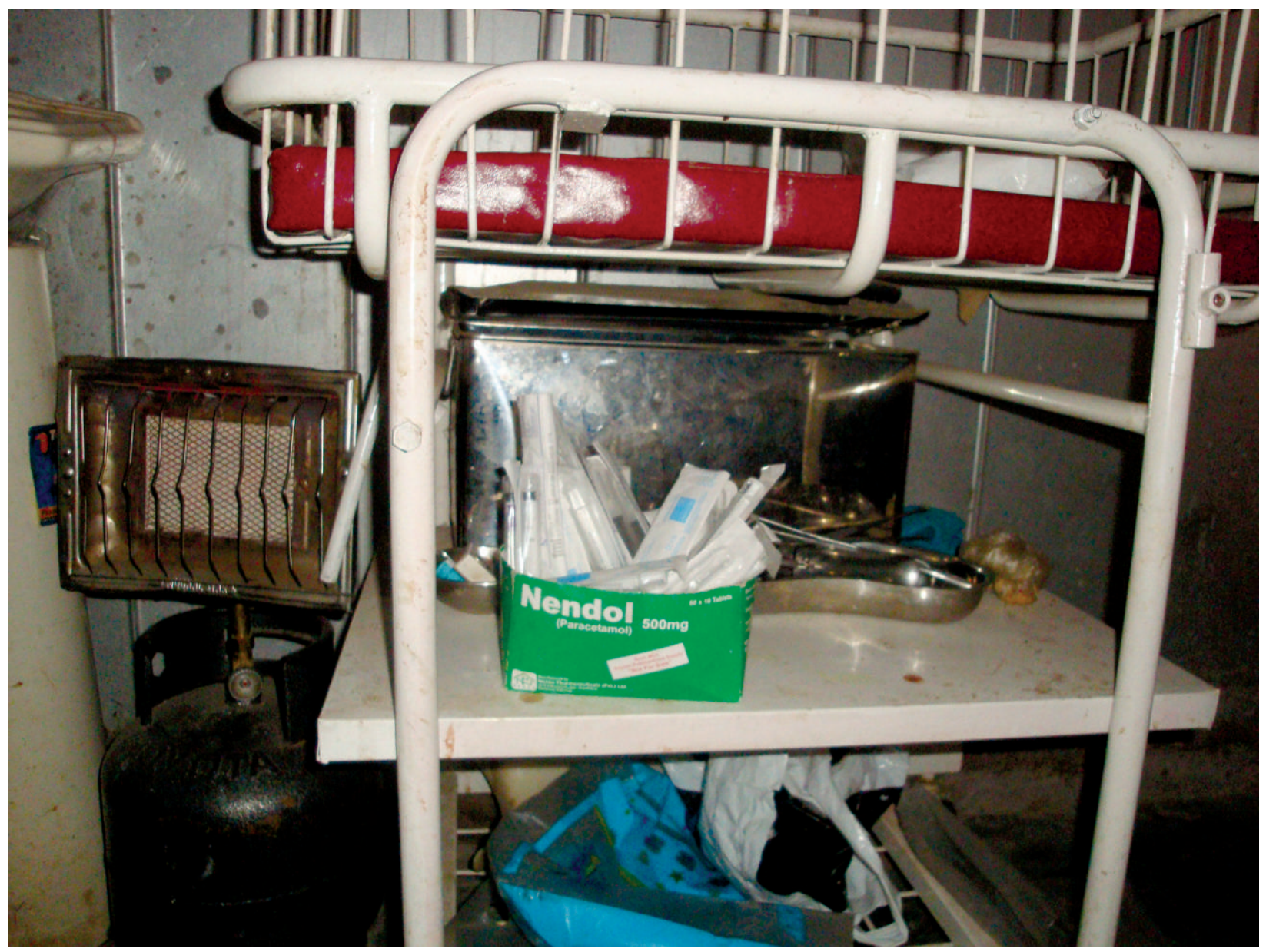

Tasleem, ${ }^{40} 42$, lives with her husband Ranoo and seven children in a small village of district Khairpur, Sindh. Although the village has no health facility of its own, it is served by a lady health worker. The nearest formal health facility is situated an hour's drive away; to visit it, villagers can take the government-provided van service, available once a day, or travel by motorcycles.

During the 26 years of her marriage, Tasleem has borne nine children, two of whom died in their infancy: her first-born lived only six days and her third son was eight months old. She has also had two pregnancies terminated. She conceived her first baby three months into her marriage, when she was 16 and there were no family planning services in her village. Four pregnancies followed in quick succession.

At that time, there was no facility available for spacing and we also did not know how to practice spacing. I was busy in my household work and did not get time as I was always stuck in household chores, children, and looking after the cows and cattle, etc.

After the fifth pregnancy, she decided to wait five to eight years before the next baby. She opted to use an intrauterine contraceptive device (IUCD), and, in the absence of other easily accessible services, went to a local dai (untrained provider), to have it inserted. Unfortunately, she began bleeding heavily afterwards, and this led

40 Names have been changed to protect respondents' privacy. 
to great weakness. She was unable to perform her chores as before, or to take care of her children. Distressed by the physical side effects, as well as their impact on her life, she had the IUCD removed after about a year.

When I kept the 'chala' (IUCD), I went through a lot of pain. I had a feeling that something was eating at me from inside and I had no strength. I stopped using the chala because, after a year, I started getting more periods and also white discharge. I had a feeling that I cannot breathe and there is some wound within my body. I started feeling uneasy-that's why I removed it. After this, I did not use any kind of family planning method.

Her own painful experience made Tasleem more receptive to stories of other women's negative experiences of using contraceptives. Such anecdotes reinforced her resolve to refrain from the use of contraceptives.

I did not use any method because I had heard that one woman had adopted family planning, due to which she got sick and was taken to Karachi for treatment, where she died. I was so afraid that I did not adopt any contraceptive method again.

Explaining why she did not seek the help of qualified family planning service providers, Tasleem says such services are too far away and, at any rate, the services offered by the public facilities are poor. She feels services providers at public facilities behave badly, talking down to clients very rudely, and not giving proper attention or time.

We don't go to government hospitals because when you go there, they don't take good care. They (service providers, especially lady doctors) consider themselves very important and are very proud ... When someone goes there, they spend money, but even then, neither are good medicines given, nor proper care. They give one tablet which is not even effective, and the 'drip' (intravenous solution) contains only water, which is not beneficial at all. I had an ultrasound done for 250 rupees but they took 5-10 hours to give the report. No woman goes there now. The facility opens at around 10:00 a.m. and closes by 2:00 p.m.

After having the IUCD removed, Tasleem conceived six more times. Afraid to use any family planning method in case there were complications and unable to bear and take care of so many children, she had two of her pregnancies terminated. Her last pregnancy was aborted the year preceding the interview. She now regrets the decision.

Frequent pregnancies and abortion made me very weak. I did not have breast milk. I also became very sick; I had no strength at all for doing household chores or any other work. Moreover we are also very poor and nowadays things are getting expensive, and it gets hard to raise your kids properly. That is why I had two induced abortions, although this is not good. It's not a small thing; it's a big thing to abort your baby.

Tasleem's story encapsulates the multifaceted odds many women face in using family planning methods, especially in rural parts of the country. Lack of access to health services made her turn to an untrained professional to use an IUCD. When she found herself facing debilitating side effects, she could not hope for help from public hospitals because of the poor way in which she had been treated in the past. As she suffered alone with no help in managing the side effects, her fears were bolstered by stories of other women's painful experiences of using modern contraceptives, and she finally decided to abandon all family planning altogether.

Tasleem has since borne four unplanned children and terminated two pregnancies. The latter decision still haunts her, and she has decided not to abort her pregnancy again if she conceives. However, she remains resolved to not practice any family planning method: fear of side effects outweighs the fear of having yet another unwanted child. 


\section{Men's Conflicts}

\section{Husbands face multiple pressures, doubts and fears about family planning methods}

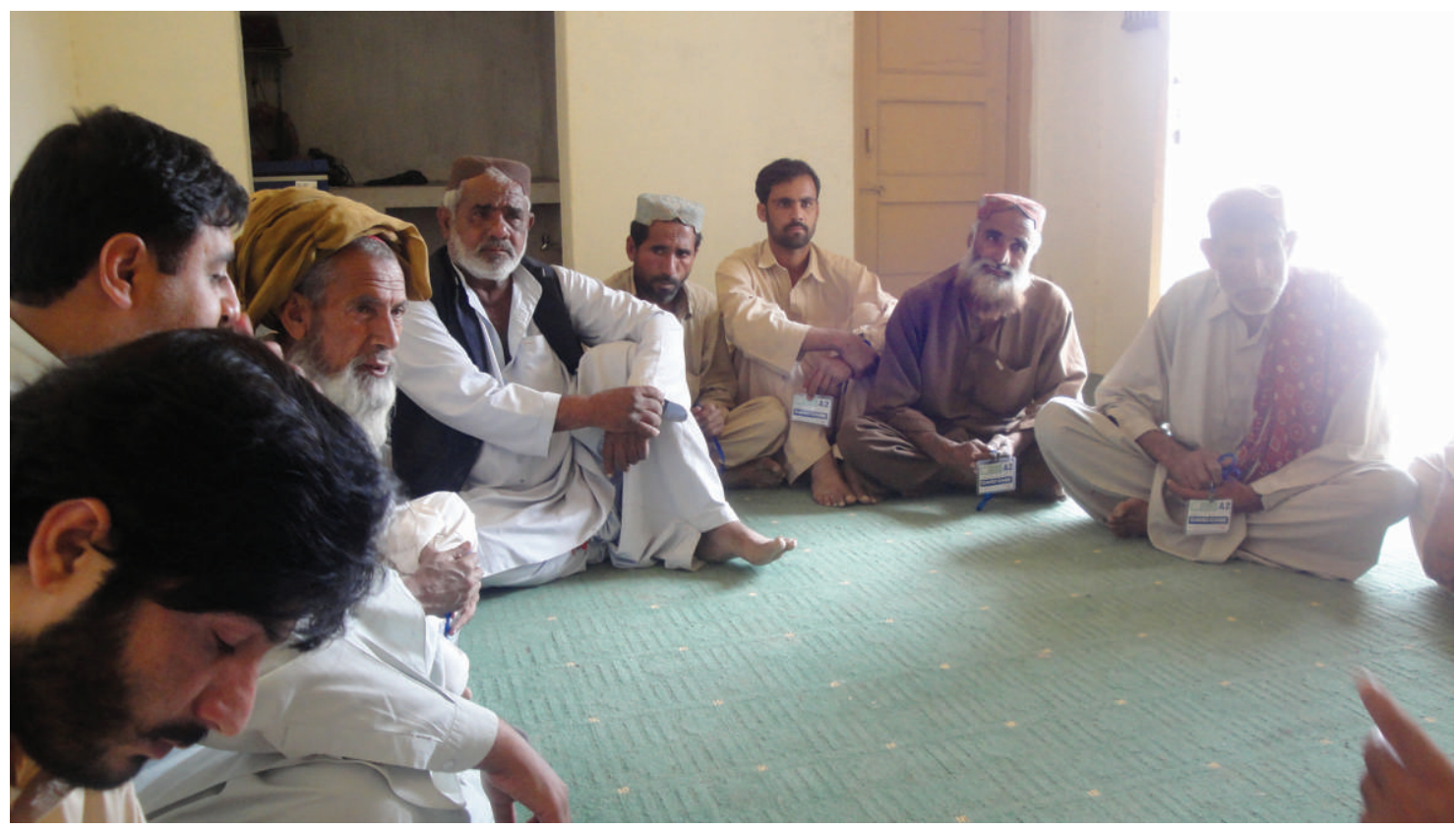

Ali, ${ }^{41}$ 36, lives in an urban area in Khyber Pakhtunkhwa, with his wife and four children and his extended family. Ali is a graduate and works as a clerk. His wife, 31, has studied till tenth grade and is a housewife. They have been married for twelve years but do not practice any family planning method, even though all types of facilities are available in their community of 12,000 .

Ali's wife became pregnant in the fifth month of their marriage, and their youngest child is now three years old. To date, Ali has not discussed family planning methods with his wife. He says there are many reasons for this, the first being that he belongs to a religious family that considers family planning a sin.

Mostly I have heard from the religious clerics that family planning is not a good thing because it is a murder; finishing a life is a murder.

His next consideration is that he is his parents' only son. A shortage of male members in the family is considered a disadvantage in many parts of the country, as well as a genealogical risk. Therefore, Ali's parents want him to have as many sons as possible, and are not in favor of family planning.

My parents do not believe in birth spacing. The reason is that I am the only son of my parents. They want me to have as many children as possible because that would be good for me.

Thirdly, Ali has financial constraints. Working as a clerk in an office, he does not earn enough to spare money for visiting health facilities and purchasing family planning methods.

Our financial condition has been bad from the start. We did not have enough resources to go to any center or facility and get information from there or buy something with money.

\footnotetext{
${ }^{41}$ Names have been changed to protect respondents' privacy.
} 
While the above three reasons have to do with his own preferences and circumstances, the remaining reasons Ali lists are concerns about the supply side of family planning-specifically, the quality of products and services available, and the potential health impacts of availing these products and services.

Thus, Ali's fourth reason for avoiding family planning is that, in his view, the quality of contraceptives available in the public facilities and in markets is poor, and he fears they will harm his wife's health.

I am not satisfied by the standard of the facilities because all these things (contraceptives) are artificial (imitations) in the market and harmful. If the government provides us with a thing, then it is certain that there will be something more fake about it. If we were to use these things for some time or some advantage ... the life of the wife could be affected ... we do not want to ruin the life of family members.

Fifthly, Ali says he is not satisfied that the staff who provide family planning services are suitably qualified. In this regard, he mentions the lady health worker (LHW) who provides contraceptives to his community. According to him, she mostly distributes only pills, and does not know how to manage their side effects.

The staff available from the government is not up to the standard, like the lady health worker who visits houses: she does not have much education and not enough experience through which she can properly perform her job and provide help in the proper manner. Often, she has one kind of pill which she gives to every woman. The pill suits some women, while, for others, they can have some reaction, because everything has a side effect. This is the reason why we have not used any method till now.

Ali is particularly apprehensive about the side effects of various family planning methods, and speaks at length about his fears concerning pills, injectables and condoms. He is concerned that while the hormonal methods can upset the menstrual cycle and cause prolonged bleeding and weight gain, condoms are unreliable and can cause skin irritation.

There is mostly something else added in the medicines. We cannot do this-that just for the advantage of one or two years, we give harm to our wife. Because of these things any side effect can occur at any time. There is another method being used a lot in the area, which is the condom. If the condom is evaluated then, in my opinion, it does not have any kind of guarantee that it would prevent pregnancy because it is not of good quality and it can break any time. There are different kinds of chemicals included in it. People can get skin irritation because of it and some other harm can be caused by it at any time. That is why we cannot create problems for ourselves, because of this reason we do not want to use this.

Different kinds of chemicals are also included in the pills and injection, due to which side effects occur in the body. Periods get disturbed, meaning that they become irregular, and along with this, often, the blood keeps on flowing continuously (prolonged periods). The weight also increases ... So these methods also have many problems. That is why we want to stay far away from these methods.

Ali is aware about the option of sterilization, but rejects it because it is permanent, and he does not want to close the door to the possibility of having more children.

We cannot get the operation done. As I said before, if we want to have children in the future, then what (would it feel like) if the whole process is eliminated and we are sitting on empty ground (in regret)?

The case of Ali demonstrates how a host of demand- and supply-side factors can converge to complicate family planning decisions for even educated and relatively better informed men. The multifaceted doubts faced by men like Ali demand an equally sophisticated response.

This calls for awareness building efforts to remove misperceptions about religious obstacles; to begin with, prevention of pregnancy needs to be distinguished clearly from the more complex issue of abortions. Likewise, apart from the desirability of smaller families, the health benefits of simply spacing births for mothers and children need to be highlighted. In the long run, a responsible and responsive health care system will address many of the apprehensions men currently harbor about family planning. 


\section{Treated "like Dogs"}

\section{Poor quality of care at public facilities discourages women who adopt family planning methods}

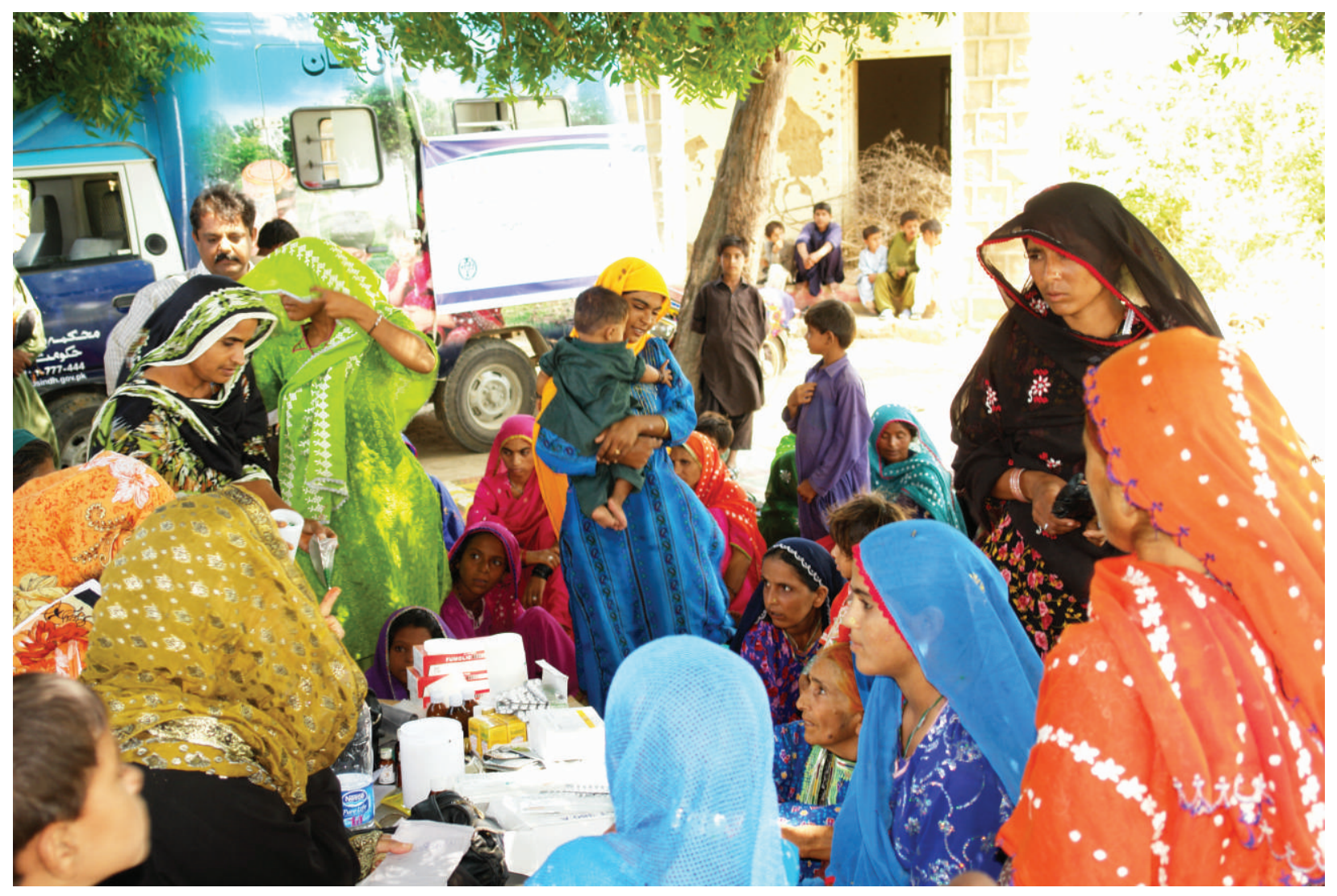

Khalda, ${ }^{42}$ 35, lives in a small village in district Rahim Yar Khan, Punjab, with her eight children, husband and his family. She is a housewife, while her 38-year-old husband works on farms. Although she is illiterate, Khalda is knowledgeable about reproductive health issues because a lady health worker, Nasreen, provides family planning information and services in the community.

Khalda was 15 when she got married. Her first six children, a son-the first-born-and five daughters, were born without any attempt at spacing as the couple wanted more sons. But after five daughters, Khalda was weak and wanted to wait a few years before the next baby. She went to a health facility and had an intrauterine contraceptive device (IUCD) inserted.

After a respite of five years, she had the IUCD removed. Two months later, she was expecting again, but again a daughter was born. The couple made another attempt for a son, and had their seventh daughter. After eight children, her husband was still in favor of trying again, but Khalda felt that her health and the family's finances would not be able to bear the load of another child; she made the difficult decision to have a tubal ligation.

I was totally in favor of family planning and wanted to stop having more kids. I got the tubal ligation, when my eighth daughter was three months old although my husband did not agree with me for the

42 Names have been changed to protect respondents' privacy. 
operation. He said, 'What if we have a son next time.' Many community women also said not to go for family planning.

Notwithstanding attempts by her husband and neighbors to dissuade her, Khalda talked to the LHW about tubal ligation who took her for surgery.

At the difficult and stressful time of her operation, Khalda found herself treated with extreme rudeness and contempt by hospital staff, including the doctor. She was scolded even while on the operating table.

She was being very rude, and scolding me, and saying lot of things like, "Why are you not taking proper deep breaths? Your operation will not go well; then keep on producing kids.' She was scolding me so much, I cannot describe it.

Private hospitals are better than this. A person goes to hospital after so much effort; at least the operation should be successful. In the government hospitals, they treat you like dogs. The staff of the hospital is very rude and they say that go back home and keep on producing kids. They told me to get up from the operating table and leave.

Her ordeal did not end here. The operation was not successful: only one tube was tied, either due to the poor skill of the doctor or carelessness. The staff of the facility did not even inform her that the operation was incomplete and she could become pregnant.

After taking my history and thumb impression, they did my operation. They did not tell me that only half of the operation had been done. I was unconscious and lying on a bed, and they gave me an injection. My daughter was with me. When I regained consciousness, the nurse who was with me told Nasreen (the LHW) that there is a chance that I could get pregnant again. So they have given me a three-month injection and asked her to continue giving me the injection. LHW Nasreen gave me the three-monthly injection only yesterday.

After a painful, humiliating and failed surgery, Khalda found herself facing a plethora of health problems that interfered with every aspect of her life and made it difficult for her to attend to the needs of her small children, husband and the household.

My operation went wrong. I had an infection. I don't know where the stitches went. My abdomen was divided into two parts. The wound was so big, it used to scare me. Whoever saw it said, 'What have you done to yourself? What will happen now?' I was really worried. When I went to the doctor for treatment, she scolded me and said that it was my fault; I had not looked after the wound properly.

I had small kids and my youngest was three months old. I could not do the household chores. I was in pain and the operation had not been done properly. My household responsibilities were affected because there was no one to take care of my little kids and feed them on time. When these kinds of problems arise, it does pose a problem. The entire system of one's life gets disrupted. How can a woman sit and relax when she has to look after the little kids, take care of the household, look after husband and work in the fields. I was told not to lift heavy weights after my operation but what can one do? If I do not do it, who else will?

The failed operation and its aftermath exacerbated the very problems Khalda had sought to alleviate. She struggled to keep up with the demands of her household and personal life. The expenses she had tried to stem through tubal ligation spiraled out of control because she now needed treatment from a good private doctor. She had to visit the doctor many times for examinations and medicine. Beside the expenditure on her treatment, she had to leave her children alone every time she visited the doctor, which upset her greatly. Mentally, physically and financially, the operation had achieved nothing except causing great distress.

I kept on taking medicines for forty days, and had three injections. The infection started to dry out. One pill for one time cost me 40 to 50 rupees. It caused a lot of problems, and our expenses increased to two or three times more. We had the operation thinking that it will cost us nothing, but we ended up paying more money. After I had the operation, three to five hundred more rupees were spent. Then the nurse 
over here gave me three injections worth three hundred rupees each. She also gave me a good wound healing cream which cost 240 rupees. She also gave me a powder to apply on the wounds and another tablet that dries the wound was worth 50- 60 rupees, which I had to take twice a day. A lot of money was spent on my treatment; much more than we had expected. Our household conditions were affected and there was a problem of money.

Khalda's case demonstrates how poor quality of care at health facilities can wreak havoc-physically, mentally and financially-in the lives of poor women who overcome great personal odds to opt for sterilization in the first place. Only one such case of complications and method failure is sufficient to convince scores of other women that a method is not worth the risks. Moreover, the case highlights why poor attitudes among service providers must be addressed, especially at public sector health facilities. Lack of sympathy and negligence are unethical and to be deplored, not only for causing tribulation to patients, but also for engendering an abiding distrust in public facilities among the women who need them most. 


\section{Fighting against the Odds of discontinuation}

\section{Side effects, and their social and financial impacts, cause frequent switching and discontinuation of contraceptive methods}

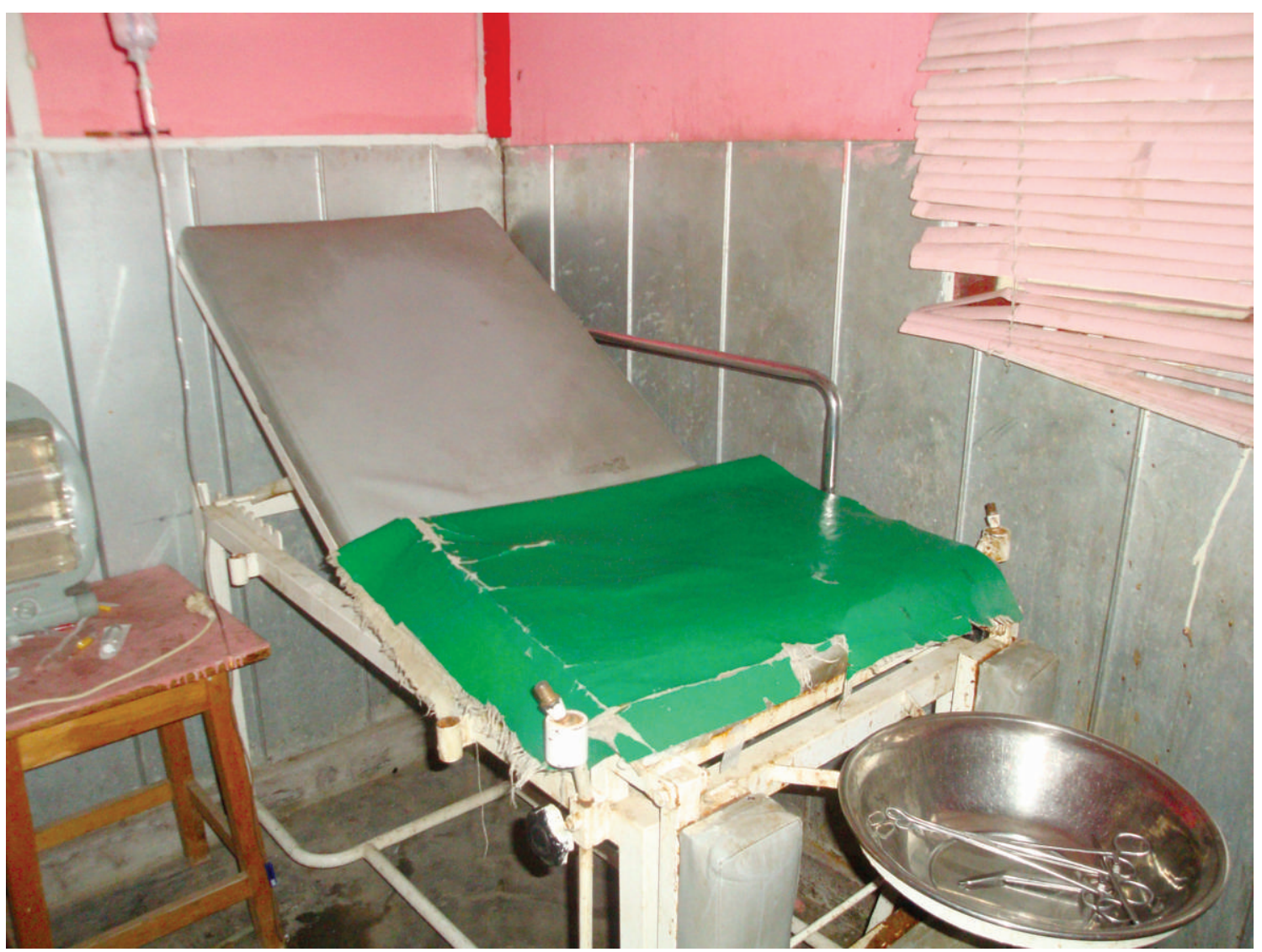

Ameer Ali,43 35, lives in Allahabad, a large village in Khyber Pakhtunkhwa, with his wife and two children in his parents' household. Ameer is a graduate and runs a shop to earn his living. His wife, 30 , has studied till seventh grade and is a housewife. Although they belong to a fairly religious community that generally frowns upon family planning, the couple has attempted to space their children from the beginning.

Allahabad is a relatively well developed village with a population of 16,000 . The men of the community work privately in agriculture or as daily-wage laborers, while some women are working in the public sector and others earn supplemental incomes through embroidery and stitching. In terms of health facilities, the area is well served. The tehsil hospital is situated just a kilometer away, while the district hospital is also at a distance of only 5 kilometers and can be reached by wagons, tongas, pickup vans and motorcycles. The community is also provided local health and family planning services by a lady health visitor (LHV), a dispenser, and a lady health worker (LHW). Traditional providers, including a hakim and untrained midwives ('dais'), are also available in the area.

Ameer Ali's wife became pregnant after four months of marriage and delivered a son. His second child, a daughter, is now two years old. Since the LHW provides door-to-door services in his community, Ameer is

43 Names have been changed to protect respondents' privacy. 
knowledgeable regarding family planning methods. After the birth of his first child, he decided to use some contraceptive methods to delay the next pregnancy and thereby protect the health of his wife and infant son. He consulted his wife and she agreed.

The decision was taken by both of us but I started the conversation. I had to take care of the health of the mother and child. There was no disagreement of any kind between us.

For two years after their first child was born, Ameer Ali's wife used injectables that were provided by the LHW. Unfortunately, she experienced severe side effects in the form of heavy and irregular bleeding. This affected her health and disturbed their marital life. As her health suffered, she was unable to pay full attention to her son and his health was also affected.

We used the injection for the first two years but it caused a lot of problems. Her periods started again and again. My wife remained sick often-even our marital life was affected to some extent, and secondly the child was young and he was not being given proper care. My wife's health was getting worse day by day.

The side effects also had an impact on their personal, financial and social life. Ameer needed to spend a lot of money on treatment for his wife, and would find himself short of money for food and other household expenses. Her health problems prevented her from attending family gatherings too. Tired of coping with the physical side effects and their negative impact on their conjugal, family, social and financial life, they decided to stop the use of injections.

Another problem was that my financial condition was getting very bad as we had to go to the doctors for treatment again and again. Whatever I earned I spent on her. There was not just the sickness in the house that had to be taken care of; there were other needs too, like food and other expenditures. Other than this, she could not go to any relatives' house for attending family gatherings. That is why we stopped using the injection; after that her condition returned to normal.

After discontinuing the use of injectables, his wife's health improved. But the couple remained resolved to delay the next pregnancy. Therefore, Ameer decided to use condoms and discussed this with his wife. She agreed.

Unfortunately, the method switch did not suit the couple either. Ameer bought condoms from the market and used them for two years. However, the method gave him less satisfaction and caused him skin irritation. Eventually he discontinued this method too. His wife got pregnant and delivered a baby girl, who is now two years old.

I did not get much pleasure in using the condom and also had irritation a lot of times because of using condom. It caused a lot of pain for one or two weeks; otherwise, it was better than the injection.

Ameer is not currently using any family planning method; he is deeply discouraged by the problems he and his wife faced, first from injectables and then from condoms.

My wife had many (health) problems and I had irritation. My financial condition got worse; I did not have enough money for treatment and there were many other problems (social, conjugal, etc.). So, for these reasons, I am not using any method these days.

However, despite his past disappointments, and notwithstanding the pressure of religious elements in his community against family planning, Ameer remains concerned about the health of his wife and future children and is willing to use contraceptive methods to delay pregnancies. His condition, however, is that the methods must be safe and free of side effects. 
Yes, we want to use a contraceptive but it should be safe and not have side effects, and (it should) be cheap. It should be easily accessible. I am considering the benefits and the health of my wife and children.

Ameer Ali's case highlights the predicament of couples who overcome social and religious barriers to proactively seek family planning services, only to find themselves facing unexpected, and at times frightening, physical side effects that deteriorate their quality of life, drain their limited resources, and generally strain their marital and social relationships. Determined couples may switch to other methods at first, but when even these prove to have side effects, disillusionment can set in and the desire to find ways to space children can be replaced by a resignation to unwanted pregnancies. As the core reason for switching and discontinuation of contraceptive methods among otherwise willing and motivated couples, the issue of side effects should be addressed through all possible means, such as introduction of better quality products, and training of service providers to provide preparatory counseling before first use, as well as effective side effect management advice and care. 


\section{‘Ghost' Providers}

\section{When female service providers are chronically absent, family planning services come to a standstill}

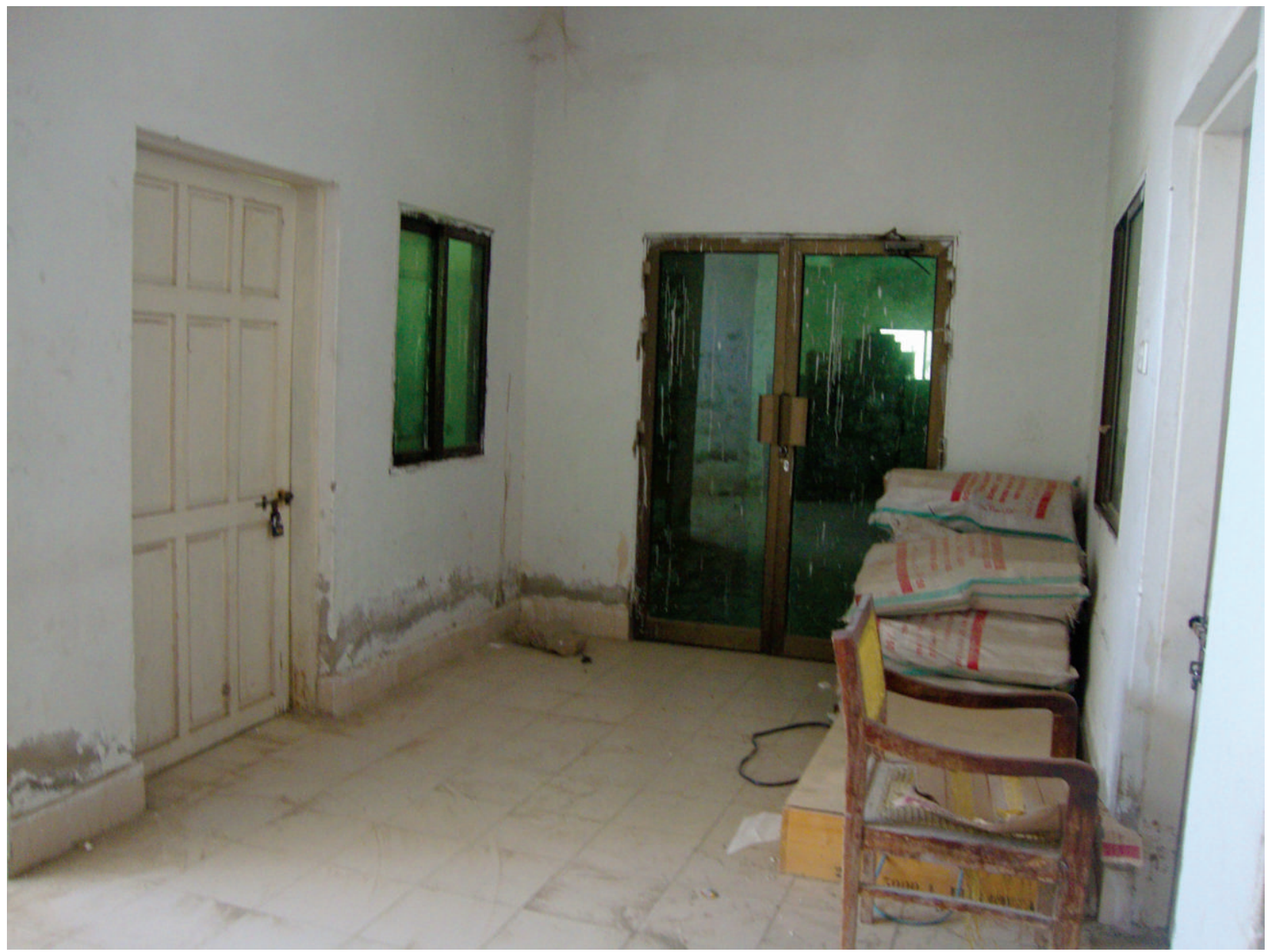

A public-sector rural health center (RHC) situated 20 kilometers away from the tehsil hospital (THQ) and 50 kilometers away from the district hospital (DHQ) presents a strange scenario. All basic amenities, such as electricity and water, appear to be available; although the condition of the building is poor and it is not clean, it is staffed and equipped. However, no family planning clients visit the facility.

The service providers appointed to work at the RHC include two male doctors, one for the morning shift and the other for the evening; one female doctor; a (male) dispenser; a male health technician; a lady health visitor (LHV); and a female nurse. However, the three female staff reportedly never show up for work: a female doctor is appointed in this facility but she is serving in any other facility; no explanation is available for the constant absence of the LHV and the nurse.

The effect of the female staff's absence is striking. Required gynecological and obstetrical equipment is available but not being used: it sits packed in boxes because no female provider is available to provide family planning or gynecological services. Only the examination couch and a bowl are utilized. A large number of delivery kits and contraceptives are stored away in boxes in the store, and the store keeper does not have sufficient knowledge about the inventory. 
Since people no longer visit the facility for family planning services, the previous month's consumption of contraceptives was zero. According to the dispenser, the facility did not request any contraceptives the previous year for the same reason. On the day of visit, the facility had 7,000 condoms, 600 oral pills, 600 injectables and 160 intrauterine contraceptive devices (IUCDs) available, still packed in boxes.

These observations indicate how crucial the presence of female service providers is if a health facility is to provide family planning services. In their absence, very limited services can be provided to the women of the communities the RHC is intended to serve. The medical officer on duty informed the study team that he treats antenatal and anemic clients; beyond that he cannot provide any family planning-related service to female clients.

The field team visited the facility twice. On the day of its first visit, on March 21, 2014, the team found the RHC open, with the dispenser, store keeper, sweeper, guard and some general patients present. A ward attendant told the team that family planning services were provided by the LHV and nurse, but they would not be in that day because it was Friday (a day when public facilities close early).

The team revisited the $\mathrm{RHC}$ five days later because the information it had collected was incomplete. The environment of the RHC was the same. There was no female service provider. The team met the medical officer, who had been working there for eight months but had no family planning training.

On the previous visit, staff had seemed uncomfortable in providing information but on the second visit they explained in detail that, eight years ago, a woman medical officer had been appointed and in her presence there had been a heavy case load, and she had also provided family planning services. But all that had changed four years ago, when she was transferred from the RHC. An LHV had been posted there for the past 16 years but she only visited the center once in this duration. The staff nurse also did not come to the RHC because she had connections with senior persons in the department and was not penalized for her absence. Therefore, there were no gynecological patients at the RHC.

The medical officer confessed he had never seen the LHV. Some local people living in surrounding area also told the team that the LHV and staff nurse had not visited the RHC for the past two years. According to the staff, the issue was known to the district manager but no action had been taken. The team was requested to convey the problem to a higher authority. 


\section{Between a Rock and a Hard Place}

\section{While local maulvis discourage people from family planning, health facilities also fail to attract clientele through good quality services}

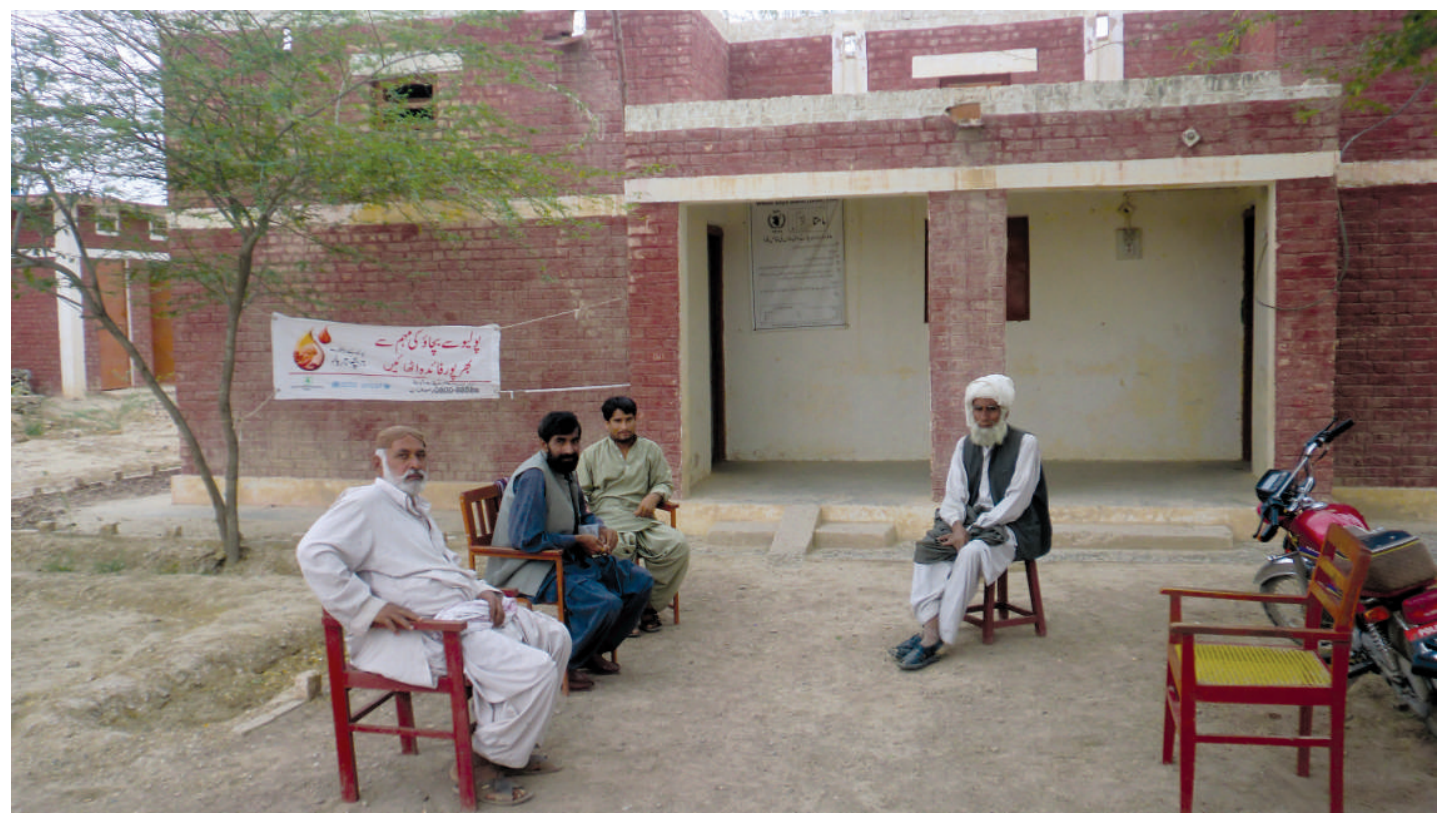

Dr. Parveen, ${ }^{44} 43$, works as a gynecologist at a large 240-bed private hospital in Punjab. Equivalent in scale to a tehsil headquarters (THQ) hospital, the facility is clean, open 24 hours, and adequately staffed. A wide range of modern, functioning equipment is available, as is a ready supply of family planning methods: Greenstar provides the contraceptive services at the facility and has also posted one of its nurses at the facility to counsel women.

In her 11-year career, Dr. Parveen has worked in both the public and the private sector. In her view, the key reasons for low use of family planning methods include religious discouragement, cultural pressure to have more sons, restrictions on female mobility, and irregular supply of contraceptives at health facilities, especially in the public sector.

In Dr. Parveen's view, Islam prohibits some but not all contraceptive methods. Birth spacing is allowed, but not permanent methods such as tubal ligation and vasectomy. In some situations, she believes, it is also impermissible to use intrauterine contraceptive devices (IUCDs). Although she comes from a very religious family, she and her husband, who holds an MBA and is a pharmacist, use contraceptives. A user of pills herself, she prefers to prescribe implants for her clients due to their fewer side effects. She does not advise injections to her clients as they cause heavy bleeding in most women.

When you are in a health facility, you should assess what causes more side effects. When I used to see patients in Nishtar Hospital, injectable clients would complain of heavy bleeding. Injectables used to really scare the clients. I used to give them different options but they never accepted injectables because of fear of side effects.

\footnotetext{
44 Names have been changed to protect respondents' privacy.
} 
In her opinion, wholesale rejection of family planning on religious grounds is an extreme view propagated by "the Taliban" and local religious leaders who lack knowledge and information. They succeed in generating misconceptions among people who are poor, illiterate, and relatively less knowledgeable about their faith. In such situations, it becomes incumbent on service providers to provide correct information, and guide people in changing their minds in favor of family planning.

It is the Taliban who say that this shouldn't happen because this is "haram" (forbidden). Islam says that whatever is destined will happen. But a person should only do what he can manage. If he bears 10 children and throws them on the road for begging, well, that is wrong to the child, isn't it?

Notwithstanding religious pressures, Dr. Parveen says, most people do start using family planning methods after they have four children-provided they have sons. A son is considered a source of security and earning in old age, and most families want to ensure they have at least two.

Usually, the parents-in-law do not allow family planning. There is pressure from the family. They think two children are not enough. There should be at least two sons. If a woman has three daughters, then she will have six just in trying to have a son.

Dr. Parveen feels that people generally want to use family planning methods but-given the religious, cultural and financial impediments-the methods should be available at their doorstep. This is particularly important because women have no decision-making power and their cultural norms do not allow them to go out freely.

The main reason is that women have no power to make decisions and have limited mobility. The second reason is that they cannot access it (family planning) at their doorsteps.

In her own experience, Dr. Parveen has found private sector facilities to be more responsive to the needs of clients than public facilities. Apart from offering more dedication and attention to clients, private providers appear to have better contraceptive supply arrangements. At the public facility she used to work at, supply of contraceptives was a great challenge and there was a chronic shortage of methods, which often left clients in the lurch.

In government facilities, supply is not regular or continuous. I have worked for 2-3 months at a BHU (basic health unit). One month they have all the supplies, but the next month, there are none. That is the problem. If a person is using condoms or pills, and if the supply is interrupted for next six months, then that is a problem for the client.

Dr. Parveen's observations indicate that while religious and cultural resistance persists, households can be pragmatic in their family planning decisions, and are willing to use contraceptives after some time. However, their ability to do so is hindered by the non-availability and non-accessibility of a regular supply of contraceptives. Ensuring a smooth supply of contraceptives to all grassroots facilities, and especially to the lady health workers who supply more remote communities, could go a long way in increasing contraceptive use and preventing couples from discontinuing. 


\section{On Shaky Ground}

\section{Service providers' personal beliefs and limited technical knowledge affect the extent and quality of care they provide}

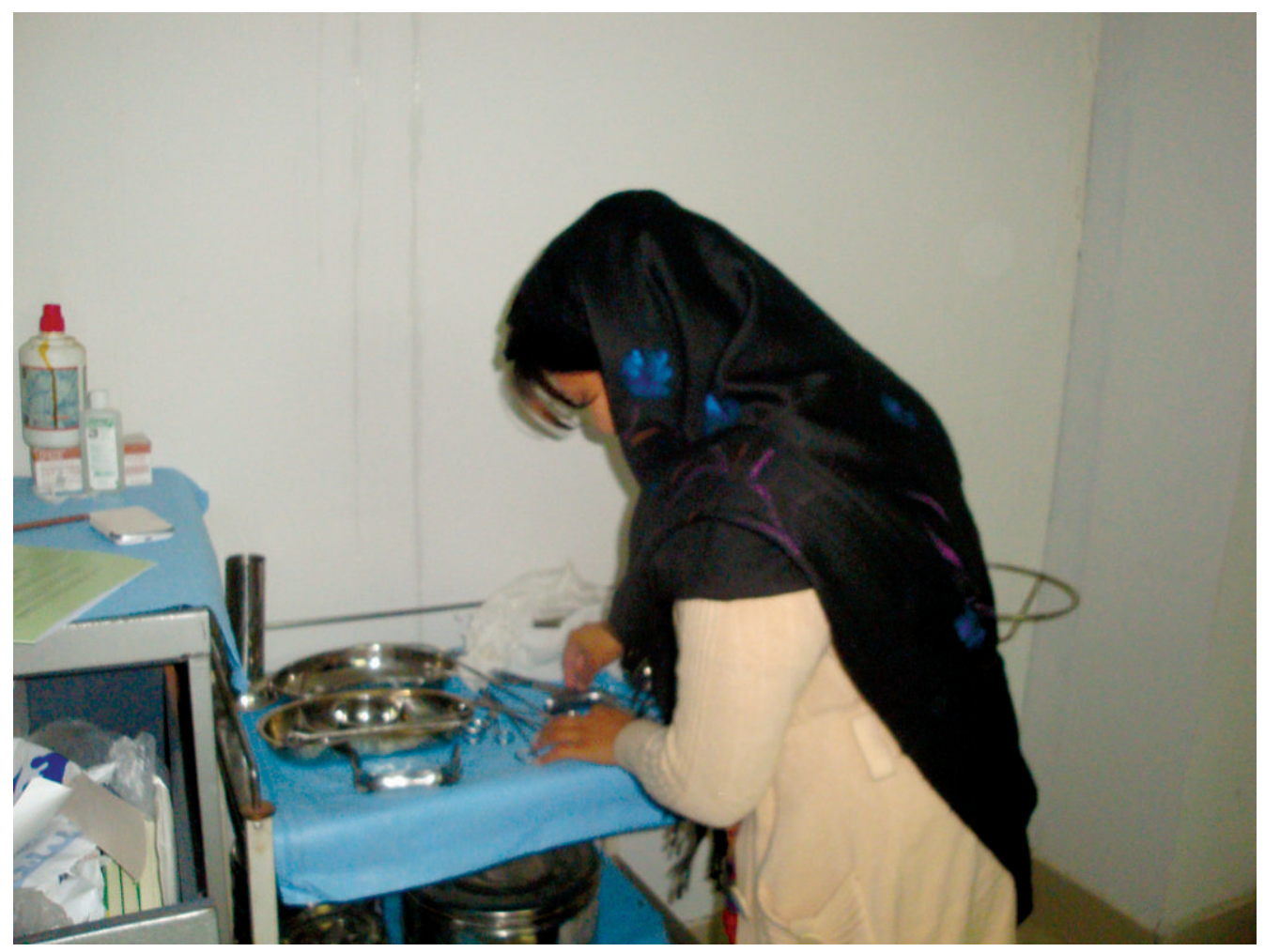

For the past 16 years, Farhana, 45 42, has been working as a lady health visitor (LHV) at a basic health unit (BHU) in district Mardan, Khyber Pakhtunkhwa. She is trained in the insertion and removal of intrauterine contraceptive devices (IUCD), counseling techniques, contraceptive management, and client-centered family planning.

Housed inside a mother and child health center $(\mathrm{MCH})$ and located in a very scenic hilly area, the BHU has a wide range of functioning equipment available. The staff is very cooperative, and contraceptive methods are readily available.

Farhana listed the main reasons why women in her community did not use contraceptives or discontinued their use. Most of the people, she explained, are poor and uneducated, with little information about the nature and benefits of family planning. Moreover, since they live in a hilly area with no system for regular transport, physically accessing health facilities can be a challenge. Some of the BHU's own clients come from remote communities that have no local facilities or service providers; the problem of physical distance is compounded by the difficult terrain, lack of transport and resources. In the rainy season, in particular, access is nearly impossible for some clients.

One of our clients (a pill user) belonging to a faraway area could not come (for resupply) due to heavy rains and she had to discontinue. This time, when she came, she was pregnant. Here, people are poor and transport is another issue for them due to which they have to discontinue family planning methods.

Farhana also attributes low contraceptive use to social and religious pressures. In her view, husbands are mostly against family planning, and women cannot reach health facilities without their permission. Some

\footnotetext{
45 Names have been changed to protect respondents' privacy.
} 
women do not practice family planning methods as they want to have a son. Others are not permitted by their mothers-in-law to use contraceptives. In addition, religious leaders, such as maulvis, consider use of contraceptives to be a sin and discourage people during sermons in mosques. These pressures add up to a difficult environment for family planning.

They (people of the community) want to know why you are not producing kids.

Fear of side effects is also a major reason why women avoid using contraceptives. According to Farhana, most women believe in rumors very quickly, and are susceptible to misconceptions regarding family planning methods and their side effects. If they use pills, they fear they will develop breast cancer and the irregular bleeding they experience will become a permanent pattern.

At times, supply-side issues can also hinder use of contraceptives. Stocks of specific methods may run out, and then clients have to be prescribed another method or are told to visit the next day. By the time many clients return though, it is too late-they are already pregnant. Farhana notes that this problem applies particularly to injectables.

Usually, we always have contraceptives available. Sometimes, if a woman comes to us who wants an injection and we are out of it, we tell her to use pills meanwhile and ask her to come back after two days. However, the woman will come back after a month and will usually be pregnant.

Married to a teacher at a government school, Farhana has three children and is currently an IUCD user. In the past, she has used injections, pills and condoms. She left all these methods due to side effects or other problems. According to her, it was difficult to remember to take pills regularly; moreover, they caused headaches; weight gain; and mental problems. She tried condoms, but one of them ruptured, and she decided it was not safe enough. She also took injections but discontinued their use due to heavy bleeding and irregularity in menses.

Injections would lead to irregular cycles and weight gain. The same side effects were caused by pills. Also, sometimes I would forget to take them. Then I also had a mental problem, so the doctor told me to stop using them. I also used the condom, but it ruptured, so we stopped using it.

At the time of the interview, Farhana had been using an IUCD for the past 15 days. She had decided that if the method did not suit her, she would get an implant, which she believed was a good method.

As she serves communities where there is considerable social and religious pressure against family planning, Farhana's own beliefs in this matter are important. She believes that Islam permits Muslims to practice family planning for two years after the birth of a child. In these intervals, a couple may adopt modern or traditional methods.

However, she also believes longer-term contraception is not acceptable and sterilization is prohibited altogether, both for women and for men. She does not suggest female sterilization to any client on her own, even if the clients have their husbands' approval. However, she refers women for this procedure when they voice their preference for it.

She is also against vasectomy, not only on religious grounds, but also because of her perception of gender roles.

The man is the king of the household. The woman has to bear children and face the problems.

Although Farhana is trained in family planning methods, her own history of method switching implies that she is not aware of ways to respond to the side effects of pills and injectables. This suggests that her knowledge about management of contraceptive side effects is insufficient, and the counseling she provides to women starting new methods or facing side effects is likely to be inadequate. It may be difficult for her to persuade clients to use methods that she herself has used and then discontinued.

Moreover, the service provider has a misconception that family planning methods are religiously permitted only for a limited duration of two years between child births. Her own disapproval of extended spacing could prevent her from providing adequate counsel to women who seek spacing for longer periods than two years. 


\section{Where there is no Doctor}

\section{The absence of a doctor severely limits the family planning services a facility can provide}

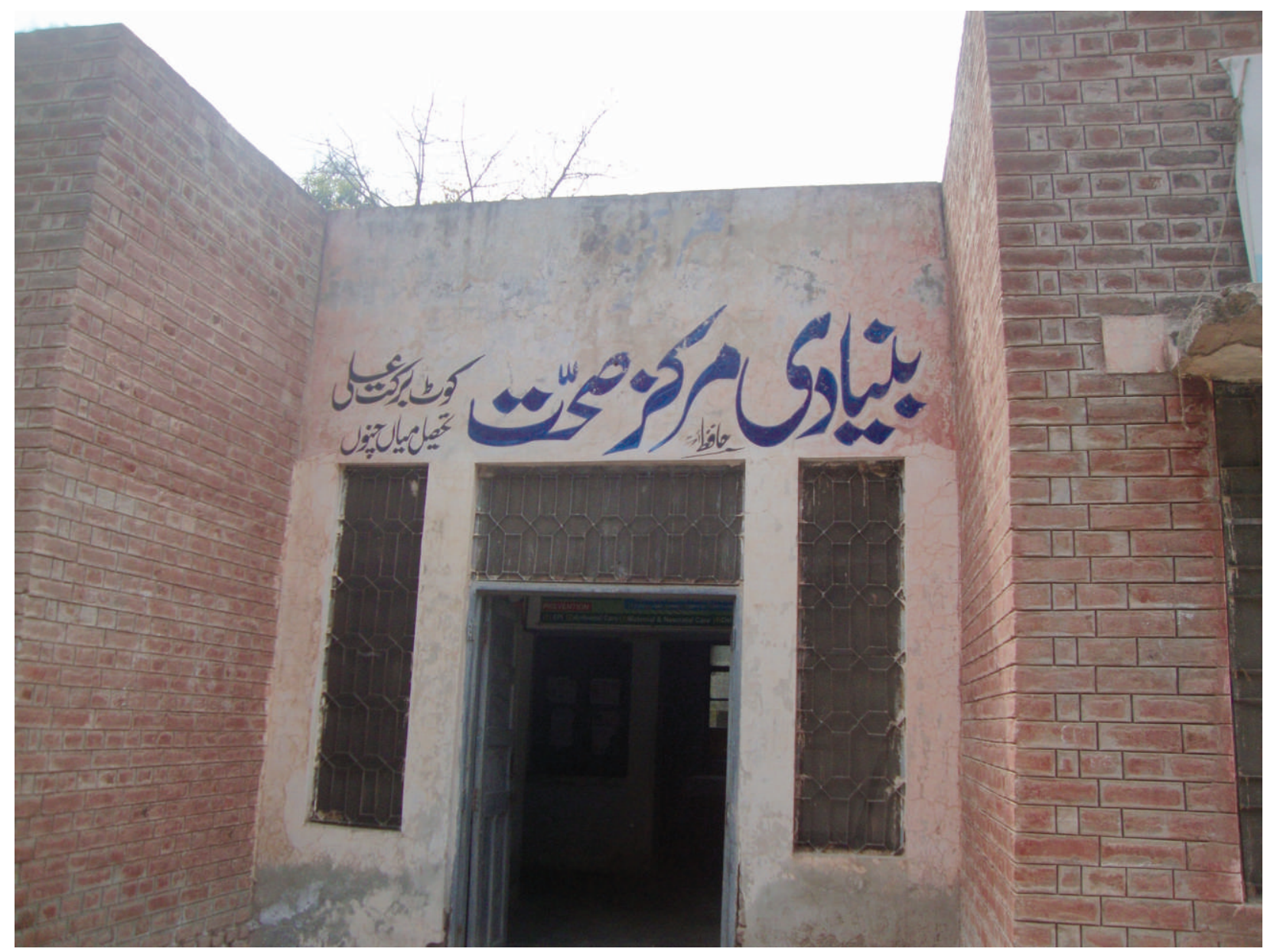

Farhan Ali,46 33, works as a dispenser at a large rural health center (RHC) in Sibi, Balochistan. The RHC is situated far from the district headquarters, in an area considered dangerous due to security threats from the Taliban, and a highly tribal culture. The building appears to be in good condition. All equipment, medicines, three types of contraceptives (pills, condoms and injections), and beds are available. However, the number of staff available is very small compared to the number of patients the facility is equipped to cater. In fact, Farhan is the only service provider currently employed by the RHC. He has been working here for 16 years.

Farhan admits that patients, especially women, have problems getting treatment at the RHC because no female service provider is working there. A lady doctor and a lady health visitor (LHV) were appointed for the past three years, but due to the dangerous location, they did not want to work there.

In the absence of essential staff members, Farhan Ali provides the family planning services that he can, which are limited. Although he holds a postgraduate science degree, he has not received any training related to family planning and has limited knowledge about contraceptive methods. In any case, as a man, he cannot provide any services to female clients, and he regrets that women who undertake the difficult trip to the facility have to be disappointed when they get there and find the facility unable to offer the assistance they need. The

\footnotetext{
46 Names have been changed to protect respondents' privacy.
} 
problem is compounded by the fact that there are no other facilities in the vicinity; to avail the full range of contraceptive services, women would need to travel 200 kilometers further to the district centers, Jacobabad or Sibi. Since transportation is expensive, and there are a host of other hurdles involved as well, most women just return home without having their reproductive needs met.

Farhan dispenses contraceptives of condoms, pills and injectables to clients. If the stock of any contraceptive runs out, as is sometimes the case with condoms, he notifies his department and, until the stock is replenished, refers clients to purchase contraceptives from the nearby market.

In his view, only about 30 percent of people in the area are in favor of family planning, and these are mostly migrants, Hindus or educated people; the majority of the native Baloch still adhere to tribal customs, which encourage large numbers of children, particularly sons. Farhan also notes that tribal customs are reinforced by religious misconceptions propagated by local religious leaders. Men are influenced and start believing that family planning is impermissible in Islam; they refuse to permit their wives to use contraceptives.

There is a Hafiz Mullah who tells one man, and then this spreads to four other men. This is how this rumor spreads. There are a lot of people who are not educated and they say that you shouldn't do it. There is a Mullah teacher, who has 13 kids, and he announces in the mosque that family planning should not be practiced because it is not allowed in Islam as God provides for everyone.

Another reason for low contraceptive use in the area is the challenge of physical access: communities are scattered, facilities located at great distances, and there is no source of transport available, which means people have to travel by camels and donkeys. To make matters worse, violent feuds among tribes and clans are common, and make travel highly risky.

There are expenses of travelling and conveyance. Some don't have conveyance so they come and go on their donkeys and camels. Another problem is that they have family enmities due to which they avoid travel.

Even when women are able to overcome the daunting resistance and access issues, Farhan points out, they do not wish to adopt a method that might have side effects because they would not know how to manage, and making repeated visits to service providers is not possible. Even if they were able to make the trip to the district centers, and even if they opted for IUCDs or sterilization, there would always be a risk of complications and no female service provider would be available locally to help them.

They have to go about 200 kilometers to Jacobabad or Sibi, which most of them cannot afford, so they don't use these methods. And if they want permanent method, then the doctor charges money, and if there is an infection, then what will they do?

Married for 16 years and a father of two, Farhan Ali is very concerned that the people of his community cannot access family planning services, which means that poor households have many children whose needs cannot be fulfilled.

The children also have rights which have to be fulfilled. If you have a lot of children, then you cannot fulfill their expenses. Their education won't be good; their needs for food will not be fulfilled.

His own family planning decisions are made with his wife's full participation, and he confidently uses condoms:

I had given my wife pills. She said, 'I am getting fat;" I won't take them,' so I am now using condoms.

Notwithstanding significant cultural and religious resistance, as well as enormous challenges of physical and financial access, women from surrounding communities are coming to the RHC where Farhan Ali works to have their reproductive health and family planning needs met. To a great extent, the fact that no female service providers are available for these women defeats the purpose of maintaining the RHC. Given the security risks, difficult terrain, large distances, lack of transportation, and restrictions on female mobility, and the 
unwillingness of female service providers to work regularly at remote health facilities, there is an urgent need to find creative alternative solutions. The answer, as Farman Ali suggests, might lie in a well-planned program of mobile health service provision.

Mobile camps with female service providers should be arranged to provide regular counseling and services to women regarding family planning methods. 


\section{Facing Stock Outs}

\section{Regular and sufficient supply of contraceptives is necessary to maintain their use}

Thirty-year-old Parveen ${ }^{47}$ is a lady health worker (LHW) who has been providing family services in district Sibi, Balochistan, for the past eight years. She caters to a population of 1,000 . Her daily schedule includes visits to five houses to provide counsel and contraceptives.

Parveen is single, has completed her secondary education, and received training in family planning a year ago. Her knowledge regarding contraceptive methods is good, and she is fortunate in serving a community that is mostly educated and does not need to be convinced to adopt family planning methods.

Thanks to Allah, the area that I am working in, the people are educated and have sense. Among them, some are teachers and some have other jobs. If they are not working themselves, they look after the house. Their husbands are educated, but there aren't any houses where there isn't practice of family planning.

However, even though all of the households in her community are willing to use contraceptives, and despite her own availability to

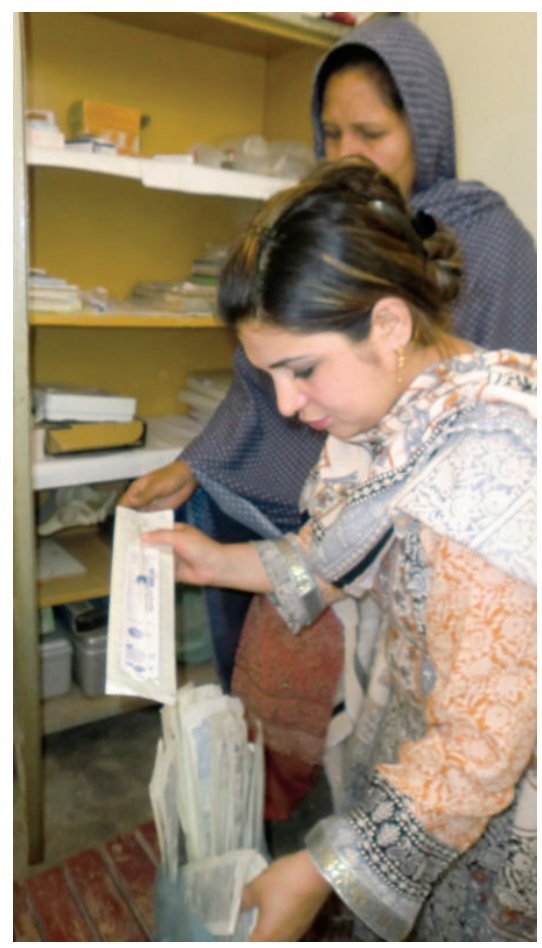
deliver contraceptives at their doorsteps, free of cost, there are frequent occasions when her clients' needs for family planning methods go unmet. The reason is non-availability of contraceptives: Parveen receives supplies of contraceptives from her department only about twice a year, and these are irregular and insufficient. The LHW therefore often faces stock-outs of all three methods-pills, condoms and injectables.

The chronic short supply of contraceptives is a cause of distress for her clients. Parveen explains that when she is out of stock, she writes a referral slip for her clients to obtain family planning methods from a nearby static facility, such as a district headquarters (DHQ) hospital. However, her clients are poor and often cannot afford the travel fare for reaching the facilities, or the cost of contraceptives. Moreover, hospitals sometimes have complicated procedures that are difficult to navigate for Parveen's clients.

Since we don't have contraceptives, we have to refer the clients to a facility. So we make them a referral 'chit' (slip). Then they have to go the hospital, plan a journey and pay for the transportation. They have to go to the sisters, they have to go to the doctors, they have to tell the doctors and then they get these things. This is the main problem that our client has to face. There are some who are poor and cannot afford it, and these things are important for them because it is obvious that they need to space.

When the Population Council's field team visited this LHW, she did not have any stock of methods available, having received her last contraceptive supply one month ago, in February 2014. She also mentioned that she received contraceptives only two times in year 2013. Parveen understands her clients' difficult situation and is frustrated by her inability to play her role effectively.

If I had contraceptives (available) according to her demand, then she would not face this problem.

She points out, correctly, that the entire problem could be easily resolved if she had contraceptives available on a regular basis to provide her community free services at their doorsteps.

${ }^{47}$ Names have been changed to protect respondents' privacy. 
When we don't have these things (contraceptives) available ... they have to go to these centers from their homes or we have to go. We bring them (contraceptives). If we already got these (contraceptives) every month, and they were available with us, it wouldn't be hard for us, nor would it be hard for our clients.

The predicament of Parveen and her community highlights how important it is to address inadequate and irregular contraceptive supply from district stores to service delivery points and LHWs. Chronic stock-outs of contraceptives greatly reduce the effectiveness of LHWs and deprive needy rural communities of regular access to family planning methods. By shifting the burden of access back to poor users, such supply problems force them to switch or discontinue family planning methods, and greatly increase the odds of unwanted pregnancies. 


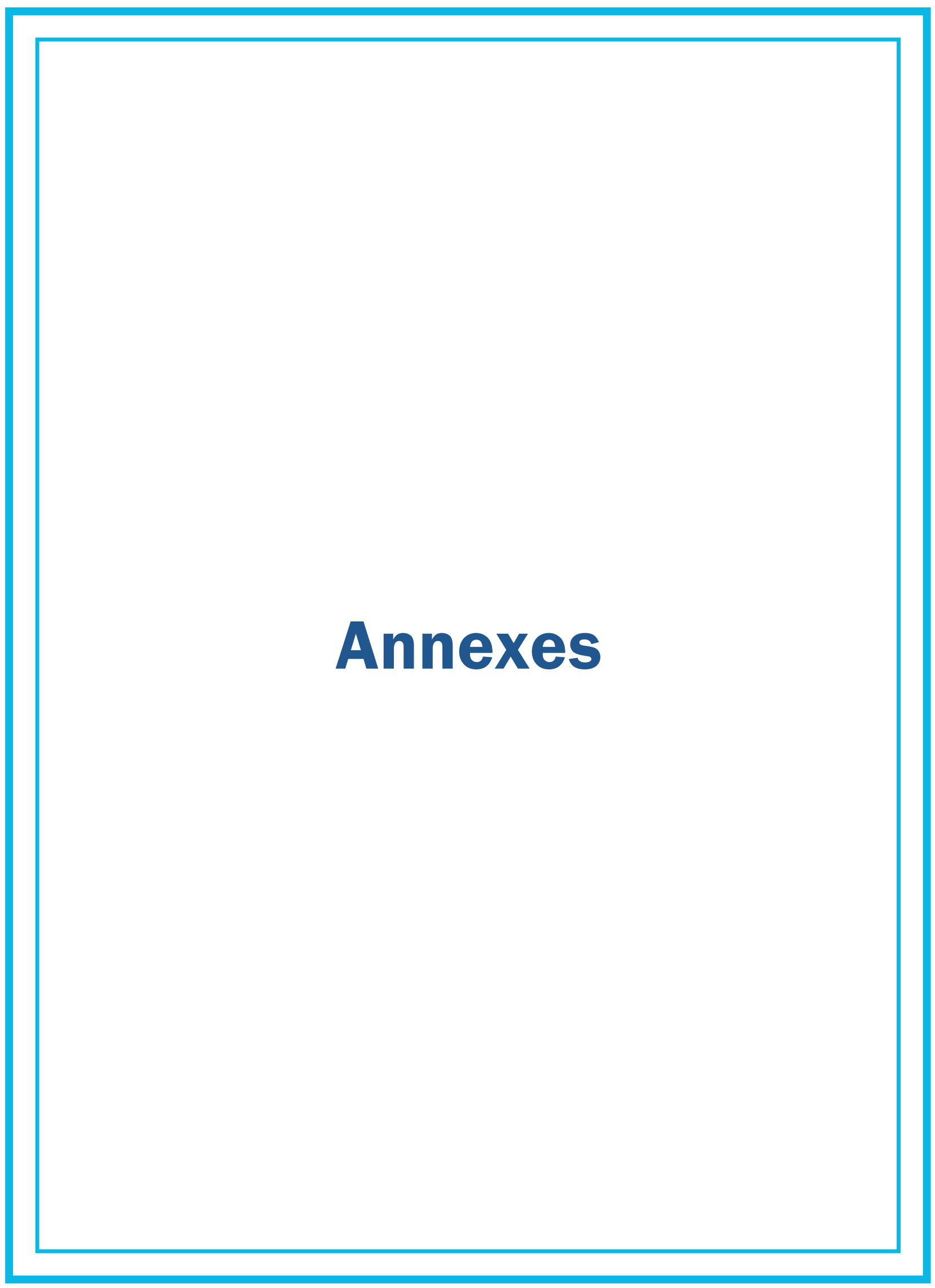




\section{Annex A: Conceptual framework of the whole study (including all 4 sub studies)}

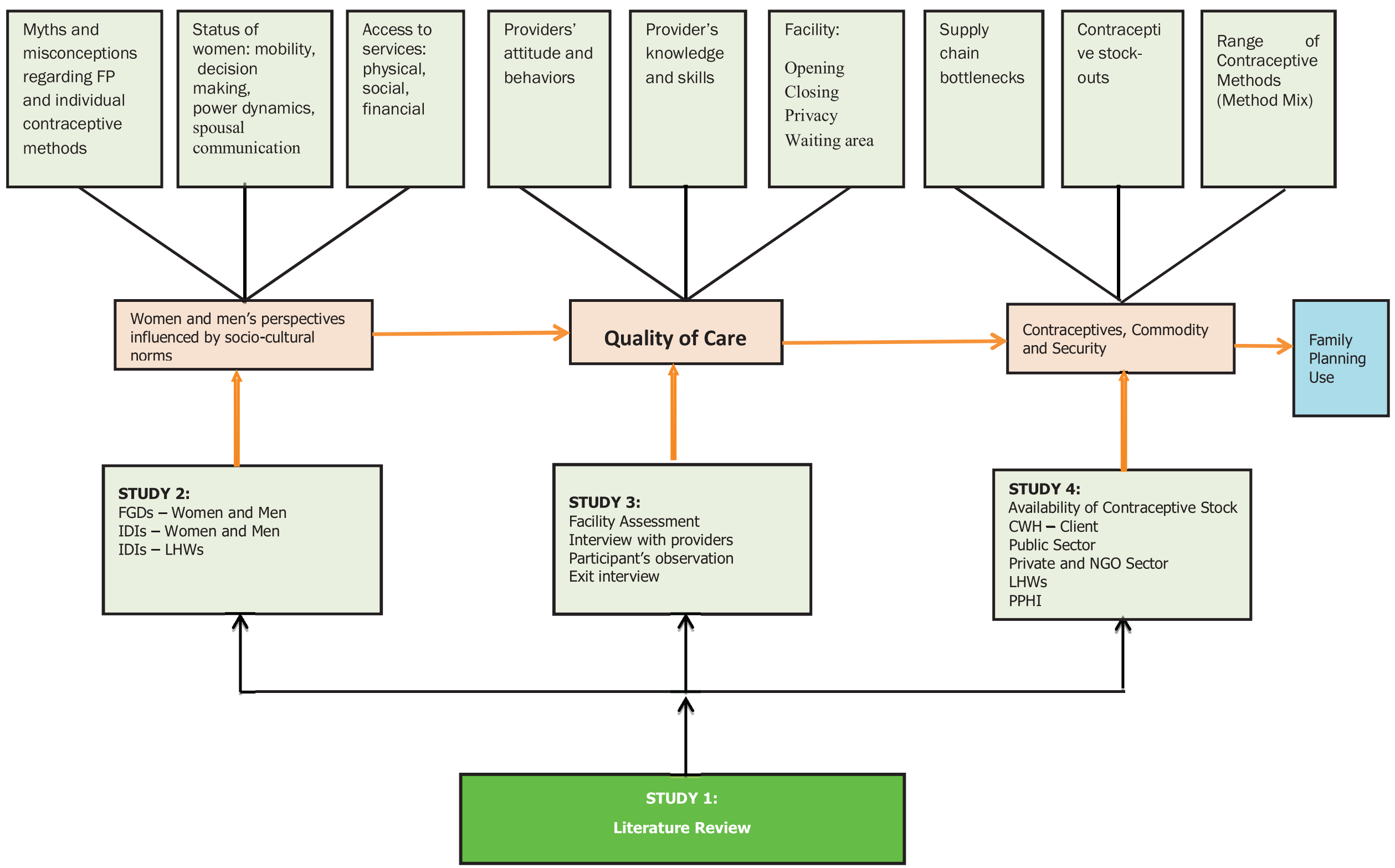




\section{Annex B: District profiles}

\begin{tabular}{|c|c|c|c|c|c|c|c|c|c|}
\hline Attributes & Khanewal & R Y Khan & Khairpur & Umerkot & Mansehra & Mardan & Sibi & Pishin & Source \\
\hline Geographical location & South & South & South & South-East & $\begin{array}{l}\text { North- } \\
\text { Eastern }\end{array}$ & North-West & West & East & \\
\hline \multicolumn{10}{|c|}{ Rank by index of multiple deprivation } \\
\hline Provincial & 26 & 33 & 11 & 20 & 16 & 8 & 6 & 2 & $\begin{array}{l}\text { Districts' Indices of Multiple } \\
\text { Deprivations for Pakistan, }\end{array}$ \\
\hline National & 58 & 76 & 50 & 84 & 64 & 44 & 47 & 13 & $\begin{array}{l}2011 \text {, Research Report } \\
\text { No.82 }\end{array}$ \\
\hline \multicolumn{10}{|l|}{ Geographical features } \\
\hline Population (000) & *2,705 & *4431 & $* * 1,992$ & $\star * 854$ & $* * 1660$ & **2300 & $\star \star 244$ & $\star * 496$ & $\begin{array}{l}\text { *Estimated as on } 2013 \text {, } \\
\text { Punjab Development } \\
\text { Statistics }\end{array}$ \\
\hline & & & & & (2013) & (2013) & & & $\begin{array}{l}* * \text { NIPS and PCO, 2011- } \\
\text { Middle years estimates }\end{array}$ \\
\hline Density & 622 & 373 & 125 & 152 & 363 & 1409 & 31 & 63 & \\
\hline Area (Sq. Km.) & 4349 & 11880 & 15910 & 5608 & 4579 & 1632 & 7796 & 7819 & \\
\hline Tehsil & 4 & 4 & 8 & 5 & 4 & 2 & 2 & 4 & \\
\hline $\begin{array}{l}\text { NER (Net enrollment rate) } \\
\text { Class } 1-5 \text {, age } 5-9 *\end{array}$ & 63 & 43 & 52 & 47 & 63 & 58 & 50 & 44 & *(PSLM 2012-13) \\
\hline \multicolumn{10}{|l|}{ Health indicator } \\
\hline $\mathrm{CPP}$ & $\star 101$ & $\star 207$ & $\star * 30$ & $\star \star 5$ & $* * * 360$ & $\star * \star 516$ & $* * * * 15 ?$ & 1 & $\begin{array}{l}\text { *MICS Punjab 2011; ** } \\
\text { MICS Punjab 2003-04 }\end{array}$ \\
\hline CPR & $\pi 40.4$ & 28.1 & $\approx \times 39$ & $\therefore \times 5$ & $\therefore \times 36.9$ & $\therefore \times ล 51.6$ & $\therefore \times \therefore \times 15.2$ & $\therefore \times \therefore \times 9.1$ & $\begin{array}{l}* * * \text { MICS KP 2010; } * * * * \\
\text { MICS Balochistan } 2010\end{array}$ \\
\hline Growth rate* & 2.5 & 3.2 & 2.7 & 3.3 & 2.4 & 3.01 & 3.6 & 3.6 & $\begin{array}{l}\text { *Average Annual Growth } \\
\text { Rate }(1981-98)\end{array}$ \\
\hline
\end{tabular}




\section{Annex C: Process of selecting 64 service providers for the study:}

In-depth interviews were conducted with a total $\mathbf{1 7 3}$ service providers, one IDI from each health facility sampled and covered in situation analysis. Structured interviews were conducted with more than one SP (all who were providing services at a health facility) however; IDI was conducted with only one provider mainly providing FP services from each facility.

All IDIs transcripts from each of the districts were read repeatedly by the team and felt the saturation point after certain interviews thus a total of $\mathbf{6 4}$ SPs were decided to be included in analysis and report (about $40 \%$ ). Other concern for cut on number was to concentrate on depth of the responses which was not possible if all 173 SPs were to be included. However, while selecting 64 SPs it was made sure not to miss any type of health facilities or cadres.

Process of selection:

- A table indicating all district level service providers by level of facility and type of sector was followed for selection of service provider.

- Selection was processed only for the facilities where a number of service providers of same cadres were interviewed at different level of facilities. As if there were 4 or 6 LHVs were interviewed from different level of public facilities, almost 2 LHVs were randomly chosen from two different or same levels of facilities.

- SPs were selected separately from public and private sector of each district.

Generally, 5 SPs were selected from Public and 3 from private sector of each district, means total 8 IDIs of SPs from each district.

- Since there was no private SP could be interviewed from Sibi district, 7 SPs were selected from public sector.

Table: Number of actual and selected service providers by public private sectors

\begin{tabular}{|c|c|c|c|c|c|c|c|}
\hline & \multicolumn{3}{|c|}{ Actual number of IDIs } & \multicolumn{3}{|c|}{ Selected number of IDIs } & \multirow[b]{2}{*}{ Coverage $\%$} \\
\hline & Public & Private & Total & Public & Private & Total & \\
\hline Qualified Gynaecologist & 8 & 11 & 19 & 2 & 3 & 5 & 36 \\
\hline MO & 6 & 1 & 7 & 1 & 0 & 1 & 25 \\
\hline WMO & 31 & 19 & 50 & 11 & 8 & 19 & 54 \\
\hline Nurse/Midwife/LHV /FHT & 69 & 25 & 94 & 19 & 10 & 29 & 47 \\
\hline FWW/FWC & 51 & 2 & 53 & 9 & 0 & 9 & 21 \\
\hline Dispenser/MHT/PHT & 5 & 3 & 8 & 1 & 0 & 1 & 17 \\
\hline Total & 170 & 61 & 231 & 43 & 21 & 64 & 39 \\
\hline
\end{tabular}

Source; Service provider 


\section{Annex D: Social-demographic characteristics of male/female respondents of FGDs (269 Women; 250 Men)}

\begin{tabular}{|c|c|c|c|c|c|c|c|c|c|}
\hline & \multicolumn{2}{|c|}{ Punjab } & \multicolumn{2}{|c|}{ Sindh } & \multicolumn{2}{|c|}{$\mathrm{KP}$} & \multicolumn{2}{|c|}{ Balochistan } & \multirow[b]{2}{*}{$\begin{array}{l}\text { Totat } \\
(\mathrm{N})\end{array}$} \\
\hline & Female & Male & Female & Male & Female & Male & Female & Male & \\
\hline No of FGDs & 8 & 8 & 8 & 8 & 8 & 8 & 8 & 8 & 64 \\
\hline \multicolumn{10}{|l|}{ Type of Community } \\
\hline Rural unserved & 17 & 8 & 19 & 8 & 14 & 17 & 13 & 17 & 113 \\
\hline Rural served & 19 & 36 & 18 & 15 & 17 & 21 & 13 & 15 & 154 \\
\hline Semi Urban & 23 & 15 & 18 & 18 & 15 & 8 & 15 & 10 & 122 \\
\hline Urban & 23 & 22 & 17 & 8 & 14 & 17 & 14 & 15 & 130 \\
\hline Mean age of respondents (years) & 31 & 33 & 31 & 33 & 31 & 39 & 30 & 34 & 33 \\
\hline \multicolumn{10}{|l|}{ Level of education } \\
\hline None & 30 & 17 & 42 & 28 & 31 & 12 & 34 & 18 & 212 \\
\hline 1-5 grades & 18 & 11 & 13 & 5 & 8 & 7 & 4 & 4 & 70 \\
\hline $6-8$ grades & 7 & 17 & 1 & 6 & 4 & 4 & 2 & 2 & 43 \\
\hline $9-10$ grades & 11 & 9 & 2 & 12 & 7 & 11 & 4 & 7 & 63 \\
\hline 11 grades and above & 7 & 6 & 3 & 7 & 6 & 10 & 6 & 14 & 59 \\
\hline \multicolumn{10}{|l|}{ Number of children } \\
\hline None & 6 & 7 & 3 & 5 & 3 & 4 & 1 & 8 & 37 \\
\hline 1-2 children & 20 & 30 & 12 & 15 & 12 & 20 & 12 & 11 & 132 \\
\hline 3-5 children & 43 & 33 & 28 & 27 & 31 & 21 & 26 & 19 & 228 \\
\hline $6-8$ children & 11 & 8 & 13 & 7 & 14 & 8 & 16 & 16 & 93 \\
\hline $9+$ children & 2 & 3 & 6 & 4 & 0 & 0 & 0 & 2 & 17 \\
\hline Total number of respondents & 82 & 81 & 72 & 49 & 60 & 63 & 55 & 57 & 519 \\
\hline
\end{tabular}




\section{Annex E: List of Technical Advisory Group (TAG)}

\begin{tabular}{l|l}
\hline Name & Designation, Department and Province \\
\hline Dr. Syeda Batool Mazhar & Head of Department, Gynecologist, PIMS, Islamabad \\
\hline Dr. Nasir Mohyuddin & Director (HRD \& Coordination), NIPS, Islamabad \\
\hline Dr. Ayesha Qureshi & Deputy Secretary (Technical), PWD, Punjab \\
\hline Dr. Shabina Raza & $\begin{array}{l}\text { Provincial Coordinator } \\
\text { National Program for Family Planning and Primary Healthcare, } \\
\text { KP }\end{array}$ \\
\hline Dr. Huma Zubair & Director Technical, PWD, KP \\
\hline Dr. Ayaz Hussain & Deputy Director, MNCH, Sindh \\
\hline Dr. Azmat Waseem & Additional Secretary, PWD, Sindh \\
\hline Dr. Amir Bakhsh & Director Health Services, Balochistan \\
\hline
\end{tabular}




\section{Annex F: Names and designations of field staff and Translators}

\begin{tabular}{|c|c|}
\hline Province & Qualitative field team \\
\hline \multirow{6}{*}{ Punjab } & Muhammad Iqbal \\
\hline & Haider Abbasi \\
\hline & Shamsa Noushani \\
\hline & Azra lqbal \\
\hline & Farhat Bibi \\
\hline & Shazma \\
\hline \multirow{4}{*}{ Sindh } & Shabana Arif \\
\hline & Farzana Khan \\
\hline & Ghulam Murtaza Soomro \\
\hline & Hizbullah Tunio \\
\hline \multirow{5}{*}{ KP } & Faisal Shahzad \\
\hline & Liaquat Shah \\
\hline & Zainab Bibi \\
\hline & Zainab Nafees \\
\hline & Naila Rasheed \\
\hline \multirow{8}{*}{ Balochistan } & Nusrat Hassan \\
\hline & Sidra Younas \\
\hline & Fahmeeda Anwer \\
\hline & Riffat Shaheen \\
\hline & Muhammad Rafiq \\
\hline & Ghulam Nabi Lehri \\
\hline & Mansoor Ahmed \\
\hline & Muhammad Hashim \\
\hline \multirow[t]{6}{*}{ Translators } & Maryam Jamil Nasir \\
\hline & Nida Mushtaq \\
\hline & Breshna Hassan \\
\hline & Ayesha Aslam \\
\hline & Naveed Noor \\
\hline & Hassan Ali Khan \\
\hline
\end{tabular}





\section{POPULATION COUNCIL \\ Ideas. Evidence. Impact.}

House 7, Street 62, F-6/3, Islamabad

Phone: 051-8445566 Fax: 051-2821401

Info.pakistan@popcouncil.org

www.popcouncil.org

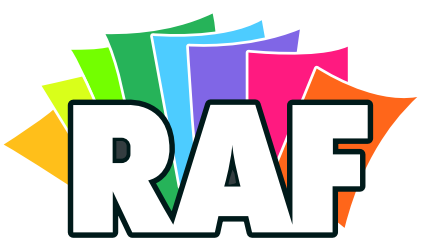

Working Towards Millennium Development Goals Research \& Advocacy Fund 